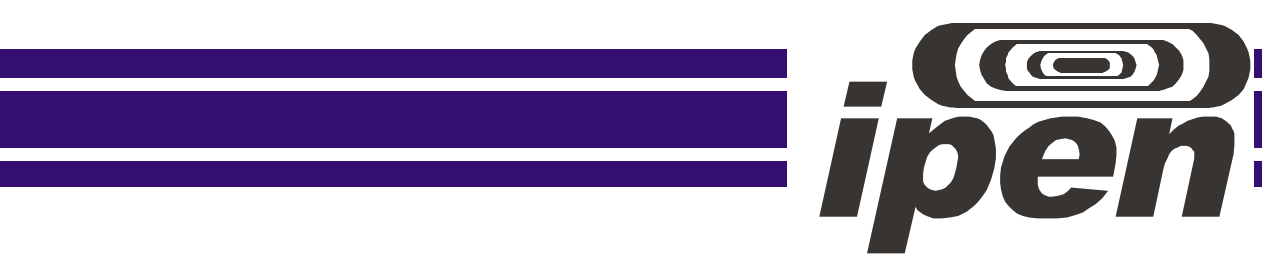

AUTARQUIA ASSOCIADA À UNIVERSIDADE DE SÃO PAULO

SÍNTESE E CARACTERIZAÇÃO DE ZEÓLITA PURA OBTIDA A PARTIR DE CINZAS VOLANTES DE CARVÃO

Juliana de Carvalho Izidoro

Tese apresentada como parte
dos requisitos para obtenção do Grau
de Doutor em Ciências na Área
de Tecnologia Nuclear - Materiais
Orientadora:
Profa. Dra. Denise Alves Fungaro


INSTITUTO DE PESQUISAS ENERGÉTICAS E NUCLEARES

Autarquia associada à Universidade de São Paulo

SÍNTESE E CARACTERIZAÇÃO DE ZEÓLITA PURA OBTIDA A PARTIR DE CINZAS VOLANTES DE CARVÃO

JULIANA DE CARVALHO IZIDORO

Tese apresentada como parte dos requisitos para obtenção do Grau de Doutor em Ciências na Área de Tecnologia Nuclear - Materiais.

Orientadora:

Dra. Denise Alves Fungaro

\section{SÃO PAULO}




\section{AGRADECIMENTOS}

À Dra. Denise Alves Fungaro por toda orientação ao longo de minha carreira acadêmica.

Ao Dr. Shaobin Wang da Curtin University of Technology, Austrália, pela co-orientação, incentivo e exemplo.

À banca examinadora composta pela Dra. Emília S. M. Seo, Dr. Mauro Aquiles La Scalea, Dr. Jivaldo do Rosário Matos e Dr. José Roberto Martinelli.

Ao Centro de Química e Meio Ambiente, Centro de Ciência e Tecnologia dos Materiais e ao Centro de Pós-graduação do Instituto de Pesquisas Energéticas e Nucleares pela infra-estrutura oferecida e pessoal qualificado.

Aos Departamentos de Engenharia Química e Química da Curtin University of Technology pela infra-estrutura oferecida.

Aos alunos e funcionários da Curtin University of Technology pelo auxílio e companheirismo durante o estágio de doutorado no exterior: Hongqi Sun, Hussein Rasool Abid, Naixin Wang, Karen Haynes, Cat Kealley, Elaine Miller, Ann Carroll, Jason Wright, Tomoko Radomirovic, Robert Herman e Tammy Atkins. Ao Conselho Nacional de Desenvolvimento Científico e Tecnológico - CNPq pelo apoio financeiro. À Coordenação de Aperfeiçoamento de Pessoal de Nível Superior - CAPES - pela bolsa PDEE de estágio de doutorando no exterior.

Ao Nilo Schneider, Pedro Pinho e ao Machado da Usina Termelétrica de Figueira (PR) pela hospitalidade, oportunidade de visitas técnicas e coleta de amostras.

Ao Marcio Zanuz da Associação Beneficente da Indústria Carbonífera de Santa Catarina (SATC) por ter nos acompanhado durante a Mina Bonito em Criciúma (SC) e pelo acompanhamento da Visita á Usina Termelétrica Jorge Lacerda (SC).

Ao Ilmar Goltara Gomes da Usina Termelétrica Jorge Lacerda (SC) pelas informações técnicas prestadas e pela oportunidade de coleta de amostras de cinzas de carvão.

À Rita Tissot e ao Amaro Machado da Usina Termelétrica de Charqueadas (RS) pelas informações técnicas, receptividade e coleta de amostras.

Ao Januário Bento Vieira Araújo da Usina Termelétrica de São Jerônimo (RS) pela coleta de amostras e pelas informações prestadas. 
Ao Luís Eduardo Piotrowicz e ao Antônio Siqueira da Usina Termelétrica Presidente Médice (RS), pela oportunidade de visitas técnicas, informações prestadas e coleta de amostras de cinzas de carvão.

Aos engenheiros Ricardo Patriarcha, Ronaldo Pando e Renato Reipert pelo auxílio prestado durante o desenvolvimento do projeto de produção de material zeolítico em escala piloto.

Às Faculdades Oswaldo Cruz pela minha formação.

Ao Dr. Jorge Moreira Vaz do IPEN pelos esclarecimentos e amizade.

Ao responsável técnico Felipe Ferrufino pela realização das análises de massa específica.

Ao Dr. Walter Ussui e à responsável técnica Sandra Cunha pela realização das análises de área superficial.

Ao Dr. Marcos Scapin pela realização das análises de fluorescência de raios $X$. Ao responsável técnico Celso Vieira de Morais pela realização das análises de microscopia eletrônica de varredura.

À Dra. Maricel Barbosa Cotrim pela realização das análises de determinação de metais.

Aos amigos Antonio del Priore Filho, Evelyn Godoi, Rebeca Piumbato Chaparro Rodrigues e Terezinha Carvalho pelo companheirismo e amizade.

Aos amigos do IPEN: Camila, Carina, Carol, Davi, Elias, Fabio, Fernando, Flavia, Gisela, Gustavo, Hélio Ferreto, Iara, Juliana Cristina, Liana, Lucilena, Martinha, Nilce, Patricia, Paula, Renan, Tharcila e Vanessa.

Aos amigos Ana Carolina Darde, Camila Justo, Débora Fernandes, Gerson Fett, Juliana Tetti, Katia Oliveira, Lidia Mattos, Luana Tavares, Patricia Colozza, Priscila Garcia, Maira Monje e Rodrigo Toledo.

A todos que contribuíram direta ou indiretamente para a execução desse trabalho. Ao meu marido Renato Reipert.

A minha mãe Irene, meu pai Olider, minha irmã Carolina e minha família.

E a Deus. 
"Um pouco de ciência nos afasta de Deus. Muito, nos aproxima." 


\title{
SÍNTESE E CARACTERIZAÇÃO DE ZEÓLITA PURA OBTIDA A PARTIR DE CINZAS VOLANTES DE CARVÃO
}

\author{
Juliana de Carvalho Izidoro
}

\section{RESUMO}

O uso de carvão mineral como fonte energética tem como consequência a geração de cinzas volantes, que é atualmente um dos resíduos mais gerados no Brasil. A primeira fase deste estudo consistiu em aplicar diferentes cinzas volantes de carvão provenientes de usinas termelétricas brasileiras na síntese de material zeolítico usando tratamento hidrotérmico clássico bem como caracterizar físico-quimicamente os produtos e as matérias primas. O conteúdo dos principais compostos formadores de estruturas de zeólitas, $\mathrm{SiO}_{2}$ e $\mathrm{Al}_{2} \mathrm{O}_{3}$, correspondeu acima de $70 \%$ para todas as amostras de cinzas. As cinzas apresentaram composição mineralógica similar com a presença de quartzo, mulita, hematita e magnetita. O tipo de zeólita formado por tratamento hidrotérmico variou em geral com a composição química das cinzas precursoras. Zeólitas NaP1 foram possíveis de serem sintetizadas somente usando-se matérias primas com baixo teor de ferro e cálcio. A zeólita $X$, por sua vez, foi obtida a partir de amostras com elevados teores de alumínio. Os valores de capacidade de troca catiônica (CTC) das zeólitas foram maiores do que os valores encontrados para as cinzas devido à elevada área específica e menor relação $\mathrm{SiO}_{2} / \mathrm{Al}_{2} \mathrm{O}_{3}$. Na segunda fase do estudo, zeólitas $A$ e $X$ com grau de pureza entre 88 e $100 \%$, respectivamente, foram sintetizadas pelo método de duas etapas com fusão prévia utilizando-se dois tipos de cinzas de carvão brasileiras com diferentes composições químicas e sem tratamento prévio. Não foram utilizadas sementes ou agentes direcionadores de estrutura durante a síntese. Um roteiro geral para a síntese de zeólitas A e X com elevado grau de pureza foi elaborado baseando-se nos estudos relatados na segunda fase deste estudo. Verificou-se por meio dos estudos de composição mineralógica e 
morfologia que o método de duas etapas com fusão prévia das cinzas é responsável pela síntese de materiais mais puros e uniformes quando comparados aos materiais sintetizados pelo tratamento hidrotérmico clássico. Os valores da relação Si/Al molar calculados para todas as zeólitas com elevado grau de pureza foram próximos aos valores teóricos presentes em literatura e seus valores de CTC representaram um aumento de 1,9 a 3,0 vezes com relação às zeólitas sintetizadas pelo tratamento hidrotérmico clássico. Um estudo da possibilidade de reaproveitamento da solução remanescente de síntese hidrotérmica clássica foi realizado. Os materiais zeolíticos resultantes apresentaram misturas de fases de zeólitas A, X e Sodalita. O projeto de uma planta em escala piloto para a produção de material zeolítico usando cinzas de carvão como matéria prima contendo a descrição do processo e a lista de equipamentos e materiais básicos é também apresentado na tese. Este projeto poderá servir de base para as usinas termelétricas a carvão que desejam agregar valor às cinzas volantes produzidas em grande escala. 


\title{
SYNTHESIS AND CHARACTERIZATION OF PURE ZEOLITE OBTAINED FROM COAL FLY ASHES
}

\author{
Juliana de Carvalho Izidoro
}

\begin{abstract}
The use of coal as an energetic source has as a consequence the fly ash generation, which is currently one of the wastes generated in greater quantities in Brazil. The first step of this study was to apply different coal fly ashes from Brazilian thermal power plants for the synthesis of zeolitic materials using a classic hydrothermal treatment as well as to characterize the physical and chemical properties of the products and the raw materials. The contents of the main compounds which are responsible for the zeolitic structure formation, $\mathrm{SiO}_{2}$ and $\mathrm{Al}_{2} \mathrm{O}_{3}$, corresponded above $70 \mathrm{wt} \%$ for all fly ash samples. The ashes presented a similar mineralogical composition with the presence of quartz, mullite, hematite and magnetite. The kind of zeolite formed by the hydrothermal treatment varied depending on the chemical composition of fly ash. NaP1 zeolite was formed only using fly ashes samples with low content of iron and calcium. $\mathrm{X}$ zeolites was synthesized using fly ashes with high content of aluminium. Cation exchange capacity (CEC) values for the zeolitic materials were higher than those of fly ash due to their higher specific surface area and lower $\mathrm{SiO}_{2} / \mathrm{Al}_{2} \mathrm{O}_{3}$ ratio. In the second stage of this study, A and X zeolites with a purity between 88 and $100 \%$, respectively, were synthesized using the two-step method with a fusion step using two kinds of Brazilian coal ashes with different chemical compositions and without pre-treatment. No seeds or structure-directing agents were used in the synthesis. A general route for the synthesis of $A$ and $X$ zeolites with high purity was developed based on the studies reported in the second stage of this study. It has been found through mineralogical composition and morphology studies that the two-step method with a fusion step of the ash is responsible for the synthesis of more pure and uniform materials when compared to materials synthesized by
\end{abstract}


conventional hydrothermal treatment. The Si/AI molar ratios values calculated for all high purity zeolites were close to the theoretical values found in the literature and their CEC values were $1.9-3.0$ times higher than those of the zeolites synthesized by classic hydrothermal treatment. A study of the reuse of the residue solution in classic hydrothermal synthesis was also performed. The resulting zeolitic materials presented mixtures of $A, X$ and Sodalite zeolites phases. The project design of a pilot-scale plant for the zeolitic material production using coal ash as a raw material containing the description of the process and the list of equipment and basic materials needed is also presented in the thesis. This project can provide a reference for coal-fired power plants which wish to add value to their fly ashes in large scale production. 


\section{SUMÁRIO}

Página

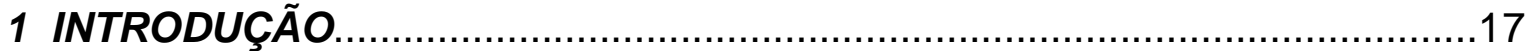

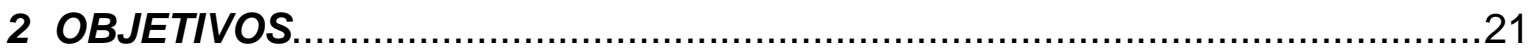

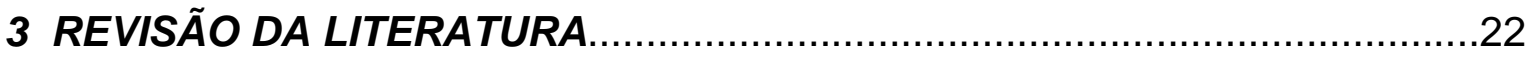

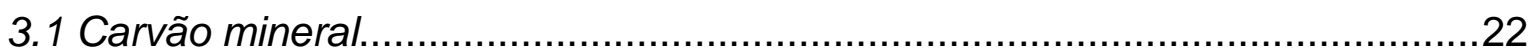

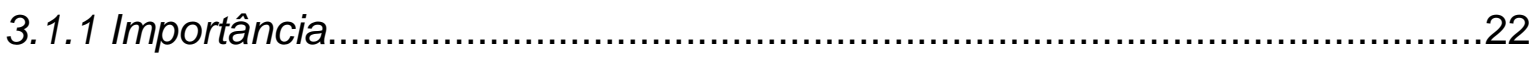

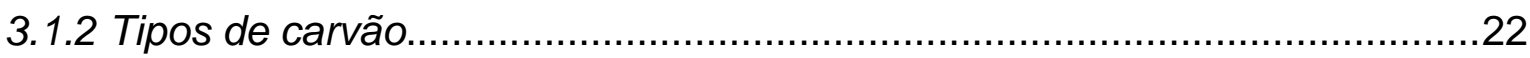

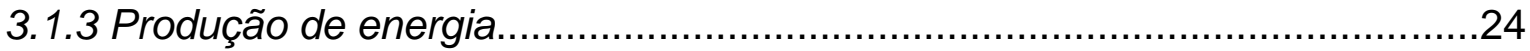

3.2 Aspectos gerais das usinas termelétricas brasileiras.................................26

3.2.1 Usina Termelétrica de Figueira.........................................................27

3.2.2 Usina Termelétrica Jorge Lacerda.......................................................28

3.2.3 Usina Termelétrica de São Jerônimo.......................................................29

3.2.4 Usina Termelétrica de Charqueadas....................................................... 30

3.2.5 Usina Termelétrica Presidente Médice..................................................... 31

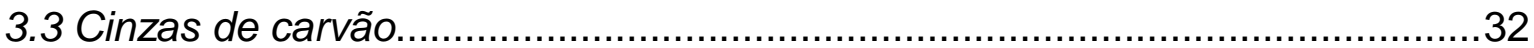

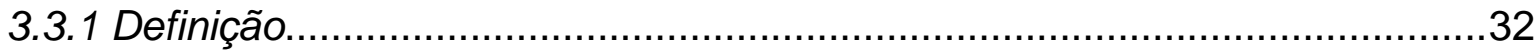

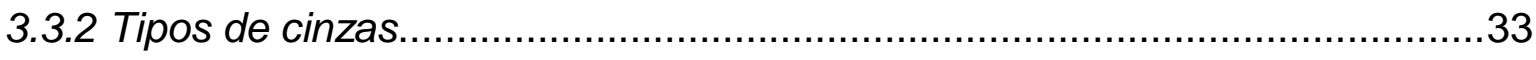

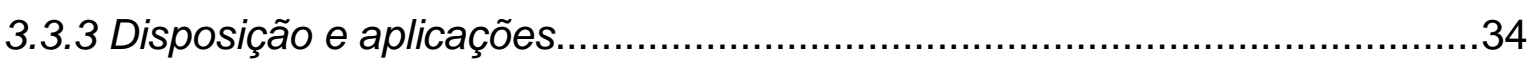

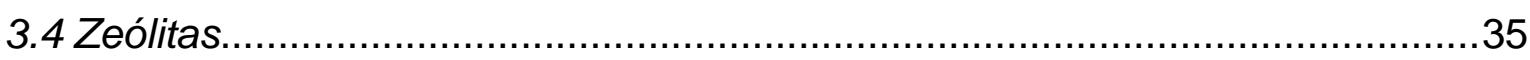

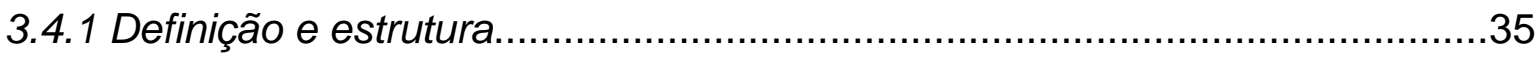

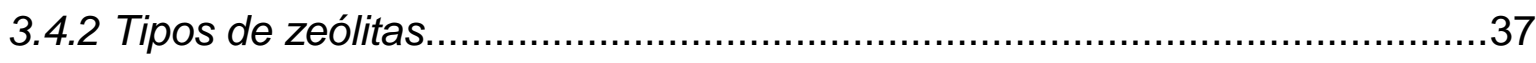

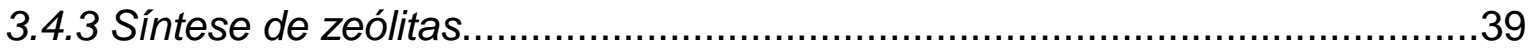

3.4.4 Síntese de zeólitas a partir de cinzas de carvão........................................40

3.4.5 Síntese de zeólitas visando à obtenção de produto puro.............................43

3.4.6 Aplicações de zeólitas de cinzas de carvão.................................................46

3.5 Caracterização de cinzas de carvão e zeólitas.............................................47

3.5.1 Massa específica.......................................................................... 48

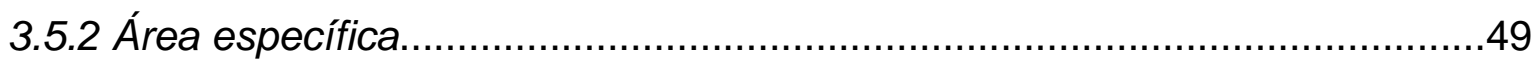


3.5.3 Morfologia. .50

3.5.4 Composição química.

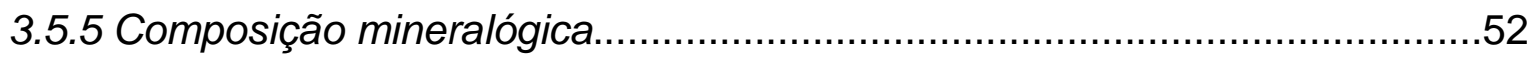

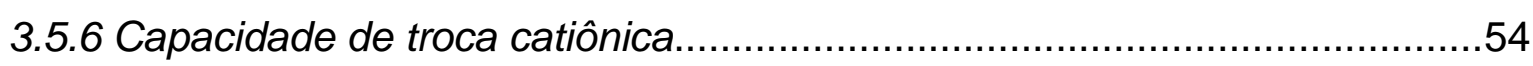

3.6 Produção de material zeolítico em maior escala...........................................55

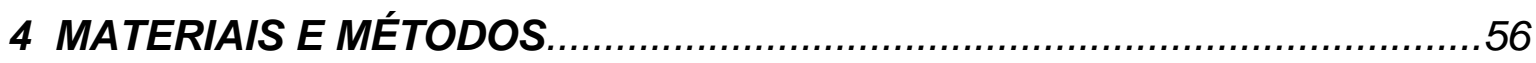

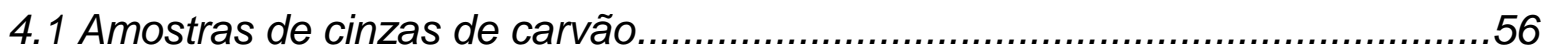

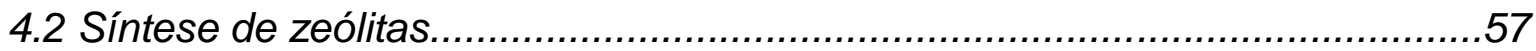

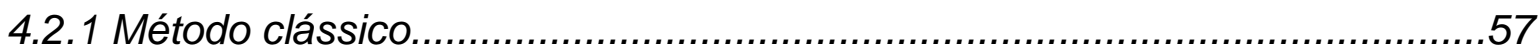

4.2.2 Método de duas etapas usando fusão..................................................58

4.2.3 Método de duas etapas usando solução remanescente de síntese

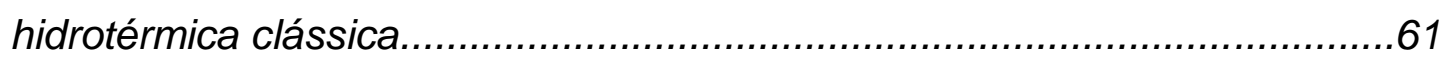

4.3 Caracterização das cinzas de carvão e dos produtos de síntese.....................63

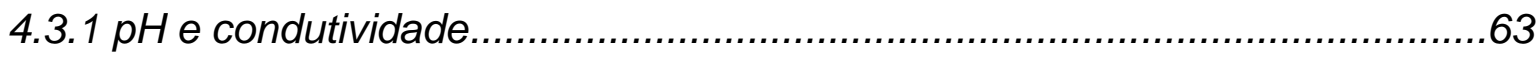

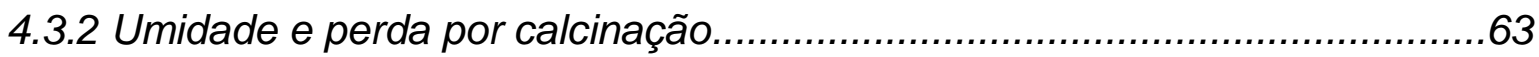

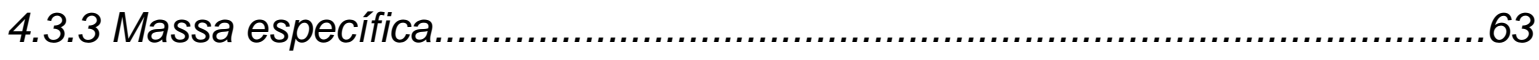

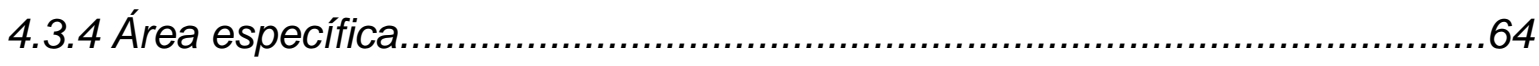

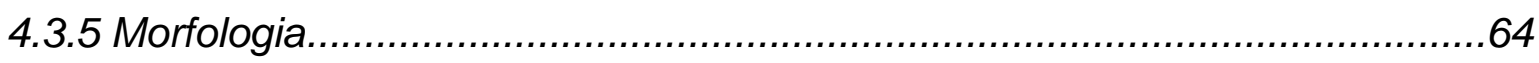

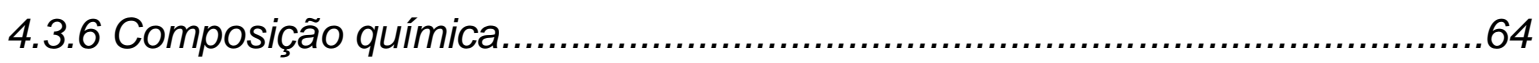

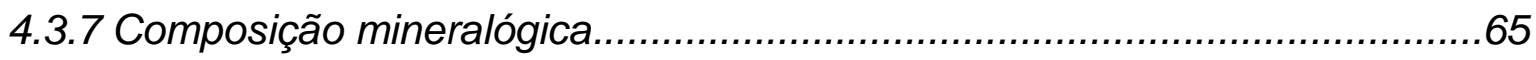

4.3.8 Capacidade de troca catiônica..............................................................66

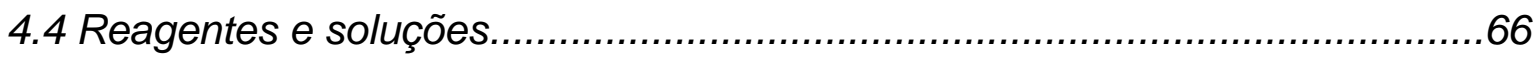

4.5 Produção de material zeolítico em maior escala..........................................67

5 RESULTADOS E DISCUSSÃO.

5.1 Caracterização de cinzas e zeólitas sintetizadas pelo método clássico............68

5.1.1 Determinação do $\mathrm{pH}$ e da condutividade ...................................................68

5.1.2 Determinação da umidade e da perda por calcinação..................................69

5.1.3 Determinação da Massa específica e da Área específica.............................71

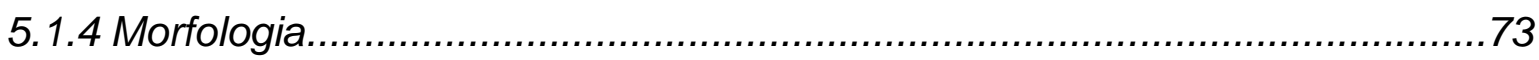

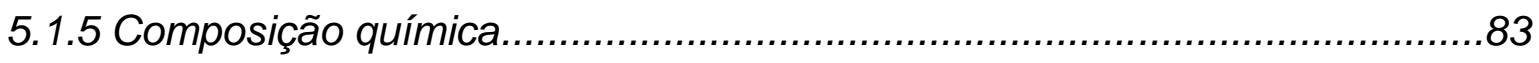

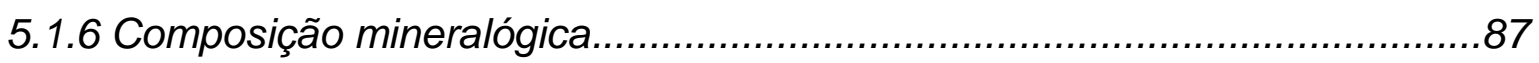

5.1.7 Determinação da Capacidade de troca catiônica........................................95

5.2 Síntese e caracterização de zeólitas com elevado grau de pureza.................97 
5.2. 1 Seleção de amostras.

5.2.1 Seleção dos parâmetros de síntese .....................................................98

5.2.2 Caracterização das zeólitas selecionadas..............................................101

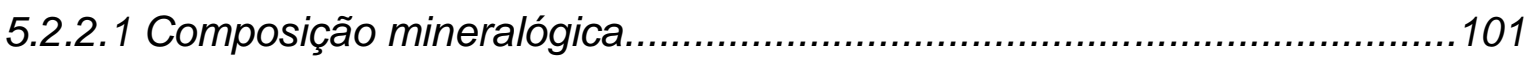

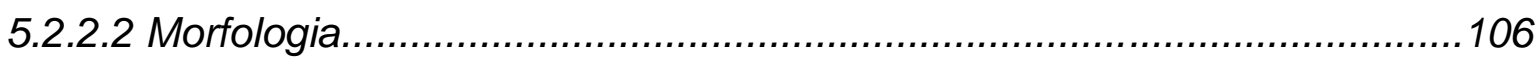

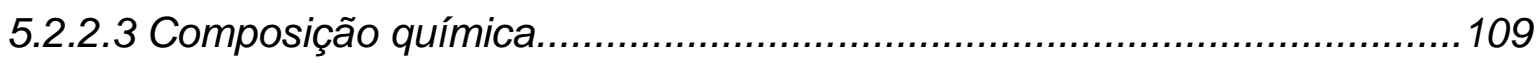

5.2.2.4 Capacidade de troca catiônica.........................................................111

5.3 Produtos sintetizados usando solução remanescente de síntese hidrotérmica clássica..........................................................................113

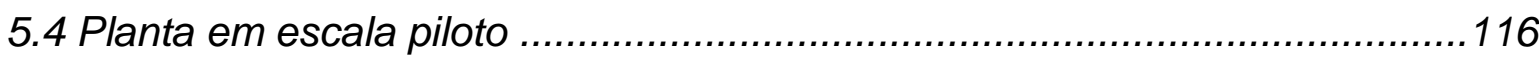

5.4.1 Descrição do processo de produção de material zeolítico..........................117

5.4.2 Lista de equipamentos e materiais........................................................122

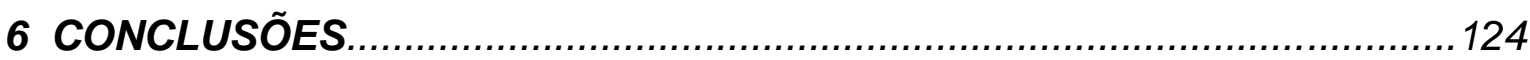

APÊNDICE A - Difratogramas de raios $X$ dos produtos zeolíticos formados no estudo de seleção dos parâmetros de síntese...127

APÊNDICE B - Difratogramas de raios $X$ das zeólitas com elevado grau de pureza sintetizadas a partir das cinzas de carvão da Usina Termelétrica Presidente Médice...................................135

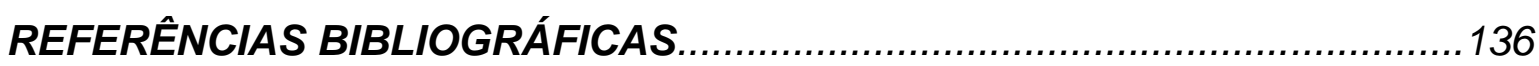




\section{LISTA DE TABELAS}

TABELA 1 - Dados das usinas termelétricas a carvão brasileiras no ano de 2009

TABELA 2 - Revisão das relações molares de $\mathrm{SiO}_{2} / \mathrm{Al}_{2} \mathrm{O}_{3}$ das cinzas volantes de carvão e os tipos de zeólitas sintetizadas de acordo com diferentes investigações.

TABELA 3 - Sistema de retenção de cinzas volantes de menor granulometria para as usinas brasileiras a carvão.

TABELA 4 - Valores de pH e condutividade para as cinzas de carvão e suas respectivas zeólitas

TABELA 5 - Valores de umidade e perda por calcinação para as cinzas de carvão.

TABELA 6 - Valores de massa e área específica para as cinzas e zeólitas...

TABELA 7 - Análise química dos compostos presentes nas cinzas de carvão (\% em massa)

TABELA 8 - Análise química dos compostos presentes nas zeólitas de cinzas de carvão (\% em massa)

TABELA 9 - Fases cristalinas identificadas nas amostras de zeólitas sintetizadas por tratamento hidrotérmico clássico.

TABELA 10 - Fórmulas químicas das fases cristalinas identificadas nas amostras de zeólitas sintetizadas por tratamento hidrotérmico clássico

TABELA 11 - Valores de Capacidade de Troca Catiônica para as zeólitas de cinzas de carvão e seus materiais precursores 
TABELA 12 - Resumo dos parâmetros usados na síntese de zeólitas puras por processo de duas etapas.

TABELA 13 - Fases cristalinas presentes nas amostras de zeólitas com elevado grau de pureza identificadas por DRFX e suas respectivas fórmulas químicas.

TABELA 14 - Estimativa semiquantitativa das porcentagens das fases presentes nas zeólitas com elevado grau de pureza

TABELA 15 - Análise química dos compostos presentes nas zeólitas com elevado grau de pureza (\% em massa)

TABELA 16 - Estimativa do rendimento da síntese de zeólitas com elevado grau de pureza obtidas pelo método de duas etapas com fusão prévia

TABELA 17 - Comparação entre a relação Si/Al molar calculada para cada zeólita com elevado grau de pureza e os valores teóricos

TABELA 18 - Valores de CTC obtidos para as zeólitas com elevado grau de pureza

TABELA 19 - Concentração dos elementos presentes nas soluções cinzas remanescentes provenientes do tratamento hidrotérmico clássico das de carvão JL e CH

TABELA 20 - Fases cristalinas presentes nas amostras dos materiais zeolíticos obtidos a partir de solução remanescente de síntese hidrotérmica clássica.

TABELA 21 - Lista de reagentes, equipamentos e materiais usados para produção de material zeolítico em planta piloto. 


\section{LISTA DE FIGURAS}

FIGURA 1 - Amostra típica de carvão da Camada Bonito, Mina Bonito I, Criciúma, Santa Catarina.

FIGURA 2 - Perfil esquemático do processo de produção de energia elétrica a partir do carvão mineral.

FIGURA 3 - Usinas Termelétricas brasileiras em operação no ano de 2009

FIGURA 4 - Usina Termelétrica de Figueira (PR).

FIGURA 5 - Usina Termelétrica Jorge Lacerda (SC)

FIGURA 6 - Usina Termelétrica de São Jerônimo (RS).

FIGURA 7 - Vista geral da Usina Termelétrica de Charqueadas (RS)

FIGURA 8 - Vista geral da Usina Termelétrica Presidente Médice (RS)........

FIGURA 9 - Representação das unidades formadoras das zeólitas: tetraedros do tipo $\mathrm{TO}_{4}$

FIGURA 10 - Estrutura da zeólita A - as linhas das estruturas representam "pontes" entre os átomos de oxigênio -O-

FIGURA 11 - Estrutura da zeólita X

FIGURA 12 - Sistemas de retenção de cinzas volantes de menor granulometria produzidas pelas usinas brasileiras a carvão: (a) Filtro de mangas (UTF); (b) Precipitador eletrostático (UTJL); (c) Saída de cinzas do Filtro ciclone (UTSJ); (d) Precipitador eletrostático (UTCH); (e) Precipitador eletrostático (UTPM)

FIGURA 13 - Fluxograma de síntese de zeólita pelo método hidrotérmico clássico a partir de cinzas de carvão. 
FIGURA 14 - Fluxograma de síntese de zeólita pelo método de duas etapas usando fusão

FIGURA 15 - Fluxograma de síntese de zeólita pelo método de duas etapas usando solução remanescente de síntese hidrotérmica clássica.

FIGURA 16 - Morfologia das cinzas volantes de carvão obtidas por microscopia eletrônica de varredura (MEV). a) CFG; b) CJL; c) CSJ; d) CCH; e) CPM

FIGURA 17 - Morfologia de uma das partículas componentes da cinza CSJ obtida por MEV com aumento de 500x

FIGURA 18 - Diferentes tipos de partículas esféricas presentes nas cinzas volantes de carvão brasileiras obtidas por MEV com aumentos de 500x e 4000x. a) e b) CJL; c) CPM

FIGURA 19 - Morfologia das zeólitas sintetizadas a partir de cinzas de carvão por tratamento hidrotérmico clássico obtidas por MEV. a) ZFG; ZJL; c) ZSJ; d) ZCH; e) ZPM

FIGURA 20 - Classificação das cinzas volantes brasileiras em função do conteúdo relativo dos principais óxidos.

FIGURA 21 - Difratograma das cinzas volantes de carvão brasileiras $(\mathrm{Q}=$ Quartzo, $\mathrm{Mu}=$ Mulita, $\mathrm{H}=$ Hematita e $\mathrm{Ma}=$ Magnetita $)$

FIGURA 22 - Difratograma da ZFG (Q = Quartzo, Mu = Mulita e S1 = zeólita Hidroxissodalita)

FIGURA 23 - Difratograma da ZJL $(Q=$ Quartzo, Mu = Mulita, S1 = Hidroxissodalita e $\mathrm{X}=$ zeólita $\mathrm{X}$ )

FIGURA 24 - Difratograma da ZSJ $(Q=$ Quartzo, $M u=$ Mulita, S1 = Hidroxissodalita e $\mathrm{X}=$ zeólita $\mathrm{X}$ ) 
FIGURA 25 - Difratograma da ZCH (Q = Quartzo, Mu = Mulita, P1 = zeólita NaP1, S1 = zeólita Hidroxissodalita e X = zeólita X)

FIGURA 26 - Difratograma da ZPM (Q = Quartzo, Mu = Mulita, P1 = zeólita NaP1 e S1 = zeólita Hidroxissodalita).

FIGURA 27 - Difratogramas dos cinco tipos de material zeolítico para comparação

FIGURA 28 - Roteiro geral para a síntese de zeólitas A e X com elevado grau de pureza a partir de cinzas de carvão.

FIGURA 29 - Difratograma da zeólita X sintetizada por processo de duas etapas a) ZXJL e b) ZXCH.

FIGURA 30 - Difratograma da zeólita A sintetizada por processo de duas etapas a) ZAJL e b) ZACH.

FIGURA 31 - Micrografia das zeólitas de alta pureza sintetizadas a partir de cinzas de carvão obtidas por MEV. a) ZXJL; b) ZXCH; c) ZAJL; d) ZACH........ 108 FIGURA 32 - Difratograma do material zeolítico ZMJL sintetizado por processo de duas etapas usando a solução JLREM.

FIGURA 33 - Difratograma do material zeolítico ZMCH sintetizado por processo de duas etapas usando solução CHREM.

FIGURA 34 - Fluxograma do processo de produção de material zeolítico sintetizado a partir de cinzas volantes de carvão por tratamento hidrotérmico clássico. 


\section{INTRODUÇÃo}

O rápido crescimento tecnológico ocorrido ao redor do mundo desde a revolução industrial não seria possível sem o uso de energia.

Embora diversas pesquisas estejam sendo direcionadas à utilização de fontes de energia renováveis, as fontes de energia não renováveis são atualmente responsáveis pela maior parte da energia produzida mundialmente.

De acordo com a International Energy Agency (IEA), o carvão é a fonte mais utilizada para geração de energia elétrica no mundo, e é responsável por aproximadamente $40 \%$ da produção de eletricidade mundial e, segundo previsões, continuará mantendo posição semelhante nos próximos 30 anos (World Energy Council, 2010).

No Brasil, estima-se que as reservas de carvão mineral são suficientes para produção de energia em usinas térmicas por aproximadamente mais 5 séculos se for considerado o consumo atual (BP Statistical Review of World Energy, 2011).

Diversos fatores contribuem para a expansão da geração de energia elétrica no Brasil por meio da queima do carvão mineral, são eles: 1) a existência de grandes jazidas na região sul do país, 2) ser um mineral de fácil extração e 3) possuir custos moderados.

O Ministério de Minas e Energia considera o carvão mineral brasileiro extremamente importante do ponto de vista estratégico, pois complementa outros tipos de fonte, como por exemplo, a hidroeletricidade (as hidrelétricas suprem 92\% da demanda de energia no país e as usinas termelétricas respondem pela geração nos períodos secos). Por isso, o Ministério de Minas e Energia incentiva a construção de usinas termelétricas a carvão, uma vez que a demanda de energia pela sociedade aumenta a cada ano. Atualmente existem no país 5 usinas termelétricas a carvão e outras 6 usinas já foram outorgadas (ANEEL, 2010). 
Ao projetar a diversificação da matriz nacional, o Plano Decenal de Expansão de Energia Elétrica (PDEE 2006/2015 - MME/EPE, 2006) prevê a expansão da utilização do carvão. Sendo assim, o Governo Federal destinou $\mathrm{R} \$ 58$ milhões do Programa de Aceleração do Crescimento (PAC) às usinas de carvão outorgadas. Além disso, outros cinco projetos, com potência total de 3.148 MW, se encontram em fase de estudos de viabilização técnico-econômica e socioambiental, segundo registra o Plano Nacional de Energia 2030 (ANEEL, 2010; EPE, 2010).

A queima de carvão mineral para a produção de energia elétrica gera grande quantidade de cinzas de carvão, que é um dos resíduos de maior geração no Brasil em termos de volume. No país, a principal aplicação industrial para as cinzas volantes geradas por essa atividade é na produção de concreto e cimento Portland (Rohde, et al., 2006), porém, a taxa de produção desses resíduos ultrapassa a taxa utilizada neste setor, fazendo com que a maior parte seja disposta em lugares impróprios, gerando problemas de ordem econômica e ambiental.

O problema é agravado pelo fato do carvão brasileiro conter alto teor de cinzas em relação aos carvões estrangeiros, o que faz com que uma quantidade maior de cinzas do que a esperada seja produzida.

Para superar este problema, outras possibilidades de aplicação para as cinzas vêm sendo estudadas no país, porém somente em escala laboratorial ou em projetos que não tiveram continuidade.

O uso de cinzas de carvão na síntese de produtos com maior valor agregado como as zeólitas, e o aumento da escala de produção desses novos produtos no país se faz urgente à medida que a quantidade dessa matéria prima tende a aumentar com a operação das novas usinas previstas.

O carvão mineral sulbrasileiro possui alto teor de matéria mineral inorgânica se comparado aos outros tipos de carvão utilizados com fins energéticos em outras usinas térmicas ao redor do mundo, além de natureza e propriedades diferentes, o que faz com que as cinzas geradas após sua queima possuam características específicas.

Sendo assim, pretendeu-se na primeira fase do presente estudo comparar diferentes cinzas volantes de carvão geradas nas cinco usinas termelétricas a carvão existentes no Brasil e aplicá-las na síntese de material 
zeolítico. As conclusões a respeito da caracterização dos diferentes produtos e de suas respectivas matérias primas relatadas na primeira fase do estudo serviu de base para a seleção de materiais para a segunda fase.

Na segunda fase do estudo, a síntese de zeólitas a partir de cinzas de carvão foi conduzida sob diferentes condições experimentais com vistas à obtenção de zeólitas $A$ e $X$ de alta pureza. Os produtos obtidos foram caracterizados por meio de técnicas de caracterização físico- químicas e analiticas.

Atualmente não existem estudos de conversão de cinzas de carvão brasileiras em zeólita pura, a qual poderá, no futuro, ser aplicada comercialmente. Não consta também na literatura atual disponível, estudos que correlacionam os parâmetros das diferentes metodologias usadas na síntese de zeólitas de alta pureza e as características das matérias primas, apresentando roteiros de tomadas de decisão com o objetivo de direcionar a síntese para a obtenção de uma zeólita pura específica.

A elaboração de um projeto em escala piloto para a produção de material zeolítico a partir de cinzas de carvão por tratamento hidrotérmico convencional contendo a descrição do processo e a lista de equipamentos e materiais necessários para a sua implementação foi realizado.

A síntese de zeólitas a partir de cinzas de carvão brasileiras relatadas em literatura somente ocorreram em escala laboratorial e a ampliação desse processo, servirá de base para a produção de zeólita em escala industrial, a qual poderá consumir quantidade significativa de cinzas, tornando a atividade de queima de carvão no Brasil mais sustentável.

Portanto, a presente tese irá verificar as seguintes hipóteses:

1- O método de duas etapas envolvendo fusão alcalina antes da síntese hidrotérmica convencional e variações dos parâmetros experimentais irá produzir zeólitas puras Na-A ou Na-X a partir de diferentes amostras de cinzas de carvão brasileiras que possuem características específicas.

2- É possível traçar um roteiro geral de síntese de zeólitas a partir de cinzas de carvão apresentando decisões a serem tomadas de 
acordo com os produtos intermediários obtidos com o objetivo de produzir zeólitas $A$ e $X$ com elevado grau de pureza.

3- É possível sintetizar zeólitas de alta pureza Na-A e Na-X usando a solução remanescente da síntese hidrotérmica clássica.

Utilizar uma metodologia experimental controlada para a síntese de zeólitas com elevado grau de pureza e caracterizar os produtos obtidos serão os meios de testar as hipóteses acima citadas. 


\section{OBJETIVOS}

Este trabalho tem como objetivo geral contribuir com a sustentabilidade das usinas termelétricas brasileiras por meio do estudo da transformação das cinzas de carvão geradas nos processos de combustão do carvão mineral em zeólitas de alta pureza, com valor agregado e com maior número de aplicações, bem como estudar a possibilidade de ampliação da produção de zeólita a partir de cinzas de carvão em escala piloto.

Objetivos específicos

1. Sintetizar zeólitas a partir de amostras de cinzas de carvão geradas em usinas termelétricas diferentes por tratamento hidrotérmico alcalino convencional.

2. Caracterizar físico-quimicamente os materiais zeolíticos e as respectivas cinzas de carvão usadas como matéria prima. Selecionar matérias primas para a síntese de produtos puros.

3. Preparar zeólitas de alta pureza a partir de diferentes cinzas de carvão brasileiras usando síntese por processo de duas etapas: variação de parâmetros e caracterização dos produtos obtidos.

4. Traçar um roteiro para a síntese de zeólitas $\mathrm{A}$ e $\mathrm{X}$ de alta pureza usando condições experimentais que se adequem a diferentes matérias primas.

5. Avaliar a possibilidade de sintetizar zeólitas $A, X$ ou misturas destas usando a solução remanescente da síntese hidrotérmica convencional com o objetivo de tornar o processo de conversão hidrotérmica direta mais econômico se for aplicado em maior escala.

6. Projetar uma planta em escala piloto de material zeolítico usando cinzas de carvão como matéria prima. 


\section{REVISÃO DA LITERATURA}

\subsection{Carvão Mineral}

\subsubsection{Importância}

O carvão é o recurso energético não renovável mais abundante no mundo (BP Statistical Review of World Energy, 2011). De acordo com a International Energy Agency - IEA - é a fonte mais utilizada para geração de energia elétrica e foi o responsável por aproximadamente $40 \%$ da produção da eletricidade mundial no ano de 2002. Ele mantém uma posição semelhante atualmente, e segundo estudos, continuará mantendo a mesma posição nos próximos 30 anos (ANEEL, 2010, World Energy Council, 2010).

As principais razões para a grande contribuição do carvão mineral no quadro de geração de energia elétrica são: a abundância das reservas e sua distribuição geográfica (em todos os continentes); baixos custos de extração; estabilidade e competitividade nos preços e a prevista diminuição das reservas baratas e convencionais de petróleo em conjunto aos seus elevados custos de extração (ANEEL, 2010; World Energy Council, 2010).

\subsubsection{Tipos de carvão}

Segundo UFRGS (2000) e Rohde et al. (2006), o carvão mineral é uma rocha sedimentar combustível constituída por duas frações intimamente misturadas: uma orgânica, composta de matéria volátil e carbono fixo, e uma fração mineral, composta por argilas, quartzo, piritas, carbonatos, etc. Sendo constituído por materiais diversos, apresenta grande variação de suas propriedades (Carrisco e Possa, 1995).

Existem diferentes critérios para classificar os diversos tipos de carvão (Carrisco e Possa, 1995). Segundo a ANEEL (2010), existem dois tipos principais: o vegetal e o mineral. O primeiro é obtido pela carbonização da lenha, 
o segundo, é formado pela decomposição da matéria orgânica (restos de plantas e árvores) durante milhões de anos. Sendo o carvão mineral o mais abundante e utilizado para a geração de energia elétrica no Brasil, será o tipo de carvão o qual será dada ênfase na presente revisão.

$\mathrm{Na}$ formação do carvão mineral, a massa vegetal acumulada e soterrada sofre transformações graduais por meio de processos bioquímicos e geoquímicos ao longo de anos, que levam à formação dos estágios subseqüentes de turfa, linhito, carvão sub-betuminoso, carvão betuminoso e antracito.

A turfa apresenta teor de carbono fixo que varia entre 55 e $60 \%$, enquanto que o antracito alcança valores na faixa de $96 \%$ para esse elemento. A quantidade de carbono fixo, elementos rochosos, minerais e água bem como efeitos do tempo, temperatura e pressão dão a variedade dos tipos de carvão mineral apresentados (UFRGS, 2000; Carrisco e Possa, 1995).

Quanto maior a quantidade do elemento carbono no carvão, maior será seu poder calorífico, ou seja, maior sua qualidade para fins energéticos. Por outro lado, o carvão apresentará menor qualidade quando apresentar maior teor de umidade e impurezas como pirita, siltito, etc. (ANEEL, 2010).

Os tipos de carvão predominantes no Brasil são dos tipos linhito, subbetuminoso e betuminoso (ANEEL, 2010). Um tipo de carvão mineral comumente encontrado no Brasil é mostrado na FIG. 1.

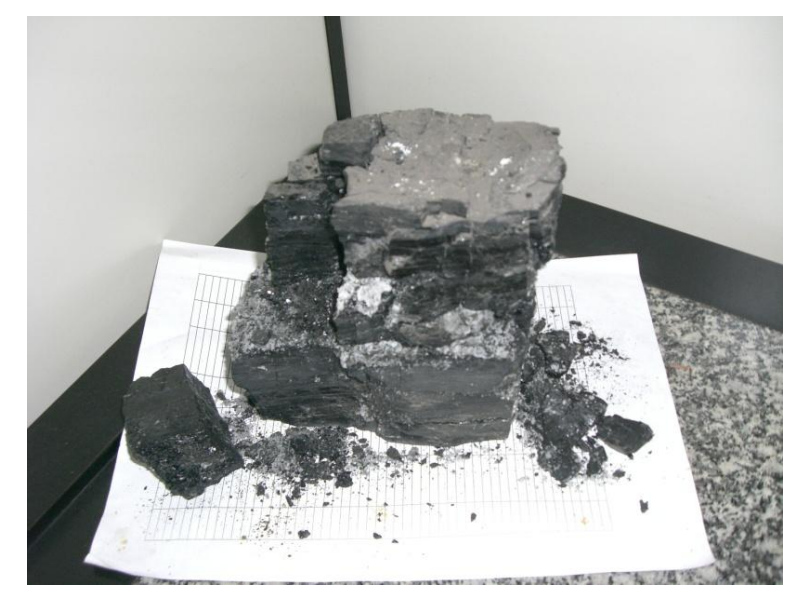

FIGURA 1 - Amostra típica de carvão da Camada Bonito, Mina Bonito I, Criciúma, Santa Catarina 
O carvão mineral brasileiro, depois de lavrado e beneficiado pode gerar dois tipos de produtos que possuem nomes comerciais: o carvão metalúrgico (do tipo betuminoso) e o carvão energético, também conhecido como carvão vapor, (dos tipos linhito, sub-betuminoso e betuminoso, dependendo da quantidade de impurezas) (ANEEL, 2010).

O carvão metalúrgico é o carvão coqueificável, ou seja, que pode ser submetido a temperaturas elevadas na ausência de oxigênio formando o coque, que por sua vez, pode ser utilizado na produção de ferro gusa. Este tipo de carvão deve atender valores máximos de umidade, teor de cinzas, enxofre e granulometria (Carrisco e Possa, 1995). O carvão energético não atende aos valores especificados para o carvão metalúrgico, e, portanto, não tem utilidade para a indústria siderúrgica, sendo utilizado para obtenção de energia (UFRGS, 2000; Carrisco e Possa, 1995).

\subsubsection{Produção de energia}

Os principais produtores mundiais de carvão mineral com fins energéticos são China, E.U.A., Austrália e Índia, que se destacam também entre os maiores consumidores mundiais (BP Statistical Review of World Energy, 2011).

A Austrália atualmente domina o mercado do comércio internacional de carvão, e por se destacar entre os maiores produtores, investe intensamente em pesquisas relacionadas com a sua extração, queima e mitigação dos impactos ambientais relacionados às suas atividades.

O Brasil ocupa 26a posição, e suas reservas, localizadas no sul do país, são suficientes para produção de energia em usina térmicas por mais 500 anos se for considerado o consumo atual (ANEEL, 2010).

A seguir, é descrito de maneira geral como se dá o processo de produção de energia elétrica por meio do carvão mineral: primeiramente o carvão é extraído do solo por meio da mineração. Segundo Campaner (2005), dependendo das condições geológicas nas quais o carvão está disposto, o acesso às camadas de carvão de uma mina pode ser tanto a céu aberto quanto em subsolo (por um poço vertical ou por um Plano Inclinado). Depois de extraído, o carvão é fragmentado e armazenado em silos. Posteriormente, pode ou não, dependendo de suas características, passar pela etapa de beneficiamento, que 
consiste na retirada de impurezas, como pirita, por exemplo, para ser posteriormente transportado à usina.

Na usina, o carvão é pulverizado e colocado para queima nas fornalhas das caldeiras. O calor liberado da queima é transferido para a água que circula nos tubos que envolvem a fornalha, transformando-a em vapor. A energia térmica contida no vapor é transformada em energia mecânica e movimenta a turbina do gerador de energia elétrica. Esse movimento dá origem à energia elétrica (ANEEL, 2010). A FIG. 2 mostra o esquema geral de produção de energia elétrica usando o carvão mineral como fonte.

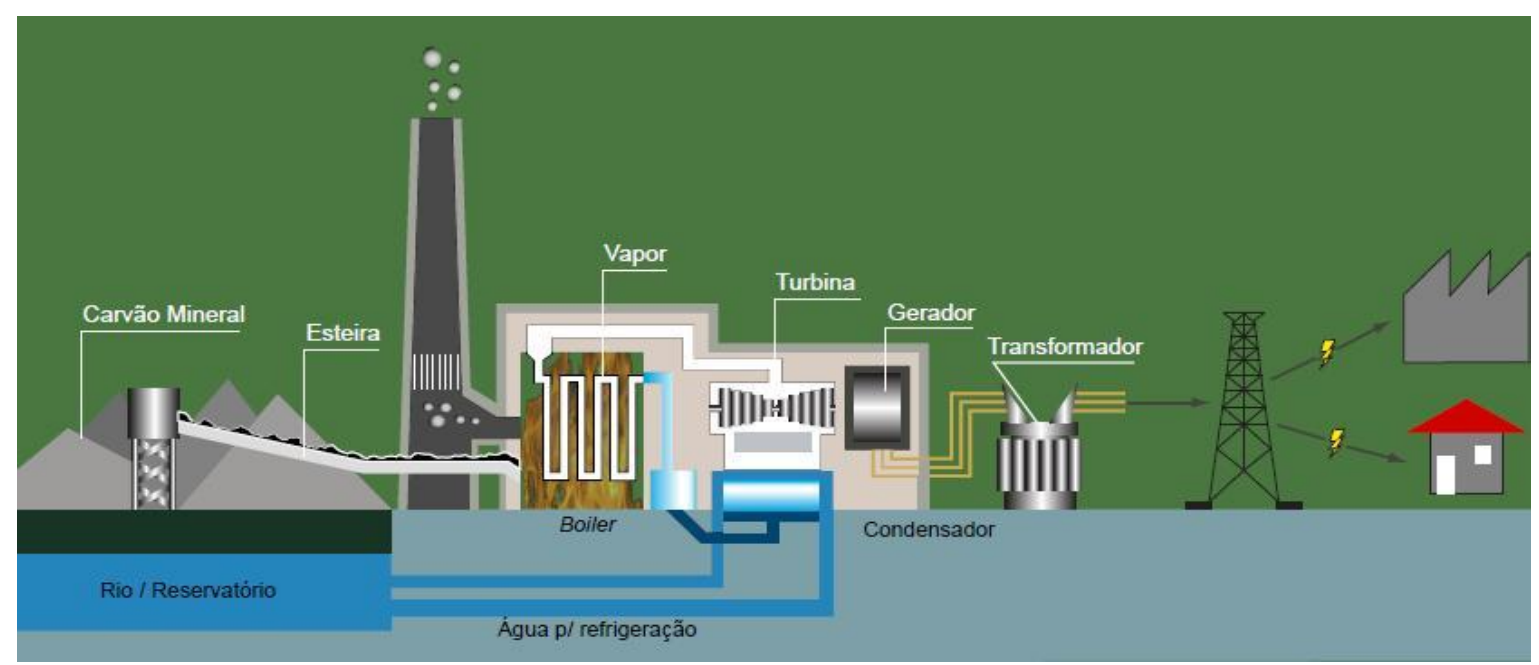

Fonte: ANEEL, 2010

FIGURA 2 - Perfil esquemático do processo de produção de energia elétrica a partir do carvão mineral

Os processos que envolvem a utilização do carvão mineral com fins energéticos necessitam de melhorias, principalmente no que diz respeito aos impactos ambientais decorrentes de sua extração e queima, como por exemplo, a geração de gases de efeito estufa (como o $\mathrm{CO}_{2}$ ), a formação de águas ácidas durante a extração de carvão, etc. Outro problema ambiental ligado a esse tipo de atividade é a geração de resíduos sólidos, as cinzas de carvão, geradas após a queima do carvão nas usinas termelétricas. 


\subsection{Aspectos gerais das usinas termelétricas brasileiras}

As usinas termelétricas que usam carvão mineral como fonte energética existentes no Brasil no ano de 2009 eram: Usina Termelétrica de Figueira, Usina Termelétrica Jorge Lacerda, Usina Termelétrica de São Jerônimo, Usina Termelétrica de Charqueadas e Usina Termelétrica Presidente Médice (FIG. 3).

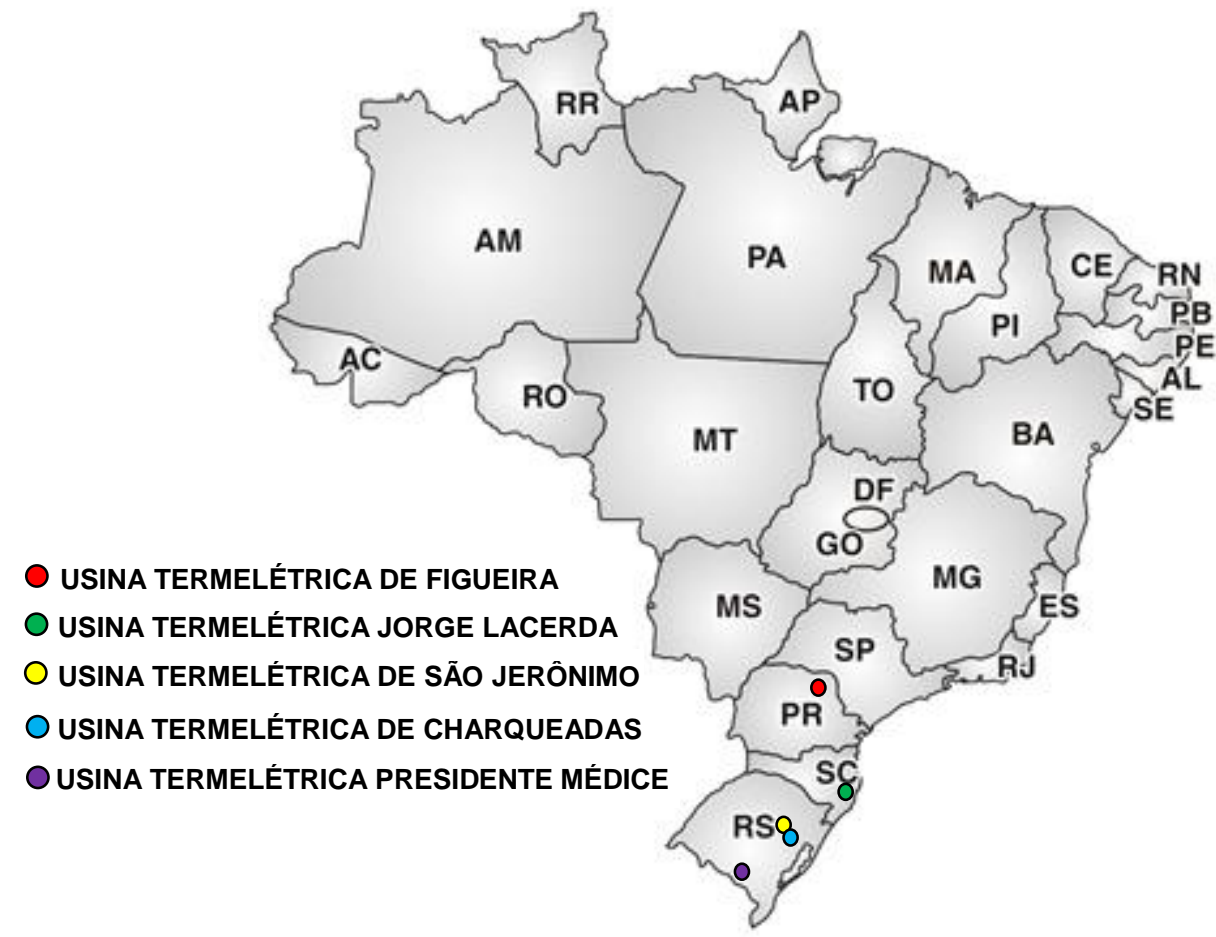

Fonte: Luster, 2010 (adaptado)

FIGURA 3 - Usinas Termelétricas brasileiras em operação no ano de 2009

Conforme mostrado na FIG. 3, as usinas estão localizadas na região sul do Brasil, onde se encontram também as reservas mais abundantes desse mineral no país.

As cinco usinas termelétricas a carvão são integradas ao Operador Nacional do Sistema Elétrico - ONS - que é a entidade brasileira responsável pela geração e transmissão de energia elétrica no Sistema Interligado Nacional SIN - sob fiscalização e regulação da Agência Nacional de Energia Elétrica ANEEL. O SIN é responsável pelo controle de $96,6 \%$ da produção de eletricidade 
do país, incluindo usinas que utilizam diferentes fontes energéticas (ANEEL, 2010). Os dados das usinas termelétricas brasileiras estão listados na TAB. 1.

TABELA 1 - Dados das usinas termelétricas a carvão brasileiras no ano de 2009

\begin{tabular}{|c|c|c|c|c|c|}
\hline $\begin{array}{c}\text { Usina } \\
\text { Termelétrica } \\
\text { a carvão }\end{array}$ & Localização & $\begin{array}{l}\text { Potência } \\
\text { (MW) }\end{array}$ & $\begin{array}{c}\text { Consumo } \\
\text { aproximado } \\
\text { de carvão } \\
\text { (ton/mês) }\end{array}$ & $\begin{array}{c}\text { \% média em } \\
\text { massa de } \\
\text { cinzas totais } \\
\text { no carvão }\end{array}$ & $\begin{array}{c}\text { Produção } \\
\text { de cinzas } \\
\text { totais } \\
\text { (ton } / \text { mês) }\end{array}$ \\
\hline Figueira & $\begin{array}{l}\text { Município de } \\
\text { Figueira (PR) }\end{array}$ & 20 & 6500 & $25 \%$ & 1625 \\
\hline $\begin{array}{c}\text { Jorge } \\
\text { Lacerda }\end{array}$ & $\begin{array}{l}\text { Município de } \\
\text { Capivari de } \\
\text { Baixo (SC) }\end{array}$ & 857 & 206000 & $42 \%$ & 86520 \\
\hline $\begin{array}{c}\text { São } \\
\text { Jerônimo }\end{array}$ & $\begin{array}{c}\text { Município de } \\
\text { São Jerônimo } \\
\text { (RS) }\end{array}$ & 20 & 6500 & $42 \%$ & 2730 \\
\hline Charqueadas & $\begin{array}{c}\text { Município de } \\
\text { Charqueadas } \\
\text { (RS) }\end{array}$ & 72 & 25000 & $52 \%$ & 13000 \\
\hline $\begin{array}{l}\text { Presidente } \\
\text { Médice }\end{array}$ & $\begin{array}{l}\text { Município de } \\
\text { Candiota (RS) }\end{array}$ & 446 & 95000 & $54 \%$ & 51300 \\
\hline
\end{tabular}

A seguir são abordados aspectos gerais de cada uma das usinas a carvão citadas anteriormente.

\subsubsection{Usina Termelétrica de Figueira}

A Usina Termelétrica de Figueira - UTFG - (FIG. 4) está localizada na região denominada vale Rio do Peixe, no Município de Figueira, estado do Paraná e pertence à Companhia Paranaense de Energia - COPEL. Atualmente é operada pela Companhia Carbonífera do Cambuí, responsável também pelas atividades de mineração (COPEL, 2010). 


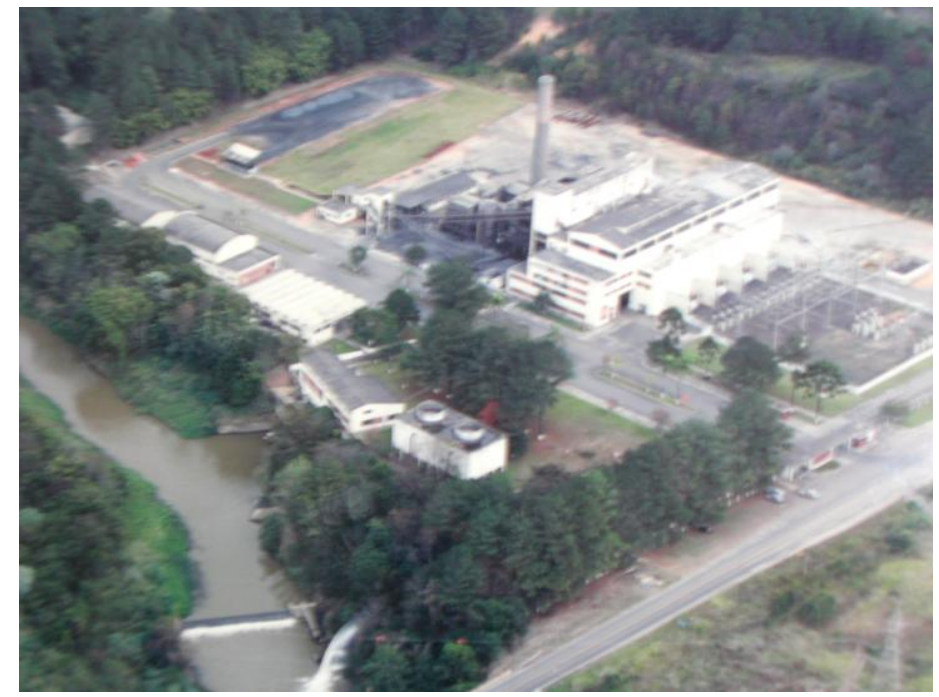

FIGURA 4 - Usina Termelétrica de Figueira (PR) Fonte: acervo da usina

O carvão usado na UTFG é extraído de minas subterrâneas, em seguida passa por processo de beneficiamento e então é encaminhado para queima. As minas de carvão e a planta de beneficiamento se encontram próximas à usina (cerca de $5 \mathrm{~km}$ de distância), na cidade de Figueira. A temperatura de queima do carvão pulverizado na UTFG varia de $1200^{\circ} \mathrm{C}$ a $1400 \stackrel{\circ}{\mathrm{C}}$.

\subsubsection{Usina Termelétrica Jorge Lacerda}

A Usina Termelétrica Jorge Lacerda (UTJL), FIG. 5, localizada no Município de Capivari de Baixo, em Santa Catarina, forma o maior complexo termelétrico a carvão da América Latina. O complexo termelétrico é composto por três fases distintas de construção, as fases $A, B$ e $C$, com capacidades de 232 MW, 262 MW e 363 MW de potência, respectivamente (Tractebel, 2010). 


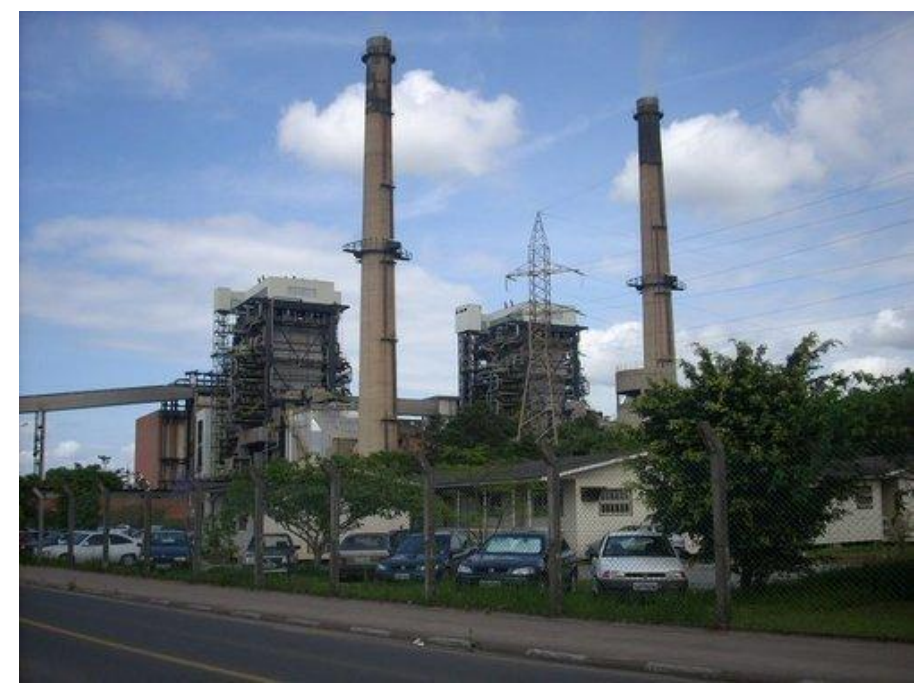

FIGURA 5 - Usina Termelétrica Jorge Lacerda (SC)

Fonte:http://mw2.google.com/mW-panoramio/photos/medium/7378140.jpg

O carvão mineral usado na UTJL é extraído de minas subterrâneas localizadas na cidade de Criciúma (SC). O carvão passa então pela etapa de beneficiamento e é transportado de caminhão por $40 \mathrm{~km}$ até a caixa de embarque, seguindo posteriormente mais $40 \mathrm{~km}$ de trem até a usina. Cerca de dez mineradoras são responsáveis em suprir a demanda de carvão de todo o complexo termelétrico.

A Tractebel Energia é a responsável pelo transporte do carvão das minas até a usina e também é a proprietária do Complexo Termelétrico Jorge Lacerda.

A temperatura da queima do carvão pulverizado por meio de arraste com ar na UTJL varia entre $1200{ }^{\circ} \mathrm{C}$ e $1400{ }^{\circ} \mathrm{C}$.

\subsubsection{Usina Termelétrica de São Jerônimo}

A Usina Termelétrica de São Jerônimo (UTSJ), FIG. 6 está localizada no Município de São Jerônimo (RS) e pertence à Companhia de Geração Térmica de Energia Elétrica - CGTEE. É a usina termelétrica mais antiga do país, inaugurada em 1953 (CGTEE, 2010). 


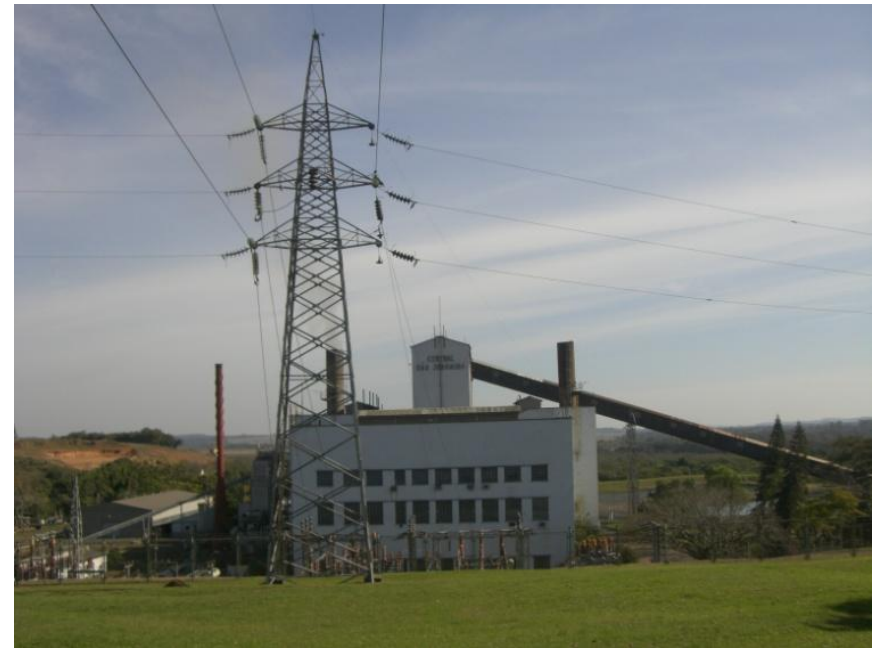

FIGURA 6 - Usina Termelétrica de São Jerônimo (RS)

O carvão usado na UTSJ chega por meio de transporte rodoviário da cidade de Minas do Leão, que fica a $40 \mathrm{~km}$ da usina. A responsável pela mineração é a Companhia Riograndense de Mineração - CRM. O carvão é extraído da Mina São Vicente, que é uma mina do tipo superficial e passa pela etapa de beneficiamento antes da queima. $O$ processo de queima se dá por combustão em grelha e ocorre em temperatura em torno de $1100 \stackrel{\circ}{\circ} \mathrm{C}$. O carvão nesse tipo de queima apresenta partículas maiores quando comparado à granulometria do carvão queimado na forma pulverizada.

\subsubsection{Usina Termelétrica de Charqueadas}

A Usina Termelétrica de Charqueadas (UTCH), FIG. 7, localizada no Município de Charqueadas (RS), pertence à Tractebel Energia. O processo de extração do carvão e entrega na usina é terceirizado e de responsabilidade da empresa de mineração Copelmi. A responsável pelos serviços de distribuição de energia e controle da substação é a Eletrosul.

O carvão usado na usina vem da cidade de Butiá, a cerca de $37 \mathrm{~km}$ da UTCH. A queima ocorre em leito pulverizado e com temperatura aproximada de $1200 \stackrel{\circ}{\circ}$. 


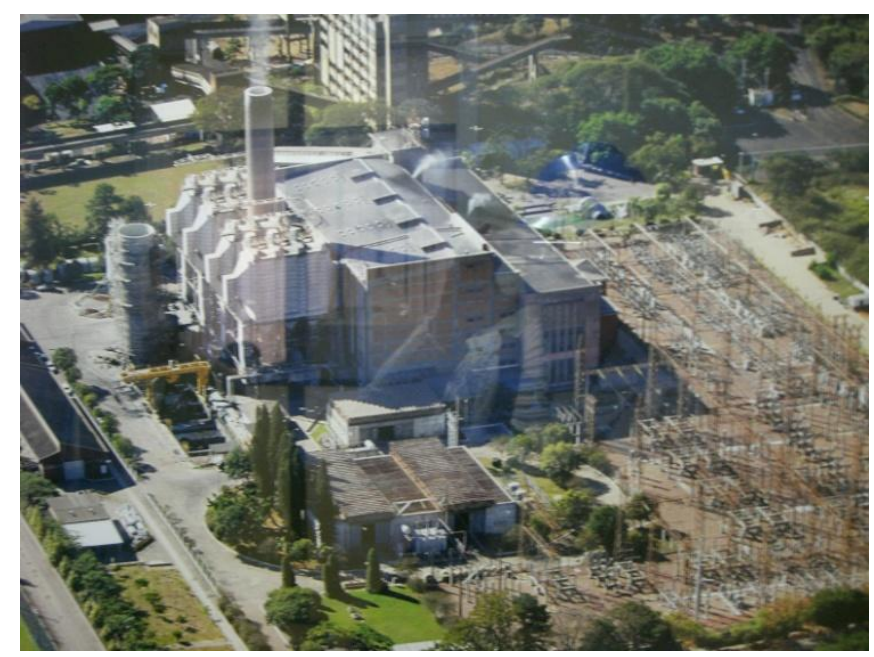

FIGURA 7 - Vista geral da Usina Termelétrica de Charqueadas (RS)

Fonte: acervo da usina

\subsubsection{Usina Termelétrica Presidente Médice}

A Usina Termelétrica Presidente Médice (UTPM), FIG. 8 está localizada no Município de Candiota (RS) e pertence à Companhia de Geração Térmica de Energia Elétrica - CGTEE.

A UTPM é composta por três fases distintas de construção, as fases $A$, B e C. A fase A é composta por duas unidades de $63 \mathrm{MW}$ cada e o carvão é queimado na forma pulverizada de maneira frontal, caracterizando-se uma queima direta (informação verbal). A fase B possui duas unidades de $160 \mathrm{MW}$ cada. $\mathrm{Na}$ fase $\mathrm{B}$, a queima do carvão ocorre de maneira tangencial em uma câmara de combustão com vortex, caracterizando-se uma queima indireta e conferindo maior homogeneização do carvão (informação verbal). A fase $C$, mais moderna e em operação desde 2011, é composta por uma única unidade de $350 \mathrm{MW}$. As temperaturas de queima nas diferentes fases variam de 1200 a $1250 \stackrel{\circ}{ } \mathrm{C}$. 


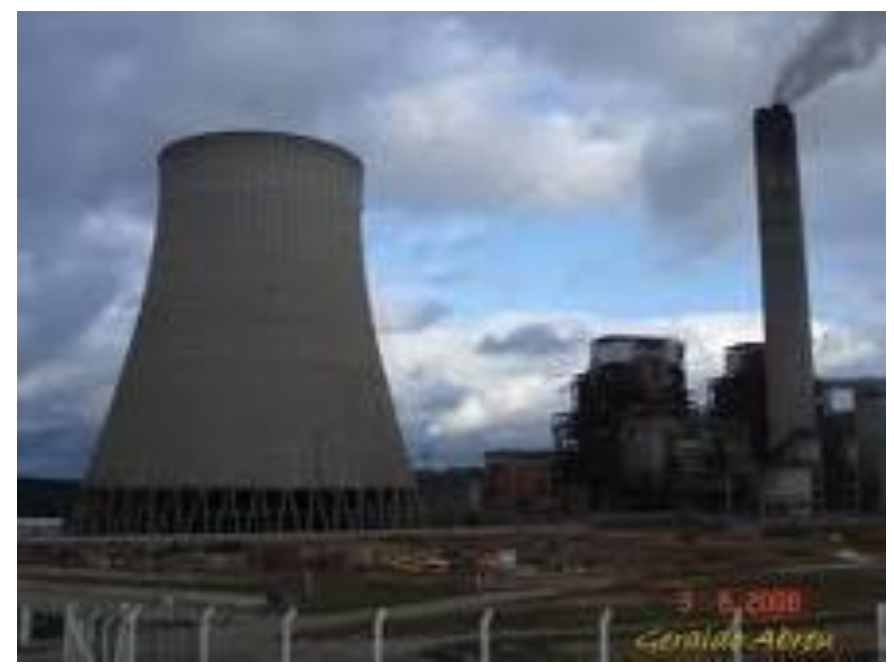

FIGURA 8 - Vista geral da Usina Termelétrica Presidente Médice (RS) Fonte: www.panoramio.com

O carvão mineral é extraído da Mina de Candiota, que é uma mina superficial localizada a $15 \mathrm{~km}$ da usina, seguindo de caminhão para uma britagem primária e sendo direcionado em seguida para queima na UTPM por meio de correias transportadoras. O carvão não passa pela etapa de beneficiamento, que se torna inviável economicamente devido as suas características químicas. A empresa responsável pelas atividades de mineração é a CRM - Companhia Riograndense de Mineração. A Mina de Candiota é a maior do país e tem previsão de durar mais 300 anos considerando-se o consumo atual de carvão pela UTPM.

\subsection{Cinzas de carvão}

\subsubsection{Definição}

Cinzas de carvão são resíduos sólidos gerados após a queima do carvão mineral em usinas termelétricas. São, portanto, os materiais remanescentes após a eliminação dos compostos voláteis presentes no carvão mediante sua queima.

As cinzas são compostas principalmente pela fração mineral do carvão precursor, porém com uma mineralogia modificada, tendo em vista a perda de 
água das argilas, decomposição dos carbonatos, oxidação dos sulfetos, etc. (Rohde et al., 2006).

Como a composição do carvão é bastante variável por se tratar de um material extraído de diferentes regiões e sob diferentes condições, as cinzas de carvão também apresentam características variáveis, devido não somente à composição do carvão que a gerou, mas também às diferentes condições de queima nas usinas. Por esses motivos, as cinzas são consideradas materiais extremamente versáteis (Ríos et al., 2009).

De modo geral, cinzas de carvão constituem-se de um pó de grãos finos com propriedades pozolânicas (capacidade de reagir com cal em presença de água) e, sendo minerais aluminosilicatos, são compostos principalmente por partículas vítreas e esféricas constituídas tanto pela fase amorfa quanto pela fase cristalina (Querol et al., 2002).

Os principais minerais encontrados nas cinzas de carvão relatados em literatura e identificados por difratometria de raios $X$ são quartzo, hematita, magnetita, mulita, anidrita, entre outros (Scott et al., 2001; Murayama et al., 2002; Umaña, 2002; Ferret, 2004; Ojha et al., 2004; Sarbak et al., 2004; Ryu et al., 2006; Querol et al., 2002 e 2007; Izidoro, 2008; Izidoro et al., 2012a; Nascimento et al., 2009).

A fórmula empírica da cinza de carvão baseada na predominância de alguns elementos chave pode ser representada por: $\mathrm{Si}_{1.0} \mathrm{Al}_{0.45} \mathrm{Ca}_{0.51} \mathrm{Na}_{0.047}$ $\mathrm{Fe}_{0.039} \mathrm{Mg}_{0.020} \mathrm{~K}_{0.013} \mathrm{Ti}_{0.011}$ (lyer e Scott 2001).

\subsubsection{Tipos de cinzas}

Diferentes tipos de cinzas são gerados após a combustão do carvão, sendo elas as escórias, de granulometria grosseira e elevado teor de carbono não queimado (10 a 20\%); as cinzas de fundo (ou pesadas), de granulometria grossa e teor de carbono não queimado de 5 a 10\%; e as cinzas volantes (ou leves), constituídas de partículas extremamente finas que são arrastadas junto com os gases de combustão nas usinas termelétricas e normalmente retidas por sistemas de filtros. Não há no Brasil um sistema de classificação formal específico para as cinzas (Rohde, et al., 2006).

As cinzas volantes produzidas no país e em outras usinas termelétricas no mundo correspondem a cerca de $70 \%$ do total de resíduos da combustão do 
carvão gerados, enquanto que as cinzas pesadas somam cerca de $30 \%$. Por esse motivo, o estudo das propriedades e aplicações das cinzas volantes é mais amplo se comparado aos outros resíduos mencionados.

Os métodos de coleta mais comuns das cinzas volantes, que são arrastadas pelos gases de combustão nas usinas, incluem precipitadores eletrostáticos, filtros de mangas ou filtros ciclones. Depois de coletadas, as cinzas geradas em usinas termelétricas do mundo todo são dispostas de formas diversas ou seguem para algum tipo de aplicação, o que ainda ocorre em pequena escala.

\subsubsection{Disposição e aplicações}

Segundo UFRGS (2000), no Brasil as cinzas são descartadas em locais que foram escolhidos por apresentarem menores custos para sua disposição.

As alternativas mais comuns no país incluem o descarte a céu aberto, aterros, minas abandonadas, lagoas de sedimentação, bacias de decantação, etc. Tais práticas normalmente resultam em diversos problemas ambientais como a contaminação da vegetação e rios em seu entorno, o uso não produtivo da terra, gastos com a manutenção desses locais, entre outros (Rohde, et al., 2006; lyer e Scott 2001). Dessa forma, reutilizar as cinzas ao invés de sua simples disposição é uma maneira inteligente do ponto de vista ambiental e econômico.

lyer e Scott (2001) apresentam uma revisão dos principais usos das cinzas de carvão estudados em todo o mundo, sendo que as principais aplicações se enquadram na síntese de materiais, como adsorventes, na área de gerenciamento de resíduos, na recuperação de materiais e na agricultura. Uma revisão mais atualizada das aplicações das cinzas de carvão é apresentada por Ahmaruzzaman (2010).

A aplicação mais comum para as cinzas volantes é na indústria de materiais de construção, porém, a taxa de produção da cinza gerada ultrapassa a taxa utilizada neste setor, fazendo com que novas aplicações sejam desenvolvidas (lyer e Scott 2001). No Brasil, a principal aplicação industrial para as cinzas leves é na produção de concreto e cimento Portland (Rohde, et al., 2006).

A conversão de cinzas volantes de carvão em zeólitas tem se mostrado uma alternativa promissora por agregar valor a este material e também por 
proporcionar aplicações mais nobres (Höller e Wirching, 1985; Henmi, 1987; Okada, 1991; Shiguemoto, 1992; Bang-Sup et al., 1995; Amrhein, 1996; Kikuchi, 1999; Iyer e Scott 2001; Querol et al., 1997a, 1997b, 2001; Izidoro et al., 2012a e 2012b).

\subsection{Zeólitas}

\subsubsection{Definição e estrutura}

Zeólitas são minerais naturais ou sintéticos com características estruturais em comum, possuindo estruturas cristalinas bem definidas (Giannetto, 1990).

São constituídas por tetraedros do tipo $\mathrm{TO}_{4}$, onde " $\mathrm{T}$ " representa diferentes átomos como, por exemplo, silício, alumínio, germânio, ferro, boro, fósforo ou cobalto (Costa et al., 2012), com predominância do alumínio e do

silício, resultando nos tetraedros de alumina $\left(\mathrm{AlO}_{4}\right)^{-5}$ e sílica $\left(\mathrm{SiO}_{4}\right)^{-4}$, respectivamente. Os átomos centrais são ligados tridimensionalmente aos átomos de oxigênio, onde cada oxigênio pertence a dois tetraedros. A unidade formadora de zeólitas pode ser observada na FIG. 9. Essa configuração tetraédrica é chamada de "unidade primária de construção" (Giannetto, 1990; Kerr, 1989).

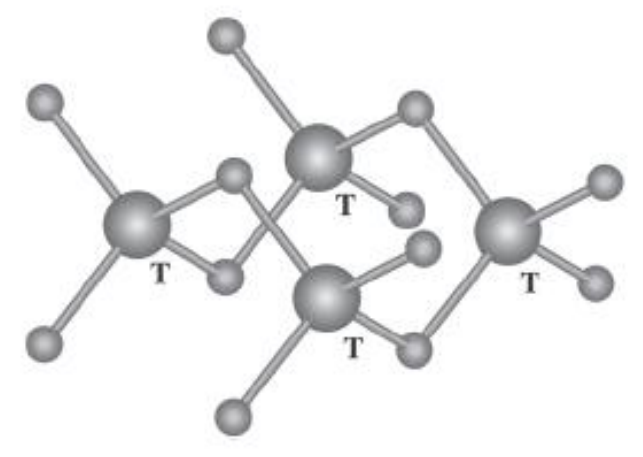

Fonte: Braga e Morgon, 2007 (adaptado)

FIGURA 9 - Representação das unidades formadoras das zeólitas: tetraedros do tipo $\mathrm{TO}_{4}$

A união dos tetraedros resulta na formação de unidades estruturais chamadas de "unidades secundárias de construção". A combinação das unidades 
secundárias conduzirá à formação de diferentes estruturas cristalinas das zeólitas (Giannetto, 1990).

Como o alumínio apresenta valência (3+) menor do que a do silício (4+), a estrutura da zeólita apresenta uma carga negativa para cada átomo de alumínio. Esta carga é balanceada por cátions de metais alcalinos ou alcalinoterrosos, chamados de cátions de compensação, intersticiais ou trocáveis (normalmente $\mathrm{Na}^{+}, \mathrm{K}^{+}$e $\mathrm{Ca}^{2+}$ ) que são livres para se moverem nos canais da rede e podem ser trocados por outros cátions em solução (Aguiar et al., 2002; Ferreira, 1998). Essa característica faz com que as zeólitas sejam excelentes trocadores de íons.

A capacidade de troca catiônica de uma zeólita está relacionada com sua relação Si/Al, já que para cada Si que foi substituído por um Al é gerada uma carga negativa, a qual é compensada por um cátion, como citado anteriormente. A preferência de uma dada zeólita por um determinado cátion é própria de sua capacidade como peneira molecular ou da competição entre a zeólita e a fase aquosa, para os cátions presentes (Ferret, 2004).

A estrutura da zeólita apresenta canais e cavidades de dimensões moleculares onde se encontram os eventuais cátions de compensação, moléculas de água ou outros adsorbatos ou sais. Esse tipo de estrutura microporosa faz com que estes materiais apresentem uma superfície interna extremamente grande em relação à sua superfície externa (Giannetto, 1990).

O que dá a variedade das zeólitas existentes, portanto, é a maneira como os tetraedros se unem, associado à possível substituição de silício por vários outros elementos, e ao tipo de íon presente nos poros (Ferreira, 1998).

Segundo Giannetto (1990), a fórmula química da célula unitária da zeólita é representada por:

$$
\mathrm{M}_{\mathrm{x} / \mathrm{n}}\left[\left(\mathrm{AlO}_{2}\right)_{\mathrm{x}}\left(\mathrm{SiO}_{2}\right)_{\mathrm{y}}\right] \cdot \mathrm{mH}_{2} \mathrm{O}
$$

onde $\mathrm{M}$ é o cátion de valência $\mathrm{n}, \mathrm{m}$ o número de moléculas de água e $\mathrm{x}+\mathrm{y}$ é $\mathrm{o}$ número de tetraedros por cela unitária. 


\subsubsection{Tipos de zeólitas}

Zeólitas podem ser encontradas na natureza em regiões onde exista ativação alcalina de rochas vulcânicas, são as chamadas zeólitas naturais. Existem aproximadamente 40 tipos de zeólitas que ocorrem naturalmente (International Zeolite Association, 2012a) e pode-se citar como exemplo de zeólitas naturais mais comuns: Analcima, Chabazita, Clinoptilolita, Erionita, Faujasita, Ferrierita, Heulandita, Laumontita, Modernita e Phillipsita (Australian Institute of High Energetic Materials, 2012).

As zeólitas naturais possuem impurezas, e conseqüentemente limitações de aplicação, por isso zeólitas sintéticas começaram a ser sintetizadas (Ferret, 2004).

As zeólitas sintéticas são obtidas a partir de soluções aquosas saturadas de composição definida de aluminatos e silicatos em geral e conduzidas à temperaturas de 25 a $300^{\circ} \mathrm{C}$ (Giannetto, 1990). Existem cerca de 200 tipos de zeólitas sintéticas (International Zeolite Association, 2012b) e podemos citar como exemplo as zeólitas A, X, Y, L, F, ZSM-5, ZSM-11, etc.

Segundo Giannetto (1990) e Tanaka e Fujii (2009) as zeólitas A e X são as zeólitas de maior utilização industrial. Ambas possuem poros e cavidades com tamanhos considerados grandes se comparados aos outros tipos de zeólitas, o que confere a elas uma grande diversidade de aplicações.

Zeólitas A e X são usadas como trocadores iônicos para diminuir a dureza de águas domésticas e industriais. Esta capacidade de troca tem sido aproveitada para utilizar essas zeólitas como suporte de fertilizantes, medicamentos e rejeitos radioativos (Giannetto, 1990).

Segundo o Australian Institute of High Energetic Materials (2012), a zeólita $A$ é a zeólita sintética mais importante atualmente. Esta zeólita é geralmente sintetizada na forma sódica e apresenta relação Si/Al entre 1,0 e 1,2 (Wang et al., 2009). Segundo Giannettto (1990), a fórmula química de célula unitária pode ser representada por:

$$
\mathrm{Na}_{96} \mathrm{Al}_{96} \mathrm{Si}_{96} \mathrm{O}_{384} \text {. } 27 \mathrm{H}_{2} \mathrm{O}
$$


A estrutura da zeólita A (FIG 10) apresenta uma grande cavidade conhecida como "supercavidade a" de diâmetro interno igual a 11,4 A. O acesso á essa grande cavidade se dá através de poros de 4,2 Å de diâmetro.

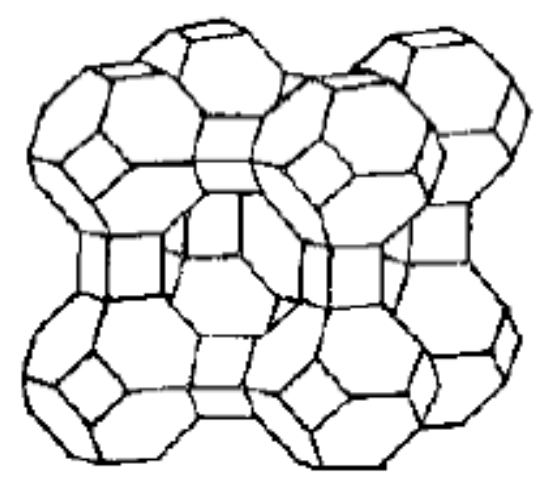

FIGURA 10 - Estrutura da zeólita A - as linhas das estruturas representam "pontes" entre os átomos de oxigênio -O-

Fonte: Aguiar et al., 2002

Dependendo do tipo de cátion de compensação presente na zeólita $A$, o tamanho de poro efetivo pode variar. Se o cátion é o potássio, o diâmetro de poro efetivo é de aproximadamente $3 \AA$, e a zeólita é conhecida como zeólita $3 A$. Se o cátion é o sódio, o diâmetro efetivo é em torno de $4 \AA$, e a zeólita é a $4 \mathrm{~A}$ (ou $\mathrm{Na}-\mathrm{A}$ ), e finalmente se o cátion de compensação é o cálcio, a zeólita é conhecida como $5 \mathrm{~A}$, por possuir tamanho de poro efetivo em torno de $5 \AA$. Cada uma dessas zeólitas terá uma aplicação industrial específica (Giannetto, 1990).

A zeólita X (FIG. 11) apresenta uma relação Si/Al entre 1,0 e 1,5 (Wang et al., 2009). Esse tipo de zeólita possui uma "supercavidade a" de diâmetro interno igual a 12,4 Å. O acesso a essa grande cavidade se dá através de poros de $8 \AA$ de diâmetro. 


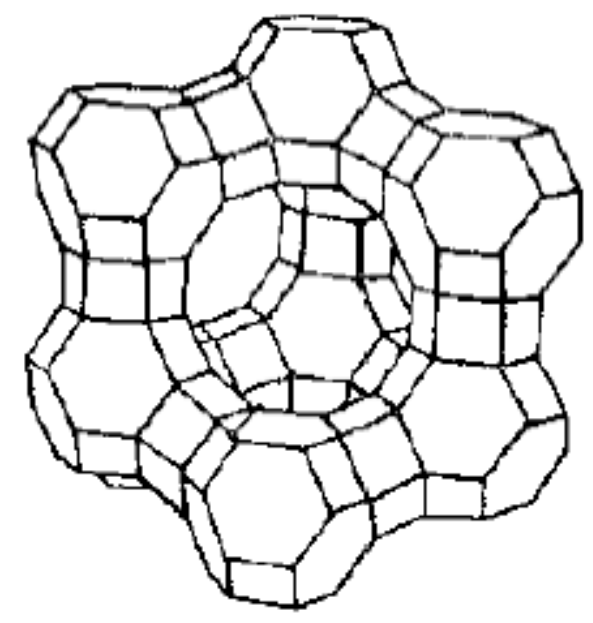

FIGURA 11 - Estrutura da zeólita X Fonte: Aguiar et al., 2002

Os canais da zeólita $X$ são suficientemente grandes para permitir 0 acesso de uma grande quantidade de moléculas orgânicas. Esse fator explica sua grande aplicação como catalisador em refinarias.

\subsubsection{Síntese de zeólitas}

Segundo Giannetto (1990), todas as zeólitas sintéticas são obtidas por algumas modificações do método proposto por Barrer em 1948. A síntese consiste na adição de álcali às fontes de alumínio e silício em proporções adequadas em meio aquoso sob temperatura controlada.

Zeólitas de diferentes estruturas são possíveis de serem sintetizadas mediante a variação da composição das soluções saturadas utilizadas e das condições experimentais como: temperatura e pressão de síntese, agitação, tempo de síntese, etc. A combinação desses fatores resultou na síntese de diversos tipos de zeólitas desde a sua descoberta em 1756 até os dias de hoje. Atualmente se conhecem mais de 10.000 patentes relacionadas com a síntese desses materiais (Giannetto, 1990).

A síntese de zeólitas pode ser realizada por qualquer matéria prima que contenha predominância de sílica e alumina, como por exemplo, argilas e cinzas da casca de arroz (Baccouche et al., 1998; Maia et al., 2007; Mignoni et al., 
2007; Foletto et al., 2009; Rahman et al., 2009). No entanto, o uso de cinza de carvão é mais explorado devido à quantidade significativa desse resíduo gerado ao redor do mundo.

A síntese de zeólitas a partir de materiais alternativos e de baixo custo teve grande desenvolvimento nas últimas décadas devido ao fato dos processos que utilizam soluções convencionais de alumínio e silício serem extremamente caros (Australian Institute of High Energetic Materials, 2012).

\subsubsection{Síntese de zeólitas a partir de cinzas de carvão}

Zeólitas podem ser sintetizadas a partir de cinzas de carvão, que além de serem materiais ricos em sílica e alumina, são abundantes e estão disponíveis em todo o globo, pois onde há produção de energia por meio da queima do carvão mineral, há quantidades consideráveis de cinzas.

Segundo Ojha et al. (2004), os primeiros pesquisadores a sintetizar zeólitas a partir de cinzas de carvão foram Höller e Wirshing em 1985, baseandose na similaridade de composição entre as cinzas e os materiais precursores das zeólitas naturais. A partir de então, vários pesquisadores do mundo passaram a sintetizar zeólitas a partir dessa matéria prima, sob diferentes condições (Henmi, 1987; Okada, 1991; Shiguemoto, 1992; Bang-Sup et al., 1995; Amrhein, 1996; Kikuchi, 1999; Querol et al., 1997a, 1997b, 2001, 2002 e 2007; Scott et al., 2001; Wang et al., 2001; Murayama et al., 2002; Umaña, 2002; Ferret, 2004; Ojha et al., 2004; Sarbak et al., 2004; Ryu et al., 2006; Izidoro, 2008; Nascimento et al., 2009; Izidoro et al., 2012a e 2012b).

O processo de síntese de zeólita a partir de cinzas de carvão envolve, em geral, a adição de um agente cáustico, normalmente hidróxidos de metais alcalinos e alcalino-terrosos, à cinza em altas temperaturas. Todas as metodologias desenvolvidas para síntese estão baseadas na dissolução das fases de cinza sustentadas por Si e Al com soluções alcalinas e a subseqüente precipitação do material zeolítico (Querol et al., 2002).

Existem basicamente três métodos para converter cinzas de carvão em zeólitas. O primeiro método consiste no tratamento hidrotérmico em uma única etapa (ou tratamento hidrotérmico clássico), no qual obtém-se somente cerca de $50 \%$ de conversão de cinza em zeólita, resultando em um produto que contém basicamente zeólita e fases não reativas das cinzas (Elliot, 2006). 
Segundo Murayama et al. (2002), o mecanismo de reação hidrotérmica envolve etapas de dissolução, condensação ou gelatinização e cristalização, onde:

a) a dissolução da cinza ocorre entre 20 - 120ㄷ․ Neste estágio, a sílica amorfa, quartzo e mulita, que são as fases de Al e Si presentes na cinza são dissolvidas. A velocidade é bastante dependente da concentração de $\mathrm{OH}^{-}$, que é o responsável por dissolver os reagentes e mantê-los em solução, propiciando sua saturação para que ocorra a formação de zeólitas (Jansen, 1991);

b) a condensação ou gelatinização é a fase onde ocorre a reação entre os íons aluminato e silicato com a formação de gel aluminossilicato (hidrogel);

c) cristalização: o hidrogel se transforma em um cristal de zeólita nesta etapa, a velocidade de reação é dependente da quantidade de $\mathrm{Na}^{+}$presente.

Segundo Murayama et al. (2002), durante o processo de ativação hidrotérmica clássica, complexos monoméricos de sílica e alumina são formados e a reação se processa por meio de íons complexos carregados negativamente segundo a equação :

$$
\mathrm{Si}(\mathrm{OH})_{4}+\mathrm{H}_{2} \mathrm{O}+\mathrm{OH}^{-} \leftrightarrow\left(\mathrm{H}_{2} \mathrm{O}\right) \mathrm{Si}(\mathrm{OH})_{5^{-}}
$$

Os complexos $\mathrm{Al}(\mathrm{OH})_{4}$ - são sujeitos à etapas de desidratação segundo a equação:

$$
2 \mathrm{Al}(\mathrm{OH})_{4^{-}} \leftrightarrow\left[(\mathrm{OH}) 3 \mathrm{Al}-\mathrm{O}-\mathrm{Al}(\mathrm{OH})_{3}\right]^{2-}+\mathrm{H}_{2} \mathrm{O}
$$

A zeolitização a partir da cinza de carvão representa, portanto, um equilíbrio de reação entre a solução alcalina e a fase sólida. Pela elevação da temperatura, a solubilidade dos íons de silica e alumina aumentam, e reações de condensação pelas neoformações de núcleos de cristais são iniciadas. O crescimento de cristais leva a uma completa dissolução de material original amorfo pela formação de diferentes fases de zeólita:

$$
\begin{gathered}
{\left[\mathrm{Na}_{\mathrm{a}}\left(\mathrm{AlO}_{2}\right)_{\mathrm{b}}\left(\mathrm{SiO}_{2}\right)_{e}{ }^{*} \mathrm{HOaN} * \mathrm{H}_{2} \mathrm{O}\right] \leftrightarrow\left[\mathrm{Na}_{x}\left(\mathrm{AlO}_{2}\right)_{x}\left(\mathrm{SiO}_{2}\right)_{\mathrm{y}}\right] * \mathrm{zH}_{2} \mathrm{O}+\text { solução }} \\
\text { íon complexo } \\
\text { zeólita }
\end{gathered}
$$


Os parâmetros mais importantes nos processos de zeolitização por processo hidrotérmico são: a composição química da cinza, a concentração e o tipo do agente de ativação, a relação líquido/sólido, a temperatura, o tempo de reação e a intensidade de agitação (Umanã, 2002).

O tratamento hidrotérmico clássico descrito anteriormente requer grandes tempos de reação, além de obter um produto final impuro com misturas de diferentes zeólitas e grandes quantidades de cinzas.

O segundo método consiste na fusão prévia da mistura cinza-álcali, seguida do tratamento hidrotérmico. A primeira etapa de fusão tem o objetivo de converter as fases cristalinas de sílica e alumina das cinzas de carvão em silicatos e aluminatos de sódio solúveis. Na segunda etapa, o produto da fusão é dissolvido em água em segue ao tratamento hidrotérmico. O método de duas etapas resulta em uma elevada conversão de cinzas de carvão em zeólitas quando comparado ao método convencional de uma etapa, e pode ser direcionado para a síntese de um único tipo de zeólita mediante a variação dos parâmetros de ativação na etapa do tratamento hidrotérmico (Shiguemoto et al, 1993, Elliot, 2006, Izidoro et al., 2012b).

Segundo Ojha et al. (2004) as reações que ocorrem durante o processo de duas etapas para a síntese de zeólitas usando cinzas de carvão podem ser representadas pelas seguintes equações:

$$
\begin{aligned}
& \mathrm{NaOH}+x \mathrm{Al}_{2} \mathrm{O}_{3} \cdot y \mathrm{SiO}_{2} \stackrel{\text { Fusão }}{\longrightarrow} \mathrm{Na}_{2} \mathrm{SiO}_{3}+\mathrm{Na}_{2} \mathrm{AlO}_{2} \\
& \mathrm{NaOH}_{(\mathrm{aq}}+\mathrm{Na}_{2} \mathrm{Al}(\mathrm{OH})_{4(\mathrm{aq})}+\mathrm{Na}_{2} \mathrm{SiO}_{3(\mathrm{aq})} \stackrel{\text { Temperatura ambiente }}{\longrightarrow} \\
& {\left[\mathrm{Na}_{x}\left(\mathrm{AlO}_{2}\right)_{y}\left(\mathrm{SiO}_{2}\right)_{z} \cdot \mathrm{NaOH} . \mathrm{H}_{2} \mathrm{O}\right](\mathrm{gel}) \quad \stackrel{50-350^{\circ} \mathrm{C}}{\longrightarrow}} \\
& \mathrm{Nap}\left[\left(\mathrm{AlO}_{2}\right)_{p}\left(\mathrm{SiO}_{2}\right)_{q}\right] \cdot h \mathrm{H}_{2} \mathrm{O} \quad \text { (cristal em suspensão) }
\end{aligned}
$$

O terceiro método consiste na síntese de zeólita também em duas etapas. Na primeira etapa o silício das cinzas de carvão é extraído por meio de agitação com solução alcalina e reage hidrotermicamente com alumínio de fonte externa na segunda etapa. Esse método também produz material zeolítico de alta 
pureza (Elliot, 2006), porém não são apontadas aplicações para o resíduo sólido gerado quando essa metodologia é utilizada.

Dependendo das condições experimentais e da composição química das cinzas utilizadas, obtêm-se diferentes tipos de zeólitas por qualquer que seja o método de síntese aplicado. As pesquisas mais recentes têm focado os processos que geram zeólitas puras ao invés de uma mistura de materiais. Geralmente, as novas melhorias estão relacionadas à introdução da etapa de fusão antes do tratamento hidrotérmico e/ou à extração de soluções alcalinas das cinzas, processos esses citados anteriormente.

\subsubsection{Síntese de zeólitas visando à obtenção de produto puro}

Dependendo da aplicação, a zeólita obtida a partir de cinzas de carvão deve apresentar maior grau de pureza e uma única fase de zeólita, pois as indústrias requerem produtos padronizados com objetivos comerciais. Deve-se, portanto, ter maior controle sobre as condições de síntese objetivando-se a obtenção de um produto específico.

Como dito anteriormente, a síntese de zeólitas a partir de cinzas de carvão por processo de duas etapas resulta em produtos com maior pureza e com maior taxa de conversão se comparada com a síntese hidrotérmica convencional.

O principal fator que limita a conversão de zeólitas de alta pureza e alta capacidade de troca catiônica a partir de cinzas de carvão pelo método convencional é o conteúdo de fases não reativas e fases resistentes de aluminosilicato, como o quartzo e a mulita presentes nas cinzas (Querol et al., 2002).

No processo de duas etapas, a fusão da mistura cinza-álcali e sua consequente reação no estado sólido, facilita a decomposição da sílica e alumina cristalinas presentes nas cinzas, resultando na formação de silicatos e aluminatos de sódio altamente reativos, os quais ficam rapidamente solúveis em água, favorecendo a formação de zeólitas e aumentando sua quantidade (Ojha et al., 2004; El-Naggar et al., 2008; Ríos et al., 2009; Santos et al., 2010).

Zeólitas com maiores tamanhos de poro e maiores capacidades de troca catiônica possuem aplicabilidade industrial mais ampla, como é o caso das zeólitas Na-A e Na-X, descritas anteriormente (Querol et al., 2002).

$\mathrm{O}$ uso do $\mathrm{NaOH}$ como agente de ativação na síntese de zeólitas é preferível, pois o sódio normalmente faz ligações fracas com a zeólita formada, 
favorecendo posteriores trocas com outros cátions, resultando na formação de produtos com maiores capacidades de trocas catiônicas (Paprocki, 2009).

Objetivando-se maximizar a quantidade de zeólita no produto final e direcionar a formação de uma única fase, Shiguemoto et al. (1993) desenvolveram a fusão alcalina das cinzas seguida do tratamento hidrotérmico para sintetizar a zeólita Na-X. O uso da fusão seguida do processo hidrotérmico fez com que a zeólita $X$ fosse seletivamente sintetizada. A adição de aluminato de sódio à cinza antes da fusão teve sucesso na obtenção da zeólita Na-A.

Hollman et al., (1999) utilizaram cinzas de carvão holandesas para a síntese de zeólitas de alta pureza em duas etapas. A primeira etapa consistiu no aquecimento das cinzas com solução de $\mathrm{NaOH}$ por um período de 6 horas à $90^{\circ} \mathrm{C}$. O filtrado foi tratado com solução de alumina para o ajuste da razão Si/Al entre 0,8 - 2,0 e seguiu para a segunda etapa, com aquecimento de $90^{\circ} \mathrm{C}$ por um período de 48 horas. As zeólitas $\mathrm{Na}-\mathrm{A}, \mathrm{Na}-\mathrm{X}$ e $\mathrm{NaP} 1$ de alta pureza foram obtidas por esse método.

Diferentes concentrações de solução de $\mathrm{NaOH}$ foram testadas para a extração de Si com adição de fonte externa de Al para a síntese de zeólita Na-A pura a partir de cinzas de carvão chinesas. O estudo mostrou que quanto maior a concentração de $\mathrm{NaOH}$ usada na etapa 1 (etapa de extração), um menor tempo de cristalização para a formação da zeólita $A$ é requerido na etapa 2 (etapa de tratamento hidrotérmico) (Wang et al., 2008).

Tanaka e Fujii (2009) sintetizaram zeólitas Na-A e Na-X por processo de duas etapas a partir de cinzas de carvão japonesas. Na primeira etapa, as cinzas foram misturadas com $\mathrm{NaOH}$ sob agitação durante 18 horas à $85^{\circ} \mathrm{C}$. $\mathrm{Na}$ segunda etapa, solução de $\mathrm{NaAlO}_{2}$ foi adicionada ao aluminossilicato amorfo dissolvido na primeira etapa e a mistura foi agitada durante 24 horas à $85^{\circ} \mathrm{C}$.

Yaping et al. (2008) desenvolveram um processo de síntese de zeólitas puras $\mathrm{Na}-\mathrm{A}$ e $\mathrm{Na}-\mathrm{X}$ em processo de duas etapas sem adição alumínio de fonte externa. O silício e o alumínio foram extraídos das próprias amostras de cinzas de carvão provenientes dos precipitadores eletrostáticos de uma usina termelétrica chinesa. $\mathrm{O}$ agente de ativação utilizado na primeira etapa de fusão foi o $\mathrm{Na}_{2} \mathrm{CO}_{3}$. O produto da fusão foi dissolvido em água destilada, passando por aquecimento e mistura subseqüente para obtenção de dois produtos: a cinza sem os silicatos solúveis e a parte solúvel, rica em silício (também chamada de solução mãe- 
remanescente). Ambos os produtos passaram para etapas posteriores com tratamentos específicos (como adição de ácido e dióxido de carbono) e tratamento hidrotérmico convencional.

Usando cinzas de carvão egípcias, El-Naggar et al. (2008) sintetizaram zeólitas $\mathrm{Na}-\mathrm{A}$ e $\mathrm{Na}-\mathrm{X}$ de alta pureza e com elevadas capacidades de troca catiônica por processo de duas etapas e fontes de sílica e alumina das próprias cinzas.

De modo geral, a obtenção de uma zeólita pura requer certos níveis de concentração das espécies que estão reagindo em solução e deve haver um equilíbrio entre a velocidade de dissolução da fase sólida, a qual gera essas espécies que irão reagir em solução e a velocidade de cristalização de zeólita. Portanto, é necessária uma fase sólida homogênea para que se possa manter este equilíbrio regulador durante a cristalização na síntese de zeólitas puras Na-A e Na-X (Giannetto, 1990).

A formação de um tipo particular de zeólita depende de forma significativa da relação $\mathrm{SiO}_{2} / \mathrm{Al}_{2} \mathrm{O}_{3}$ do material de partida (Barrer, 1982). Uma revisão das diferentes relações $\mathrm{SiO}_{2} / \mathrm{Al}_{2} \mathrm{O}_{3}$ de cinzas volantes de carvão e os tipos de zeólitas sintetizadas a partir das mesmas, com enfoque nas zeólitas de maior aplicação, é dada na TAB. 2.

De acordo com a TAB. 2, os estudos citados mostram que é possível a síntese de zeólita de elevada pureza a partir de cinzas de carvão provenientes de usinas termelétricas de diferentes partes do mundo, no entanto, algumas desvantagens relacionadas com a síntese puderam ser observadas até 0 momento: (1) somente um tipo de cinza de carvão foi usado, portanto, não existe conclusão se a mesma metodologia era adequada à síntese de zeólita a partir de cinzas diferentes; (2) usando-se a metodologia de extração de soluções das cinzas, ocorre a geração de resíduos sólidos com a presença de compostos em que não há interesse; (3) o uso de sementes ou agentes direcionadores de estrutura, o uso de pré-tratamento das cinzas ou a aplicação de longos tempos de cristalização (dias ou semanas) são fatores que tornam as sínteses extremamente caras. 
TABELA 2 - Revisão das relações molares de $\mathrm{SiO}_{2} / \mathrm{Al}_{2} \mathrm{O}_{3}$ das cinzas volantes de carvão e os tipos de zeólitas sintetizadas de acordo com diferentes investigações.

\begin{tabular}{lcl}
\hline Tipo de zeólita & $\begin{array}{c}\text { Relação molar } \\
\mathrm{SiO}_{2} / \mathrm{Al}_{2} \mathrm{O}_{3}\end{array}$ & Pesquisador \\
\hline $\mathrm{Na}-\mathrm{X}$ e CAN & 2,06 & Ríos et al., 2009 \\
$\mathrm{Na}-\mathrm{X}$ e Na-A & 3,72 & Shigemoto et al., 1993 \\
$\mathrm{Na}-\mathrm{X}, \mathrm{Na}-\mathrm{A}$ e NaP & 3,83 & Chang e Shih, 1998 \\
$\mathrm{Na}-\mathrm{X}$ eNa-A & 3,83 & Chang e Shih, 2000 \\
$\mathrm{Na}-\mathrm{Y}, \mathrm{Na}-\mathrm{X}$ e Na-A & 3,41 & Rayalu et al., 2000 \\
$\mathrm{Na}-\mathrm{X}$ & 3,12 & Ojha et al., 2004 \\
$\mathrm{Na} \mathrm{A-X} \mathrm{(mistura)}$ & 3,21 & El-Naggar et al., 2008 \\
$\mathrm{Na}-\mathrm{A}$ & 2,53 & Wang et al., 2008 \\
$\mathrm{Na}-\mathrm{P} 1, \mathrm{Na}-\mathrm{X}$ e Na-A & 3,22 & Yaping et al., 2008 \\
$\mathrm{Na}-\mathrm{A}$ e Na-X & 4,18 & Tanaka et al., 2009 \\
\hline
\end{tabular}

A síntese de zeólita de alta pureza a partir de cinzas torna-se um desafio ainda maior pelo fato de cada cinza ser única e possuir diferentes composições químicas, natureza e propriedades.

De acordo com o exposto, a síntese de zeólita de alta pureza a partir de cinzas de carvão brasileiras usando-se metodologia adequada às mesmas se mostra um campo de estudo bastante complexo.

\subsubsection{Aplicações de zeólitas de cinzas de carvão}

O exame dos dados apresentados por diferentes autores revela que uma das principais aplicações potenciais das zeólitas de cinzas de carvão obtidas por tratamento hidrotérmico convencional é a assimilação de íons metálicos tóxicos de águas residuárias (Querol et al., 2002). Diversos trabalhos descrevem o estudo da remoção de íons metálicos tóxicos de soluções aquosas e de efluentes líquidos industriais (Singer e Bergaut, 1995; Srinivasan e Grutzeck, 
1999; Kolousek et al., 1993; Endres, 2001; Gobbi et al., 2004; Querol et al., 2001; Fungaro e Izidoro, 2004 e 2006a; Izidoro e Fungaro, 2007; El-Naggar et al., 2008).

Outras aplicações para as zeólitas de cinzas de carvão foram testadas para o tratamento de solos e melhoria no crescimento de plantas (Ferret, 2004); na inativação de íons metálicos tóxicos ou radioativos de solos (Lin et al., 1998; Moreno et al., 2001a; Umanã, 2002; Fungaro et al., 2004); no tratamento de drenagem ácida de mina (Moreno et al., 2001b; Fungaro e Izidoro, 2006b, Paprocki, 2009); como agente imobilizador de resíduo metalúrgico (FernándezPereira et al., 2002); no descoramento de óleo vegetal (Fungaro e Izidoro, 2006c); como peneiras moleculares para purificação de gás (Querol et al., 2001), adsorventes em filtros de água e ar (García, 2001), na remoção de corantes em água (Fungaro et al., 2005; Fungaro et al., 2009a; Fungaro et al., 2009b; Carvalho et al., 2010), entre outras.

Zeólitas de cinzas de carvão com elevado grau de pureza, sintetizadas por processos de duas etapas, podem ainda possuir aplicações mais nobres, similares às aplicações das zeólitas sintetizadas a partir de soluções saturadas de silicatos e aluminatos, como por exemplo, remover íons $\mathrm{Ca}^{2+}$ e $\mathrm{Mg}^{2+}$ de águas industriais, servir de catalisadores ou suporte para catalisadores em indústrias petroquímicas (Costa et al., 2012), purificar gases (como por exemplo $\mathrm{SO}_{\mathrm{x}}, \mathrm{NO}_{\mathrm{x}}$, $\mathrm{CO}_{2}$, entre outros), remover íons metálicos tóxicos em geral e íons amônio para tratamento de efluentes.

\subsection{Caracterização de cinzas de carvão e zeólitas}

No estudo de qualquer tipo de material, seja ele natural ou sintético, a etapa de caracterização constitui uma ferramenta indispensável para a compreensão de suas propriedades e aplicações. Devido às limitações inerentes a cada uma das técnicas de caracterização, faz-se necessário o uso de técnicas variadas de modo que a caracterização como um todo seja mais completa.

Conhecer as características físicas e químicas das cinzas de carvão e das zeólitas de cinzas de carvão é o primeiro passo para sua aplicação em novos produtos e a conseqüente minimização dos impactos ambientais causados por usinas termelétricas.

No presente estudo é dada uma breve revisão das técnicas utilizadas para a determinação da massa específica, área específica, morfologia, 
composição química, composição mineralógica, e capacidade de troca catiônica de cinzas e zeólitas.

\subsubsection{Massa específica}

A massa específica é a razão entre a massa e o volume de um dado material. Para materiais particulados, como no caso de cinzas e zeólitas, a massa pode ser determinada facilmente por meio de uma balança analítica. A determinação do volume, por sua vez, requer a utilização de equipamentos que levem em consideração os espaços vazios entre as partículas que compõem o material, ou seja, a porosidade.

O volume de um material particulado (descontando-se o volume de poros) pode ser determinado por meio do picnômetro de gás. Normalmente utiliza-se gás Hélio $(\mathrm{He})$ por ser inerte e possuir átomos pequenos, o que permite sua maior penetração nos poros da amostra e a determinação do volume de forma mais precisa (Moura e Figueiredo, 2002).

O picnômetro de He possui uma câmara para a colocação da amostra e uma câmara para a expansão do gás, ambas de volumes conhecidos e calibradas previamente, separadas por uma válvula de expansão (Moura e Figueiredo, 2002).

A análise inicia-se com a colocação da amostra em porta-amostra e passa por uma acomodação, cujo objetivo é a compactação do material. O portaamostra é colocado no equipamento e as condições de análise são determinadas.

A massa da amostra, determinada previamente por meio de uma balança analítica, é um dado de entrada nas condições de análise. A amostra passa por uma limpeza por meio de purgas de gás He, para remoção de impurezas, umidade e agentes contaminantes das câmaras. Normalmente utilizase número de purgas igual a 30 como condição padrão do equipamento. A pressão da purga e a pressão de enchimento da câmara são também padronizadas pelo aparelho e possuem valores de 19,0 psig. O parâmetro corrida de precisão possui valor padrão igual a 30, por meio desse parâmetro, o aparelho considera satisfatória a análise quando cinco leituras consecutivas apresentarem variações de no máximo $0,05 \%$, encerrando a análise automaticamente. 0 número de corridas determina o número de leituras que serão realizadas por análise (Salgado Junior, 2004). 
Segundo Salgado Junior (2004), o grau de fidelidade dos resultados é determinado pela taxa de equilíbrio e seu valor influi diretamente na velocidade da análise.

A massa específica é calculada automaticamente pelo equipamento, por meio da relação entre a massa do sólido que foi previamente introduzida como dado de entrada nas condições de análise e o volume calculado por meio da variação de pressão do gás nas duas câmaras citadas anteriormente (Moura e Figueiredo, 2002).

\subsection{2 Área específica}

A área da superfície externa das partículas por unidade de massa é definida como área específica (Aguiar et al., 2002).

A área específica é determinada por meio de processos de adsorção/dessorção, que são processos físicos e/ou químicos na qual uma substância (adsorbato) é extraída de uma fase e concentrada na superfície de uma outra fase (adsorvente), sendo denominada com um fenômeno de superfície (Rebelo, 2000).

Determina-se a área específica de materiais sólidos por meio da quantidade de adsorbato, geralmente gasoso, necessária para recobrir a superfície de um material adsorvente (Teixeira, et al., 2001).

Em sistemas fechados e mantidos à temperatura constante, a quantidade do adsorbato que adere à superfície do adsorvente é proporcional ao decréscimo da pressão do gás e ao aumento de massa do adsorvente (Teixeira, et al., 2001). Os dados obtidos desses processos de interação adsorvente/adsorbato são utilizados em diversos modelos para o cálculo de área específica, dentre eles, o método BET.

A técnica de BET, baseada na adsorção e dessorção de nitrogênio gasoso é de ampla utilização para a determinação da área específica em diversos campos como, por exemplo, na industria de alimentos, cosméticos, aeroespacial, agricultura, materiais de construção, equipamentos médicos, petroquímica, farmacêutica, entre outros (Quantachrome Instruments, 2010).

O nome da técnica se deve à teoria proposta por Brunauer, Emmett e Teller (BET) onde a quantidade do gás adsorvido, expresso pelo seu volume, é calculado pela diminuição da pressão do gás por meio da lei dos gases ideais. 
Conhecendo-se a área ocupada por uma molécula adsorvida (fixo para o nitrogênio na temperatura estabelecida) é possível o cálculo da área específica do material obtida por tratamento matemático (Teixeira, et al., 2001).

Para que a técnica de BET forneça bons resultados, as impurezas da superfície da amostra devem ser removidas por meio do processo de degaseificação, que consiste no aquecimento da amostra sob pressão reduzida ou sob uma baixa vazão de gás inerte. O processo de degaseificação pode ser acoplado ao equipamento medidor de área específica ou ocorrer em um degaseificador propriamente dito (Quantachrome Instruments, 2010).

No equipamento para as medidas de adsorção/dessorção, um frasco contendo a amostra é inserido em uma câmara que contém nitrogênio líquido. Em seguida, são determinadas as condições de medida. Uma temperatura fixa é determinada mediante um banho de circulação externo, e em seguida, o gás é introduzido na amostra em pequenas quantidades. As moléculas de gás se aderem aos poucos à superfície do sólido adsorvente, formando uma monocamada que a recobre. À medida que as pressões parciais do gás (adsorbato) se aproximam do ponto de saturação, os poros são completamente preenchidos pelo gás e então são traçadas as isotermas de adsorção do gás adsorvido. O gás é removido da superfície da amostra aos poucos, gerando as isotermas de dessorção (Quantachrome Instruments, 2010).

Um software próprio da instrumentação calcula, por meio da teoria de BET, a quantidade de moléculas adsorvidas e dessorvidas da superfície do adsorbato e utiliza esse dado para calcular a área da superfície do adsorvente (Quantachrome Instruments, 2010).

\subsubsection{Morfologia}

A morfologia de materiais pode ser estudada pela obtenção de imagens por meio da microscopia eletrônica de varredura, a qual fornece micrografias com resoluções superiores às fornecidas por microscopia óptica, a qual é limitada por efeitos de difração da ordem de grandeza do comprimento de onda da luz (Skoog, et al., 2002).

Em um microscópio eletrônico de varredura, a superfície de uma amostra sólida é varrida com um feixe de elétrons. Vários tipos de sinais são produzidos pela superfície neste processo, incluindo elétrons espalhados, 
secundários e Auger, fótons de fluorescência de raios $X$ e fótons de várias energias. Todos esses sinais têm sido usados para estudos de superfícies, mas os dois mais comuns são os elétrons retroespalhados e secundários para estudos das imagens e emissão de raios $X$ para análises qualitativas e quantitativas (Skoog, et al., 2002).

As amostras que conduzem eletricidade são mais fáceis de estudar, porque o fluxo livre de elétrons minimiza o acúmulo de carga e a possibilidade de degradação térmica da amostra. Uma série de técnicas foi desenvolvida para se obter imagens de microscopia eletrônica de amostras não-condutoras. 0 procedimento mais comum envolve o recobrimento da superfície com um filme metálico fino (Skoog, et al., 2002).

\subsubsection{Composição Química}

A composição química de materiais sólidos, líquidos e gasosos pode ser facilmente determinada pela técnica de fluorescência de raios $X$ (FRX), a qual permite identificar e quantificar elementos químicos de quase toda a tabela periódica.

Quando uma amostra é irradiada com raios $X$ primários, o elétron da camada mais interna do átomo é ejetado, ocasionando um vazio. O átomo excitado volta para o estado fundamental por meio de uma série de transições eletrônicas. Esse processo de transição eletrônica emite raios $X$ fluorescentes característicos. Tal fenômeno é conhecido como fluorescência de raios $X$ (Skoog, et al., 2002; UFSC, $2010^{1}$ ).

Portanto, cada elemento emite radiação característica (de energia e comprimento de onda definidos) que são detectados, e utilizados para análises qualitativas. As informações quantitativas dos elementos presentes na amostra têm relação direta com a intensidade da radiação emitida (Skoog, et al, 2002).

Segundo Fonseca (2007), apud Jenkins e de Vries (1970), a técnica de fluorescência de raios $X$ pode ser dividida nas categorias de comprimento de onda dispersivo (seqüencial ou simultâneo), energia dispersiva e especiais (fonte de radiação sincrotron, reflexão total e indução por partícula).

\footnotetext{
${ }^{1}$ http://www.materials.ufsc.br
} 
A técnica de fluorescência por dispersão de energia (EDXRF) apresenta menor resolução que a técnica por dispersão de comprimento de onda (WDXRF), porém é também amplamente utilizada para análises rápidas e exploratórias (Fonseca, 2007).

A fluorescência de raios $X$ por dispersão de comprimento de onda (WDXRF) utilizando o método de parâmetros fundamentais (FP), fornece análises semi-quantitativas e multielementares, além de serem não destrutivas e rápidas. Este método relaciona a intensidade fluorescente teórica dos elementos químicos por meio de amostras de composição química conhecida e a intensidade fluorescente medida, podendo, dessa forma, determinar a composição química desconhecida (Scapin, 2003).

A técnica de fluorescência de raios $X$ não é muito sensível para a detecção de elementos leves, devido, em parte, a emissão Auger provocada que reduz a intensidade da fluorescência de raios $X$ na amostra (Fonseca, 2007).

\subsubsection{Composição Mineralógica}

A técnica de difratometria de raios $X(D F R X)$ possui ampla aplicação no campo de caracterização de materiais devido às informações que fornece sobre a composição mineralógica, o arranjo dos átomos e o estudo de detalhes do reticulado cristalino de vários materiais (Atkins e Jones, 2001; Padilha e Filho, 1985).

Para a identificação dos compostos presentes em cinzas de carvão e zeólitas, a DFRX é uma ferramenta indispensável pelo fato desse tipo de material possuir diversos compostos na forma cristalina.

Raios X são gerados tanto pela desaceleração dos elétrons num alvo metálico quanto pela excitação dos elétrons dos átomos do alvo. Um alvo de cobre bombardeado por elétrons é considerado um bom alvo por produzir uma linha forte CuKa (Kittel, 1978).

O fenômeno de difração ocorre porque raios $X$ são espalhados pelo ambiente ordenado de um cristal, causando interferências entre as ondas de raios $X$. As interferências construtivas e destrutivas formam padrões capazes de fornecer informações relativas às características dos compostos presentes em uma amostra. A difração ocorre quando o comprimento de onda da radiação é comparável aos espaçamentos característicos dentro do objeto que causa a 
difração. Portanto, para se obter padrões de difração de camadas de átomos, é necessário usar uma radiação com um comprimento de onda comparável ao espaçamento das camadas, que é o caso dos raios X (Atkins e Jones, 2001, Skoog et al., 2002).

Segundo Kittel (1978), os principais métodos de difração são: o Método de Laue, que é usado para a determinação da orientação de cristais em experiências de física do estado sólido; o Método do cristal giratório usado para a determinação da configuração das enzimas, determinação da forma de moléculas, entre outras aplicações; e o Método do pó para amostras pulverizadas.

$\mathrm{Na}$ técnica de difratometria pelo método do pó, um feixe de raios $X$ monocromático é direcionado para uma amostra pulverizada, espalhada em um suporte, e a intensidade de difração é medida quando um detector é movido em diferentes ângulos. $O$ padrão obtido é característico do material na amostra e pode ser identificado por comparação com padrões de uma base de dados do sistema ICDD (Joint Committee on Powder Diffraction Standards - JCPDS) da International Union of Cristallography (Atkins \& Jones, 2001; Scapin, 2003).

Sendo assim, a difratometria de raios $X$ pelo método do pó fornece uma impressão digital da amostra. Também pode ser utilizada para identificar o tamanho e o tipo da cela unitária medindo-se o espaçamento das linhas no padrão da difração (Atkins e Jones, 2001).

A equação central para analisar os resultados em um experimento de difratometria pelo método do pó é a equação de Bragg (Eq. 3).

$$
2 d \operatorname{sen} \theta=\lambda
$$

Onde, $\theta$ são os ângulos na qual a interferência construtiva ocorre com o espaçamento $d$, das camadas de átomos nas amostras para raios $X$ de comprimento de onda $\lambda$ (Atkins e Jones, 2001).

Os raios $X$ são refletidos pelo cristal somente se o ângulo de incidência satisfaz a condição estabelecida pela Lei de Bragg (Skoog, et al., 2002).

A composição química e mineralógica das cinzas de carvão são as variáveis chave para a determinação de sua reatividade (lyer e Scott 2001). 


\subsubsection{Capacidade de troca catiônica}

Troca iônica é o processo no qual uma ou várias espécies iônicas são adsorvidas acompanhadas simultaneamente pelo processo de dessorção de uma quantidade equivalente de espécies iônicas (Bruno, 2000).

Entende-se por Capacidade de Troca Catiônica (CTC), a quantidade de cátions que um determinado material pode adsorver e trocar. No caso dos aluminossilicatos, a troca de cátions é possível devido ao desequilíbrio das cargas elétricas presentes em sua estrutura cristalina e à presença de cátions trocáveis fixos eletrostaticamente para compensar estes desequilíbrios (Aguiar et al., 2002).

Para as zeólitas de cinzas de carvão, a troca de átomos de Si por átomos de Al no processo de síntese, resulta na formação de uma estrutura aniônica nas zeólitas que é compensada por íons sódio do agente de ativação (hidróxido de sódio) utilizado na síntese. Os íons $\mathrm{Na}^{+}$neutralizam as cargas negativas da estrutura da zeólita formada e podem ser trocados por outros íons metálicos em solução aquosa.

A preferência com que um trocador exibe por determinado cátion tem relação com a energia livre de hidratação do íon, o tamanho do raio iônico hidratado, a valência do cátion, a interação cátion/superfície do material adsorvente, a diferença entre a concentração das fases, entre outros fatores (Izidoro, 2008; Aguiar et al., 2002).

Existem diversos métodos descritos em literatura para a determinação de CTC para zeólitas, porém não existe uma metodologia padrão para essa determinação (Paprocki, 2009).

Segundo Aguiar et al. (2002), o método mais utilizado para a determinação de CTC para aluminossilicatos consiste na saturação do material com uma solução de acetato de sódio ou potássio e o posterior deslocamento destes cátions pelo cátion amônio, por tratamento com uma solução de acetato de amônio. A quantidade do íon $\mathrm{Na}^{+}$deslocado pelo $\mathrm{NH}_{4}^{+}$é normalmente determinada em solução por espectroscopia com fonte de plasma acoplado indutivamente (ICP).

A CTC é normalmente expressa em miliequivalentes de íons por unidade de massa do material adsorvente em gramas (meq $\mathrm{g}^{-1}$ ). 
Diversas aplicações das zeólitas de cinzas de carvão se devem a sua capacidade de trocar íons, por isso, a determinação da CTC neste material é extremamente importante.

\subsection{Produção de material zeolítico em maior escala}

A produção de zeólita em escala piloto ou industrial é o próximo passo na busca da sustentabilidade pelas usinas termelétricas a carvão por proporcionar o uso de quantidades significativas de cinzas.

O processo de síntese de zeólita em maior escala em uma única etapa é mais viável economicamente do que a síntese em duas etapas, pois esta última requer grandes quantidades de calor na etapa de fusão da mistura cinza-álcali, consumindo grandes quantidades de energia, o que inviabilizaria o processo.

No ano de 1989, com o objetivo de produzir zeólita a partir de cinzas em escala comercial, a empresa Nippon Steel Corp. construiu na cidade de Tokai, Japão, uma "Planta de demonstração para produção de zeólita a partir de cinza leve". A síntese de zeólita foi feita mediante tratamento convencional e os produtos obtidos na forma de pó e agregados eram comercializados (Clean Japan Center, 1991).

Também no Japão, na cidade de Osaka, uma planta de produção de zeólita de cinzas de carvão em escala comercial é operada por Maeda Corporation. Os produtos dessa empresa são usados na purificação de água, adsorção de íons metálicos e na área de desodorização (Elliot, 2006).

Biniwale et al. (2001) fizeram uma estimativa de custo para a produção da zeólita A usando cinzas de carvão indianas. A análise de custo foi baseada em um processo em batelada para a produção de $2500 \mathrm{~kg}$ de zeólita e o retorno de investimento foi estimado em um período de 42 meses. O custo de produção de zeólita estimado é de 25 a 30\% menor que a zeólita comercial análoga tipo A.

Umaña (2002) sintetizou zeólitas a partir de cinzas de carvão espanholas em escala piloto por tratamento convencional com o objetivo de comprovar a reprodutibilidade dos experimentos realizados em escalas menores. Os estudos foram realizados nas instalações da empresa Clariant $S$. $A$. na Espanha, e os produtos obtidos em escala piloto foram similares aos produtos obtidos em escala de laboratório. 
Uma das maiores usinas termelétricas a carvão do mundo, a Chubu Electric Power's Hekinan Thermal Power Station, localizada na cidade de Hekinan, Japão, produziu entre os anos de 2004 e 2011 aproximadamente 3000 toneladas de zeólitas de cinzas de carvão. O produto era utilizado em equipamentos para a desodorização de amônia, purificação de água, e melhoria do solo para o cultivo de plantas (Chubu Electric Power, 2010).

Um processo de produção de zeólitas em planta piloto usando $130 \mathrm{~kg}$ de cinzas de carvão foi proposto pela empresa japonesa KEM Corporation. O equipamento desenvolvido foi baseado nos estudos de Moriyama et al. (2005). A inovação do processo consiste em diminuir os tempos de reação usando misturador de alta pressão, menores quantidades de solução alcalina e retirada de água durante o processo. 


\section{MATERIAIS E MÉTODOS}

\subsection{Amostras de cinzas de carvão}

As cinzas volantes geradas nas usinas termelétricas a carvão são produzidas em quantidades bem superiores às cinzas pesadas. Sendo assim, as amostras escolhidas para o presente estudo foram as cinzas volantes geradas em cada uma das cinco usinas a carvão existentes no Brasil no ano de 2009.

As amostras foram coletadas no mês de Julho do ano de 2009 e foram simbolizadas por: CFG, CJL, CSJ, CCH e CPM, para representar as cinzas provenientes das usinas UTFG, UTJL, UTSJ, UTCH e UTPM, respectivamente, descritas no item 3.2.

As cinzas foram coletadas diretamente do sistema de retenção de cinza volante de menor granulometria próprio de cada usina e estão listados na TAB. 3. Os sistemas de retenção estão representados na FIG. 12. As cinzas foram utilizadas no presente estudo sem nenhum tratamento prévio.

TABELA 3 - Sistema de retenção de cinzas volantes de menor granulometria para as usinas brasileiras a carvão

\begin{tabular}{ccc}
\hline Usina & Cinza coletada & Sistema de retenção \\
\hline UTFG & CFG & Filtro de mangas \\
UTJL & CJL & Precipitadores eletrostáticos \\
UTSJ & CSJ & Filtro ciclone \\
UTCH & CCH & Precipitadores eletrostáticos \\
UTPM & CPM & Precipitadores eletrostáticos \\
\hline
\end{tabular}




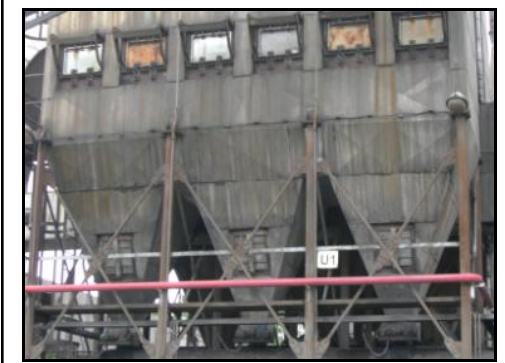

(a)

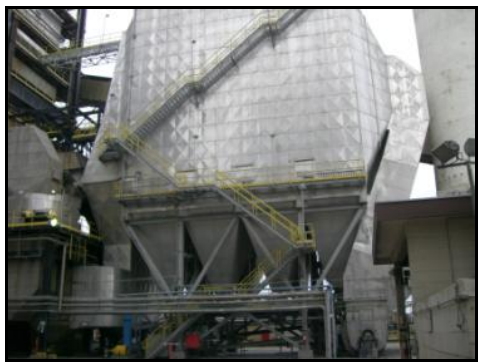

(b)

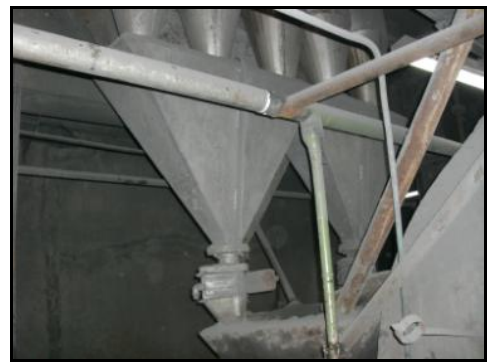

(c)

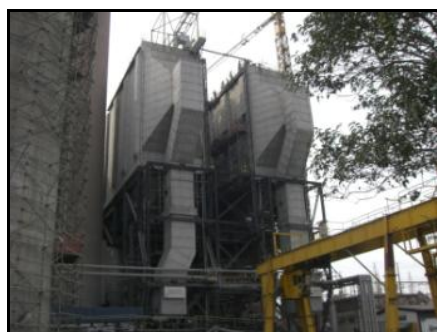

(d)

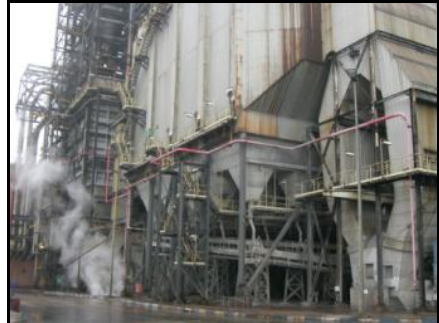

(e)

FIGURA 12 - Sistemas de retenção de cinzas volantes de menor granulometria produzidas pelas usinas brasileiras a carvão: (a) Filtro de mangas (UTF);

(b) Precipitador eletrostático (UTJL); (c) Saída de cinzas do Filtro ciclone (UTSJ); (d) Precipitador eletrostático (UTCH); (e) Precipitador eletrostático (UTPM)

\subsection{Síntese de zeólitas}

\subsubsection{Método Clássico}

A metodologia do tratamento hidrotérmico clássico para as cinzas de carvão consistiu na adição de $160 \mathrm{~mL}$ de NaOH 3,5 mol L ${ }^{-1}$ a $20 \mathrm{~g}$ de cinzas secas (relação cinzas/solução $0,125 \mathrm{~g} \mathrm{~mL}^{-1}$ ). A suspensão foi colocada em béquer de teflon com vidro de relógio na parte superior e aquecida em estufa, a $100 \stackrel{\circ}{\mathrm{C}}$, por 24 h. Filtração em papel de filtro quantitativo (Nalgom 3400, diâmetro $=150 \mathrm{~mm}$ ), lavagem com água desionizada até $\mathrm{pH} \sim 9$ e secagem do material a $40^{\circ} \mathrm{C} \mathrm{em}$ estufa por $12 \mathrm{~h}$ foram as etapas posteriores (Henmi, 1987). Na FIG. 13 é mostrado o fluxograma do processo de síntese. 


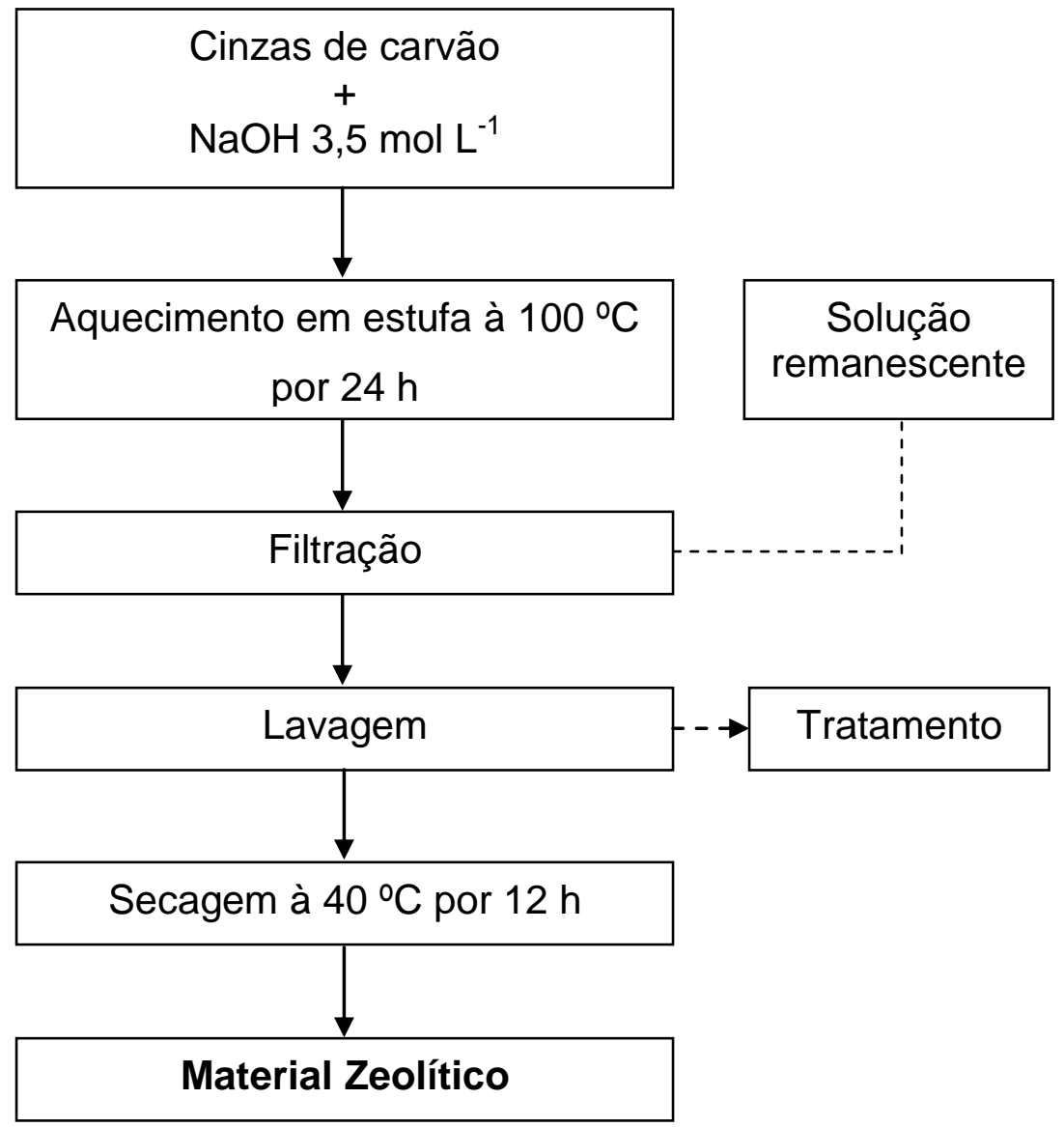

FIGURA 13 - Fluxograma de síntese de zeólita pelo método hidrotérmico clássico a partir de cinzas de carvão

As zeólitas sintetizadas a partir de cada uma das cinzas volantes pelo método convencional foram simbolizadas no presente trabalho por ZFG, ZJL, $\mathrm{ZSJ}, \mathrm{ZCH}$ e ZPM, para representar as zeólitas originadas a partir das cinzas provenientes das usinas UTFG, UTJL, UTSJ, UTCH e UTPM, respectivamente.

\subsubsection{Método de duas etapas usando fusão}

Duas amostras de cinzas de carvão ( $\mathrm{CJL}$ e $\mathrm{CCH}$ ) foram selecionadas após a conclusão da primeira etapa do estudo para a síntese de zeólitas A e X de alta pureza. Ambas as cinzas foram usadas sem pré-tratamento e não foram utilizadas sementes ou agentes direcionadores de estrutura durante a síntese.

Diversas metodologias de síntese de zeólitas puras A e X usando-se diferentes temperaturas, proporções cinza/ $\mathrm{NaOH}$, tempos de agitação e cristalização, adição ou não adição de alumínio, etc., foram testadas ao longo de meses paralelamente à observação e interpretação de difratogramas de raios $X$ 
dos produtos obtidos de modo a determinar as ótimas condições de síntese adequadas à síntese dos produtos desejados.

O tempo de cristalização e a quantidade de alumínio adicionado foram estritamente controlados uma vez que ambos os parâmetros são cruciais para evitar a formação de outras fases quando a zeólita que se deseja obter está sendo formada (Chang e Shih, 1998; Wang et al., 2008).

A síntese da zeólita $X$ ocorreu moendo-se $10 \mathrm{~g}$ de cinzas volantes de carvão com $12 \mathrm{~g}$ de hidróxido de sódio. A mistura foi colocada em cadinho de porcelana e aquecida em mufla a $550{ }^{\circ} \mathrm{C}$ por uma hora. Depois de resfriar a temperatura ambiente, aluminato de sódio e água foram adicionados à mistura previamente moída para o controle da razão molar. A suspensão foi então agitada à temperatura ambiente por $16 \mathrm{~h}$ e aquecida em estufa à $100^{\circ} \mathrm{C}$ por $24 \mathrm{~h}$. Depois de resfriar à temperatura ambiente, a suspensão foi filtrada e o sólido foi lavado com $1 \mathrm{~L}$ de água desionizada. A etapa posterior foi secagem a $105^{\circ} \mathrm{C}$ por $16 \mathrm{~h}$ em estufa. Os produtos obtidos foram simbolizados por ZXJL e ZXCH, baseandose na fonte de cinzas de carvão da qual foram gerados, provenientes das usinas UTCH e UTJL, respectivamente (Izidoro et al., 2012b).

Para a síntese de zeólita $A$, um processo semelhante ao da zeólita $X$ foi realizado, variando-se apenas a quantidade de aluminato de sódio utilizado (calculado para cada amostra de relação $\mathrm{SiO}_{2} / \mathrm{Al}_{2} \mathrm{O}_{3}$ específica) e o tempo de tratamento hidrotérmico aplicado, que ocorreu durante $7 \mathrm{~h}$. As zeólitas A obtidas foram simbolizadas por ZAJL e ZACH.

Menores tempos no tratamento hidrotérmico para a síntese de zeólita $A$ foram aplicados devido a mais rápida formação dessa zeólita, a qual apresenta cristais cúbicos, quando comparada à zeólita $X$, formada por cristais octaédricos. Sendo assim, a estrutura maior e mais complexa da zeólita $X$ requer maiores tempos de cristalização (Petrovic et al., 1993).

A síntese detalhada das zeólitas X e A é apresentada no fluxograma da FIG. 14. 

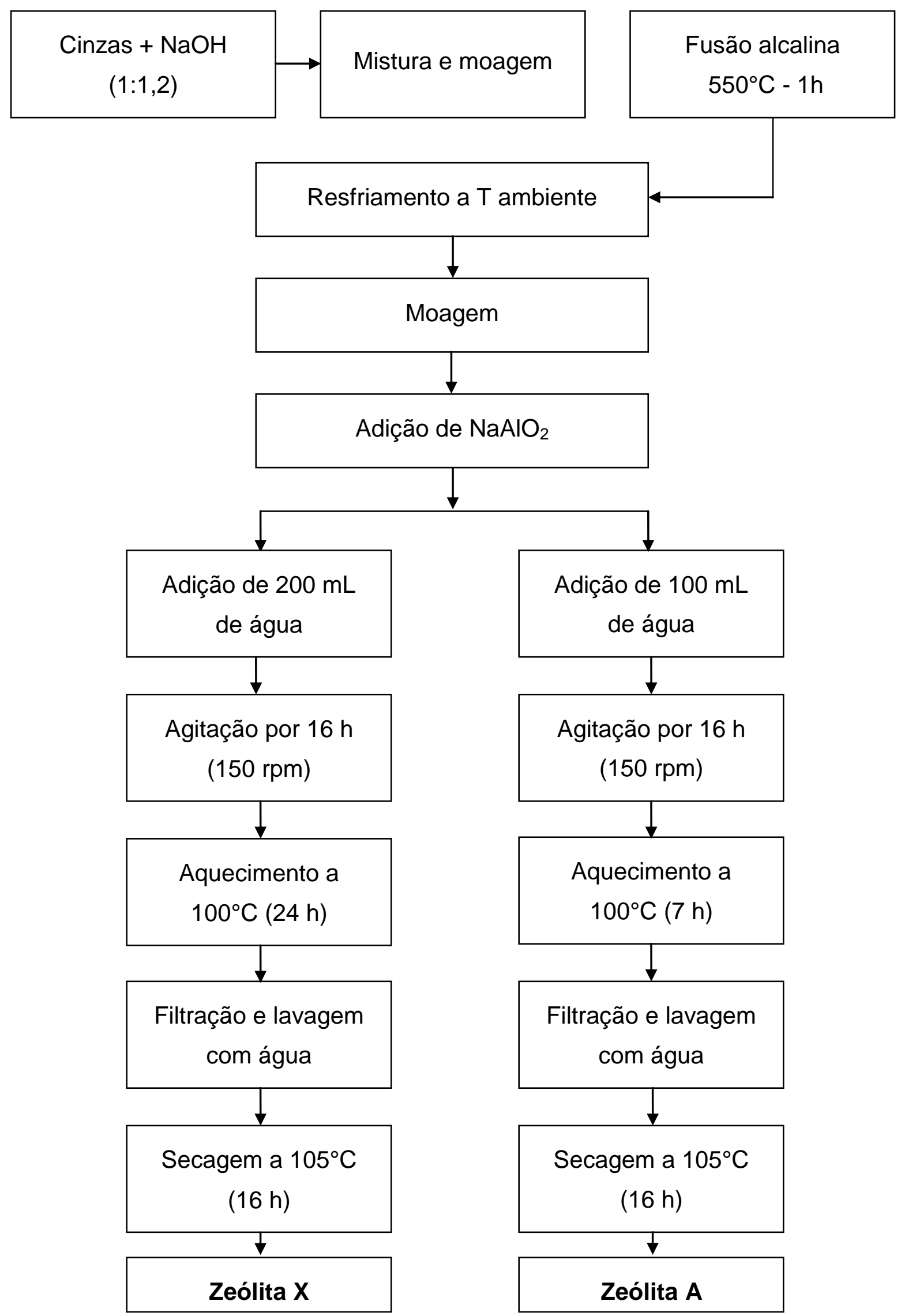

FIGURA 14 - Fluxograma de síntese de zeólita pelo método de duas etapas usando fusão 


\subsubsection{Método de duas etapas usando solução remanescente de síntese hidrotérmica clássica}

O estudo da possibilidade de reaproveitamento da solução remanescente de síntese hidrotérmica clássica foi realizado usando-se as soluções geradas após a etapa de filtração do tratamento hidrotérmico clássico descrito no item 4.2.1e ilustrado na FIG. 13.

As soluções remanescentes obtidas a partir das cinzas CJL e CCH foram usadas para a síntese de novos produtos zeolíticos para comparação com os produtos obtidos pelos outros métodos usando as mesmas matérias primas.

Usando-se $20 \mathrm{~g}$ de cinzas de carvão e $160 \mathrm{~mL}$ de hidróxido de sódio 3,5 mol. $\mathrm{L}^{-1}$ para a reação hidrotérmica, obteve-se cerca de $30 \mathrm{~mL}$ de solução remanescente, a qual foi submetida nas análises químicas de espectrometria de emissão óptica com plasma de argônio (ICP-OES - Spectroflame M120) e espectrofotometria de absorção atômica com atomização por forno de grafita (GFAAS - Perkin-Elmer Analyst 800) para a quantificação dos elementos presentes.

$\mathrm{O}$ ajuste de $\mathrm{pH}$ das soluções remanescentes em torno de $2 \mathrm{com} \mathrm{HNO}_{3}$ concentrado (Labsynth Produtos para laboratório Ltda.) foi necessário antes das amostras serem submetidas aos ensaios. As amostras de solução remanescente provenientes do tratamento hidrotérmico das cinzas de carvão CJL e CCH foram nomeadas como JLREM e CHREM, respectivamente.

Os resultados da análise química quantitativa de ambas as soluções remanescentes mostraram que a síntese de novos produtos zeolíticos era possível devido à presença abundante de silício (elemento estrutural formador de zeólitas). Porém, a quantidade de alumínio era insuficiente e deveria ser adicionada com o objetivo de sintetizar as zeólitas $A$ e $X$, de elevado interesse comercial.

Para a síntese de novos produtos zeolíticos, preparou-se uma mistura de $150 \mathrm{~mL}$ de solução de $\mathrm{NaOH}$ 1,75 mol L-1 e aluminato de sódio, usado como como fonte de alumínio em quantidade calculada para cada amostra específica com objetivo de sintetizar zeólitas A e X. A mistura foi homogeneizada durante 10 min em agitador magnético. Em seguida, a solução remanescente da síntese hidrotérmica anterior foi adicionada à mistura a qual foi agitada novamente durante $1 \mathrm{~min}$. A mistura então seguiu para aquecimento a $100^{\circ} \mathrm{C}$ durante $20 \mathrm{~h}$. 
Os cristais formados passaram posteriormente pelas etapas de filtração em papel de filtro quantitativo (Nalgom 3400 , diâmetro $=150 \mathrm{~mm}$ ), lavagem com água desionizada até $\mathrm{pH} \sim 9$ e secagem do material a $105^{\circ} \mathrm{C}$ em estufa por $3 \mathrm{~h}$. Na FIG. 15 é mostrado o fluxograma do processo de síntese. Os produtos obtidos foram misturas de zeólitas e foram simbolizados no presente estudo por ZMJL e $\mathrm{ZMCH}$ para representar os produtos provenientes das cinzas $\mathrm{CJL}$ e $\mathrm{CCH}$, respectivamente.

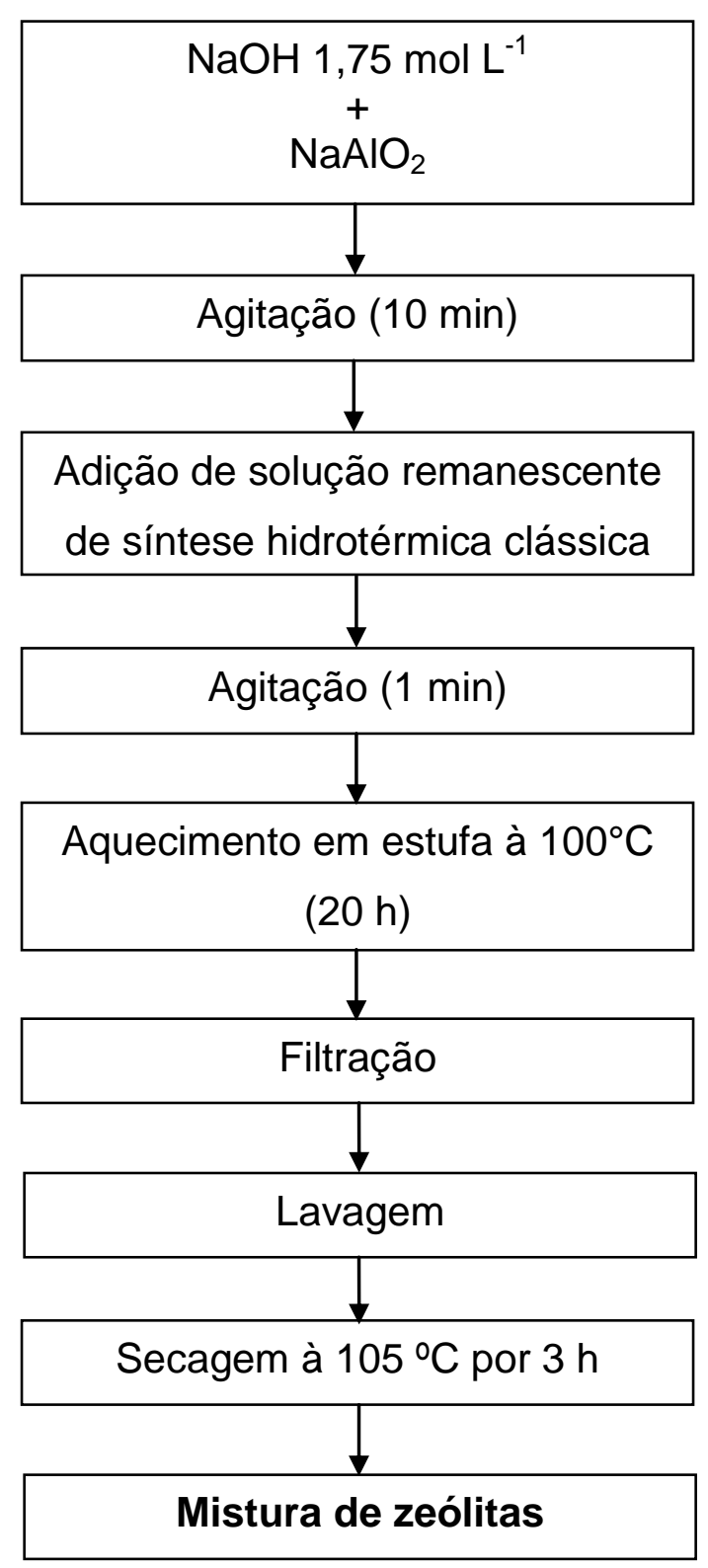

FIGURA 15 - Fluxograma de síntese de zeólita pelo método de duas etapas usando solução remanescente de síntese hidrotérmica clássica 


\subsection{Caracterização das cinzas de carvão e dos produtos de síntese}

\subsection{1 $\mathrm{pH}$ e condutividade}

Para os ensaios de $\mathrm{pH}$ e condutividade, 0,25 $\mathrm{g}$ das amostras de cinza ou zeólita sintetizadas por tratamento convencional foram colocadas em contato com $25 \mathrm{~mL}$ de água desionizada (milli-Q plus, Millipore). A mistura foi agitada por $24 \mathrm{~h}$ em agitador mecânico (Ética - Mod. 430 / Orbital Shaker Incubator - Mod. SF-670) a $120 \mathrm{rpm}$. Em seguida, as amostras foram filtradas e o pH (MS Tecnopon - Mod. MPA 210 / TPS - Mod. WP-81) e a condutividade (BEL Engineering - Mod. W12D) foram determinadas (Umanã, 2002; Wang e Zhu, 2006).

\subsubsection{Umidade e perda por calcinação}

Os conteúdos de umidade e perda por calcinação das cinzas de carvão em estudo foram calculados de acordo com a perda de massa das amostras submetidas ao aquecimento de $105^{\circ} \mathrm{C}$ durante $24 \mathrm{~h}$ em estufa e de $1050^{\circ} \mathrm{C}$ durante $4 \mathrm{~h}$ em mufla para cada um dos ensaios, respectivamente, e expressos em porcentagem. A massa utilizada foi de 0,5 g (Umaña, 2002).

\subsubsection{Massa específica}

O picnômetro de He do Laboratório de Metrologia do Centro do Combustível Nuclear (CCN) do Instituto de Pesquisas Energéticas e Nucleares (IPEN) da marca Micromeritcs Instrument Corporation, modelo Accupyc 1330 foi utilizado para a determinação de massa específica de cinzas e zeólitas sintetizadas pelo tratamento hidrotérmico convencional. Foi utilizado cilindro de gás He 4.5 (99,995\% de pureza).

A massa das amostras foi determinada em balança analítica e funcionou como dado de entrada nas condições de medida do equipamento. Após a determinação de massa, as amostras foram inseridas em porta amostra e foram determinadas as condições de medida padrão do picnômetro utilizado a seguir: número de purgas: 30; pressão de purga: 19,5 psig; número de repetições (corridas): 30; pressão de preenchimento: 19,5 psig; taxa de equilíbrio: 0,005 psig/min; porcentagem de variação: 0,05\%; temperatura de ensaio: $23,0^{\circ} \mathrm{C}$. Todas as leituras foram feitas em triplicata. 


\subsection{4 Área específica}

Para a determinação de área específica das cinzas de carvão e dos produtos zeolíticos da primeira fase do estudo, um grama de cada amostra foi colocado primeiramente em porta-amostra e submetido ao degaseificador Nova 1000 Degasser, Modelo Nova 1000, para retirada de voláteis e umidade durante um período de 12 horas a $150 \stackrel{\circ}{\circ}$ no banho de areia. O porta-amostra foi retirado do sistema e inserido no equipamento de adsorção/dessorção.

$\mathrm{A}$ área específica pelo método BET foi determinada pelo equipamento BET Surface Area Analyser, versão 3.11, Quanta Chrome Nova - 1200. A massa específica e a massa das amostras foram dados de entrada nas condições de medida do equipamento. O equipamento forneceu os valores finais de área específica, calculadas por meio das isotermas de adsorção e dessorção de nitrogênio em condições de pressão reduzida de $0,1 \mathrm{mmHg}$. Essa medida foi realizada no Centro de Ciência e Tecnologia dos Materiais (CCTM) do Instituto de Pesquisas Energéticas e Nucleares (IPEN).

\subsubsection{Morfologia}

Para verificação da morfologia das cinzas de carvão e das zeólitas sintetizadas por tratamento hidrotérmico convencional, as amostras foram colocadas em suporte metálico e recobertas com uma fina camada de Au para torná-las condutoras e gerar imagens de melhores resoluções. $O$ equipamento utilizado foi o microscópio eletrônico de varredura (MEV), modelo XL30, marca Philips, com aumentos de 500, 1000 e 4000x a 15 kV. Esse ensaio foi realizado no Centro de Ciência e Tecnologia dos Materiais (CCTM) do Instituto de Pesquisas Energéticas e Nucleares (IPEN).

A morfologia das zeólitas de elevada pureza obtidas na segunda fase do estudo foram verificadas usando o microscópio eletrônico de varredura Zeiss EVO 40 XVP, do departamento de física da Curtin University of Technology, Perth, Austrália. As amostras foram previamente cobertas com uma fina camada de ouro para tornarem-se condutoras antes da obtenção das imagens.

\subsubsection{Composição química}

A composição química das cinzas e zeólitas sintetizadas pelo método convencional e pelo método de duas etapas com fusão prévia foi determinada 
pelo espectrômetro de fluorescência de raios X modelo RIX 3000, da marca Rigaku Company com sistema de dispersão de comprimento de onda (WDXRF) do Centro de Química e Meio Ambiente (CQMA) do Instituto de Pesquisas Energéticas e Nucleares (IPEN). O método utilizado para determinação semiquantitativa foi de parâmetros fundamentais (FP) (Lanchance e Claisse, 1995; Buhrke, et al, 1998; Scapin, 2003).

A técnica utilizada foi a de pó solto, na qual a amostra é colocada diretamente em porta amostra metálico em quantidade suficiente para preenchêlo, e acomodada manualmente. Um filme de polietileno foi utilizado para recobrir a amostra para que durante a análise não houvesse perda de material.

\subsubsection{Composição mineralógica}

As amostras de cinzas de carvão e zeólitas de cinzas de carvão sintetizadas por tratamento hidrotérmico convencional e pelo método de duas etapas usando solução remanescente de síntese anterior foram colocadas em porta amostra de vidro e analisadas em difratômetro de raios $X$ Rigaku modelo Miniflex II com monocromador e com radiação Cu K- $\alpha$, gerada a $30 \mathrm{kV}$ e $15 \mathrm{~mA}$. $A$ velocidade de varredura era de $0,05 \% / s$ e com $2 \theta$ variando entre 5 e 80 graus.

A identificação das fases cristalinas (composição mineralógica) se fez com auxílio do programa de computador PDXL Software (programa da Rigaku) e do banco de dados de padrões de difração do International Centre for Diffraction Data (ICDD)/Joint Committee on Power Diffraction Standards (JCPDS). Essa análise foi realizada no Centro de Química e Meio Ambiente (CQMA) do Instituto de Pesquisas Energéticas e Nucleares (IPEN).

A determinação das fases presentes nas zeólitas de alta pureza sintetizadas pelo método de duas etapas com fusão foram obtidas pelo difratômetro de raio $X$ Bruker-AXS D8 Advance Power Diffractometer usando radiação $\mathrm{Cu} \mathrm{K}-\alpha$, gerada a $40 \mathrm{kV}$ e $40 \mathrm{~mA}$. A velocidade de varredura era de $0,02^{\circ}$ s e variou de 5 a $80^{\circ} 2 \theta$. A identificação de fases foi feita com o auxílio do banco de dados de padrões de difração do International Centre for Diffraction Data (ICDD) com a ajuda da base de dados do programa Diffrac Plus EVA Bruker. Essa análise foi realizada no departamento de física da Curtin University of Technology, Perth, Austrália. 
Para estimativa semiquantitativa das porcentagens das fases presentes nas zeólitas de alta pureza obtidas pelo método de duas etapas com fusão prévia utilizou-se o software PDXL e o banco de dados de padrões de difração ICDD do CQMA do IPEN. A estimativa foi feita usando-se o método da razão de intensidade relativa, Relative Intensity Ratio Method - RIR Method -, no qual o software estima as porcentagens das fases presentes baseando-se na razão de intensidade entre a amostra e o padrão identificado no banco de dados.

\subsubsection{Capacidade de troca catiônica}

Os estudos de Capacidade de Troca Catiônica (CTC) de cinzas e zeólitas sintetizadas pelo tratamento hidrotérmico convencional foram feitos pela saturação de $1,0 \mathrm{~g}$ de amostra com $100 \mathrm{~mL}$ de solução de acetato de sódio $1 \mathrm{~mol} \mathrm{~L}^{-1}\left(\mathrm{CH}_{3} \mathrm{COONa} \cdot 3 \mathrm{H}_{2} \mathrm{O}\right)$. A suspensão foi agitada à temperatura ambiente por $24 \mathrm{~h}$ à $120 \mathrm{rpm}$. Em seguida, as amostras foram filtradas e o retido no filtro, lavado com 1,0 L de água desionizada e seco em estufa a $80^{\circ} \mathrm{C}$. As amostras secas foram pesadas e agitadas à temperatura ambiente por $24 \mathrm{~h}$ à 120 rpm com $100 \mathrm{~mL}$ de solução de acetato de amônio $1 \mathrm{~mol} \mathrm{~L}^{-1}\left(\mathrm{CH}_{3} \mathrm{COONH}_{4}\right)$.

A suspensão foi filtrada e o íon $\mathrm{Na}^{+}$deslocado pelo íon $\mathrm{NH}_{4}{ }^{+}$foi determinado. Para as cinzas de carvão e os materiais zeolíticos da primeira fase, a concentração do íon $\mathrm{Na}^{+}$foi determinada pela técnica de espectrometria de emissão óptica com plasma indutivamente acoplado (ICP-OES).

A concentração do íon sódio trocado nas zeólitas de alta pureza sintetizadas na segunda fase do estudo foi, por sua vez, determinado pelo espectrofotômetro de absorção atômica (Varian - Spectraa-50) do departamento de Engenharia Química da Curtin University of Technology, Perth, Austrália.

A quantidade do íon sódio, expressa em $\mathrm{mg} \mathrm{L}^{-1}$ foi convertida em unidades usuais de CTC, miliequivalentes-grama (meq $\mathrm{g}^{-1}$ ).

\subsection{Reagentes e soluções}

Todos os reagentes usados são de grau analítico.

Para síntese de material zeolítico por tratamento hidrotérmico convencional utilizou-se hidróxido de sódio Merck. Para a síntese de zeólitas de alta pureza usando fusão prévia, hidróxido de sódio (97\%) e aluminato de sódio (100 \%) obtidos da Sigma-Aldrich Pty. Ltd. (Austrália) foram usados. 
Na síntese de zeólitas pelo método de duas etapas usando solução remanescente de síntese anterior utilizou-se hidróxido de sódio e aluminato de sódio, ambos da Merck.

\subsection{Produção de material zeolítico em maior escala}

A descrição do processo de produção de material zeolítico em escala piloto foi feita usando-se o mínimo de automação possível no processo.

O levantamento de todos os equipamentos e materiais básicos necessários para a produção de material zeolítico a partir de cinzas de carvão por processo em batelada foi realizado.

As características do processo foram generalizadas de modo que a planta piloto pudesse ser alocada em qualquer uma das usinas termelétricas a carvão atualmente presentes no Brasil.

Para a elaboração do fluxograma do processo utilizou-se o programa AutoCAD (Versão 2009). 


\section{RESULTADOS E DISCUSSÃO}

\subsection{Caracterização de cinzas e zeólitas sintetizadas pelo método clássico}

A primeira parte do presente estudo consistiu em caracterizar os cinco tipos de cinzas de carvão das diferentes usinas e suas respectivas zeólitas, sintetizadas pelo método hidrotérmico clássico (Izidoro et al., 2012a). O objetivo desta etapa foi comparar materiais precursores e produtos de modo que fossem selecionadas matérias primas para estudos posteriores de síntese de zeólitas, visando à obtenção de produtos mais puros.

\subsubsection{Determinação do $\mathrm{pH}$ e da condutividade}

Na TAB. 4 estão listados os valores de pH e condutividade de cinzas de carvão e suas respectivas zeólitas.

TABELA 4 - Valores de pH e condutividade para as cinzas de carvão e suas respectivas zeólitas

\begin{tabular}{cccccc}
\hline Amostra & $\mathrm{pH}$ & $\begin{array}{c}\text { Condutividade } \\
(\mu \mathrm{S})\end{array}$ & Amostra & $\mathrm{pH}$ & $\begin{array}{c}\text { Condutividade } \\
(\mu \mathrm{S})\end{array}$ \\
\hline CFG & 8,2 & 538,0 & ZFG & 9,0 & 495,0 \\
CJL & 8,0 & 259,0 & ZJL & 8,4 & 389,0 \\
CSJ & 7,9 & 188,8 & ZSJ & 8,3 & 318,0 \\
CCH & 7,8 & 201,0 & ZCH & 9,3 & 431,0 \\
CPM & 7,6 & 203,0 & ZPM & 8,9 & 481,0 \\
\hline
\end{tabular}

De acordo com a TAB. 4, os valores de $\mathrm{pH}$ encontrados para as diferentes amostras de cinzas foram muito próximos, variando entre 7,6 e 8,2. Segundo Ferret (2004), o pH das cinzas de carvão varia entre 4,5 e 12 dependendo das características geoquímicas do carvão precursor. 
Os valores de $\mathrm{pH}$ das soluções aquosas contendo cinzas são justificados pela presença dos ânions carbonato, hidrogenocarbonato, óxido ou hidróxido que formam compostos com os cátions $\mathrm{K}^{+}, \mathrm{Ca}^{2+}, \mathrm{Mg}^{2+}$ e $\mathrm{Na}^{+}$presentes nas cinzas. Tais compostos, quando dissolvidos, provocam a alcalinidade da suspensão (Paprocki, 2009)

$\mathrm{O} \mathrm{pH}$ das suspensões de zeólitas variou entre 8,3 e 9,3. Esse aumento de $\mathrm{pH}$ com relação às cinzas precursoras ocorreu devido à utilização de $\mathrm{NaOH}$ na síntese de zeólitas pelo tratamento hidrotérmico convencional.

Os valores de condutividade se relacionam com a presença de determinados elementos presentes nas cinzas de carvão como $\mathrm{As}, \mathrm{B}, \mathrm{Ba}, \mathrm{Cd}, \mathrm{Co}$, $\mathrm{Cr}$, Cu, Li, Mo, Se, Sr, etc., que podem sofrer dissolução (Depoi et al., 2008). Os valores encontrados para as cinzas de carvão no presente estudo variaram entre $188,8 \mu \mathrm{S}$ (CSJ) e $538,0 \mu \mathrm{S}$ (CFG).

Depoi et al. (2007) determinou a condutividade para diferentes amostras de cinzas leves brasileiras. A amostra de Figueira, como no presente estudo, apresentou valor elevado quando comparado às outras amostras. Segundo este estudo, isso se deve ao baixo teor de cinzas presentes no carvão de Figueira, o que possibilita a solubilização de um maior número de compostos e consequentemente maior quantidade de íons presentes em solução.

Os valores de condutividade encontrados para as zeólitas de cinzas de carvão foram próximos ou maiores que os valores encontrados para os materiais precursores devido à presença de cátions trocáveis nas estruturas das zeólitas formadas mediante tratamento hidrotérmico e identificadas posteriormente por difratometria de raios $X$.

\subsubsection{Determinação da Umidade e da perda por calcinação}

A determinação dos parâmetros de umidade e perda por calcinação é freqüentemente realizada para as cinzas de carvão, pois pode indicar seu melhor ou pior desempenho na síntese de zeólitas.

$\mathrm{Na}$ TAB. 5 são mostrados os valores de umidade e perda por calcinação das cinzas de carvão estudadas.

De acordo com a TAB 5., todas as amostras de cinzas de carvão apresentaram baixos valores de umidade $(<3 \%$ em massa) por terem sido coletadas diretamente dos filtros ou precipitadores eletrostáticos que reteram as 
cinzas dos gases de combustão os quais apresentavam elevadas temperaturas. Os valores encontrados estão em concordância com os valores obtidos por Umaña (2002) para diferentes cinzas de origem espanhola e sul-africana provenientes de usinas termelétricas com queima de carvão na forma pulverizada.

TABELA 5 - Valores de umidade e perda por calcinação para as cinzas de carvão

\begin{tabular}{ccc}
\hline Amostra & $\begin{array}{c}\text { \% Umidade } \\
\text { em massa }\end{array}$ & $\begin{array}{c}\text { \% Perda por calcinação } \\
\text { em massa }\end{array}$ \\
CFG & 0,800 & 9,13 \\
CJL & 1,40 & 15,1 \\
CSJ & 3,00 & 15,2 \\
CCH & 0,600 & 2,60 \\
CPM & 0,600 & 1,44 \\
\hline
\end{tabular}

No estudo de perda por calcinação, as cinzas CSJ e CJL apresentaram os valores mais altos com relação às outras cinzas, sendo 15,2\% e 15,1\% em massa, respectivamente. A cinza CFG apresentou valor intermediário de 9,13\%, e as cinzas CCH e CPM apresentaram valores de 2,60\% e 1,44\%, respectivamente.

A perda por calcinação das cinzas se deve geralmente à presença de carvão não queimado (indicando a eficiência de combustão de uma usina termelétrica) e fases minerais não estáveis a altas temperaturas (Umaña, 2002).

Sendo assim, de acordo com o estudo de perda por calcinação, a ordem decrescente de eficiência das usinas termelétricas brasileiras a carvão é a seguinte: UTPM > UTCH > UTFG > UTJL > UTSJ. Essa ordem de eficiência está concordante com o estudo realizado por Depoi et al. (2008), o qual mostra que as cinzas de carvão com os maiores teores de carbono orgânico total são as cinzas provenientes das usinas de São Jerônimo, Jorge Lacerda e Figueira.

O sistema de combustão do carvão na Usina de São Jerônimo é o único que ocorre em grelha, e o carvão nesse tipo de queima apresenta partículas maiores quando comparado à granulometria do carvão queimado na forma pulverizada (todas as outras usinas apresentam queima do carvão na forma pulverizada). Sendo assim, o carvão de maior granulometria tem mais dificuldade 
para ser queimado por completo e irá contribuir para a formação de cinzas ricas em carvão não queimado, resultando, portanto, em queima de menor eficiência na usina. Conclui-se, portanto, que a forma de queima do carvão em grelha, que é pouco eficiente, pode ter contribuído para o alto valor de perda por calcinação encontrado para a CSJ.

A natureza do carvão utilizado para queima nas Usinas de Jorge Lacerda e Figueira e a provável baixa eficiência de combustão de ambas as usinas são fatores que provavelmente contribuíram para os altos valores de perda por calcinação encontrados para essas amostras quanto comparada às outras.

Comparando-se os valores obtidos nos estudos de umidade e perda por calcinação para as cinzas de carvão, observa-se que as amostras que apresentaram elevada perda por calcinação também apresentaram elevados teores de umidade. Isso ocorreu devido ao conteúdo de carvão não queimado, capaz de adsorver água com facilidade, presente nessas amostras.

Um elevado conteúdo de umidade e perda por calcinação influi de forma negativa na síntese de zeólitas, pois implica em uma menor quantidade de fases reativas durante a síntese (Umaña, 2002). Dessa forma, as cinzas CCH e CPM devem apresentar melhores características para a síntese de zeólitas (se levarmos em consideração somente esses dois parâmetros), pois ambas mostraram baixos valores de umidade e perda por calcinação. $O$ valor intermediário de perda por calcinação encontrado para a CFG provavelmente não afetará o processo de zeolitização desse material.

\subsubsection{Determinação da Massa específica e da Área específica}

$\mathrm{Na}$ TAB. 6 são mostrados os valores de massa e área específica de cinzas e zeólitas determinadas por picnometria de He e BET, respectivamente.

Todas as cinzas de carvão e zeólitas de cinzas de carvão estudadas apresentaram valores muito próximos de massa específica (ou densidade real), conforme pode ser observado na TAB. 6. De modo geral, as zeólitas apresentaram valores de massa específica menores que os valores encontrados para as cinzas. O valor médio encontrado para as cinzas de carvão foi de $2,39 \mathrm{~g} \mathrm{~cm}^{-3}$ e para as zeólitas o valor médio foi de $2,18 \mathrm{~g} \mathrm{~cm}^{-3}$. Esses valores indicam que o processo de zeolitização produz um material menos compacto do que o material precursor. 
TABELA 6 - Valores de massa e área específica para as cinzas e zeólitas

\begin{tabular}{cccccc}
\hline Amostra & $\begin{array}{c}\text { Massa } \\
\text { Específica } \\
\left(\mathrm{g} \mathrm{cm}^{-3}\right)\end{array}$ & $\begin{array}{c}\text { Área } \\
\text { Superficial } \\
\text { Específica } \\
\text { BET }\left(\mathrm{m}^{2} \mathrm{~g}^{-1}\right)\end{array}$ & Amostra & $\begin{array}{c}\text { Massa } \\
\text { Específica } \\
\left(\mathrm{g} \mathrm{cm}^{-3}\right)\end{array}$ & $\begin{array}{c}\text { Área } \\
\text { Superficial } \\
\text { Específica } \\
\text { BET }\left(\mathrm{m}^{2} \mathrm{~g}^{-1}\right)\end{array}$ \\
\hline CFG & $2,40 \pm 0,002$ & 8,73 & ZFG & $2,00 \pm 0,001$ & 65,8 \\
CJL & $2,26 \pm 0,004$ & 9,66 & ZJL & $2,01 \pm 0,001$ & 134 \\
CSJ & $2,46 \pm 0,003$ & 30,0 & ZSJ & $2,24 \pm 0,001$ & 146 \\
CCH & $2,54 \pm 0,008$ & 3,27 & ZCH & $2,20 \pm 0,002$ & 56,7 \\
CPM & $2,31 \pm 0,014$ & 1,39 & ZPM & $2,45 \pm 0,001$ & 65,8 \\
\hline
\end{tabular}

Segundo Hemmings e Berry (1985), partículas ricas em fase vítrea e fases cristalinas de mulita e quartzo, apresentam massa específica na faixa de 2,0 a $2,5 \mathrm{~g} \mathrm{~cm}^{-3}$. Todas as cinzas e zeólitas estudadas se enquadraram nessa faixa e apresentaram esses dois compostos, identificados posteriormente pela técnica de difração de raios $X$.

No estudo de área específica, os valores encontrados para as cinzas, observados na TAB. 6 têm concordância com os valores obtidos para diferentes amostras de cinzas leves de carvão caracterizadas por Umaña (2002).

A determinação da área específica para as cinzas de carvão pode ser considerada um parâmetro mais importante do que a distribuição granulométrica uma vez que está mais relacionada com a reatividade das cinzas (Rohde et al., 2006).

Cinzas com maiores superfícies de contato possuem maior reatividade com os agentes de ativação durante a síntese de zeólitas, resultando em maiores rendimentos de síntese. Isso ocorre devido à maior facilidade de solubilização dos compostos formadores de zeólitas na matriz de cinzas com elevadas áreas. Sendo assim, de acordo com a área específica encontrada, a ordem decrescente de reatividade das cinzas é: $\mathrm{CSJ}>\mathrm{CJL}>\mathrm{CFG}>\mathrm{CCH}>\mathrm{CPM}$.

Apesar da CSJ ser composta por partículas de maior granulometria (mostrado no estudo de morfologia posteriormente), é também a cinza que possui 
maior porosidade, fato que se reflete na sua elevada área específica encontrada, no valor de $30,0 \mathrm{~m}^{2} \mathrm{~g}^{-1}$.

O sistema de combustão do carvão por grelha da UTSJ é bem antigo e considerado de baixa eficiência, o que contribui para a formação de cinzas com grande quantidade de carvão não queimado e conseqüentemente maior quantidade do elemento carbono na amostra (Depoi et al., 2008). Grandes quantidades de carvão não queimado presentes em partículas de cinzas volantes de carvão contribuem para elevadas áreas específicas (Wang e Wu, 2006).

As características morfológicas das cinzas e a presença de partículas de aluminossilicatos de alta porosidade são fatores que contribuem para as variações dos valores de área específica encontrados para as diferentes amostras.

Os valores de área específica encontrados para as zeólitas foram maiores do que os valores encontrados para as suas respectivas cinzas precursoras em todos os casos, pois no processo de zeolitização, os cristais de zeólita se aglomeram ao redor das cinzas que não reagiram, formando superfícies irregulares, com maior superfície de contato, resultando em elevadas áreas específicas. Além disso, a elevada área superfícial interna presente nos compostos formados após o tratamento hidrotérmico das cinzas contribui de forma significativa para os elevados valores de área específica encontrados para as zeólitas.

A ordem decrescente de área específica encontrada para os materiais zeolíticos foi ZSJ > ZJL > ZPM > ZCH > ZFG. Os valores variaram de $56,7 \mathrm{~m}^{2} \mathrm{~g}^{-1}$ para a $Z \mathrm{CH}$ a $146 \mathrm{~m}^{2} \mathrm{~g}^{-1}$ para a ZSJ. Essas variações se devem às características das cinzas de carvão utilizadas na síntese, tipos de zeólitas formadas e características morfológicas das amostras.

A massa e a área específica das cinzas e das zeólitas também estão relacionadas com a forma das partículas, que serão discutidas no estudo da morfologia das amostras por microscopia eletrônica de varredura.

\subsubsection{Morfologia}

A técnica de microscopia eletrônica de varredura foi utilizada no presente trabalho para complementar as outras técnicas de caracterização e para 
avaliação da forma das partículas presentes nas amostras de cinzas e zeólitas formadas no estudo de suas morfologias.

As micrografias dos cinco tipos de cinzas estudados são mostradas na FIG. 16.
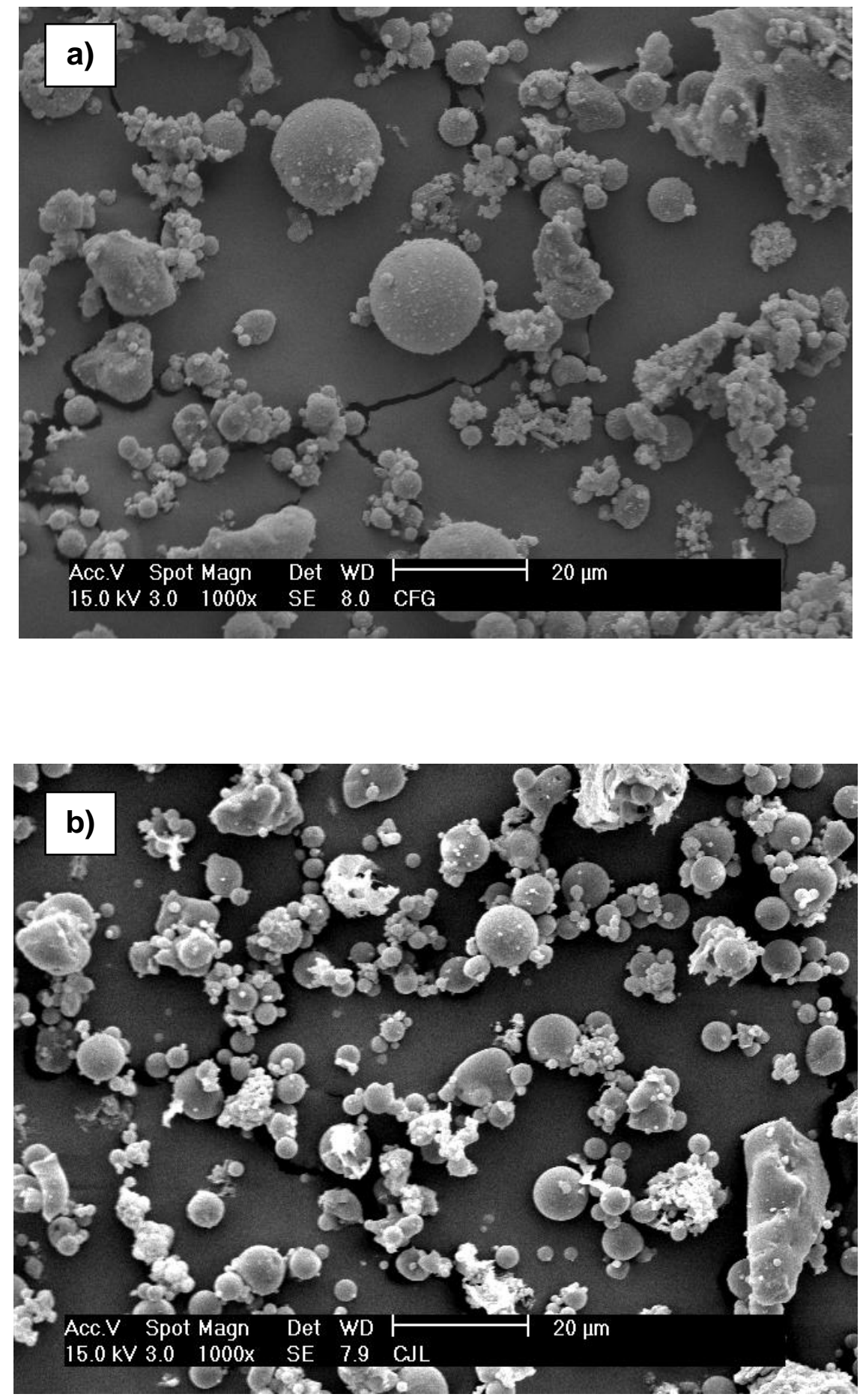

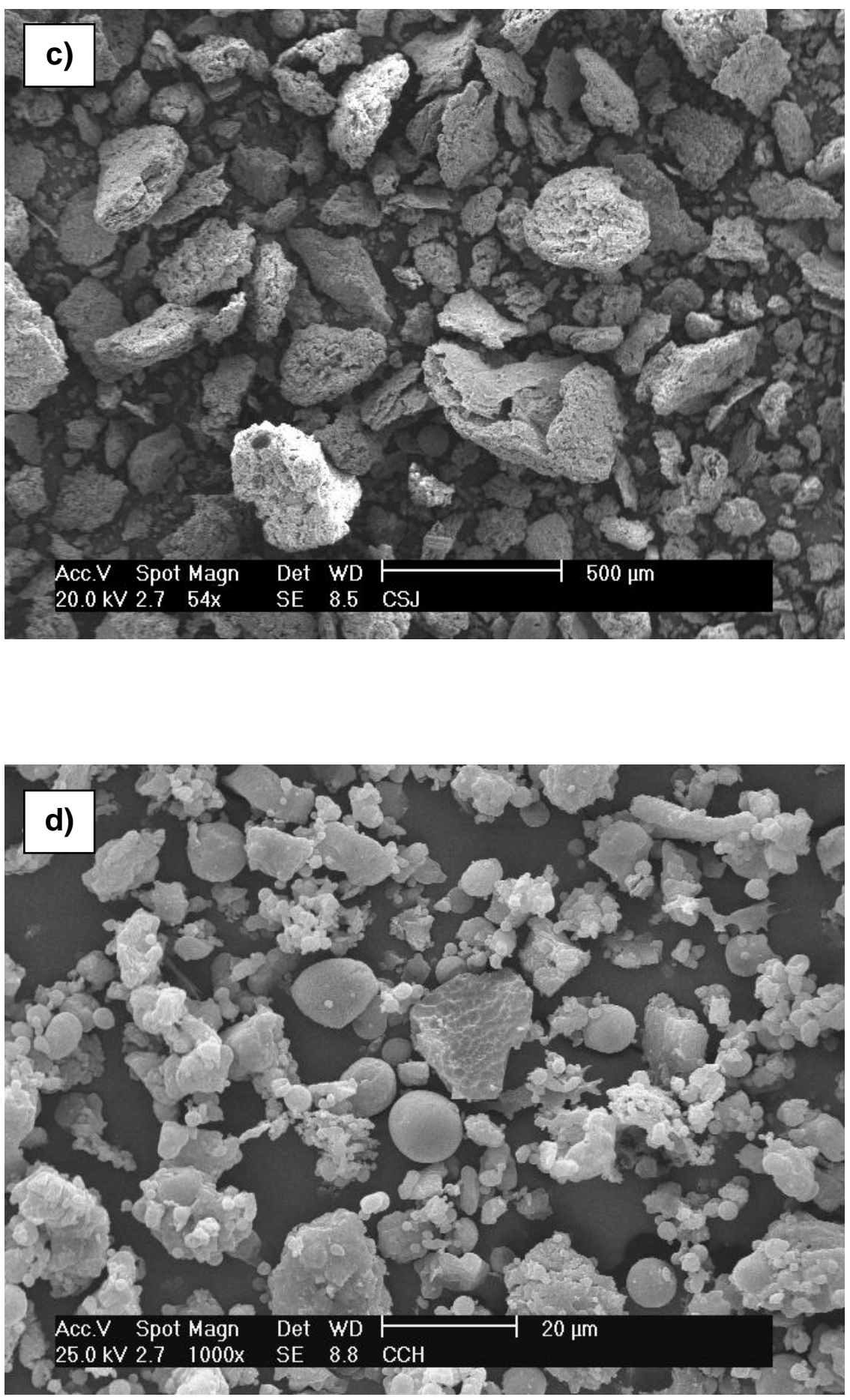


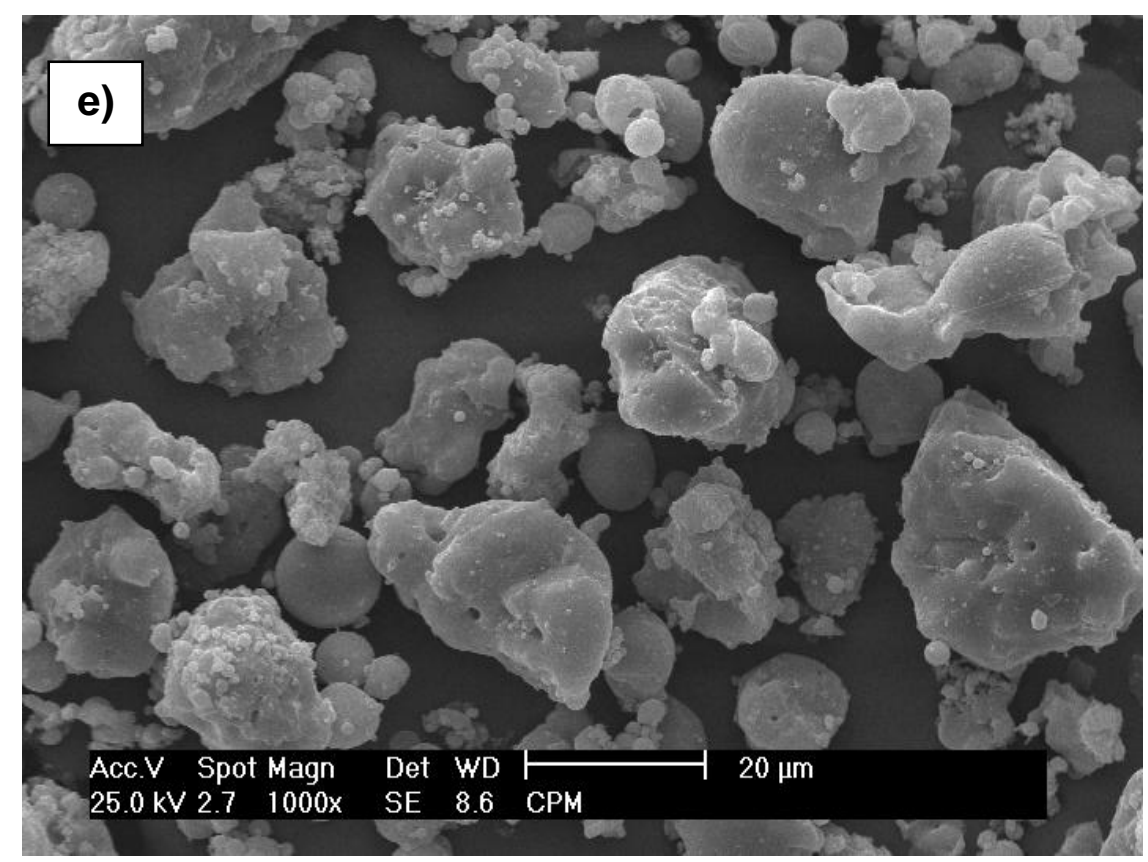

FIGURA 16 - Micrografia das cinzas volantes de carvão obtidas por microscopia eletrônica de varredura (MEV). a) CFG; b) CJL; c) CSJ; d) CCH; e) CPM

Cinzas de carvão possuem um aspecto típico caracterizado pela presença de formas esféricas de diferentes diâmetros e partículas irregulares de tamanhos variados. Diferentes estados físicos da sílica presente em amostras de cinzas de carvão são responsáveis pela forma das partículas de tamanhos irregulares (Sarbak et al., 2004) essa característica também se observa em partículas que sofreram rápido resfriamento (Umaña, 2002; Paprocki 2009).

As condições de queima do carvão nas usinas determinam a morfologia das partículas de cinzas volantes. Quando a queima do carvão ocorre na forma pulverizada, as cinzas resultantes contêm predominantemente partículas esféricas e partículas com formas irregulares (Rohde et al., 2006).

A forma esférica apresentada por esses materiais é resultado das forças de tensão superficial atuantes durante a queima do carvão em elevadas temperaturas nas usinas termelétricas para minimizar a energia livre superficial (Hemmings e Berry, 1988; Umaña, 2002).

De acordo com a FIG. 16, as amostras CFG, CJL, CCH e CPM (provenientes da queima de carvão na forma pulverizada) apresentam morfologias semelhantes e aspectos característicos de cinzas de carvão, similar ao que foi observado em outros estudos (Singh e Kolay, 2002; 
Sarbak et al., 2004; Pires e Querol, 2004; Ojha et al., 2004; El-Naggar et al., 2008). As micrografias dessas amostras são mostradas com aumento de 1000x, com exceção da amostra CSJ.

A micrografia da cinza CSJ foi a única que foi apresentada com aumento de 54x para que suas partículas constituintes fossem melhor observadas (FIG. 16 - c), pois essa cinza é formada por partículas extremamente grandes se comparadas ao outros tipos. De modo geral, a CSJ é formada por aglomerados de partículas com diferentes formas e tamanhos. Não há presença de formas esféricas de diâmetros variados como nas outras amostras. A micrografia de uma das partículas componentes da CSJ é mostrada com aumento de 500x na FIG. 17 .

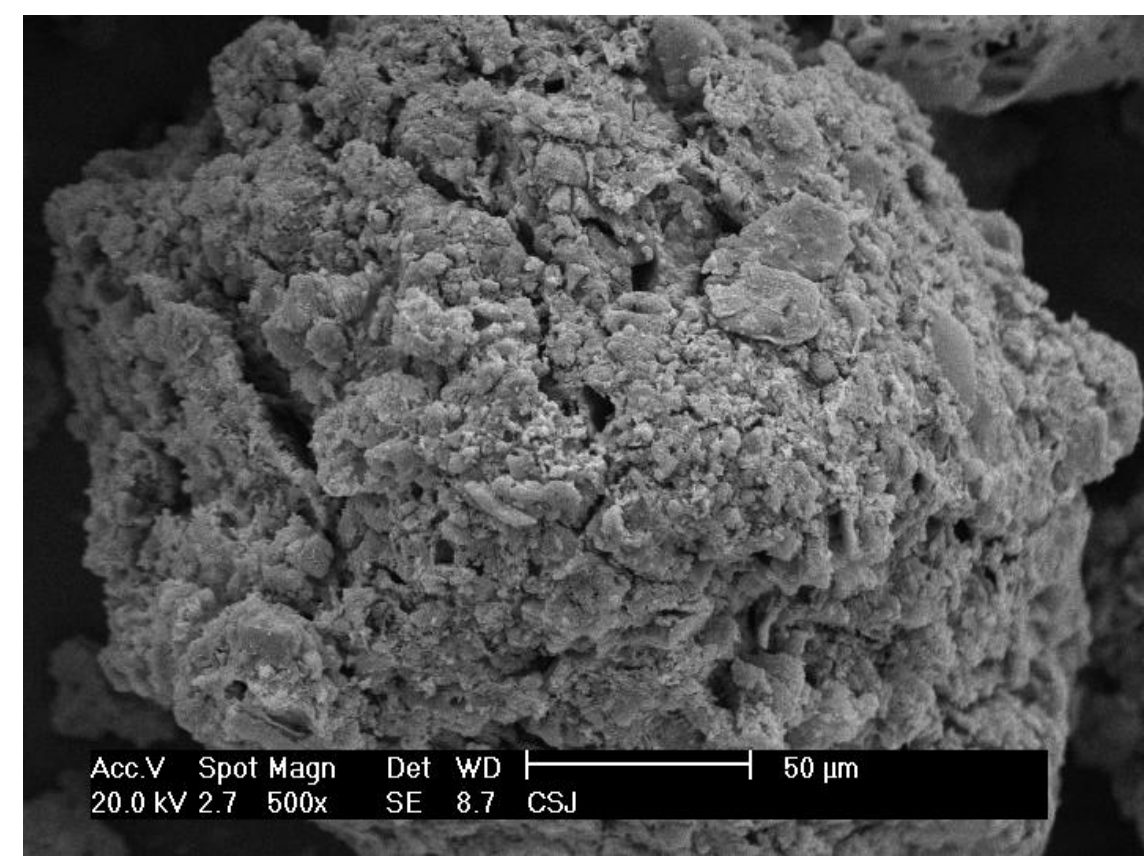

FIGURA 17 - Micrografia de uma das partículas componentes da cinza CSJ obtida por MEV com aumento de 500x

Segundo Umaña (2002), o aspecto esponjoso das partículas da CSJ, observado na FIG. 17 e similiar ao observado por este pesquisador, é característico de amostras de cinzas com elevado conteúdo de carvão não queimado, fato que foi comprovado pelos altos valores de perda por calcinação e área específica encontrados. Essa morfologia é resultado do sistema de combustão por grelha utilizado na UTSJ, o qual apresenta baixa eficiência. 
De modo geral, as cinzas volantes brasileiras são consideradas heterogêneas por possuírem partículas de tamanhos variados, tanto esféricas como irregulares.

As partículas esféricas podem ser compactas (FIG. 18a), ocas, também chamadas de cenosferas (FIG. 18b) ou ainda partículas que possuem outras partículas menores em seu interior ou pleurosferas (FIG. 18c). As partículas ocas são formadas devido à expansão de gases como $0 \mathrm{CO}_{2}$ e/ou vapor de água dentro do carvão quando este está sendo queimado (Ríos et al., 2009).
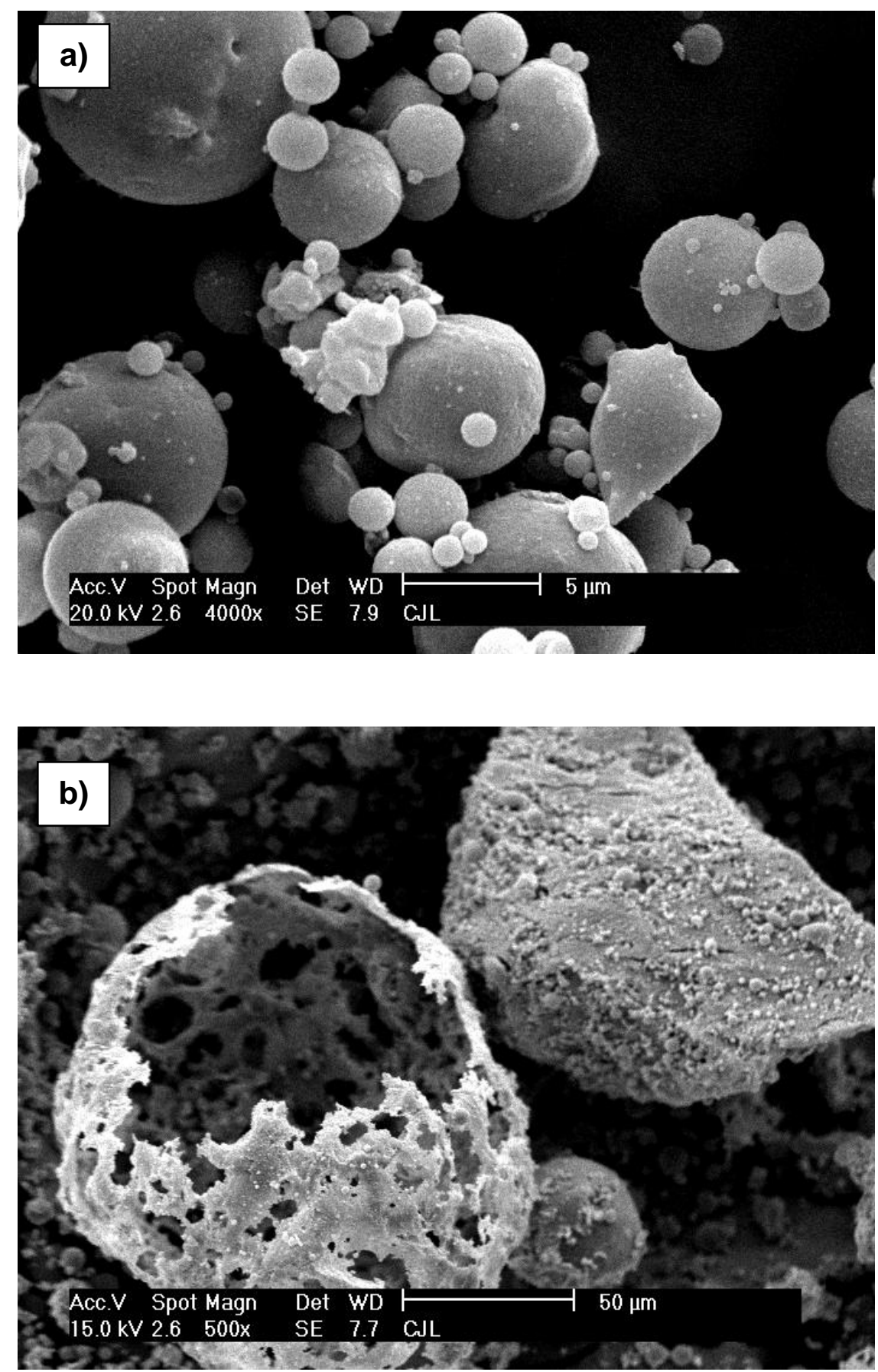


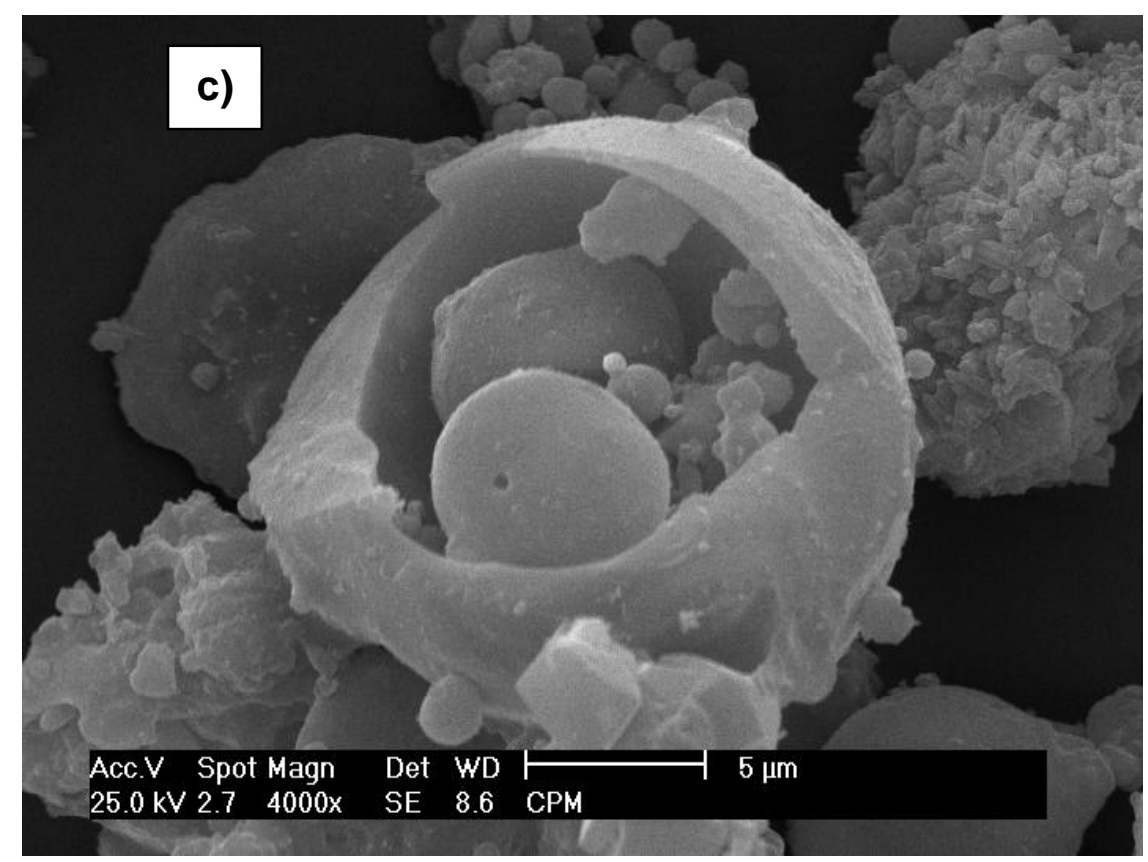

FIGURA 18 - Diferentes tipos de partículas esféricas presentes nas cinzas volantes de carvão brasileiras obtidas por MEV com aumentos de 500x e 4000x. a) e b) CJL; c) CPM

Comparando-se os valores de área específica determinados para as cinzas de carvão (TAB. 6) e as morfologias apresentadas para as mesmas amostras (FIG. 16), observou-se que quanto menores as partículas presentes nas cinzas, maior a área superficial apresentada. O tamanho das partículas presentes nas cinzas aumentou de acordo com a seguinte ordem: CJL $<\mathrm{CFG}<\mathrm{CCH}<$ CPM. Essa ordem corrobora com a sequencia decrescente dos valores de área específica determinados para as mesmas amostras. Somente a amostra CSJ não se enquadrou nessa tendência observada pelo fato desse material ser formado por partículas de tamanho elevado quando comparado às outras amostras, apresentado aspecto poroso e caracterizado por elevada área superficial, de acordo com as explicações acima citadas.

Ainda dentro do estudo de morfologia, as micrografias dos cinco tipos de zeólitas obtidos por tratamento hidrotérmico convencional são mostradas na FIG. 19. 

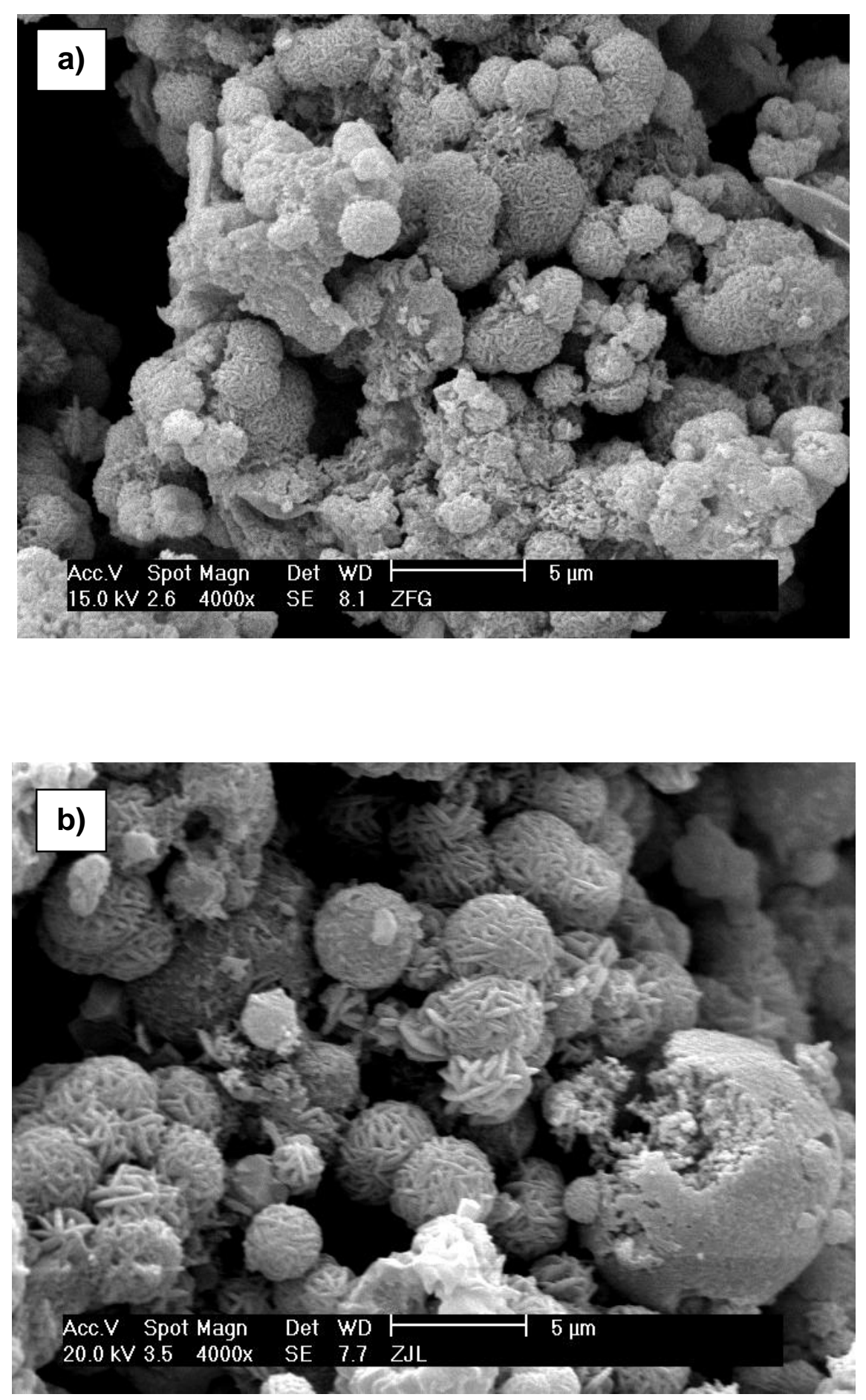

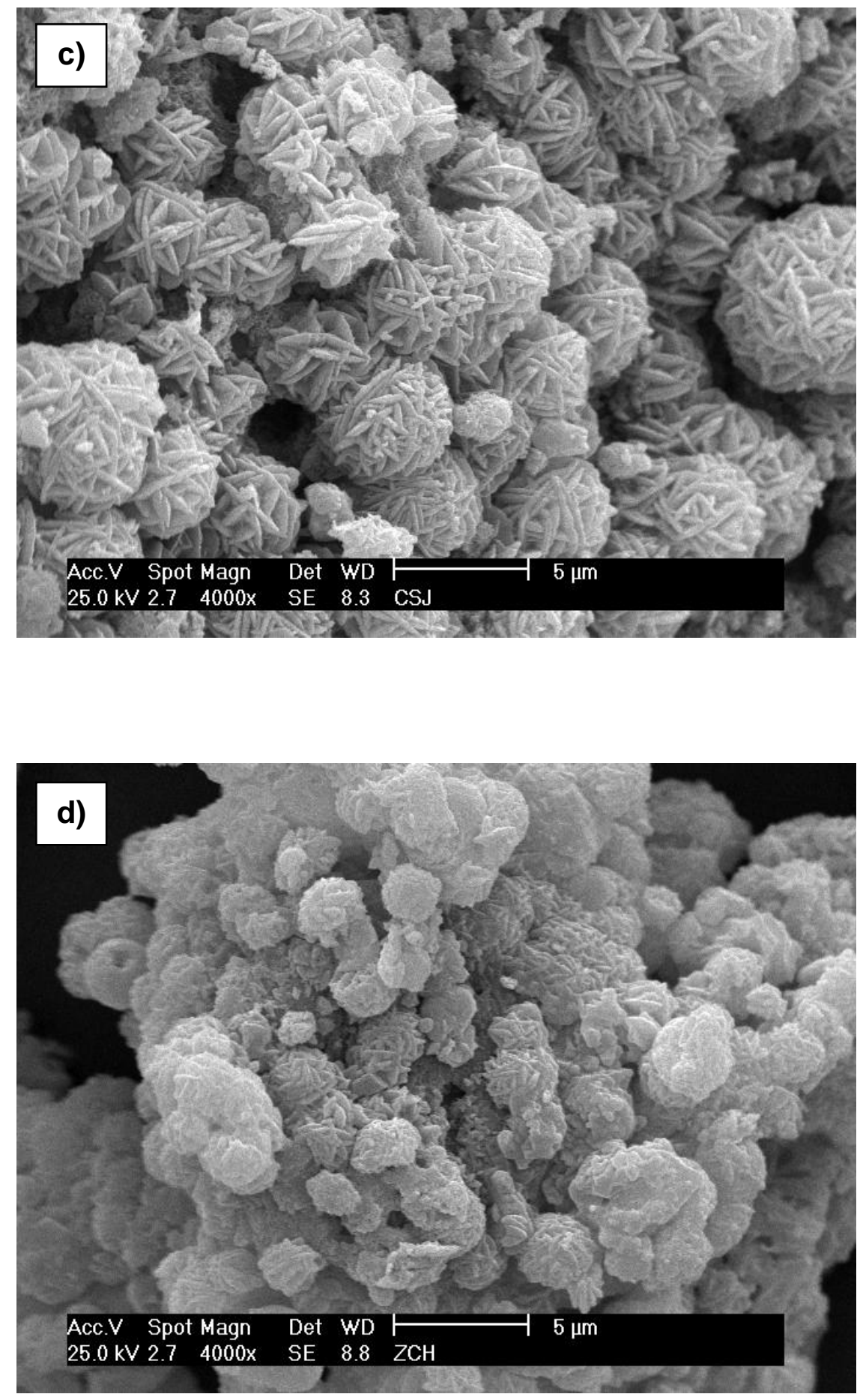


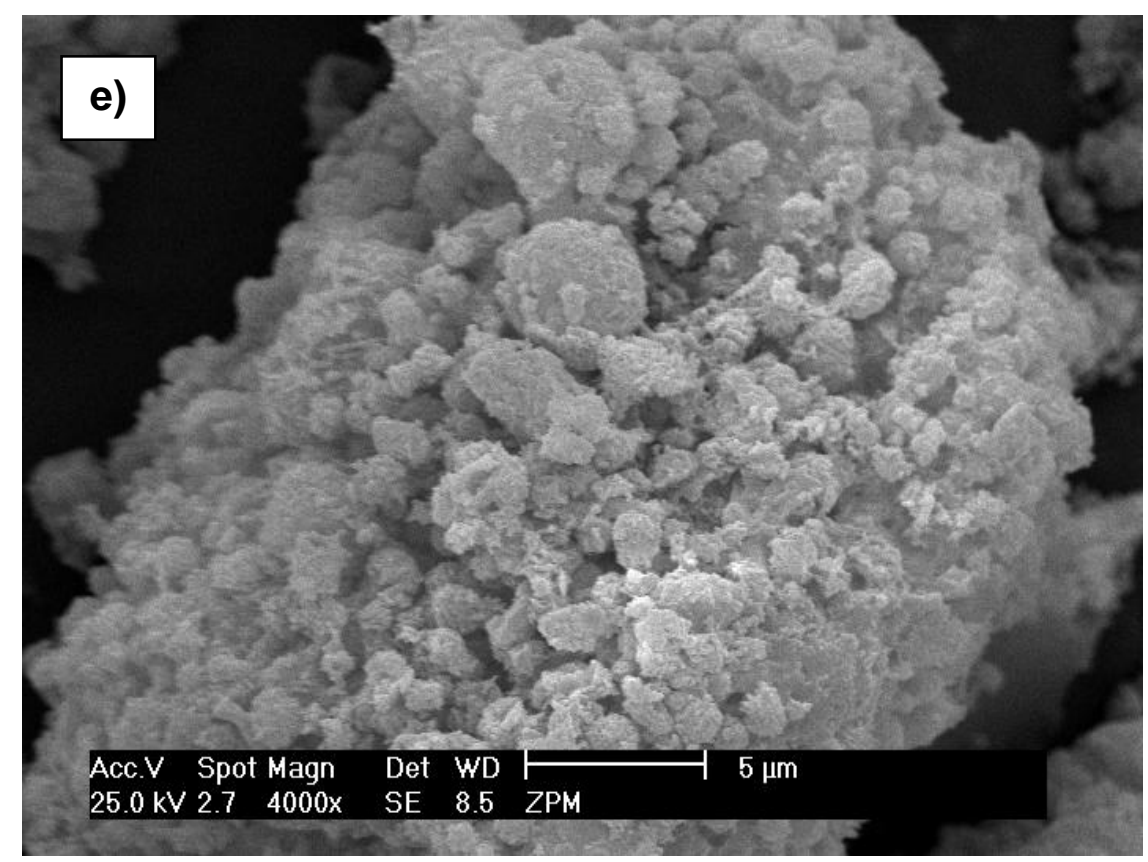

FIGURA 19 - Micrografia das zeólitas sintetizadas a partir de cinzas de carvão por tratamento hidrotérmico clássico obtidas por MEV. a) ZFG; b) ZJL; c) ZSJ;

d) $\mathrm{ZCH}$; e) ZPM

Comparando-se as FIG. 19 e 16 que mostram as morfologias das zeólitas e das cinzas precursoras, respectivamente, observa-se de forma clara que houve uma mudança morfológica desses materiais após o tratamento hidrotérmico, evidenciada pela formação de cristais regulares mostrados com aumento de 4000x por MEV na FIG. 19. As zeólitas apresentadas são, de modo geral, formadas principalmente por conjuntos de microesferas aglomeradas de diâmetro similar e recobertas por partículas de formatos semelhantes. Esse aspecto está relacionado também com o fato de que as zeólitas precipitam sobre a superfície das partículas de cinzas que não reagiram após a síntese hidrotérmica (Singh e Kolay, 2002; Ojha et al., 2004). Isso pode ser comprovado pelo aumento do diâmetro médio das partículas após o processo de zeolitização.

De acordo com a FIG. 19, as zeólitas ZFG, ZJL, ZSJ e ZCH possuem partículas com características similares, diferindo apenas no tamanho dos cristais e na quantidade. As zeólitas ZJL e ZSJ, representadas nas FIG. 19b e 19c, respectivamente, foram as zeólitas que apresentaram maiores quantidades dessas partículas formadas com relação às outras amostras, o que certamente 
contribuiu com seus elevados valores de área específica determinados. A zeólita ZPM apresentou morfologia não uniforme e diferente das demais (FIG. 19e).

Observou-se que quanto maior a área específica das zeólitas sintetizadas pelo método convencional (TAB. 6), maior a quantidade de partículas regulares (zeólitas formadas) que recobrem as esferas que formam esses materiais, mostradas no estudo de morfologia (FIG. 19).

As diferenças de morfologia observadas para as diferentes amostras podem também ser resultado da seleção de diferentes regiões a serem ampliadas pelo microscópio eletrônico de varredura quando a análise de morfologia estava sendo realizada.

\subsubsection{Composição química}

O potencial de aplicação das cinzas de carvão é definido pela sua composição química, que foi determinada por fluorescência de raios $X$ para as diferentes amostras de cinzas e se encontra na TAB.7. Os compostos presentes são derivados da fração inorgânica presente no carvão, por isso os resultados são apresentados na forma de óxidos.

De acordo com a TAB.7, não houve grandes variações entre os conteúdos dos principais componentes das diferentes amostras de cinzas. Pequenas variações nas quantidades dos principais compostos das cinzas ocorrem devido aos diferentes tipos de carvão usados para queima nas usinas.

O conteúdo dos principais compostos formadores de estruturas de zeólitas, $\mathrm{SiO}_{2}$ e $\mathrm{Al}_{2} \mathrm{O}_{3}$, correspondeu acima de $70 \%$ para todas as amostras de cinzas de carvão estudadas. O conteúdo de $\mathrm{SiO}_{2}$ variou de $48,4 \%$ para a CFG a $62,4 \%$ para a CPM e o conteúdo de $\mathrm{Al}_{2} \mathrm{O}_{3}$ variou de $22,9 \%$ para a CPM a $32,6 \%$ para a $\mathrm{CCH}$.

As cinzas de carvão brasileiras apresentaram diferentes conteúdos de ferro, que é considerado inibidor para a formação de zeólitas por não ser reativo durante a síntese (Ferret, 2004; Umaña, 2002, Ríos et al., 2009). Por esse motivo, alguns estudos de síntese de zeólitas usam a remoção desse elemento antes do tratamento hidrotérmico convencional das cinzas. A quantidade de ferro variou de $3,6 \%$ para a $\mathrm{CCH}$ a $10,2 \%$ para a CFG. 
TABELA 7 - Análise química dos compostos presentes nas cinzas de carvão (\% em massa)

\begin{tabular}{cccccc}
\hline Óxido & CFG & CJL & CSJ & CCH & CPM \\
\hline $\mathrm{SiO}_{2}$ & 48,4 & 50,3 & 54,5 & 57,5 & 62,4 \\
$\mathrm{Al}_{2} \mathrm{O}_{3}$ & 23,8 & 29,8 & 26,7 & 32,6 & 22,9 \\
$\mathrm{Fe}_{2} \mathrm{O}_{3}$ & 10,2 & 6,70 & 5,00 & 3,60 & 4,90 \\
$\mathrm{~K}_{2} \mathrm{O}$ & 4,60 & 5,30 & 3,00 & 2,00 & 3,00 \\
$\mathrm{CaO}$ & 4,70 & 2,70 & 2,80 & 1,40 & 2,40 \\
$\mathrm{TiO}_{2}$ & 1,70 & 2,20 & 3,80 & 1,60 & 1,10 \\
$\mathrm{SO}_{3}$ & 2,10 & 1,40 & 2,90 & 0,40 & 0,500 \\
$\mathrm{MgO}$ & 1,70 & 1,10 & 1,00 & 0,70 & 1,10 \\
$\mathrm{Na}_{2} \mathrm{O}$ & 1,30 & - & - & - & 1,30 \\
$\mathrm{P}_{2} \mathrm{O}_{5}$ & 0,200 & 0,170 & 0,110 & 0,0900 & 0,0900 \\
$\mathrm{ZnO}$ & 0,300 & 0,100 & 0,0300 & 0,0200 & 0,0200 \\
$\mathrm{MnO}$ & 0,100 & 0,0700 & 0,0400 & 0,0200 & 0,0300 \\
$\mathrm{PbO}_{\mathrm{SiO}} / \mathrm{Al}{ }_{2} \mathrm{O}_{3}$ & 0,110 & 0,0300 & - & 0,0160 & - \\
\hline
\end{tabular}

Os conteúdos de óxidos de $\mathrm{Ca}, \mathrm{Mg}$ e $\mathrm{S}$, foram menores do que $5 \%$ para todas as amostras. Segundo Ferret (2004), esses elementos são prejudiciais na formação de zeólitas.

O cálcio influi negativamente na síntese de zeólitas devido á possível formação de fases de silicato de cálcio hidratado durante o tratamento hidrotérmico ao invés da formação de fases zeolíticas propriamente ditas (Ríos et al., 2009).

A amostra de cinza CFG apresentou conteúdo de PbO de 0,110\%. Segundo Depoi (2007), deve-se ter um rigoroso critério de deposição e/ou utilização dessa cinza devido à facilidade com que esse elemento é lixiviado. Depoi (2007) também determinou a concentração de elementos traços e minoritários para diferentes amostras de cinzas de carvão brasileiras e fez 
estudos de lixiviação para essas amostras. A pesquisadora concluiu mediante os resultados obtidos que se deve ter cautela na utilização das cinzas brasileiras a fim de que os elementos tóxicos não sejam lançados ao meio ambiente. A amostra de Figueira é a que deve-se ter mais cuidado devido às concentrações elevadas de elementos tóxicos como $\mathrm{As}, \mathrm{Hg}, \mathrm{Cd}$, entre outros.

A relação $\mathrm{SiO}_{2} / \mathrm{Al}_{2} \mathrm{O}_{3}$ calculada para as cinzas de carvão variaram de 1,69 a 2,72. Esses valores indicam boa possibilidade de síntese de zeólitas (Shiguemoto et al., 1993).

Segundo Umaña (2002), os resultados obtidos por FRX permitem agrupar as cinzas volantes dependendo de sua composição. O gráfico ternário apresentado na FIG. 20 mostra o caráter predominante apresentado pelas cinzas volantes brasileiras.

De acordo com a FIG. 20, as cinzas brasileiras, de modo geral, apresentam predominância nos conteúdos de silício e alumínio e são, portanto, materiais aluminossilicosos. Cinzas com elevadas concentrações de aluminossilicatos têm um alto potencial para a síntese de zeólitas.

A composição química das diferentes amostras de zeólitas de cinzas de carvão também foi determinada por fluorescência de raios $X$. Os resultados encontram-se na TAB. 8.

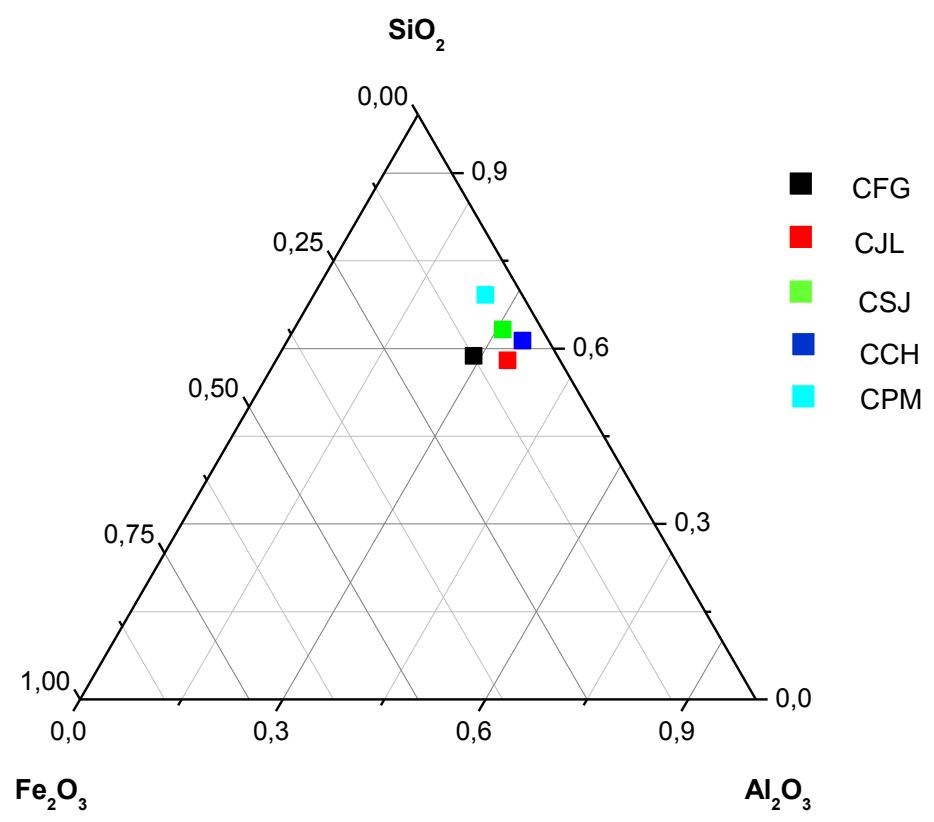

FIGURA 20 - Classificação das cinzas volantes brasileiras em função do conteúdo relativo dos principais óxidos 
De acordo com os resultados da TAB. 8, as zeólitas apresentaram, de modo geral, elevados conteúdos de sílica, alumina, óxido férrico e óxido de sódio. Encontraram-se os óxidos de cálcio, titânio, magnésio, enxofre, potássio, e outros compostos em quantidades menores que $6 \%$. O baixo conteúdo de impurezas como $\mathrm{Ca}$ e $\mathrm{S}$ potencializa o uso desses materiais.

O conteúdo de sódio está relacionado com a sua incorporação no material zeolítico pela síntese hidrotérmica, onde utilizou-se $\mathrm{NaOH}$ como agente de ativação. A exposição do material em soluções com maiores concentrações de $\mathrm{NaOH}$ durante a síntese pode aumentar a quantidade de $\mathrm{Na}$ fixo na estrutura da zeólita (Scott et al., 2001). A presença de outros metais na FRX mostra que durante a síntese não houve a total troca por íons $\mathrm{Na}^{+}$na zeólita.

TABELA 8 - Análise química dos compostos presentes nas zeólitas de cinzas de carvão (\% em massa)

\begin{tabular}{cccccc}
\hline Óxido & ZFG & ZJL & ZSJ & ZCH & ZPM \\
\hline $\mathrm{SiO}_{2}$ & 36,5 & 36,6 & 43,6 & 41,5 & 42,4 \\
$\mathrm{Al}_{2} \mathrm{O}_{3}$ & 27,3 & 38,0 & 32,9 & 37,2 & 34,9 \\
$\mathrm{Fe}_{2} \mathrm{O}_{3}$ & 12,8 & 8,30 & 5,40 & 5,60 & 7,80 \\
$\mathrm{Na}_{2} \mathrm{O}$ & 9,20 & 6,90 & 9,10 & 9,80 & 6,70 \\
$\mathrm{CaO}$ & 6,10 & 3,60 & 3,70 & 2,10 & 3,50 \\
$\mathrm{TiO}_{2}$ & 2,00 & 2,70 & 2,30 & 2,20 & 1,50 \\
$\mathrm{MgO}^{2}$ & 2,00 & 1,40 & 0,700 & 0,700 & 1,80 \\
$\mathrm{SO}$ & 1,90 & 1,30 & 1,00 & 0,300 & 0,600 \\
$\mathrm{~K}_{2} \mathrm{O}$ & 1,00 & 0,800 & 1,00 & 0,500 & 0,700 \\
$\mathrm{ZnO}$ & 0,300 & 0,0900 & 0,0400 & 0,0300 & 0,0300 \\
$\mathrm{MnO}^{n}$ & 0,200 & 0,100 & 0,0400 & 0,0300 & 0,0600 \\
$\mathrm{PbO}^{2}$ & 0,100 & 0,0300 & - & 0,0110 & 0,0150 \\
$\mathrm{P}_{2} \mathrm{O}_{5}$ & 0,0600 & 0,0600 & 0,0700 & 0,0600 & 0,0500 \\
$\mathrm{SiO}_{2} / \mathrm{Al}_{2} \mathrm{O}_{3}$ & 1,34 & 0,96 & 1,32 & 1,12 & 1,21 \\
\hline
\end{tabular}


A razão $\mathrm{SiO}_{2} / \mathrm{Al}_{2} \mathrm{O}_{3}$, relacionada com a capacidade de troca catiônica foi determinada para as diferentes zeólitas. De modo geral, quanto menor é a razão $\mathrm{SiO}_{2} / \mathrm{Al}_{2} \mathrm{O}_{3}$, maior é a quantidade de $\mathrm{Al}^{3+}$ na amostra e consequentemente, maior é a capacidade de troca catiônica do material, já que para cada Si que foi substituído por um Al é gerada uma carga negativa, a qual é compensada por um cátion (Ferreira, 1998, Querol et al., 2002). Os valores encontrados variaram entre 0,96 e 1,34. Esses valores são menores que os valores encontrados para as cinzas precursoras, indicando que o processo de zeolitização contribuiu para o aumento de capacidade de troca catiônica das zeólitas com relação às cinzas.

Os valores da razão $\mathrm{SiO}_{2} / \mathrm{Al}_{2} \mathrm{O}_{3}$ não podem ser considerados como absolutos pois os átomos detectados por fluorescência de raios $\mathrm{X}$ podem ou não fazer parte da rede cristalina das zeólitas formadas. Portanto, a relação $\mathrm{SiO}_{2} / \mathrm{Al}_{2} \mathrm{O}_{3}$ encontrada bem como os cátions trocáveis são da amostra e não necessariamente da rede cristalina (Ferreira, 1998).

Comparando-se a quantidade de $\mathrm{SiO}_{2}$ nas cinzas de carvão e nas respectivas zeólitas, verifica-se que o conteúdo desse composto nos produtos zeolíticos decresceu em todas as amostras. Dessa forma, o filtrado obtido após a etapa de aquecimento na ativação hidrotérmica das cinzas e que não foi incorporado ao material zeolítico pode conter quantidade significativa de sílica. Essa solução, portanto, tem potencial para ser usada na síntese de mais produtos por conter este composto fundamental para a formação de estrutura de zeólitas.

O cálculo do rendimento da conversão de cinzas de carvão em material zeolítico usando o tratamento hidrotérmico convencional não é possível de ser realizado baseando-se apenas nos dados de fluorescência de raios $X$ obtidos, pois parte da sílica incorporada no material zeolítico não faz parte somente da estrutura das zeólitas formadas, mas também do quartzo ainda presente no material final. Os difratogramas que comprovam a presença de quartzo são mostrados no item seguinte que tratam da composição mineralógica de cinzas e zeólitas.

\subsubsection{Composição mineralógica}

A técnica de difratometria de raios $X$ permitiu a identificação das fases cristalinas presentes nas cinzas volantes de carvão e nas zeólitas formadas a 
partir desses materiais. Na FIG. 21 são mostrados os difratogramas das amostras de cinzas de carvão estudadas.

A diferença de intensidade relativa dos picos de difração encontrados para as diferentes amostras (FIG. 21) podem indicar diferentes proporções das fases encontradas, assim como pode ser resultado da preparação de amostra nos ensaios de difratometria de raios $X$. As diferenças entre as quantidades dos compostos encontrados nas diferentes amostras podem ser atribuídas às diferentes condições de combustão do carvão nas usinas termelétricas uma vez que a formação destes materiais é dependente da temperatura e da taxa de resfriamento (Ferret, 2004).

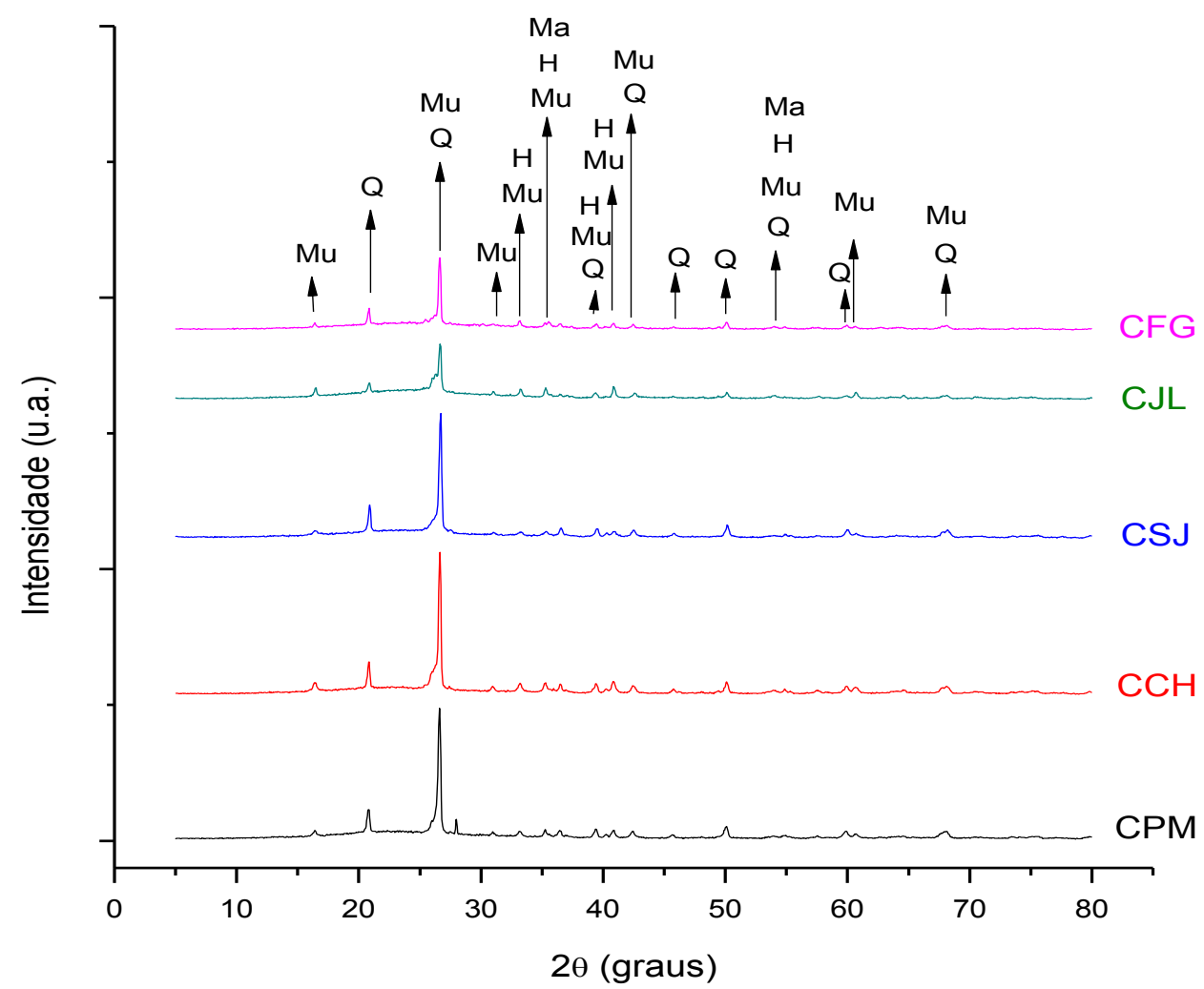

FIGURA 21 - Difratograma das cinzas volantes de carvão brasileiras ( $\mathrm{Q}=$ Quartzo, $\mathrm{Mu}=$ Mulita, $\mathrm{H}=$ Hematita e Ma = Magnetita $)$

A mulita presente nas cinzas é resultante das reações que ocorrem durante a combustão do carvão. O quartzo, por sua vez, está presente no carvão precursor e não funde nas condições de queima nas usinas termelétricas. A presença de hematita e magnetita nas cinzas é decorrente da oxidação de 
sulfetos de ferro na forma de pirita, normalmente presente no marcassita e pirrotita presentes no carvão queimado (Rohde et al., 2006).

A presença de fases de aluminossilicatos como o quartzo e a mulita nas cinzas favorece a formação de zeólitas por tratamento hidrotérmico. Por outro lado, a presença de óxidos de ferro (como hematita e magnetita), reduz a formação de zeólitas a partir desses materiais, como mencionado anteriormente.

$\mathrm{Na}$ análise dos dados obtidos por difração de raios $X$ para os materiais zeolíticos sintetizados por tratamento hidrotérmico convencional, são apresentados difratogramas detalhados de cada uma das amostras (FIG. 22 a FIG. 26) bem como um difratograma comparativo geral (FIG. 27).

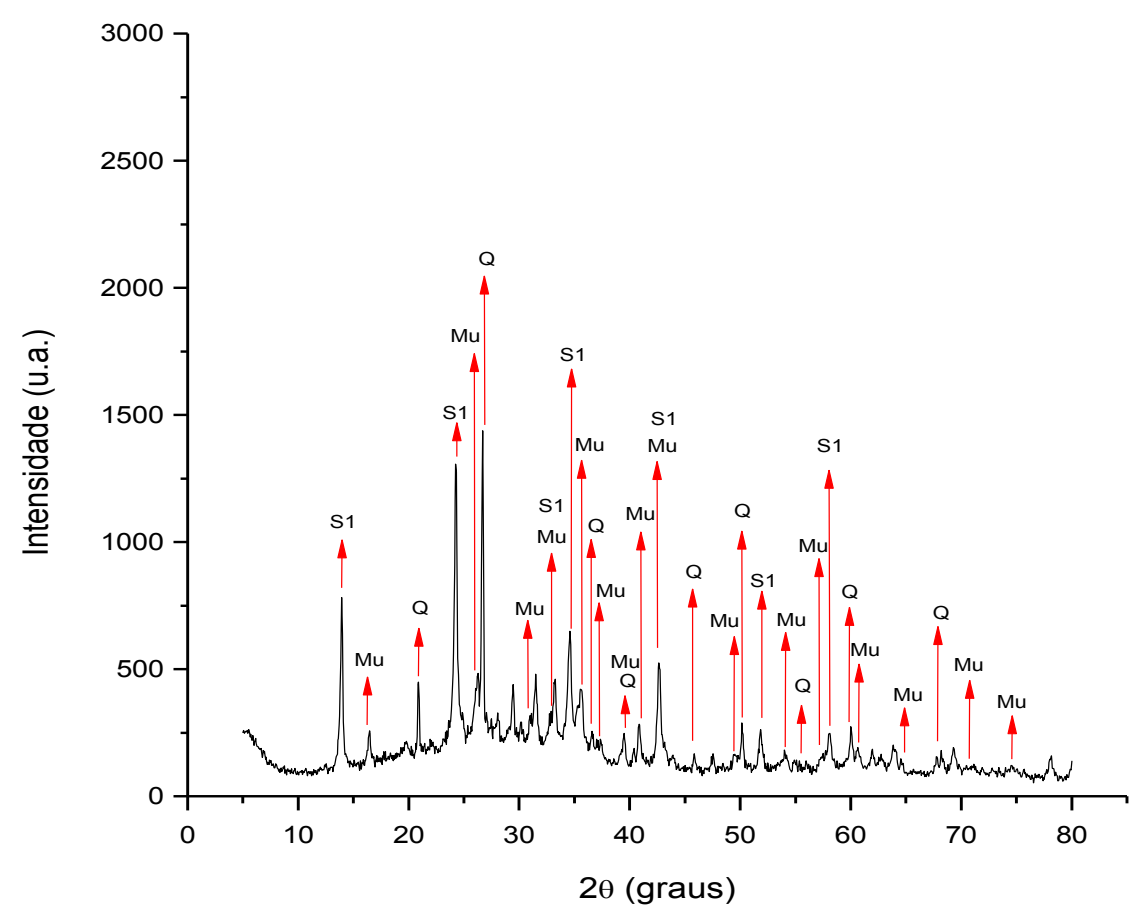

FIGURA 22 - Difratograma da ZFG (Q = Quartzo, Mu = Mulita e S1= zeólita Hidroxissodalita) 


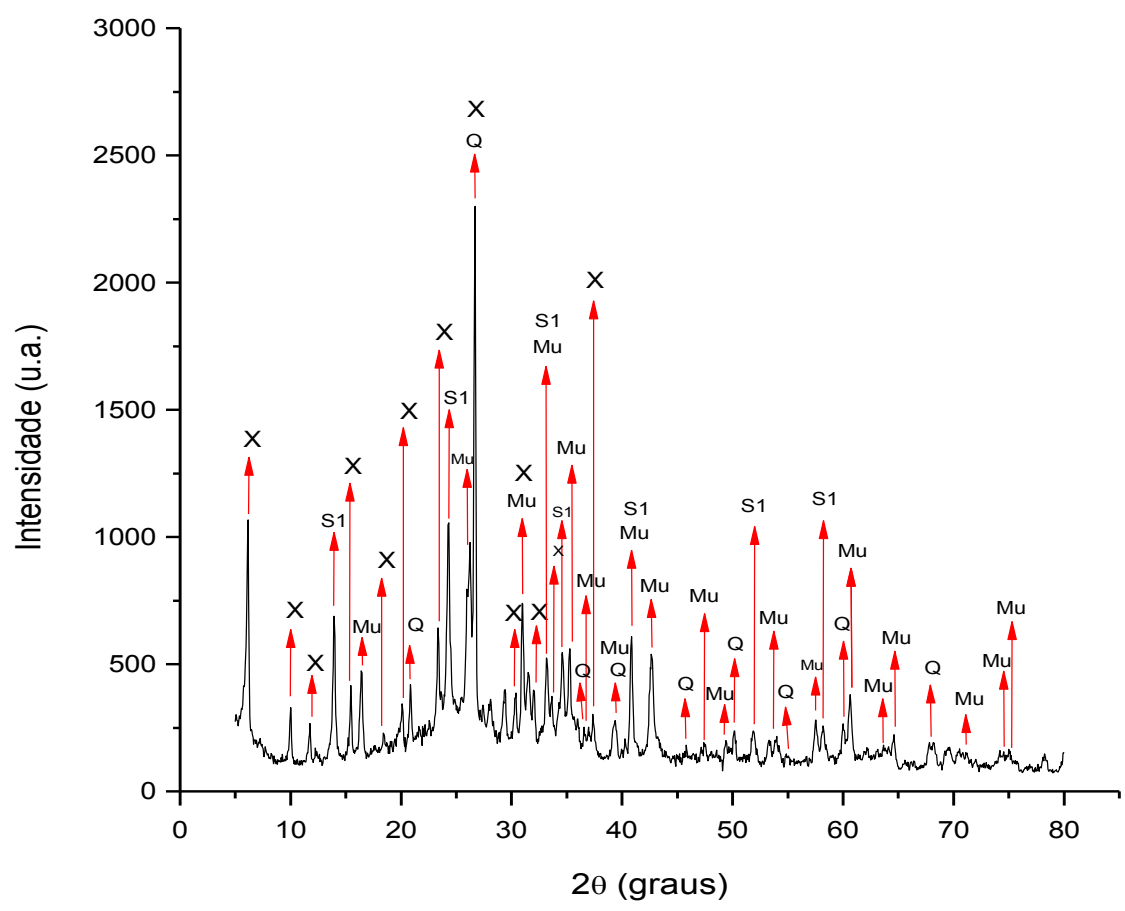

FIGURA 23 - Difratograma da ZJL ( $Q$ = Quartzo, Mu = Mulita, S1 = Hidroxissodalita e $X=$ zeólita $X$ )

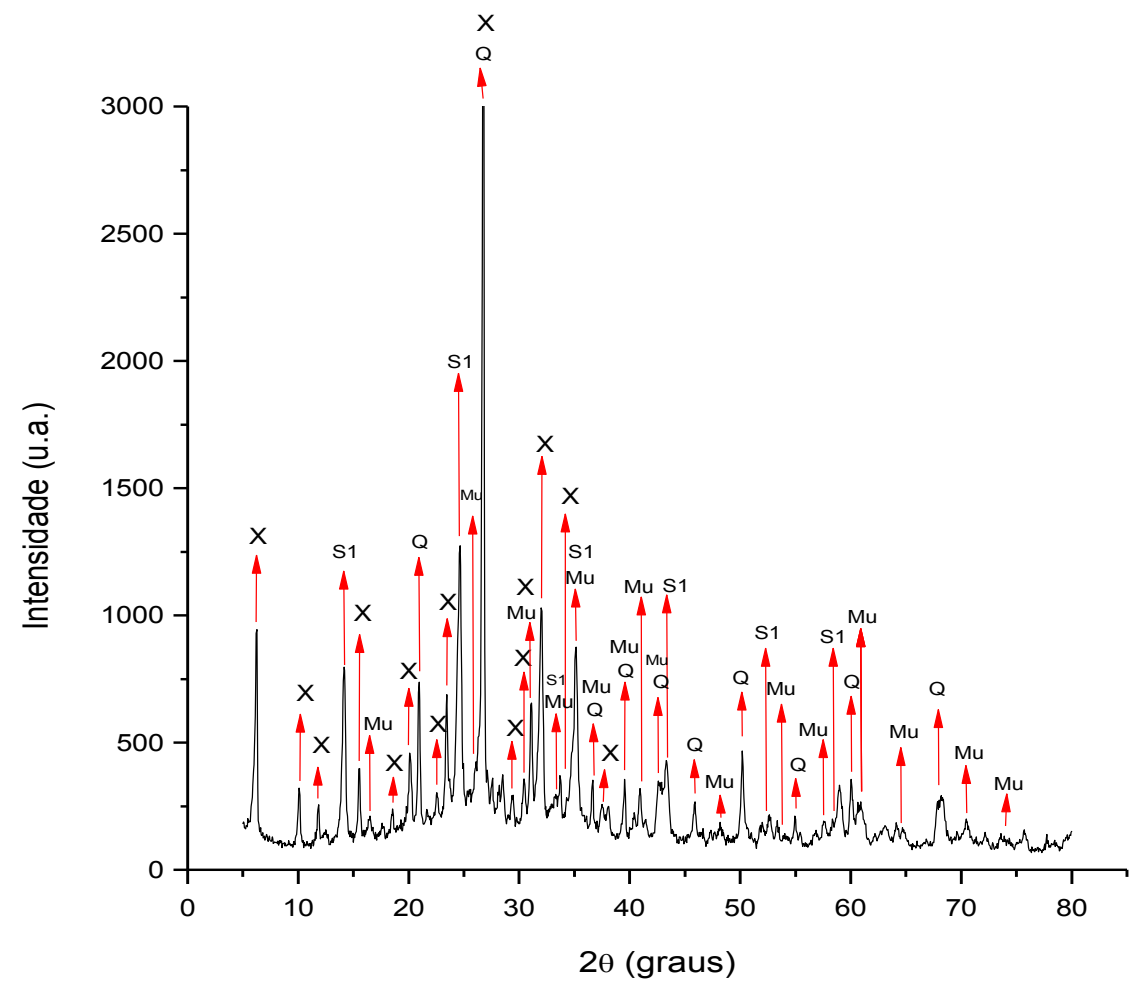

FIGURA 24 - Difratograma da ZSJ Q = Quartzo, Mu = Mulita, $S 1$ = Hidroxissodalita e $X=$ zeólita $X$ ) 


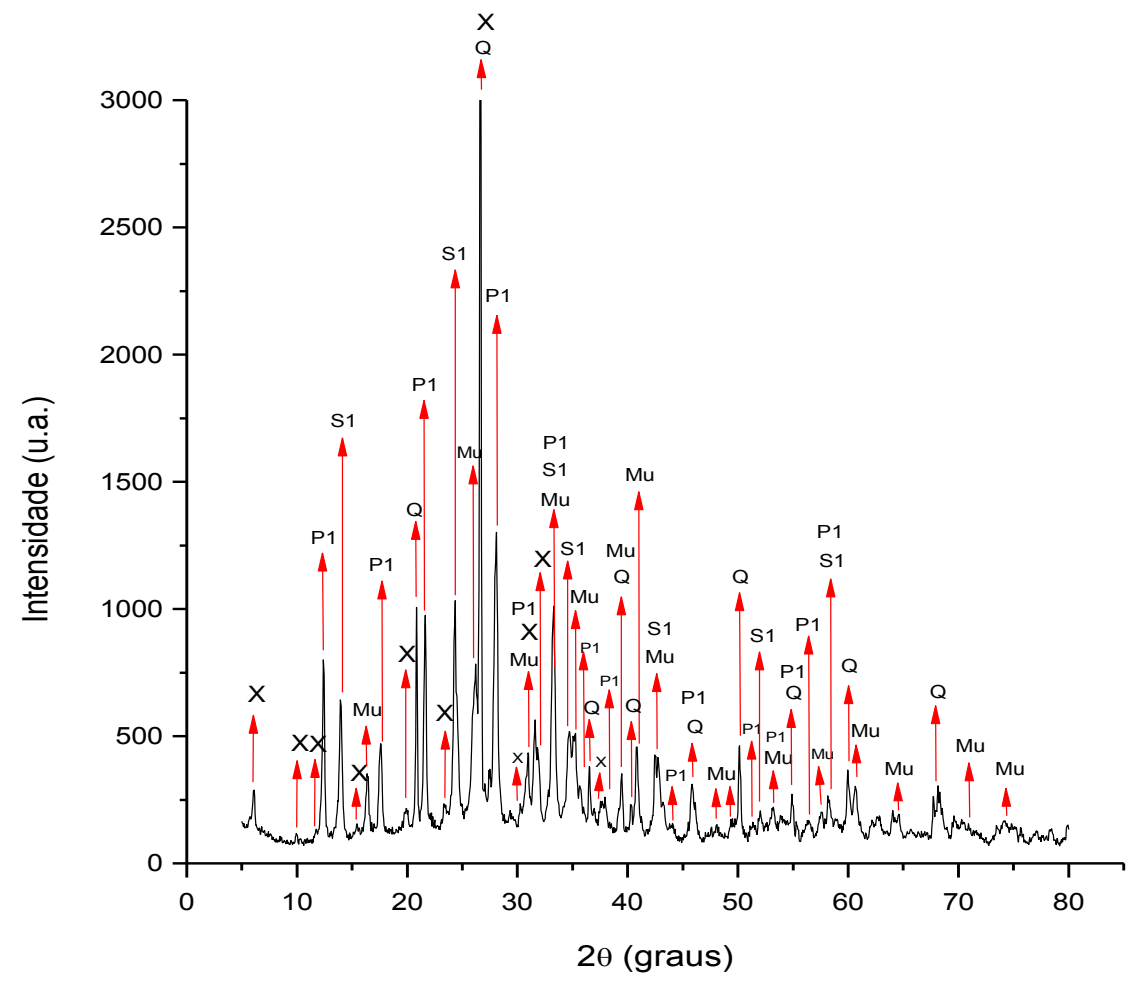

FIGURA 25 - Difratograma da ZCH (Q = Quartzo, Mu = Mulita, P1 = zeólita NaP1, $\mathrm{S} 1$ = zeólita Hidroxissodalita e $\mathrm{X}=$ zeólita $\mathrm{X}$ )

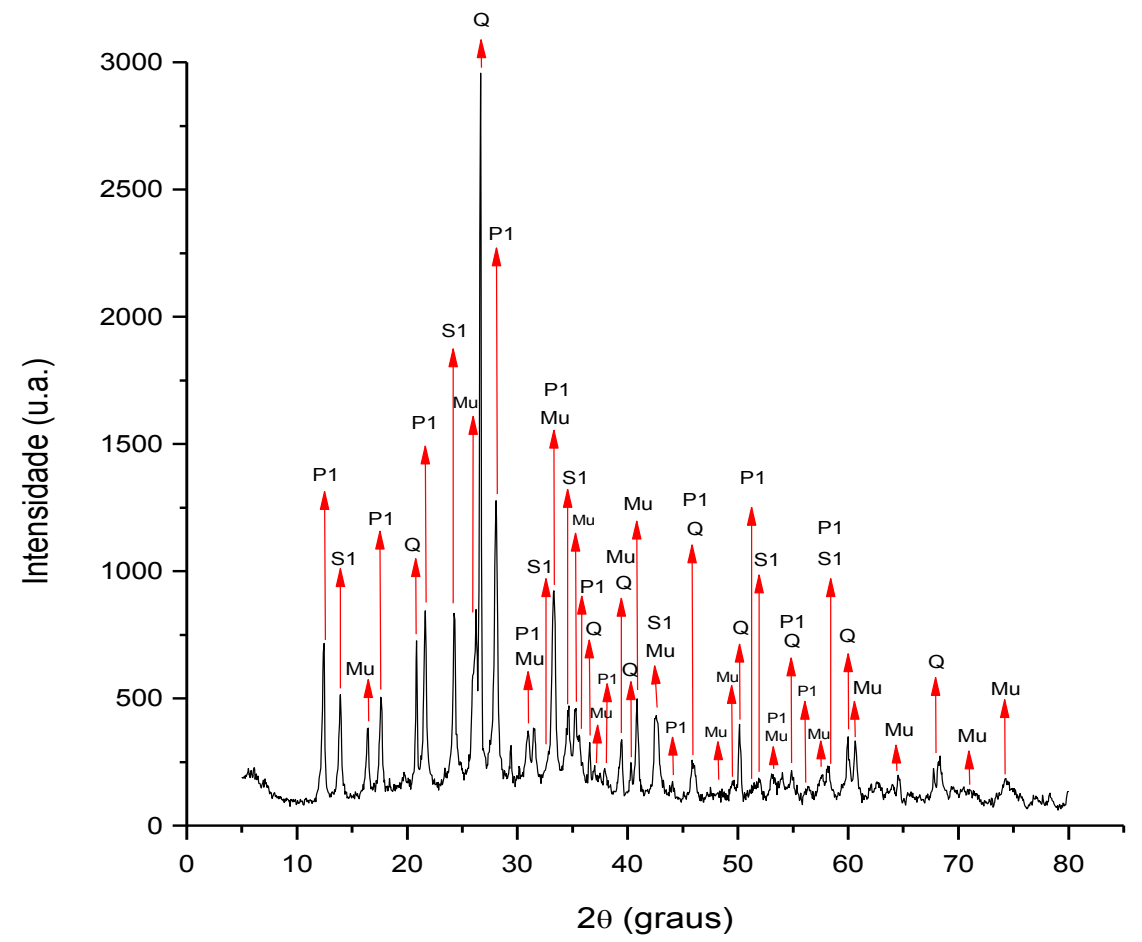

FIGURA 26 - Difratograma da ZPM (Q = Quartzo, Mu = Mulita, P1 = zeólita NaP1 e $\mathrm{S} 1$ = zeólita Hidroxissodalita) 


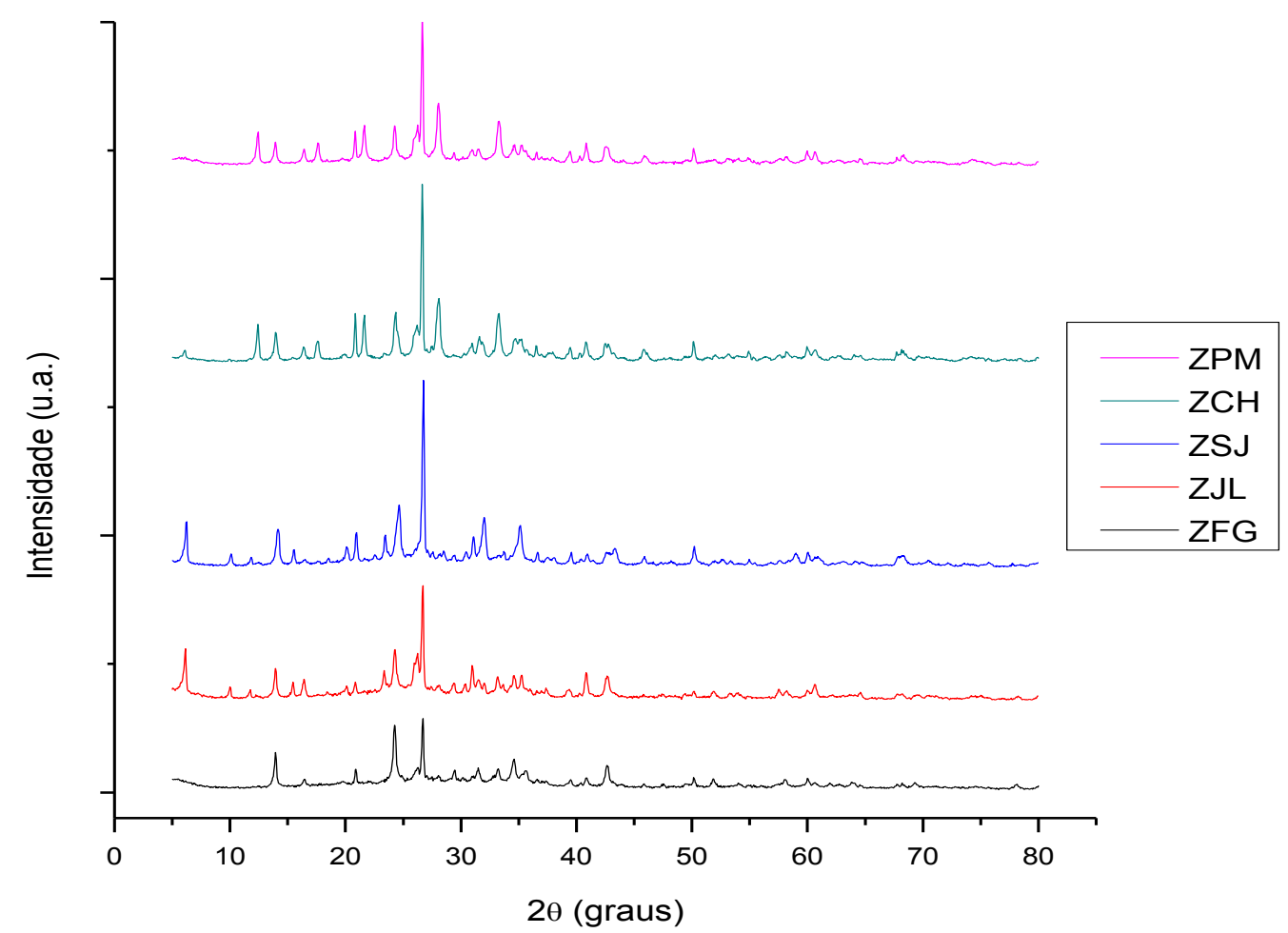

FIGURA 27 - Difratogramas dos cinco tipos de material zeolítico para comparação

Nas TAB. 9 e 10 são apresentadas as fases cristalinas encontradas para cada uma das amostras de zeólitas bem como as fórmulas químicas de cada fase, respectivamente.

TABELA 9 - Fases cristalinas identificadas nas amostras de zeólitas sintetizadas por tratamento hidrotérmico clássico

\begin{tabular}{cc}
\hline Amostra & Fases cristalinas \\
\hline ZFG & Q, Mu, S1 \\
ZJL & Q, Mu, S1, X \\
ZSJ & Q, Mu, S1, X \\
ZCH & Q, Mu, P1, S1, X \\
ZPM & Q, Mu, P1, S1 \\
\hline
\end{tabular}


TABELA 10 - Fórmulas químicas das fases cristalinas identificadas nas amostras de zeólitas sintetizadas por tratamento hidrotérmico clássico

\begin{tabular}{cc}
\hline Fases cristalinas & Fórmula química \\
\hline Quartzo $(\mathrm{Q})$ & $\mathrm{SiO}_{2}$ \\
Mulita $(\mathrm{Mu})$ & $\mathrm{Al}_{4,44} \mathrm{Si}_{1,56} \mathrm{O}_{9,78}$ \\
Hidroxissodalita (S1) & $1.08 \mathrm{Na}_{2} \mathrm{OAl}_{2} \mathrm{O}_{3} 1.68 \mathrm{SiO}_{2} 1.8 \mathrm{H}_{2} \mathrm{O}$ \\
Zeólita X (X) & $\mathrm{Na}_{2} \mathrm{Al}_{2} \mathrm{Si}_{2,5} \mathrm{O}_{9} .6,2 \mathrm{H}_{2} \mathrm{O}$ \\
$\mathrm{NaP1}(\mathrm{P} 1)$ & $\mathrm{Na}_{6} \mathrm{Al}_{6} \mathrm{Si}_{10} \mathrm{O}_{32} \cdot 12 \mathrm{H}_{2} \mathrm{O}$ \\
\hline
\end{tabular}

De modo geral, quartzo e mulita não podem ser dissolvidos substancialmente durante o processo hidrotérmico clássico e permanecem na zeólita. Essas duas fases foram encontradas, embora em quantidades variadas, em todas as amostras (FIG. 22 a FIG. 26). Sendo assim, os compostos responsáveis pela formação de zeólitas mediante o tratamento utilizado nessa primeira fase do estudo foram principalmente $\mathrm{SiO}_{2}$ e $\mathrm{Al}_{2} \mathrm{O}_{3}$ amorfos, descontandose a parte perdida durante a etapa de filtração do tratamento. Embora todas as cinzas de carvão apresentassem similares porcentagens em massa para $\mathrm{SiO}_{2} \mathrm{e}$ $\mathrm{Al}_{2} \mathrm{O}_{3}$ (determinadas pela técnica de fluorescência de raios $\mathrm{X}$ ), as quantidades desses compostos amorfos foram provavelmente diferentes para cada amostra e responsáveis pela formação de zeólitas de diferentes tipos e quantidades.

De acordo com a intensidade relativa dos picos observada por meio do programa PDXL, a mulita pode estar presente na ZSJ em pouca quantidade. Porém, a identificação dessa fase é prejudicada pela sobreposição de picos observada no difratograma (FIG.24). Dessa forma, existem indícios não conclusivos da presença de mulita na amostra ZSJ.

Como mostrado na TAB. 9, a zeólita hidroxissodalita (S1) foi formada em todos os produtos. Esse tipo de zeólita possui alta estabilidade mediante variações de temperatura que podem ocorrer durante a síntese de zeólitas usando cinzas de carvão como matéria prima e normalmente cristaliza-se entre 80 e $140^{\circ} \mathrm{C}$ (Poole et al., 2000). 
Observando-se o difratograma da zeólita ZFG (FIG. 22) verifica-se que foi formada somente uma fase de zeólita após o tratamento hidrotérmico da cinza precursora: a zeólita hidroxissodalita (S1). Isso ocorreu provavelmente devido ao elevado conteúdo de elementos que inibem a formação de zeólitas (como ferro e cálcio, os quais apresentaram \% em massa de 10,2 e 4,7\%, respectivamente) e a presença de outras impurezas com elevadas concentrações, presentes na cinza precursora (CFG) e mostrados no estudo de composição química.

Por outro lado, a cinza que apresentou os menores conteúdos de ferro e cálcio - compostos estes responsáveis pela diminuição da reatividade do meio durante a síntese e interferência na dissolução do Si e $\mathrm{Al}$ - a cinza $\mathrm{CCH}$, deu origem a um produto $(\mathrm{ZCH})$ que apresentou 3 tipos de zeólitas: hidroxissodalita (S1), NaP1 (P1) e traços de zeólita $X(X)$. A maior formação de zeólitas pela amostra de $\mathrm{CCH}$ também pode estar relacionada com a quantidade de alumínio presente na amostra da cinza precursora no valor de $32,6 \%$, que é uma quantidade superior à quantidade encontrada para as outras amostras de cinzas (estudo de composição química, item 5.1.5). Como dito anteriormente, sendo o alumínio um elemento estrutural de zeólitas, sua quantidade influencia na formação desses materiais.

As amostras ZJL, ZSJ e ZPM apresentaram, cada uma delas, duas fases de zeólitas: as zeólitas $X(X)$ e hidroxissodalita (S1) para as amostras de ZJL e ZSJ e as zeólitas NaP1 (P1) e hidroxissodalita (S1) para a ZPM.

A formação de zeólita NaP1 (presentes nas amostras ZCH e ZPM) foi possível apenas usando-se cinzas de carvão com baixo conteúdo de ferro e cálcio, como as cinzas $\mathrm{CCH}$ e CPM. A zeólita $X$, por sua vez (presentes nas amostras de ZJL, ZSJ e ZCH), foi possível de ser sintetizada apenas usando-se cinzas com elevado teor de alumínio, como as cinzas CJL, CSJ e CCH (TAB. 7).

Cabe ressaltar que a identificação das fases nas amostras de zeólitas de cinzas de carvão é dificultada devido à sobreposição dos picos presentes em todas as amostras. Sendo assim, a caracterização mineralógica por meio da técnica de difratometria de raios $X$ nessa fase do presente estudo serviu como análise comparativa das amostras de diferentes procedências.

As diferentes composições químicas e morfologias das cinzas de carvão utilizadas para a síntese de zeólitas por tratamento hidrotérmico 
convencional influenciaram no tipo e na quantidade de zeólitas formadas bem como no tamanho dos cristais de zeólitas observados no estudo de morfologia.

Além disso, o Si e o Al presente nas cinzas é dissolvido em diferentes proporções durante a síntese hidrotérmica na seguinte ordem: fase amorfa > quartzo > mulita (Querol et al., 2002). Como resultado, cinzas com similar relação Si/Al não irão necessariamente resultar na síntese dos mesmos produtos, usando-se as mesmas condições de ativação. O que determinará a formação de zeólitas durante o tratamento hidrotérmico convencional (o qual não dissolve todo o conteúdo de quartzo e mulita), portanto, será o conteúdo de fase amorfa de Si e Al na matriz de cinza (Querol et al., 2002).

Sendo assim, diferenças nos conteúdos de fases amorfa/cristalina nas amostras de cinzas podem ter influenciado na quantidade e no tipo de zeólita sintetizada por tratamento hidrotérmico convencional mostrados nessa fase do estudo.

\subsubsection{Determinação da capacidade de troca catiônica}

Os valores de capacidade de troca catiônica - CTC - encontrados para as cinzas de carvão e suas respectivas zeólitas são mostradas na TAB. 11 .

TABELA 11 - Valores de Capacidade de Troca Catiônica para as zeólitas de cinzas de carvão e seus materiais precursores

\begin{tabular}{cccc}
\hline Amostra & CTC meq $~^{-1}$ & Amostra & CTC meq ${ }^{-1}$ \\
\hline CFG & 0,035 & ZFG & 1,4 \\
CJL & 0,026 & ZJL & 1,3 \\
CSJ & 0,027 & ZSJ & 1,5 \\
CCH & 0,026 & ZCH & 1,9 \\
CPM & 0,026 & ZPM & 1,6 \\
\hline
\end{tabular}

De acordo com a TAB. 11, os valores de CTC para as cinzas de carvão foram muito próximos e variaram entre 0,026 e 0,035 meq $\mathrm{g}^{-1}$. As zeólitas apresentaram valores entre 1,3 e 1,9 meq $\mathrm{g}^{-1}$. Os valores de CTC encontrados para cinzas e zeólitas estão concordantes com os valores relatados em literatura (Paprocki, 2009). 
De forma geral, houve um aumento da CTC de 40 vezes ou mais para cada amostra após o processo de zeolitização. Os valores de CTC das zeólitas foram maiores do que os valores para os seus materiais precursores devido à elevada área específica encontrada, às menores razões $\mathrm{SiO}_{2} / \mathrm{Al}_{2} \mathrm{O}_{3}$ determinadas e à formação de fases zeolíticas mostradas nos respectivos difratogramas. Os valores de CTC encontrados para as zeólitas indicam que estes materiais possuem um elevado potencial para utilização como trocadores iônicos.

Segundo Scott et al. (2001), a variação nos valores de CTC entre as zeólitas depende do tipo e quantidade de zeólita formada.

As zeólitas que apresentaram somente uma ou duas fases zeolíticas identificadas pela técnica de difração de raios $X$, as zeólitas ZFG, ZJL, ZSJ e ZPM (TAB. 9 - item 5.1.6) foram também as que tiveram menor valor no estudo de CTC.

A zeólita ZCH apresentou CTC no valor 1,9 meq $\mathrm{g}^{-1}$, o maior valor observado para as zeólitas sintéticas. Isso se deve provavelmente ao fato de ter sido a amostra com maior número de fases zeolíticas identificadas por difratometria de raios $X$ (TAB. 9 - item 5.1.6). Zeólitas NaP1 geralmente possuem maior facilidade para trocar $\mathrm{NH}_{4}{ }^{+}$do que zeólitas hidroxissodalita, as quais possuem tamanho de poro menores (Ryu et al., 2006). Além disso, a amostra de cinza que deu origem a esse material $(\mathrm{CCH})$ apresentou um dos menores valores de umidade e perda por calcinação (TAB. 5 - item 5.1.2). Baixos valores desses dois últimos parâmetros citados contribuem para a formação de zeólitas, pois implica em uma menor quantidade de fases reativas durante a síntese, como dito anteriormente.

A zeólita ZJL, por sua vez, apresentou CTC no valor 1,3 meq $\mathrm{g}^{-1}$, 0 menor valor observado. A cinza que deu origem a esse produto (CJL) apresentou um dos valores mais altos de perda por calcinação (TAB. 5 - item 5.1.2).

O conteúdo de ferro nas cinzas precursoras mostrou ter grande influência sobre a capacidade de troca catiônica dos produtos obtidos a partir das mesmas após síntese hidrotérmica. Em geral, quanto maior a quantidade de ferro na cinza precursora, menor a capacidade de troca catiônica do produto zeolítico, pois como citado anteriormente, cinzas com elevado teor de ferro inibem a formação de zeólitas, resultando na formação de produtos com menor CTC. 
As diferenças entre os produtos zeolíticos obtidos por tratamento alcalino convencional das cinzas de carvão mostradas pela caracterização na primeira etapa do estudo podem limitar sua comercialização, por isso, estudos de síntese de zeólita de alta pureza a partir de cinzas de carvão foram feitos.

\subsection{Síntese e caracterização de zeólitas com elevado grau de pureza}

\subsubsection{Seleção de amostras}

A próxima fase do estudo consistiu em sintetizar zeólitas com elevado grau de pureza utilizando-se metodologia adequada e aplicável a diferentes matérias primas. A síntese de zeólitas puras $\mathrm{A}$ e $\mathrm{X}$ a partir de cinzas de carvão brasileiras, de características específicas, sem 0 uso de sementes ou direcionadores de estrutura e sem a utilização de longos tempos de cristalização, é inédita.

Sendo assim, a escolha das amostras para a segunda fase do estudo baseou-se na seleção de duas amostras de cinzas de carvão que resultaram em produtos com características opostas, de modo que a metodologia desenvolvida para a síntese pudesse abranger matérias primas distintas, porém, obtendo-se os mesmos produtos puros.

De acordo com a primeira etapa do estudo, as cinzas provenientes das usinas de Figueira (CFG) e São Jerônimo (CSJ) foram consideradas muito diferentes das demais amostras de cinzas de carvão. A primeira amostra, por apresentar elevada quantidade de impurezas, e a segunda, por ser resultante de um processo de queima antigo, o qual resulta na formação de cinzas com características morfológicas bem diferentes das demais.

A cinza CJL apresentou um dos valores mais altos de perda por calcinação, além de ter gerado um produto com a menor CTC se comparada às outras zeólitas obtidas. A cinza $\mathrm{CCH}$, por sua vez, se mostrou a melhor matéria prima na síntese de zeólitas por ter apresentado baixos valores de umidade e perda por calcinação, grande quantidade de alumínio em sua composição química e ter gerado um produto $(\mathrm{ZCH})$ com maior número de fases identificadas por difração de raios $\mathrm{X}$ e maior capacidade de troca catiônica - CTC.

Optou-se por utilizar como parâmetro comparativo para a seleção de amostras, a capacidade de troca catiônica dos produtos obtidos na primeira 
etapa, pelo fato dessa característica ser a mais importante na aplicação de zeólitas. Sendo assim, as matérias primas selecionadas para a segunda fase do estudo foram as cinzas CJL e CCH.

Essa escolha parte da hipótese que é possível utilizar uma metodologia que se aplique à matérias primas com características diferentes e que geraram produtos com variações extremas de CTC, de modo a obter-se o mesmo tipo de produto final de elevada pureza. Ou seja, se for possível sintetizar zeólita com elevado grau de pureza a partir da cinza que gerou a zeólita de menor CTC na primeira etapa (CJL), também será possível utilizar a cinza que gerou um produto com características opostas $(\mathrm{CCH})$, para a síntese de zeólita com elevado grau de pureza, usando mesma metodologia.

\subsubsection{Seleção dos parâmetros de síntese}

Para a seleção de metodologia adequada à síntese de zeólitas $\mathrm{A}$ e $\mathrm{X}$ com elevado grau de pureza usando-se as duas matérias primas selecionadas, fixou-se os seguintes parâmetros: razão cinza/NaOH na proporção 1:1,2, temperatura e tempo de fusão de $550^{\circ} \mathrm{C}$ e $1 \mathrm{~h}$, respectivamente, tempo de cura (envelhecimento) antes do tratamento hidrotérmico de $16 \mathrm{~h}$, e secagem a $105^{\circ} \mathrm{C}$ durante $16 \mathrm{~h}$. Outros parâmetros como adição de fonte de alumínio, volume de água adicionado antes da cura e cristalização e temperatura e tempo usados no tratamento hidrotérmico variaram para as diferentes sínteses. O resumo dos parâmetros usados nas diferentes sínteses bem como os produtos obtidos encontra-se na TAB. 12.

Verificou-se que o tipo de fonte de alumínio adicionado influenciou de forma significativa na síntese de zeólitas. Conforme observado na TAB. 12, nas sínteses onde se utilizou alumínio na forma de hidróxido de alumínio, esse composto não foi dissolvido e foi incorporado ao produto final, verificando-se a presença do mesmo no difratograma de raios $X$ dos produtos obtidos $e$ apresentados na referida tabela (sínteses 3, 4, 5 e 6). Por esse motivo, optou-se por utilizar alumínio na forma de aluminato de sódio, que além de ser dissolvido com mais facilidade na etapa de cura da síntese, também possui estrutura semelhante à estrutura de zeólitas, e, portanto, maior facilidade de ser convertido nesses tipos de materiais. 
TABELA 12 - Resumo dos parâmetros usados na síntese de zeólitas com elevado grau de pureza por processo de duas etapas

\begin{tabular}{|c|c|c|c|c|c|c|}
\hline $\begin{array}{l}\mathrm{N}^{\circ} \mathrm{da} \\
\text { Síntese }\end{array}$ & $\begin{array}{c}\text { Matéria } \\
\text { Prima }\end{array}$ & $\begin{array}{c}\text { Adição } \\
\text { de Al }\end{array}$ & $\mathrm{V}_{\mathrm{H} 2 \mathrm{O}}(\mathrm{mL})$ & $\mathrm{T} /{ }^{\circ} \mathrm{C}$ & $t / h$ & $\begin{array}{c}\text { Produtos } \\
\text { (traços) }\end{array}$ \\
\hline 1 & CJL & - & 100 & 100 & 6 & $\mathrm{X}(\mathrm{A}, \mathrm{Q}, \mathrm{M})$ \\
\hline 2 & $\mathrm{CCH}$ & - & 100 & 100 & 6 & $X(A, S, Q, M)$ \\
\hline 3 & CJL & $\mathrm{Al}(\mathrm{OH})_{3}$ & 100 & 100 & 6 & $\mathrm{Al}, \mathrm{X}(\mathrm{Q})$ \\
\hline 4 & $\mathrm{CCH}$ & $\mathrm{Al}(\mathrm{OH})_{3}$ & 100 & 100 & 6 & Al, X (Q) \\
\hline 5 & CJL & $\mathrm{Al}(\mathrm{OH})_{3}{ }^{*}$ & 100 & 100 & 6 & $\mathrm{Al}, \mathrm{X}(\mathrm{Q})$ \\
\hline 6 & $\mathrm{CCH}$ & $\mathrm{Al}(\mathrm{OH})_{3}{ }^{*}$ & 100 & 100 & 6 & Al, X (Q) \\
\hline 7 & CJL & $\mathrm{NaAlO}_{2}$ & 100 & 80 & 3 & $A(Q)$ \\
\hline 8 & $\mathrm{CCH}$ & $\mathrm{NaAlO}_{2}$ & 100 & 80 & 3 & $A(Q)$ \\
\hline 9 & CJL & - & 100 & 100 & 7 & $X(A, Q)$ \\
\hline 10 & $\mathrm{CCH}$ & - & 100 & 100 & 7 & $X(A, Q)$ \\
\hline 11 & CJL & - & 100 & 100 & 16 & $X, S(Q, H)$ \\
\hline 12 & $\mathrm{CCH}$ & - & 100 & 100 & 16 & $S, Q(H)$ \\
\hline 13 & CJL & - & 200 & 100 & 24 & $S(X, Q, H)$ \\
\hline 14 & $\mathrm{CCH}$ & - & 200 & 100 & 24 & $\mathrm{~S}, \mathrm{Q}(\mathrm{H})$ \\
\hline 15 & CJL & $\mathrm{NaAlO}_{2}$ & 100 & 100 & 7 & $A(S)^{\star *}$ \\
\hline 16 & $\mathrm{CCH}$ & $\mathrm{NaAlO}_{2}$ & 100 & 100 & 7 & $A(Q, S) * *$ \\
\hline 17 & CJL & $\mathrm{NaAlO}_{2}$ & 200 & 100 & 24 & $X^{\star \star}$ \\
\hline 18 & $\mathrm{CCH}$ & $\mathrm{NaAlO}_{2}$ & 200 & 100 & 24 & $X^{* *}$ \\
\hline 19 & CJL & - & 280 & 100 & 48 & $\mathrm{~S}(\mathrm{Q}, \mathrm{H})$ \\
\hline 20 & $\mathrm{CCH}$ & - & 280 & 100 & 48 & $S, Q(H)$ \\
\hline
\end{tabular}

A influência da adição de alumínio foi testada durante todo o desenvolvimento do processo de seleção dos parâmetros de síntese adequados à obtenção de zeólitas de alta pureza. Os produtos sintetizados com adição de 
alumínio de fonte externa apresentaram difratogramas com fases mais puras das zeólitas de interesse do que os produtos sintetizados sem a adição desse elemento. Isso ocorreu pelo fato das duas matérias primas utilizadas conterem alumínio em quantidade inferior à necessária para a síntese de zeólitas $\mathrm{A}$ e $\mathrm{X}$, que possuem relação Si/Al específicas. A quantidade de alumínio adicionada em cada síntese variou com o tipo de matéria prima e foi calculada ajustando-se a relação $\mathrm{Si} / \mathrm{Al}$ do produto desejado com base nas quantidades de silício e alumínio préexistentes nas amostras de cinzas (obtidas por fluorescência de raios $\mathrm{X}$ no estudo de composição química).

Verificou-se que maiores tempos de cristalização e maiores temperaturas durante o tratamento hidrotérmico, conduzem à formação de fases zeolíticas com menores tamanho de poro, como é o caso da zeólita sodalita (S), a qual possui maior estabilidade nessas condições.

A quantidade de água adicionada em cada síntese foi controlada de modo a se evitar que ao final do tratamento hidrotérmico não houvesse material líquido sobrenadante, pois a ausência do mesmo faz com que a temperatura do sólido resultante se eleve, conduzindo à formação de fases zeolíticas de menor interesse, como por exemplo, a zeólita sodalita, citada anteriormente. Sendo assim, as sínteses que foram realizadas com tempos de cristalização maiores também foram realizadas com adição de maiores volumes de água.

O critério utilizado para selecionar as amostras de zeólitas A e X com elevado grau de pureza baseou-se na análise dos difratogramas de raios $X$ dos produtos obtidos em cada síntese. Os produtos que apresentaram uma única fase principal de zeólita e maior grau de cristalinidade foram escolhidos para serem submetidos às caracterizações físicas e químicas posteriores.

As zeólitas A com elevado grau de pureza selecionadas foram resultantes das sínteses de números 15 e 16, e simbolizadas no presente trabalho por ZAJL e ZACH, respectivamente. As zeólitas $X$ selecionadas foram resultantes das sínteses de números 17 e 18 e simbolizadas por ZXJL e ZXCH, respectivamente. A metodologia detalhada usada para a síntese de cada tipo de zeólita selecionada foi mostrada no item referente a materiais e métodos.

Conforme mostrado na TAB. 12, as zeólitas $X$ foram formadas após a utilização de maiores tempos de cristalização quando comparados aos tempos usados para a síntese de zeólitas A. Esse comportamento já era esperado, pois a 
estrutura da zeólita $X$ é maior e mais complexa do que a estrutura da zeólita $A$, e, portanto, requer mais tempo para sua formação (Petrovic et al., 1993).

Os difratogramas de raios $X$ das zeólitas que não foram selecionadas encontram-se nas FIG. 1 a 16 do Apêndice A da presente tese.

O estudo das matérias primas usadas, dos parâmetros das diferentes sínteses relatadas e dos produtos obtidos em cada uma das sínteses, permitiu traçar um roteiro geral para a síntese de zeólitas A e X. O roteiro está representado na FIG. 28 e pode ser usado para auxiliar as tomadas de decisão ou como ponto de partida para novas pesquisas onde se deseja obter as zeólitas A e $\mathrm{X}$ com elevado grau de pureza sintetizadas a partir de cinzas de carvão.

\subsubsection{Caracterização das zeólitas selecionadas}

\subsubsection{Composição mineralógica}

A difratometria de raios $X$ é a principal técnica para identificação de zeólitas de cinzas de carvão usada atualmente. Nas FIG. 29 e 30 são apresentados os difratogramas das zeólitas X e A com elevado grau de pureza, respectivamente, obtidas a partir das duas diferentes cinzas de carvão brasileiras.

$\mathrm{Na}$ TAB. 13 é apresenta as fases cristalinas encontradas para cada amostra bem como as fórmulas químicas de cada fase. Na TAB. 14 é mostrada a estimativa semiquantitativa das porcentagens das fases encontradas para cada material.

De acordo com os difratogramas apresentados na FIG. 29, os produtos de síntese apresentaram somente uma fase única de zeólita $X$ pura, independentemente da cinza utilizada. Os resultados da estimativa semiquantitativa das porcentagens das fases presentes em ambas as amostras mostrados na TAB. 14 comprovaram esses resultados. Os picos de quartzo e mulita normalmente encontrados nos difratogramas de zeólitas sintetizadas pelo método convencional desapareceram devido ao uso da etapa de fusão, a qual é responsável por dissolver esses componentes, para que zeólitas possam ser formadas com maiores rendimentos de síntese nos estágios subsequentes. 


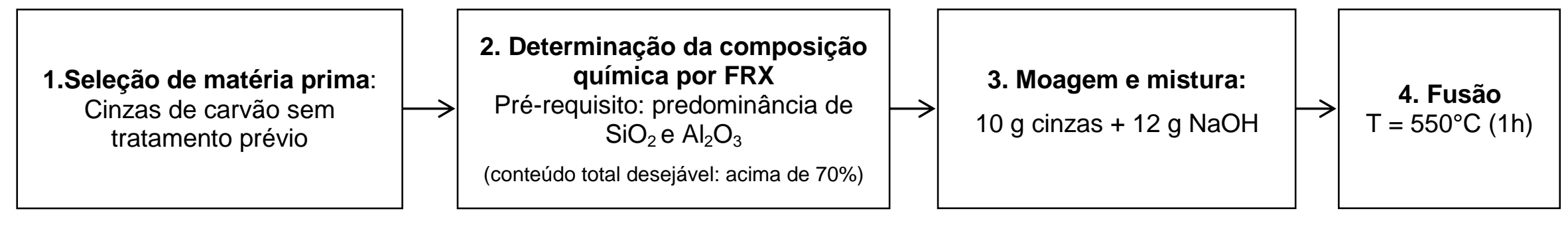

\begin{tabular}{|c|c|c|c|}
\hline $\begin{array}{c}\text { 5.Resfriamento } \\
T_{\text {amb }}(1 \mathrm{~h}) \text { e moagem }\end{array}$ & $\begin{array}{l}\text { 6. Adição de } \mathrm{NaAlO}_{2} \text { para } \\
\text { ajuste da relação Si/Al } \\
\text { •Zeólita } \mathrm{A}=1,0-1,2 \\
\text { •Zeólita } X=1,0-1,5\end{array}$ & $\begin{array}{l}\text { 7. Adição de água de acordo } \\
\text { com o tempo de cristalização } \\
\qquad \begin{array}{c}t=24 \mathrm{~h}, \mathrm{~V}=200 \mathrm{~mL} \\
\mathrm{t}=7 \mathrm{~h}, \mathrm{~V}=100 \mathrm{~mL}\end{array}\end{array}$ & $\begin{array}{c}\text { 8. Cura ou } \\
\text { envelhecimento } \\
\text { Agitação a } 150 \mathrm{rpm}(16 \mathrm{~h})\end{array}$ \\
\hline
\end{tabular}

\begin{tabular}{|c|} 
9. Cristalização \\
$\begin{array}{c}\text { Aquecimento a } 100^{\circ} \mathrm{C} \\
\bullet \text { Zeólita } \mathrm{A}=7 \mathrm{~h} \\
\bullet \text { Zeólita } \mathrm{X}=24 \mathrm{~h}\end{array} \rightarrow \longrightarrow \begin{array}{c}\text { Produto com sobrenadante: } \\
\text { seguir para item } 10 \\
\text { Produto somente com fase } \\
\text { sólida:voltar para a etapa } 7 \mathrm{e} \\
\text { aumentar o volume de água }\end{array}$
\end{tabular}$\rightarrow \rightarrow \begin{gathered}\text { 10. Filtração, lavagem e } \\
\text { secagem dos produtos } \\
\text { a } 105^{\circ} \mathbf{C}(16 \mathrm{~h})\end{gathered} \rightarrow \begin{gathered}\text { 11. Caracterização } \\
\text { mineralógica dos produtos } \\
\text { obtidos por DFRX }\end{gathered}$

\begin{tabular}{|c|c|}
\hline 12. Análise dos produtos finais & 13. Tomadas de decisão \\
\hline A) Se houver presença de quartzo, mulita, & A) Voltar na etapa 4 e aumentar temperatura de fusão. \\
\hline B) Se houver presença de fase de alumínio & B) Voltar na etapa 6 e diminuir a quantidade de $\mathrm{NaAlO}_{2}$. \\
\hline $\begin{array}{l}\text { C) Se houver formação de zeólitassodalita, } \\
\text { hidroxisodalita ou outras semelhantes }\end{array}$ & $\begin{array}{l}\text { C) Voltar na etapa } 9 \text { (cristalização) e diminuir o tempo e/ou a temperatura } \\
\text { de aquecimento. }\end{array}$ \\
\hline D) Se houver mistura de fases de zeólitas A e X & $\begin{array}{l}\text { D) Voltar na etapa 9: } \\
\text { - Para favorecer formação de zeólita A: diminuir o tempo de cristalização. } \\
\text { - Para favorecer formacão de zeólita A: aumentar o tempo de cristalizacão. }\end{array}$ \\
\hline
\end{tabular}

FIGURA 28 - Roteiro geral para a síntese de zeólitas A e X com elevado grau de pureza a partir de cinzas de carvão 


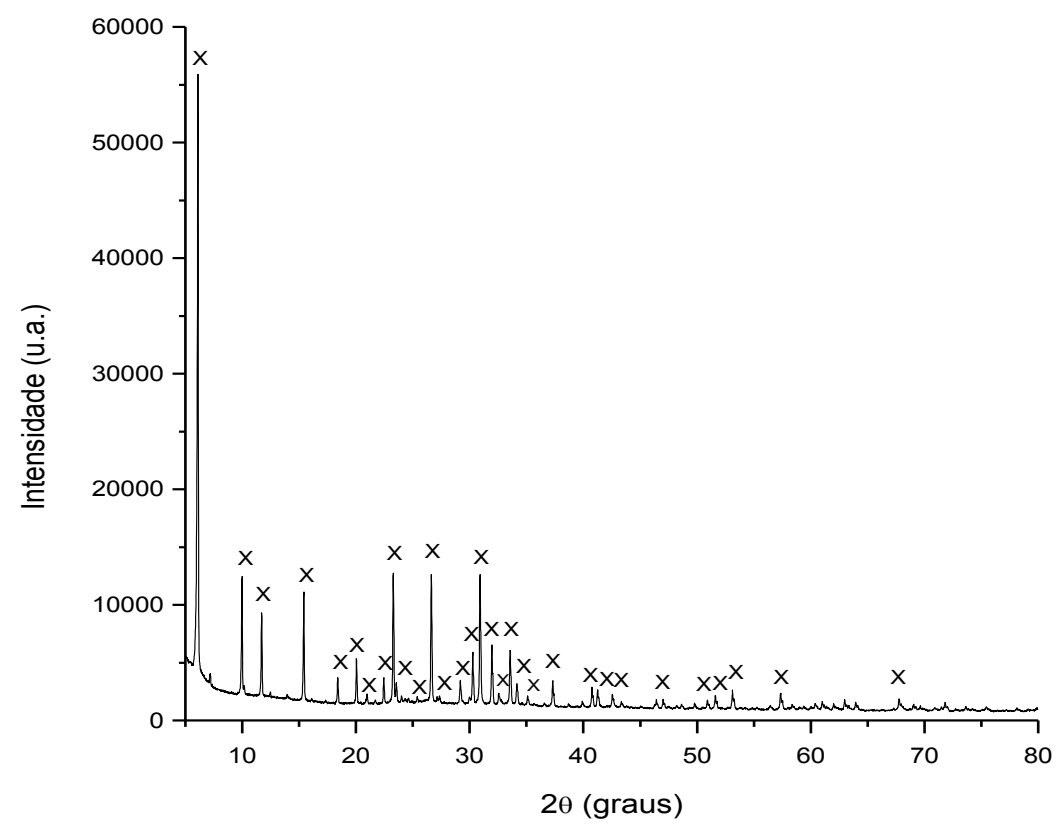

(a)

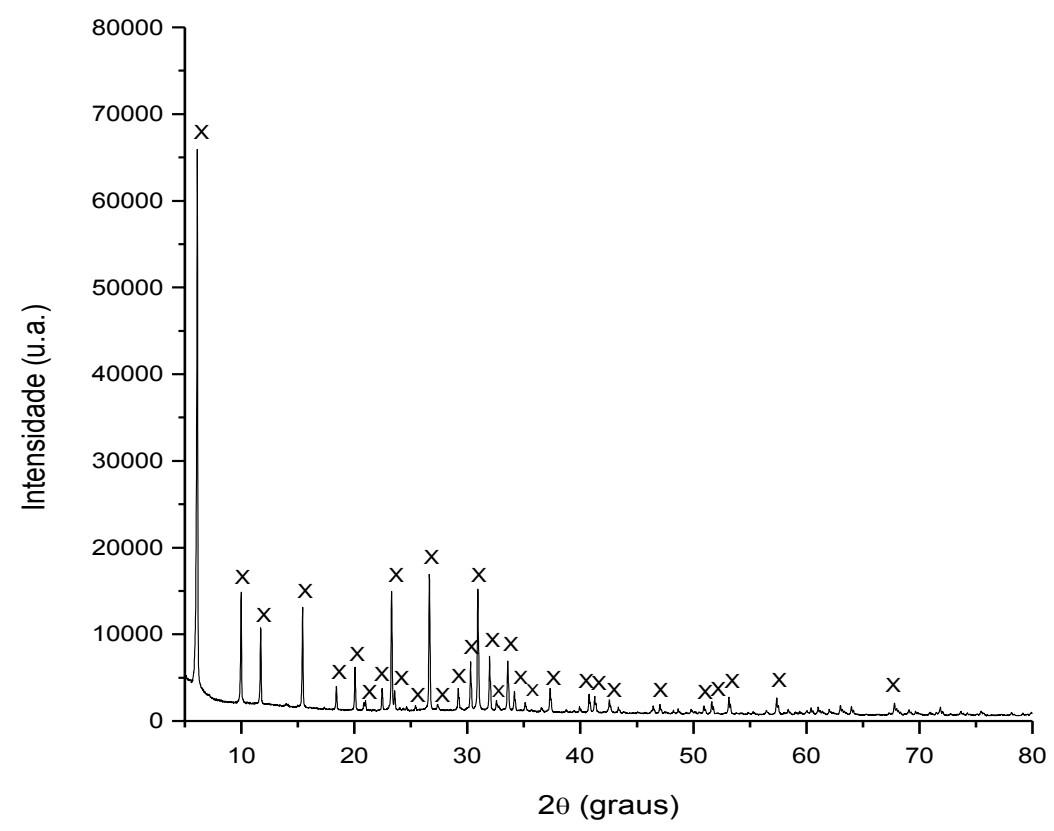

(b)

FIGURA 29 - Difratograma da zeólita X sintetizada por processo de duas etapas a) ZXJL e b) ZXCH 


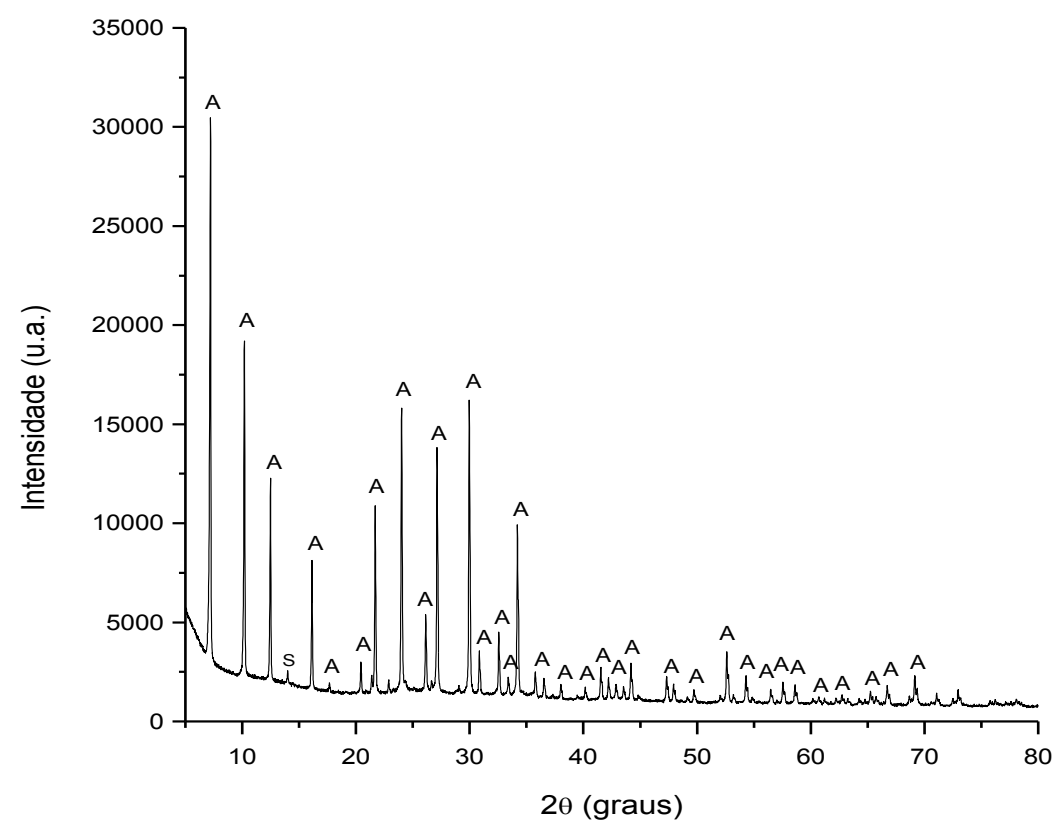

(a)

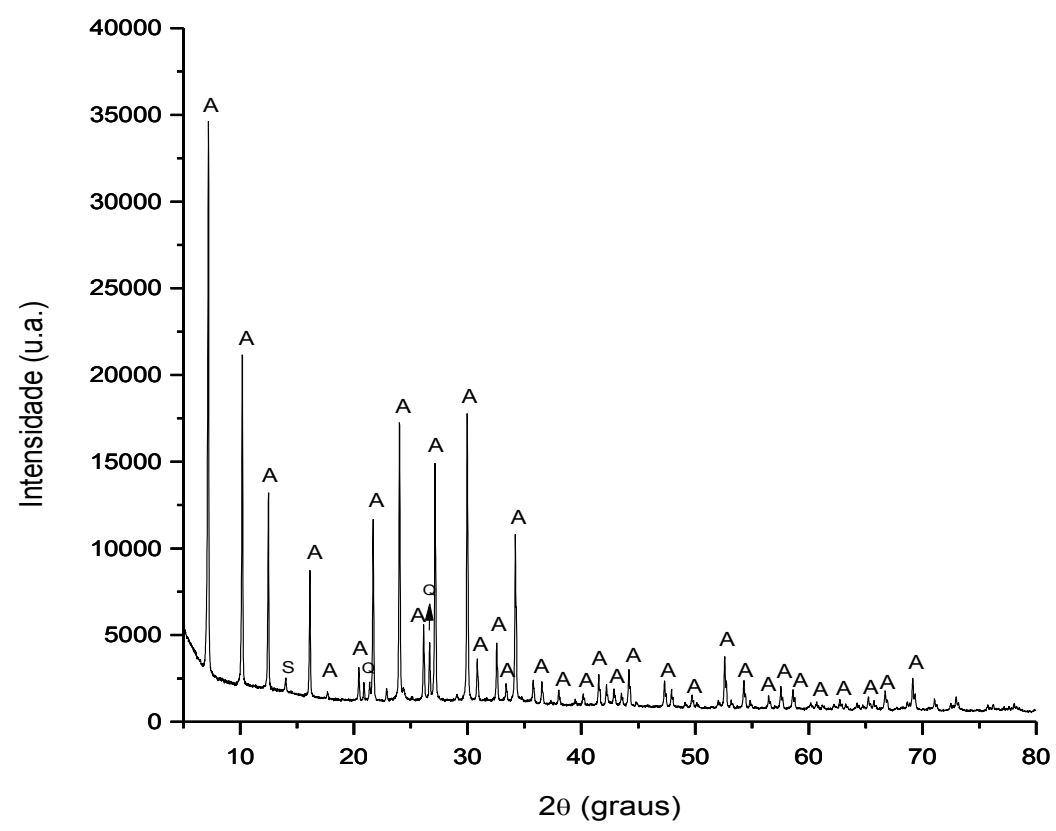

(b)

FIGURA 30 - Difratograma da zeólita A sintetizada por processo de duas etapas a) ZAJL e b) ZACH 
TABELA 13 - Fases cristalinas presentes nas amostras de zeólitas com elevado grau de pureza identificadas por DRFX e suas respectivas fórmulas químicas

\begin{tabular}{ccc}
\hline Amostra & Fases cristalinas & Fórmula química \\
\hline ZXJL & Zeólita X (X) & $\mathrm{Na}_{2} \mathrm{Al}_{2} \mathrm{Si}_{2,5} \mathrm{O}_{9} \cdot 6,2 \mathrm{H}_{2} \mathrm{O}$ \\
ZXCH & Zeólita X (X) & $\mathrm{Na}_{2} \mathrm{Al}_{2} \mathrm{Si}_{2,5} \mathrm{O}_{9} \cdot 6,2 \mathrm{H}_{2} \mathrm{O}$ \\
& Zeólita A (A) & $\mathrm{Na}_{2} \mathrm{Al}_{2} \mathrm{Si}_{1,85} \mathrm{O}_{7,7} \cdot 5,1 \mathrm{H}_{2} \mathrm{O}$ \\
ZAJL & Zeólita Sodalita (S) & $\mathrm{Na}_{6}\left(\mathrm{AlSiO}_{4}\right)_{6} \cdot 4 \mathrm{H}_{2} \mathrm{O}$ \\
& Zeólita A (A) & $\mathrm{Na}_{2} \mathrm{Al}_{2} \mathrm{Si}_{1,85} \mathrm{O}_{7,7} \cdot 5,1 \mathrm{H}_{2} \mathrm{O}$ \\
ZACH & Quartzo (Q) & $\mathrm{SiO}_{2}$ \\
& Zeólita Sodalita (S) & $\mathrm{Na}_{6}\left(\mathrm{AlSiO}_{4}\right)_{6} \cdot 4 \mathrm{H}_{2} \mathrm{O}$ \\
\hline
\end{tabular}

TABELA 14 - Estimativa semiquantitativa das porcentagens das fases presentes nas zeólitas com elevado grau de pureza

\begin{tabular}{ll}
\hline Zeólita de alta pureza & Conteúdo por fase \\
\hline ZXJL & Zeólita $X=100,0 \%$ \\
ZXCH & Zeólita X $=100,0 \%$ \\
ZAJL & Zeólita $A=98,0 \%$ \\
& Zeólita sodalita $=2,00 \%$ \\
ZACH & Zeólita $A=88,0 \%$ \\
& Quartzo $=11,9 \%$ \\
& Zeólita sodalita $=0,1 \%$ \\
\hline
\end{tabular}

Cabe ressaltar que a presença de outros compostos que podem estar presentes nas amostras provavelmente se encontram na fase amorfa e em quantidades pequenas, por isso não foram detectados pela técnica de difratometria de raios $X$. Esses compostos foram identificados pela técnica de fluorescência de raios $X$, cujos resultados são mostrados adiante. 
De modo geral, pode-se concluir que os produtos sintetizados pelo método descrito na presente tese usando diferentes matérias primas são considerados como produtos de alta pureza pelo fato das porcentagens das fases de zeólitas puras A e X presentes nas amostras terem variado de 88 a $100 \%$.

\subsubsection{Morfologia}

As imagens geradas pela técnica de microscopia eletrônica de varredura podem ser usadas como técnica complementar para confirmar a presença das fases identificadas por difração de raios $\mathrm{X}$.

No estudo da morfologia de zeólitas e de acordo com a literatura, a zeólita $X$ apresenta estrutura octaédrica na forma de cristais bipiramidais (Shiguemoto et al., 1993; Chang e Shih, 1998; Hollman et al., 1999; Ríos et al., 2009; Tanaka e Fujii, 2009). Enquanto que a zeólita A, por sua vez, apresenta estrutura cúbica (Shiguemoto et al., 1993; Wang et al., 2008; Yaping et al., 2008; Tanaka e Fujii, 2009).

Na FIG. 31 é mostrada a micrografia das amostras de zeólitas $\mathrm{X}$ e $\mathrm{A}$ de alta pureza sintetizadas a partir das diferentes matérias primas no presente estudo.

De acordo com a FIG. 31, as zeólitas X (FIG. 31a e 31b) e as zeólitas A (FIG. 31c e 31d) podem ser vistas com clareza e são compatíveis com o formato descrito na literatura citada, apresentando estrutura octaédrica na forma de cristais bipiramidais e estrutura cúbica, respectivamente. Esses resultados confirmam a presença das fases identificadas por difratometria de raios $X$.

A FIG. 31 mostra que as zeólitas $X$ apresentaram cristais de tamanhos similares, enquanto que as zeólitas $A$ apresentaram cristais de tamanhos variáveis para cada matéria prima usada. Segundo Hui e Chao (2006) e Wang et al. (2008), o mesmo tipo de zeólita pode apresentar diferente tamanho de cristal devido à diferença na taxa de crescimento dos mesmos durante o tratamento hidrotérmico. Isso pode ter sido causado pela diferença de conteúdo de fases amorfas e cristalinas das cinzas utilizadas. 

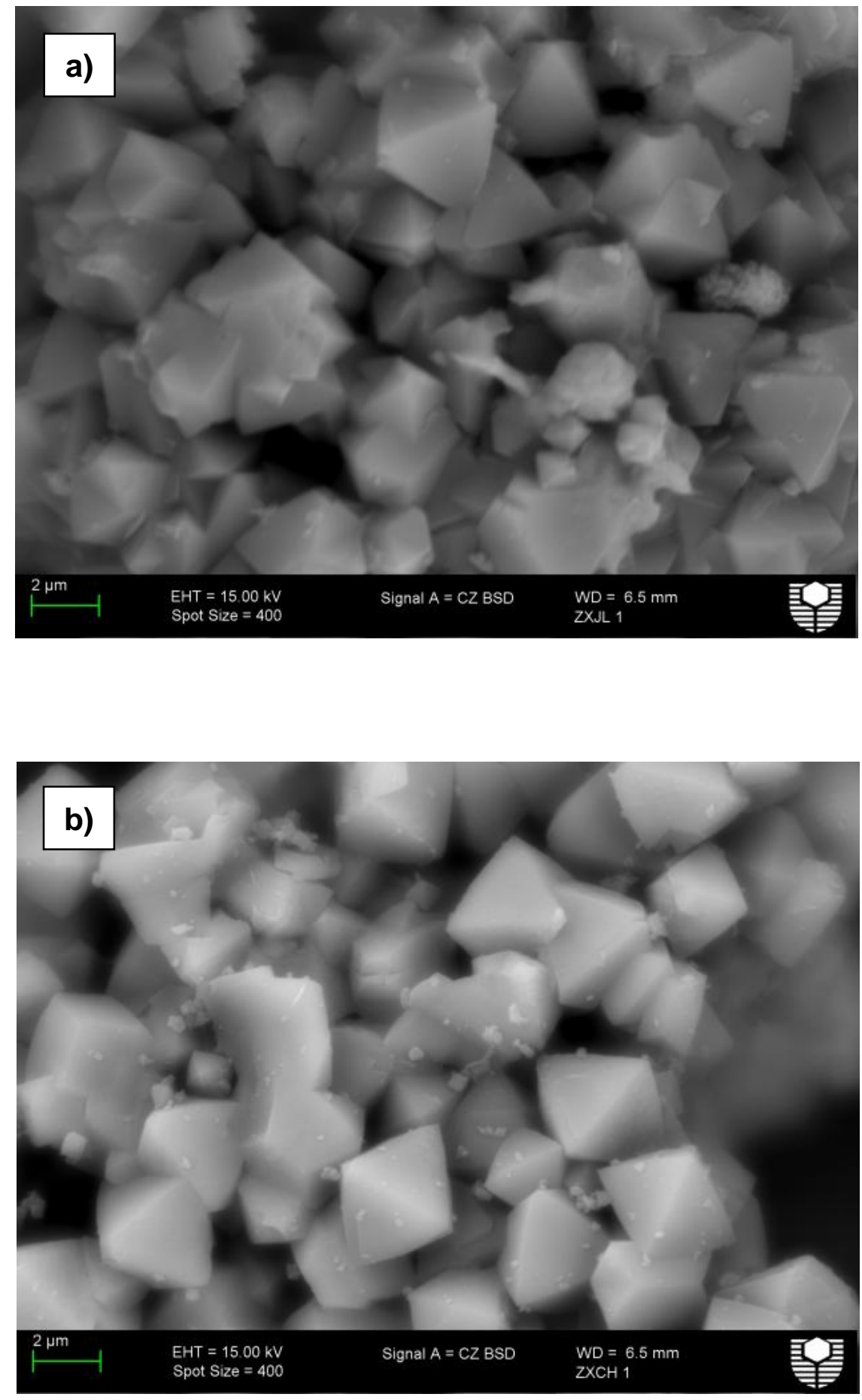

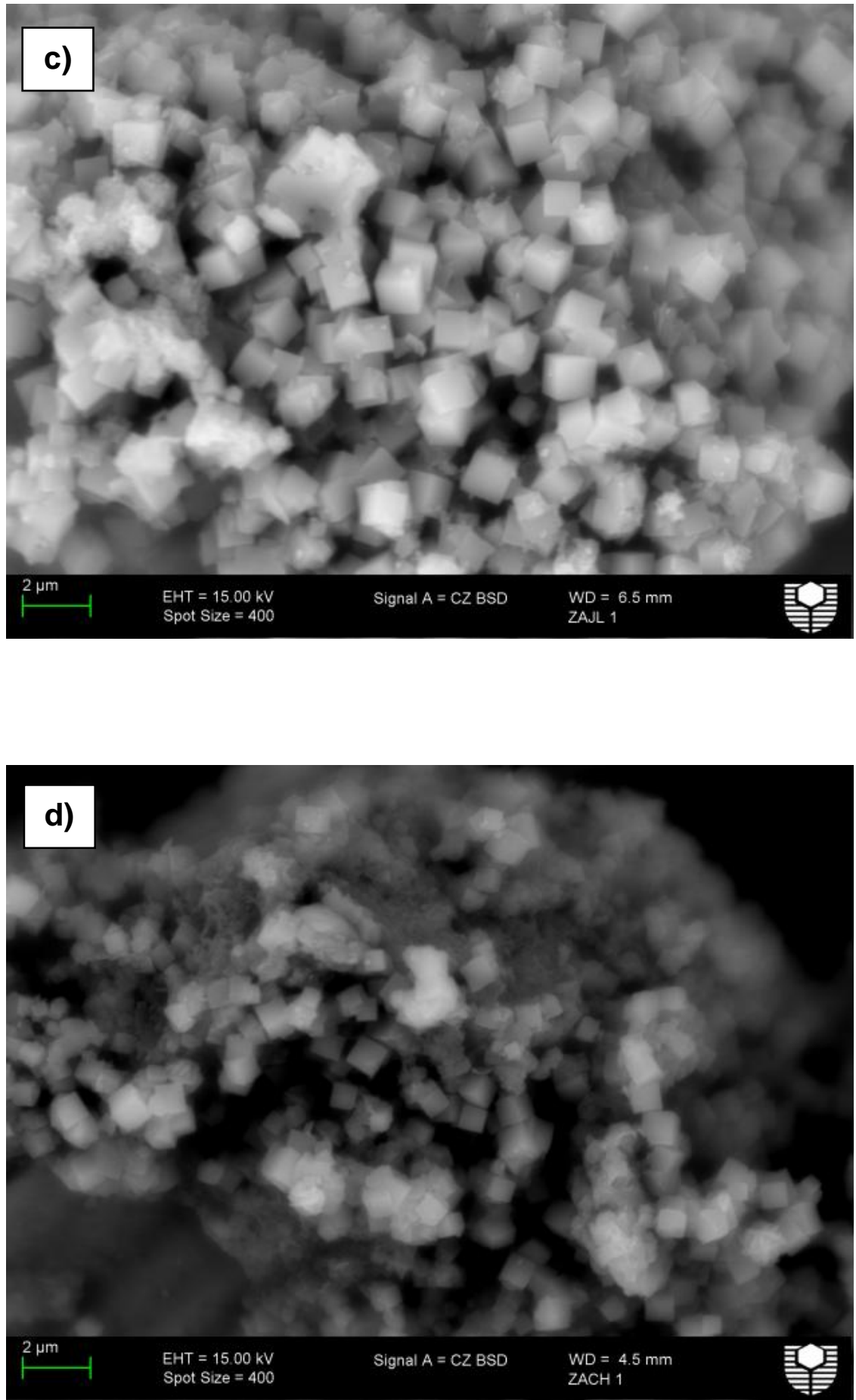

FIGURA 31 - Micrografia das zeólitas de alta pureza sintetizadas a partir de cinzas de carvão obtidas por MEV. a) ZXJL; b) ZXCH; c) ZAJL; d) ZACH

Comparando-se a morfologia dos produtos de síntese obtidos pelo tratamento hidrotérmico clássico (FIG. 19) e pelo método de duas etapas com fusão prévia das cinzas (FIG. 31), verifica-se que o segundo método citado produz um material mais puro e uniforme, o que certamente contribui para sua 
futura aplicação industrial uma vez que as indústrias em geral requerem produtos padronizados com objetivos comerciais.

\subsubsection{Composição química}

$\mathrm{Na}$ TAB. 15 são mostradas as composições químicas das zeólitas com elevado grau de pureza determinadas por fluorescência de raios $X$.

TABELA 15 - Análise química dos compostos presentes nas zeólitas com elevado grau de pureza (\% em massa)

\begin{tabular}{ccccc}
\hline Óxido & ZXJL & ZXCH & ZAJL & ZACH \\
\hline $\mathrm{SiO}_{2}$ & 38,8 & 42,1 & 38,0 & 40,1 \\
$\mathrm{Al}_{2} \mathrm{O}_{3}$ & 29,3 & 31,3 & 33,5 & 34,9 \\
$\mathrm{Na}_{2} \mathrm{O}$ & 16,7 & 17,9 & 16,9 & 18,7 \\
$\mathrm{Fe}_{2} \mathrm{O}_{3}$ & 6,7 & 4,00 & 4,90 & 2,70 \\
$\mathrm{CaO}$ & 2,90 & 1,70 & 2,10 & 1,20 \\
$\mathrm{TiO}_{2}$ & 1,90 & 1,60 & 1,40 & 1,10 \\
$\mathrm{~K}_{2} \mathrm{O}$ & 1,70 & 0,700 & 1,70 & 0,800 \\
$\mathrm{MgO}$ & 1,00 & 0,600 & 0,900 & 0,400 \\
$\mathrm{SO}_{3}$ & 0,600 & 0,0900 & 0,300 & 0,0800 \\
$\mathrm{ZnO}$ & 0,0800 & 0,0200 & 0,0400 & $<0,0200$ \\
$\mathrm{MnO}$ & 0,0800 & 0,0200 & 0,200 & 0,0200 \\
$\mathrm{PbO}_{\mathrm{SiO}} / \mathrm{Al} \mathrm{O}_{3}$ & 1,32 & 1,34 & 1,13 & - \\
\hline & 0,0200 & $<0,0200$ & $<0,0200$ & 1,15 \\
\hline
\end{tabular}

De acordo com os resultados da TAB. 15, as amostras apresentaram, de modo geral, elevados conteúdos de sílica, alumina e óxido de sódio, elementos formadores das zeólitas $\mathrm{A}$ e $\mathrm{X}$ identificadas por difração de raios $\mathrm{X}$, cujas fórmulas foram mostradas na TAB. 13.

Comparando-se o conteúdo dos óxidos de ferro, cálcio, titânio, potássio, entre outras impurezas presentes nas zeólitas A e X sintetizadas no presente 
estudo e o conteúdo das impurezas presentes nas zeólitas comerciais correspondentes, cujas composições químicas são mostradas em Wang et al. (2009), verifica-se que as zeólitas sintéticas não representam nenhum risco à saúde pública e ao meio ambiente pois todas as impurezas apresentaram quantidades inferiores a 7\%, conforme mostrado na TAB. 15. A razão $\mathrm{SiO}_{2} / \mathrm{Al}_{2} \mathrm{O}_{3}$ em massa foi determinada para os diferentes materiais e variou entre 1,13 e 1,34.

O cálculo do rendimento da síntese de zeólitas com elevado grau de pureza foi estimado utilizando-se a quantidade de sílica presente nas cinzas precursoras e na quantidade do mesmo composto presente nos produtos finais, determinados por fluorescência de raios $X$. Os resultados encontram-se na TAB. 16.

TABELA 16 - Estimativa do rendimento da síntese de zeólitas com elevado grau de pureza obtidas pelo método de duas etapas com fusão prévia

\begin{tabular}{ccccc}
\hline Amostra & $\begin{array}{c}\mathrm{m}_{\mathrm{SiO} 2} / \mathrm{g} \\
\text { (cinza precursora }-10 \mathrm{~g})\end{array}$ & $\begin{array}{c}\mathrm{m}_{\text {final }} / \mathrm{g} \\
\text { (produto) }\end{array}$ & $\begin{array}{c}\mathrm{m}_{\mathrm{SiO} 2} / \mathrm{g} \\
\text { (zeólita pura) }\end{array}$ & Rendimento \\
\hline ZXJL & 5,03 & 12,71 & 4,93 & $98,0 \%$ \\
ZXCH & 5,75 & 12,33 & 5,19 & $90,3 \%$ \\
ZAJL & 5,03 & 13,07 & 4,86 & $96,6 \%$ \\
ZACH & 5,75 & 14,03 & 4,95 & $86,1 \%$ \\
\hline
\end{tabular}

De acordo com a TAB. 16, os rendimentos de síntese variaram entre 86,1 e 98,0 \%, indicando que a metodologia de síntese escolhida pode apresentar viabilidade técnica se for utilizada em maior escala, por ter apresentado elevados rendimentos de conversão.

Baseando-se nos resultados de composição química, as relações Si/Al molares para cada zeólita com elevado grau de pureza foram calculadas e comparadas com os valores teóricos presentes em literatura. Os resultados encontram-se na TAB. 17. 
TABELA 17 - Comparação entre a relação Si/Al molar calculada para cada zeólita com elevado grau de pureza e os valores teóricos

\begin{tabular}{ccc}
\hline Amostra & Relação Si/Al molar & Relação Si/Al teóricos \\
\hline ZXJL & 1,12 & $1,00-1,50^{\mathrm{a}, \mathrm{b}}$ \\
ZXCH & 1,14 & $1,00-1,50^{\mathrm{a}, \mathrm{b}}$ \\
ZAJL & 0,96 & $1,00-1,20^{\mathrm{a}, \mathrm{b}}$ \\
ZACH & 0,98 & $1,00-1,20^{\mathrm{a}, \mathrm{b}}$ \\
\hline
\end{tabular}

a(Shiguemoto, et al., 1995)

b(Wang et al., 2009)

De acordo com a TAB. 17, os valores da relação Si/Al molar calculados para todas as zeólitas foram próximos aos valores teóricos presentes em literatura. Os valores desse parâmetro para ambas as zeólitas $X$ foram maiores do que os valores encontrados para as zeólitas $A$, seguindo tendência constante em literatura. Conforme dito anteriormente, zeólitas com menores relação Si/Al possuem maior capacidade de troca cationica e vice versa. Sendo assim, as zeólitas A são as que provavelmente possuem maior CTC quando comparadas às zeólitas X. Os resultados de CTC para as zeólitas com elevado grau de pureza são mostrados no próximo tópico.

\subsubsection{Capacidade de troca catiônica}

Os valores de capacidade de troca catiônica (CTC) das zeólitas com elevado grau de pureza estão listados na TAB. 18.

De acordo com a TAB. 18 os valores de CTC das zeólitas com elevado grau de pureza variaram de 3,1 a 3,9 meq $\mathrm{g}^{-1}$. Esses valores estão na mesma faixa dos valores encontrados em literatura para zeólitas de alta pureza sintetizadas a partir de cinzas de carvão de outras nacionalidades (Hollman et al., 1999; Yaping et al., 2008). 
TABELA 18 - Valores de CTC obtidos para as zeólitas com elevado grau de pureza

\begin{tabular}{cc}
\hline Amostra & CTC $\left(\mathrm{meq} \mathrm{g}^{-1}\right)$ \\
\hline ZXJL & 3,1 \\
ZXCH & 3,6 \\
ZAJL & 3,9 \\
ZACH & 3,9 \\
\hline
\end{tabular}

Os valores de CTC apresentados pelas zeólitas com elevado grau de pureza são acima de 100 vezes maiores do que aqueles encontrados para os materiais precursores e de 1,9 a 3,0 vezes maiores do que os produtos obtidos por conversão hidrotérmica direta, respectivamente, mostrados na primeira fase do estudo.

As zeólitas $A$ apresentaram maiores valores de CTC com relação às zeólitas $X$ devido à menor relação $S i / A l$ que esse tipo de zeólita possui (TAB. 17). A menor relação Si/Al na estrutura da zeólita produz uma maior deficiência de carga. Sendo assim, a estrutura em questão precisa de mais cátions $\mathrm{Na}^{+}$para compensar o excesso de carga negativa e consequentemente mais cátions trocáveis existem na estrutura, conferindo maiores valores de CTC (Wang et al., 2009).

Para concluir a segunda fase do presente estudo, optou-se por sintetizar as zeólitas A e X com elevado grau de pureza usando as cinzas provenientes da Usina Termelétrica Presidente Médice, CPM, caracterizadas na primeira fase do estudo, para verificar se a metodologia aplicada às amostras CJL e $\mathrm{CCH}$ se adequava a essa outra matéria prima (as cinzas CFG e CSJ foram consideradas muito diferentes das demais de acordo com as conclusões mostradas na primeira fase). Os produtos obtidos a partir da CPM foram similares aos produtos obtidos a partir das outras matérias primas. Os difratogramas de raios $X$ das zeólitas ZXPM e ZAPM, respectivamente, encontram-se nas FIG. 1 e 2 do Apêndice $B$ da presente tese. 


\subsection{Produtos sintetizados usando solução remanescente de síntese}

\section{hidrotérmica clássica}

O estudo da possibilidade de reaproveitamento da solução remanescente da síntese hidrotérmica convencional foi feito usando-se as soluções geradas após a etapa de filtração deste tratamento, usado para sintetizar material zeolítico na primeira fase do estudo. As soluções remanescentes obtidas a partir das cinzas CJL e CCH, e nomeadas por JLREM e CHREM, respectivamente, foram usadas para a síntese de novos produtos zeolíticos para comparação com os produtos obtidos pelos outros métodos que usaram as mesmas matérias primas.

Primeiramente, as soluções remanescentes foram submetidas à análises químicas para a quantificação dos elementos presentes. As concentrações dos elementos encontrados para cada amostra foram listados na TAB. 19.

TABELA 19 - Concentração dos elementos presentes nas soluções remanescentes provenientes do tratamento hidrotérmico clássico das cinzas de carvão $\mathrm{JL}$ e CH

\begin{tabular}{ccc}
\hline Elementos & $\begin{array}{c}\text { Concentração }\left(\mu \mathrm{mL}^{-1}\right) \\
\text { JLREM }\end{array}$ & $\begin{array}{c}\text { Concentração }\left(\mu \mathrm{gL}^{-1}\right) \\
\text { CHREM }\end{array}$ \\
\hline $\mathrm{Na}$ & $11890 \pm 8$ & $12180 \pm 25$ \\
$\mathrm{Si}$ & $2308 \pm 6$ & $2792 \pm 7$ \\
$\mathrm{~K}$ & $873 \pm 11$ & $405 \pm 4$ \\
$\mathrm{Al}$ & $27,8 \pm 0,5$ & $35,9 \pm 0,2$ \\
$\mathrm{P}$ & $5,6 \pm 0,2$ & $2,68 \pm 0,09$ \\
$\mathrm{Ti}$ & $3,2 \pm 0,1$ & $7,3 \pm 0,2$ \\
$\mathrm{Zn}$ & $3,11 \pm 0,08$ & $0,52 \pm 0,04$ \\
$\mathrm{~S}$ & $1,73 \pm 0,09$ & $2,0 \pm 0,1$ \\
$\mathrm{Fe}$ & $1,44 \pm 0,06$ & $2,28 \pm 0,06$ \\
$\mathrm{Mg}$ & $0,130 \pm 0,006$ & $0,158 \pm 0,005$ \\
$\mathrm{Mn}$ & $0,033 \pm 0,003$ & $0,034 \pm 0,002$ \\
$\mathrm{Ca}$ & $<0,50$ & $<0,50$ \\
$\mathrm{~Pb}$ & $0,026 \pm 0,009$ & $0,025 \pm 0,009$
\end{tabular}

${ }^{*}$ Analisado por GF-AAS 
De acordo com os resultados da análise química mostrados na TAB. 19, as quantidades dos elementos predominantes nas soluções remanescentes das duas amostras obedeceram a seguinte ordem decrescente: $\mathrm{Na}>\mathrm{Si}>\mathrm{K}>\mathrm{Al}>$ Outros. Esses resultados indicam que ambas as soluções podem ser usadas para sintetizar novos materiais zeolíticos devido à presença abundante de silício (elemento estrutural formador de zeólitas) e sódio (cátion trocável e presente em quantidade superior ao potássio). A quantidade de alumínio, porém, mostrou-se insuficiente e deverá ser complementada pela adição desse elemento por fonte externa se o objetivo for o de sintetizar zeólitas de elevado interesse comercial, como as zeólitas A e X.

Sendo assim, as concentrações dos elementos $\mathrm{Si}$ e Al nas soluções remanescentes foram utilizadas para o cálculo da quantidade de alumínio na forma de $\mathrm{NaAlO}_{2}$ a ser adicionada para o ajuste da relação Si/Al na faixa estabelecida para a síntese de zeólitas A e X.

A síntese dos novos materiais zeolíticos usando metodologia descrita no tópico referente a materiais e métodos resultou nos produtos cujos difratogramas são mostrados nas FIG. 32 e 33 para as amostras ZMJL e ZMCH, respectivamente.

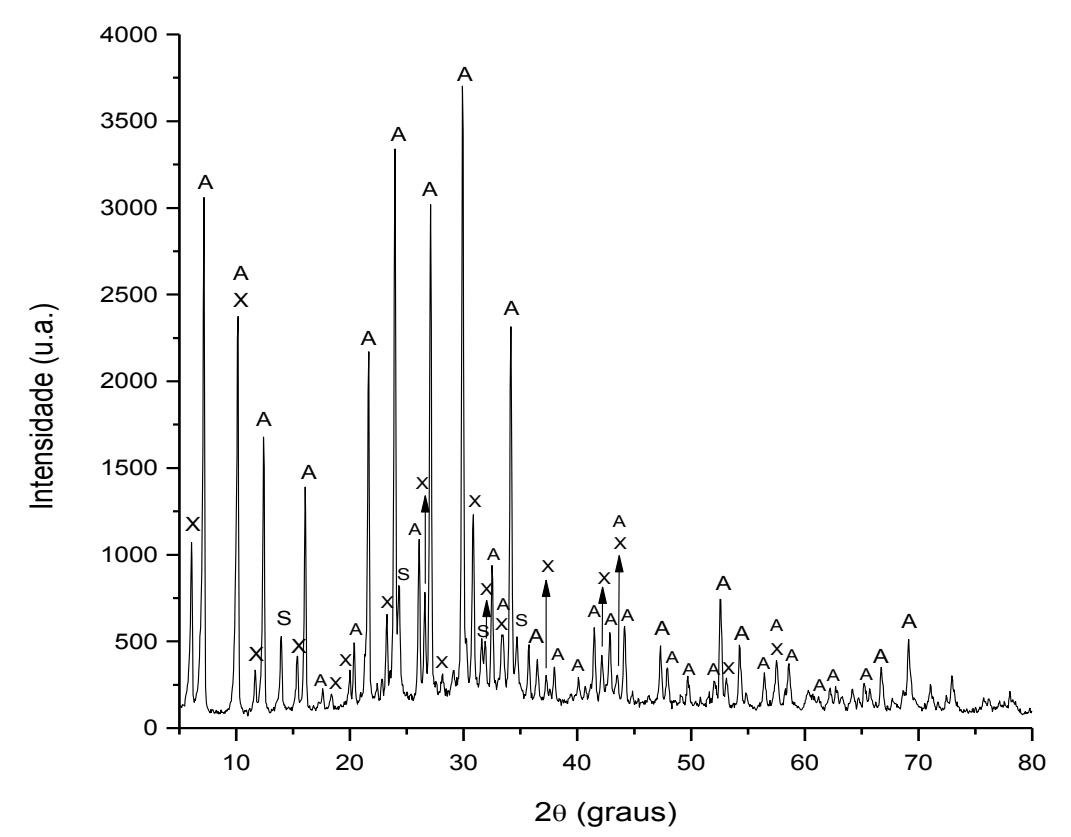

FIGURA 32 - Difratograma do material zeolítico ZMJL sintetizado por processo de duas etapas usando a solução JLREM 


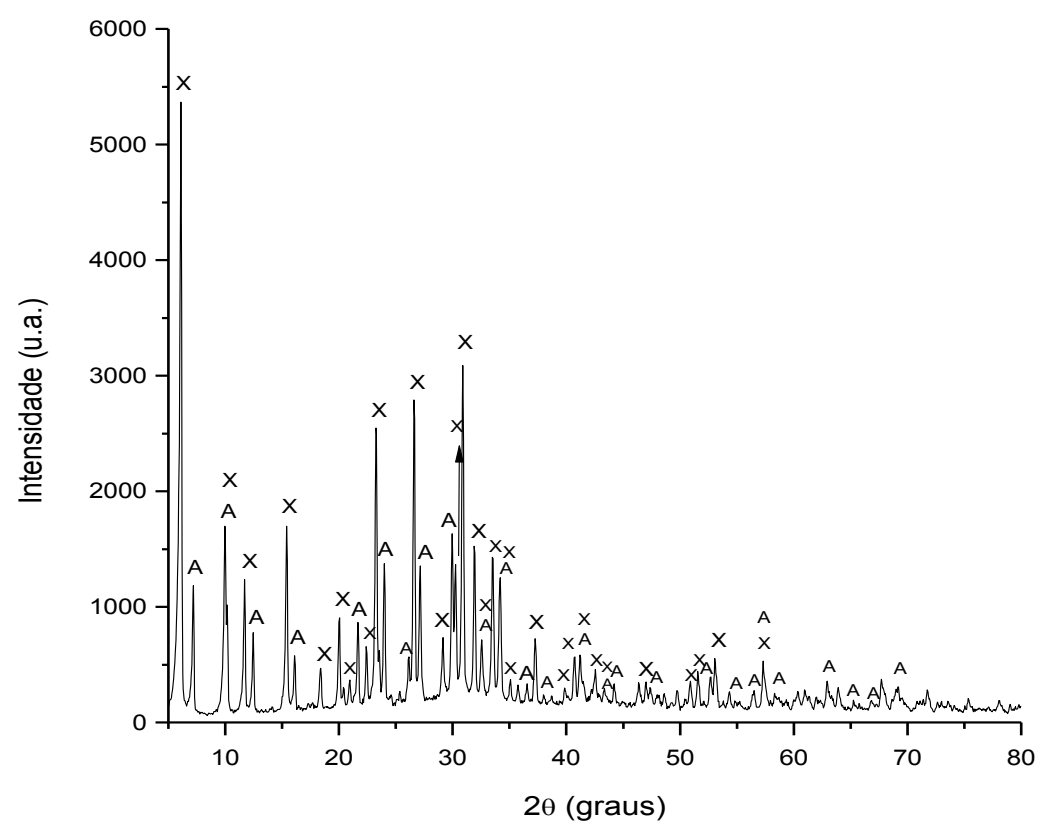

FIGURA 33 - Difratograma do material zeolítico ZMCH sintetizado por processo de duas etapas usando solução CHREM

Verificou-se por meio dos difratogramas de raios $\mathrm{X}$ mostrados nas FIG. 32 e 33 que a utilização da solução remanescente de síntese hidrotérmica convencional para a síntese de novos produtos zeolíticos é possível. Ambos os materiais zeolíticos sintetizados apresentaram misturas de fases de zeólitas. As fases encontradas para cada amostra bem como suas respectivas fórmulas químicas são apresentadas na TAB. 20.

TABELA 20 - Fases cristalinas presentes nas amostras dos materiais zeolíticos obtidos a partir de solução remanescente de síntese hidrotérmica clássica

\begin{tabular}{clc}
\hline Amostra & \multicolumn{1}{c}{ Fases cristalinas } & Fórmula química \\
\hline ZMJL & Zeólita X (X) & $\mathrm{Na}_{2} \mathrm{Al}_{2} \mathrm{Si}_{2,5} \mathrm{O}_{9} \cdot 6,2 \mathrm{H}_{2} \mathrm{O}$ \\
& Zeólita $\mathrm{A}(\mathrm{A})$ & $\mathrm{Na}_{2} \mathrm{Al}_{2} \mathrm{Si}_{1,85} \mathrm{O}_{7,7} \cdot 5,1 \mathrm{H}_{2} \mathrm{O}$ \\
& Zeólita Sodalita (S) & $\mathrm{Na}_{4} \mathrm{Al}_{3} \mathrm{Si}_{3} \mathrm{O}_{12}(\mathrm{OH})$ \\
\multirow{2}{*}{ ZMCH } & Zeólita X (X) & $\mathrm{Na}_{2} \mathrm{Al}_{2} \mathrm{Si}_{2,5} \mathrm{O}_{9} \cdot 6,2 \mathrm{H}_{2} \mathrm{O}$ \\
& Zeólita $\mathrm{A}(\mathrm{A})$ & $\mathrm{Na}_{2} \mathrm{Al}_{2} \mathrm{Si}_{1,85} \mathrm{O}_{7,7} \cdot 5,1 \mathrm{H}_{2} \mathrm{O}$ \\
\hline
\end{tabular}


A mistura de fases de zeólitas obtidas a partir das soluções remanescentes de síntese hidrotérmica convencional mostradas nas FIG. 32 e 33 provavelmente ocorreu devido à presença de impurezas que não foram capazes de serem dissolvidas durante o processo de conversão e permaneceram na solução, dificultando o direcionamento da síntese para a obtenção de somente uma única fase de zeólita.

Comparando-se os produtos sintetizados a partir das soluções remanescentes de síntese hidrotérmica convencional e as zeólitas de alta pureza sintetizadas por processo de duas etapas com fusão prévia, verificou-se que as impurezas presentes nos produtos obtidos pelo segundo método não influenciou ou teve baixa influência na síntese quando o objetivo era obter as zeólitas $A$ ou X. A etapa de fusão provavelmente contribuiu para a dissolução completa das impurezas que poderiam causar influência na síntese das zeólitas de interesse e provavelmente foram removidas nas etapas posteriores ao tratamento hidrotérmico.

Além disso, a quantidade de silício disponível para a síntese de zeólitas quando o método de duas etapas com fusão prévia foi utilizado foi bem maior do que a quantidade desse elemento disponível para a síntese usando a solução remanescente, o que também pode ter contribuído para a obtenção de zeólitas mais puras pelo primeiro método citado.

\subsection{Planta em escala piloto}

Todas as usinas termelétricas que usam carvão mineral como fonte energética existentes no Brasil atualmente produzem cinzas volantes de carvão adequadas para a síntese de material zeolítico por tratamento hidrotérmico convencional, como mostrado na primeira parte do presente estudo. Sendo assim, foi elaborado um projeto em escala de planta piloto capaz de converter cinzas volantes de carvão em material zeolítico contendo a descrição do processo e a lista de equipamentos e materiais necessários para a sua implementação.

A produção de material zeolítico a partir de cinzas de carvão, seja em escala piloto ou em escala industrial, deve ocorrer nas proximidades das usinas termelétricas a carvão geradoras de cinzas. Isso é explicado pelo alto custo de transporte no Brasil (não seria viável transportar materiais de baixo custo como as 
cinzas), além de grandes distâncias provavelmente percorridas por se tratar de um país de grande área territorial.

Por outro lado, o preço do material zeolítico produzido - o qual possui maior valor agregado do que as cinzas precursoras - deve suprir os eventuais gastos com transporte com a finalidade de chegar aos potenciais compradores desse produto.

Outro fator determinante na viabilidade econômica do processo de produção de material zeolítico em escala piloto seria o tipo de processo de conversão de cinzas em zeólitas. Como dito anteriormente, é mais viável produzir material zeolítico por meio de síntese hidrotérmica convencional, por se tratar de um processo de custo menor quando comparado ao processo de duas etapas, o qual requer grandes quantidades de calor na etapa de fusão da mistura cinzaálcali, consumindo grandes quantidades de energia, o que inviabilizaria o processo.

O tópico a seguir faz uma breve descrição do processo de produção de material zeolítico em escala piloto usando processo hidrotérmico convencional.

\subsubsection{Descrição do processo de produção de material zeolítico}

O fluxograma do processo de produção de material zeolítico sintetizado a partir de cinzas de carvão é mostrado na FIG. 34.

A descrição do processo de produção de material zeolítico foi detalhada abaixo e estimada para o consumo de $100 \mathrm{~kg}$ de cinzas de carvão por batelada. As etapas foram divididas em preparo dos reagentes e preparo do material zeolítico:

\section{1- Preparo dos reagentes:}

a) Cinzas: $100 \mathrm{~kg}$ de cinzas são transportados manualmente do sistema de armazenamento de cinzas volantes da usina para o local onde a planta piloto está localizada;

- Cálculo do volume do recipiente onde serão colocados os $100 \mathrm{~kg}$ de cinzas:

Em laboratório, a densidade aparente das cinzas é de aproximadamente $0,6 \mathrm{~g} \mathrm{~mL}^{-1}$, portanto, para $100 \mathrm{~kg}$ de cinzas, o volume do recipiente requerido é de aproximadamente $167 \mathrm{~L}$. O recipiente adequado à essa função disponível comercialmente possui volume de $175 \mathrm{~L}$. 


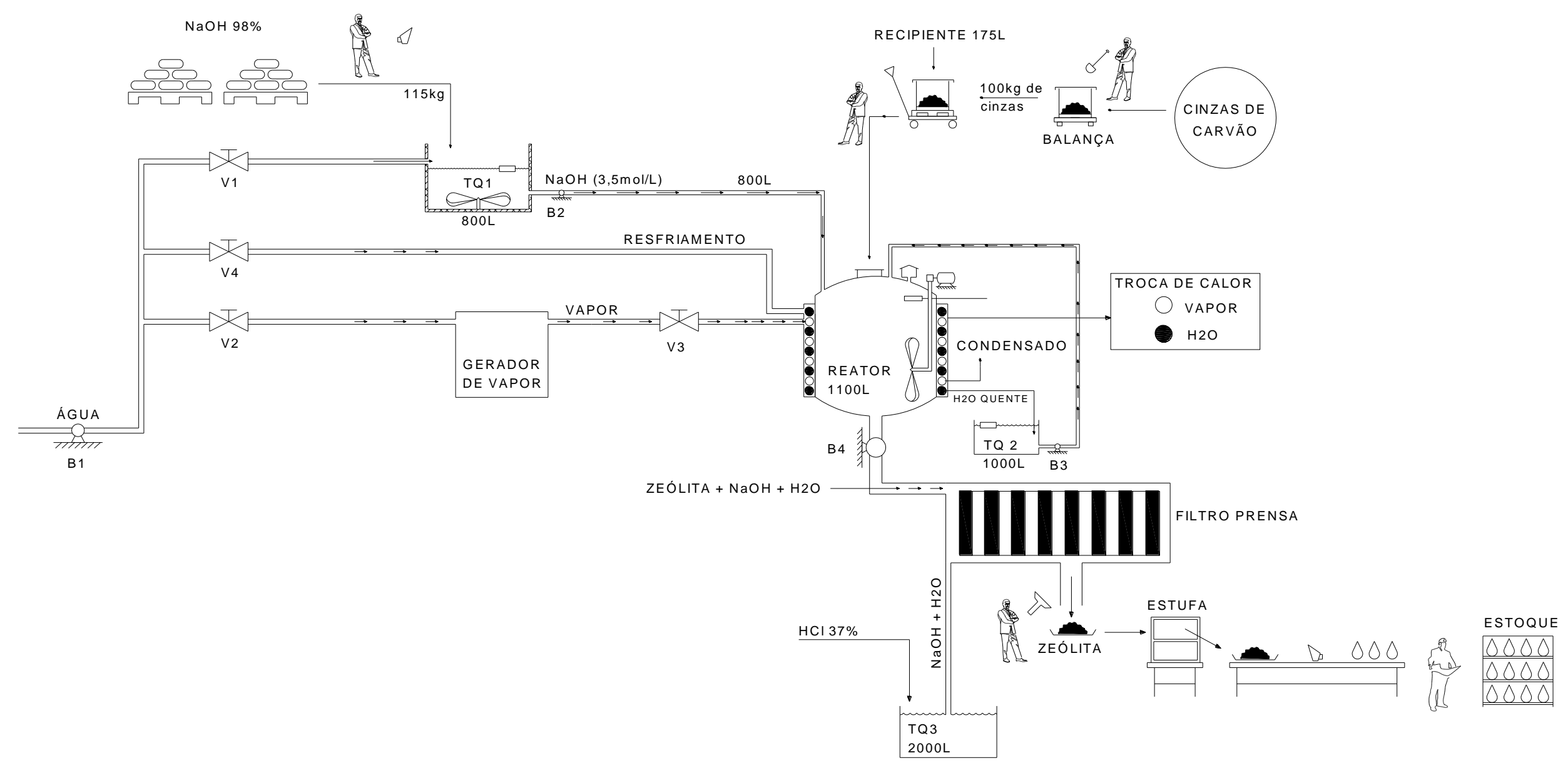

FIGURA 34 - Fluxograma do processo de produção de material zeolítico sintetizado a partir de cinzas volantes de carvão por tratamento hidrotérmico clássico 
b) Hidróxido de sódio $3,5 \mathrm{~mol} \mathrm{~L}^{-1}(\mathrm{NaOH})$ : $400 \mathrm{~L}$ de água são bombeados do reservatório de água da usina para o Tanque 1. O sistema de mistura do tanque é ligado. Pesa-se $115 \mathrm{~kg}$ de $\mathrm{NaOH}$ (98\%) e coloca-se no Tanque 1 juntamente com a água. Faz-se a homogeneização da mistura. Completa-se com água até a marca de 800L, faz-se a homogeneização;

- Cálculo do volume da solução da solução de $\mathrm{NaOH} 3,5 \mathrm{~mol} \mathrm{~L}^{-1}$ :

A relação massa de cinza / volume da solução de $\mathrm{NaOH}$ usada para a produção de material zeolítico em escala laboratorial é $0,125 \mathrm{~kg} / \mathrm{L}$ ). Portanto, para $100 \mathrm{~kg}$ de cinzas, o volume de $\mathrm{NaOH} 3,5 \mathrm{~mol} \mathrm{~L}^{-1}$ requerido será $=800 \mathrm{~L}$.

- Cálculo da massa de $\mathrm{NaOH}(98 \%)$ necessária à preparação da solução de $\mathrm{NaOH} 3,5 \mathrm{~mol} \mathrm{~L}^{-1}$ :

$\mathrm{m}=3,5 \mathrm{~mol} \mathrm{~L}^{-1} \times 40 \mathrm{~g} \mathrm{~mol}^{-1} \times 800 \mathrm{~L}$

$m=112 \mathrm{~kg}(98 \%)$, portanto: $m=115 \mathrm{~kg}(100 \%)$

O hidróxido de sódio é comercializado em sacos de polietileno de $25 \mathrm{~kg}$, portanto, são necessários 4 sacos e $15 \mathrm{~kg}$ por batelada.

\section{2- Preparo do material zeolítico:}

a) $\mathrm{NaOH} 3,5 \mathrm{~mol} / \mathrm{L}$ é encaminhado do Tanque 1 para o reator.;

b) Adiciona-se $100 \mathrm{~kg}$ de cinzas de carvão ao reator sob agitação;

c) O Reator é agitado durante 1 hora para homogeneização;

d) Água é bombeada para o gerador de vapor. O vapor gerado aquece o reator a $100^{\circ} \mathrm{C}$ durante 24 horas. Depois da reação o reator é desligado;

- Cálculo do consumo de água aproximado para aquecimento do reator à $100^{\circ} \mathrm{C}$ por 24 horas:

Segundo os dados do gerador de vapor adequado à essa função e disponível comercialmente, são necessários $475 \mathrm{~L}$ de água por hora. Para 24 horas de operação, são necessários, portanto, 11400 L de água.

e) O reator é resfriado com cerca de $3300 \mathrm{~L}$ de água de resfriamento da usina;

- Cálculo da quantidade da água de resfriamento:

Para que a água do Tanque 2, que será utilizada posteriormente, fique com temperatura aproximada de $40^{\circ} \mathrm{C}$, a variação de temperatura esperada será de $100^{\circ} \mathrm{C}-40^{\circ} \mathrm{C}=60^{\circ} \mathrm{C}$. 
Sendo assim, a quantidade de calor a ser resfriado será:

$\mathrm{Q}=\mathrm{m}^{\circ} \times \mathrm{C} \times \Delta \mathrm{T} \rightarrow \mathrm{Q}=1100 \mathrm{~L} \times 1 \mathrm{cal} \mathrm{g}^{-1}{ }^{\circ} \mathrm{C}^{-1} \times 60^{\circ} \mathrm{C} \rightarrow \mathrm{Q}=66000 \mathrm{cal}$

$\mathrm{C}=$ calor específico da substância (água $=1,0 \mathrm{cal} / \mathrm{g}^{\circ} \mathrm{C}$ ).

A água de resfriamento entra à uma temperatura média de cerca de $20^{\circ} \mathrm{C} \mathrm{e}$ sai com temperatura aproximada de $40^{\circ} \mathrm{C}$, portanto:

$\Delta \mathrm{T}=40^{\circ} \mathrm{C}-20^{\circ} \mathrm{C}=20^{\circ} \mathrm{C}$. Sendo assim, a quantidade de água para resfriamento será:

$\mathrm{Q}=\mathrm{m}^{\circ} \times \mathrm{C} \times \Delta \mathrm{T} \rightarrow 66000 \mathrm{cal}=\mathrm{m}^{\circ} \times 1 \mathrm{cal} \mathrm{g}^{-1}{ }^{\circ} \mathrm{C}^{-1} \times 20^{\circ} \mathrm{C} \rightarrow \mathrm{m}^{\circ}=3300 \mathrm{~L}$.

f) $1000 \mathrm{~L}$ da água de resfriamento que sai do reator é armazenada no Tanque 2 (essa água deve se encontrar à uma temperatura aproximada de $\left.40^{\circ} \mathrm{C}\right)$;

g) $100 \mathrm{~L}$ da água armazenada no Tanque 2 é bombeada e colocada no reator (com os produtos da reação) para fluidizar a amostra. Espera-se 45 minutos;

h) A suspensão é enviada para o Filtro Prensa para separação Sólido/Líquido. O líquido que sai do Filtro Prensa é encaminhado para o Tanque 3 para ser tratado posteriormente;

i) O restante da àgua do tanque 2 (aproximadamente $900 \mathrm{~L}$ ) é encaminhado para o reator para a limpeza do mesmo e em seguida, encaminhado para o filtro prensa para a lavagem da zeólita. O líquido resultante da lavagem é enviado para o Tanque 3 (junto com o líquido proveniente do reator);

- Cálculo do volume do tanque 3:

Composto pelos efluentes alcalinos a serem neutralizados e o ácido a ser utilizado para neutralização:

Volume dos efluentes alcalinos $=800$ (reator) +900 (fluidização da amostra mais lavagem do reator), portanto volume total $=1700 \mathrm{~L}$

Volume do ácido $=232 \mathrm{~L}$.

Portanto, o volume total do tanque 3 será $=2000 \mathrm{~L}$.

- Cálculo da quantidade aproximada de $\mathrm{HCl} 37 \%$ a ser adicionada no tanque 3 para neutralização do efluente alcalino:

O efluente alcalino proveniente do reator, com concentração aproximada de $3,5 \mathrm{~mol} \mathrm{~L}^{-1}$ de $\mathrm{NaOH}$ é diluído até atingir volume final de $1700 \mathrm{~L}$, portanto, o cálculo da concentração desse efluente diluído é:

$M_{1} \cdot V_{1}=M_{2} \cdot V_{2} \rightarrow 3,5 \mathrm{~mol} \mathrm{~L}^{-1} .800 \mathrm{~L}=\mathrm{M}_{2} \cdot 1700 \mathrm{~L} \rightarrow \mathrm{M}_{2}=1,65 \mathrm{~mol} \mathrm{~L}^{-1}$ 
Para neutralização com $\mathrm{HCl}$, ocorre a seguinte reação:

$\mathrm{NaOH}+\mathrm{HCl} \rightarrow \mathrm{NaCl}+\mathrm{H}_{2} \mathrm{O}$ (proporção 1:1), portanto, será necessária uma concentração de $1,65 \mathrm{~mol} \mathrm{~L}^{-1}$ de $\mathrm{HCl}$ para neutralizar o efluente alcalino.

Concentração do $\mathrm{HCl} 37 \%$ :

$\mathrm{HCl}$ técnico disponível comercialmente a $37 \%\left(\mathrm{~d}=1,19 \mathrm{~kg} \mathrm{~L}^{-1}\right)$

$C=\tau$.d $\rightarrow C=0,37.1,19 \mathrm{~kg} \mathrm{~L}^{-1} \rightarrow C=0,4403 \mathrm{~kg} \mathrm{~L}^{-1}$

$\mathrm{C}=\mathrm{M} . \mathrm{MM} \rightarrow \mathrm{M}=\mathrm{C} / \mathrm{MM} \rightarrow \mathrm{M}=0,4403 \mathrm{~kg} \mathrm{~L}^{-1} / 36,5 \mathrm{~g} \mathrm{~mol}^{-1} \times 1000 \mathrm{~g} \rightarrow$ $\mathrm{M}=12,06 \mathrm{~mol} \mathrm{~L}^{-1}$

$1,65 \mathrm{~mol}-------1 \mathrm{~L}$

$\mathrm{X}$ $1700 \mathrm{~L} \rightarrow \mathrm{X}=2800 \mathrm{~mol}$

$1 \mathrm{~L} \mathrm{HCl} 37 \%$ $12,06 \mathrm{~mol}$

$\mathrm{X}$ $2800 \mathrm{~mol} \rightarrow \mathrm{X}=232 \mathrm{~L}$ por batelada

j) $\mathrm{O} \mathrm{pH}$ do efluente do Tanque 3 é medido. Adiciona-se $\mathrm{HCl} 37 \%$ para neutralização e descarte (ou adiciona-se drenagem ácida de mina, efluente gerado durante as atividades carboníferas, para neutralização).

OBS: Estudo prévios irão verificar a possibilidade do uso da drenagem acida de mina para neutralização e irão verificar a concentração dos metais presentes neste efluente;

k) Um operador retira a torta do Filtro Prensa com uma espátula e a coloca em bandejas de aço de $24 \mathrm{~L}$;

I) As bandejas contendo material zeolítico são colocadas na estufa para secagem;

m) Em uma bancada, um operador coloca o produto seco da estufa e o ensaca;

n) Os pacotes são armazenados em uma estante para estoque.

Estima-se que o processo descrito acima tenha duração de 1 batelada por semana, resultando em aproximadamente 4 bateladas por mês. A quantidade de água utilizada para o preparo de soluções, resfriamento do reator, produção de vapor, lavagem do material zeolítico bem como a limpeza geral da planta ficou estimada em cerca de $20000 \mathrm{~L}$ por batelada. 


\subsubsection{Lista de equipamentos e materiais}

Na TAB. 21 é mostrada a lista de reagentes, equipamentos e materiais usados para a síntese de material zeolítico a partir de cinzas volantes de carvão por processo hidrotérmico convencional baseada na descrição do processo acima.

TABELA 21 - Lista de reagentes, equipamentos e materiais usados para produção de material zeolítico em planta piloto

\begin{tabular}{ll}
\hline Reagentes & Lista de Materiais e Equipamentos \\
& Hidróxido de sódio (NaOH - 98\% em escamas) \\
& HCl Técnico 37\% para tratar o efluente \\
Equipamentos & Balança Eletrônica para pesagem de $100 \mathrm{~kg}$ de cinzas \\
& Tanque 1 - NaOH (3,5 mol/L) - com isolamento e misturador \\
& Reator de aço inox com sistema de agitação e aquecimento \\
& Gerador de vapor para aquecimento do reator \\
& Tanque 2 - Reservatório Vertical de fundo plano \\
& Filtro prensa para separação sólido/líquido \\
& Tanque 3 - Tanque de mistura para processos \\
& Estufa de secagem com acessórios (bandejas internas) \\
& Bomba 1 - Centrífuga em ferro fundido - para transporte de \\
& água da usina para o processo \\
& Bombas 2 e 3 - Vertical em polipropileno - para transporte \\
& de NaOH 3,5 mol/L e água do Tanque 2 para o reator, \\
& respectivamente \\
& Bomba 4 - Diafragma em polipropileno - para retirada do \\
produto do reator & Pallet para transporte das cinzas (1 unidade) e estoque de \\
& NaOH $98 \%$ em escamas (1 unidade) \\
& Recipiente de 175 L para estoque de cinzas \\
& Pá para retirada das cinzas (2 unidades) \\
& Paleteira manual para transporte do pallet de cinzas \\
Materiais &
\end{tabular}


Concha cerealista para manipular o $\mathrm{NaOH}$ sólido

Indicador universal para controle de $\mathrm{pH}$

Espátula para retirada de zeólita do Filtro

Mesa para estufa

Bancada para manuseio do produto final

Concha cerealista para zeólita seca (2 unidades)

Sacos para armazenamento do produto final

Estante para estoque do produto final

Armário para guardar conchas, espátulas, e outros

Equipamentos de Proteção individual

Devido às diferenças de espaço disponível para operação da planta piloto pelas usinas termelétricas, as quais podem resultar em diferentes layouts da planta, optou-se por não colocar no projeto descrito a instalação de tubulações, válvulas, conexões e bombas. Os custos com mão de obra também deverão ser previstos pela usina termelétrica juntamente com os custos adicionais com água e energia elétrica.

O processo descrito acima poderá servir de base para as usinas termelétricas a carvão que desejam agregar valor às cinzas volantes que são produzidas atualmente em grandes quantidades e são descartadas sem utilização. Cabe ressaltar que esse processo poderá sofrer alterações devido às diferentes características de cada usina e espaço disponível, devendo, portanto, ser reavaliado quando for instalado para se adequar as necessidades de cada local. Optou-se, por exemplo, por adicionar um gerador de vapor no processo, porém, as usinas podem optar por instalar uma tubulação que use o vapor gerado na própria usina ou os gases de combustão para aquecer o reator, reduzindo, dessa forma, os custos de produção. 


\section{CONCLUSÕES}

Na primeira etapa do estudo, as cinzas de carvão das cinco usinas termelétricas a carvão do Brasil mostraram-se adequadas para a obtenção de material zeolítico por tratamento hidrotérmico clássico.

Os materiais zeolíticos apresentaram relações $\mathrm{SiO}_{2} / \mathrm{Al}_{2} \mathrm{O}_{3}$ menores às encontradas para seus materiais precursores indicando que o processo de zeolitização contribuiu para o aumento de capacidade de troca catiônica desses materiais.

No estudo de composição mineralógica, as cinzas de carvão brasileiras apresentaram difratogramas muito semelhantes, que indicam composição mineralógica similar para todas as amostras, com as seguintes fases inorgânicas presentes: quartzo, mulita, hematita e magnetita.

O material zeolítico ZFG apresentou somente uma fase de zeólita após o tratamento hidrotérmico, a zeólita Hidroxissodalita, enquanto que as amostras ZJL, ZSJ e ZPM apresentaram, cada uma delas, duas fases, sendo as zeólitas $X$ e Hidroxissodalita para as amostras de ZJL e ZSJ e as zeólitas NaP1 e Hidroxissodalita para a ZPM. A amostra de ZCH foi a que apresentou maior quantidade de fases de zeólitas, sendo elas as zeólitas NaP1, Hidroxissodalita e traços de zeólita $X$.

O tipo de zeólita formada por tratamento hidrotérmico clássico variou em geral com a composição química das cinzas precursoras. Zeólitas NaP1 foram possíveis de serem sintetizadas somente usando-se matérias primas com baixo teor de ferro e cálcio (CCH e CPM). A zeólita X, por sua vez, só foi obtida a partir de amostras de cinzas com elevados teores de alumínio (CJL, CSJ e CCH).

Os valores de CTC dos materiais zeolíticos foram maiores do que os valores encontrados para as cinzas devido à elevada área específica e menor relação $\mathrm{SiO}_{2} / \mathrm{Al}_{2} \mathrm{O}_{3}$. Os valores de CTC entre 1,3 e 1,9 meq g ${ }^{-1}$ indicaram que 
esses materiais possuem um elevado potencial para utilização como trocadores iônicos.

As matérias primas que resultaram em produtos zeolíticos de menor e maior CTC, as cinzas CJL e CCH, respectivamente, foram escolhidas para os estudos de síntese de zeólita com elevado grau de pureza.

Zeólitas A e X com grau de pureza entre 88 e 100\%, respectivamente, foram sintetizadas pelo método de duas etapas com fusão prévia utilizando-se os dois tipos de cinzas de carvão brasileiras com diferentes composições químicas e sem tratamento prévio. Não foram utilizadas sementes ou agentes direcionadores de estrutura durante a síntese.

Um roteiro geral para a síntese de zeólitas $A$ e $X$ com elevado grau de pureza foi elaborado com o objetivo de auxiliar futuras pesquisas onde se deseja obter esses tipos de materiais a partir de cinzas de carvão. A elaboração do roteiro baseou-se no estudo dos parâmetros das diferentes sínteses relatadas na segunda fase deste estudo e dos produtos obtidos em cada uma das sínteses.

Verificou-se por meio dos estudos de composição mineralógica e morfologia que o método de duas etapas com fusão prévia das cinzas é responsável pela síntese de materiais mais puros e uniformes quando comparados aos materiais sintetizados pelo tratamento hidrotérmico clássico.

Os rendimentos da síntese de zeólitas com elevado grau de pureza variaram entre 86,1 e 98,0 \%, indicando que a metodologia de síntese escolhida pode apresentar viabilidade técnica se for utilizada em maior escala, por ter apresentado elevados rendimentos de conversão.

Os valores da relação Si/Al molar calculados para todas as zeólitas com elevado grau de pureza foram próximos aos valores teóricos presentes em literatura.

Os valores de CTC das zeólitas com elevado grau de pureza variaram de 3,1 a 3,9 meq $\mathrm{g}^{-1}$, representando um aumento de 1,9 a 3,0 vezes com relação às zeólitas sintetizadas pelo tratamento hidrotérmico clássico.

O estudo da possibilidade de reaproveitamento da solução remanescente de síntese hidrotérmica clássica proveniente da conversão hidrotérmica das cinzas de Jorge Lacerda e Charqueadas foi feito com adição de alumínio de fonte externa. Os materiais zeolíticos resultantes apresentaram misturas de fases de zeólitas A e X e A, X e Sodalita, para as amostras de ZMJL 
e ZMCH, respectivamente. Trabalhos futuros que explorem novas condições de síntese de zeólitas utilizando a solução remanescente de síntese hidrotérmica clássica são necessários. Estes estudos podem contribuir para tornar o processo de conversão hidrotérmica direta mais econômico se for aplicado em maior escala.

O projeto de uma planta em escala piloto para a produção de material zeolítico usando cinzas de carvão como matéria prima contendo a descrição do processo e a lista de equipamento e materiais básicos necessários foi elaborado.

Verificou-se por meio da presente tese que é possível a obtenção de diferentes produtos a partir de cinzas volantes de carvão como as zeólitas $\mathrm{A}$ e X com elevado grau de pureza (obtidas por processo de duas etapas com fusão prévia), misturas de zeólitas $A$ e $X$ (obtidas pelo reaproveitamento da solução remanescente de síntese hidrotérmica clássica) e materiais zeolíticos mais heterogêneos (obtidos pela conversão hidrotérmica direta). Este estudo poderá contribuir, dessa forma, com a sustentabilidade das usinas termelétricas a carvão uma vez que os resíduos gerados por esse tipo de atividade poderão ser utilizados para a produção de zeólitas com diferentes especificações e aplicações.

A utilização de zeólitas de alta pureza e elevada capacidade de troca catiônica sintetizadas a partir de cinzas em aplicações nobres, similares às aplicações das zeólitas sintetizadas a partir de soluções supersaturadas de silicatos e aluminatos, se mostra promissora e sustentável devido à utilização de material abundante e de baixo custo, como as cinzas volantes de carvão.

Melhorias na metodologia de síntese de zeólita de alta pureza com relação à redução de gastos de energia envolvidos nas etapas de fusão da mistura cinza/álcali e na moagem dos produtos bem como a redução do tempo total de síntese, a qual é realizada em um tempo total de cerca de uma semana, são assuntos que deverão ser explorados em futuros trabalhos.

A otimização do processo de duas etapas com vistas ao aumento de escala para planta piloto e posteriormente para escala industrial também se mostra um campo de estudo o qual deverá ser explorado. 
APÊNDICE A - Difratogramas de raios $X$ dos produtos zeolíticos formados no estudo de seleção dos parâmetros de síntese

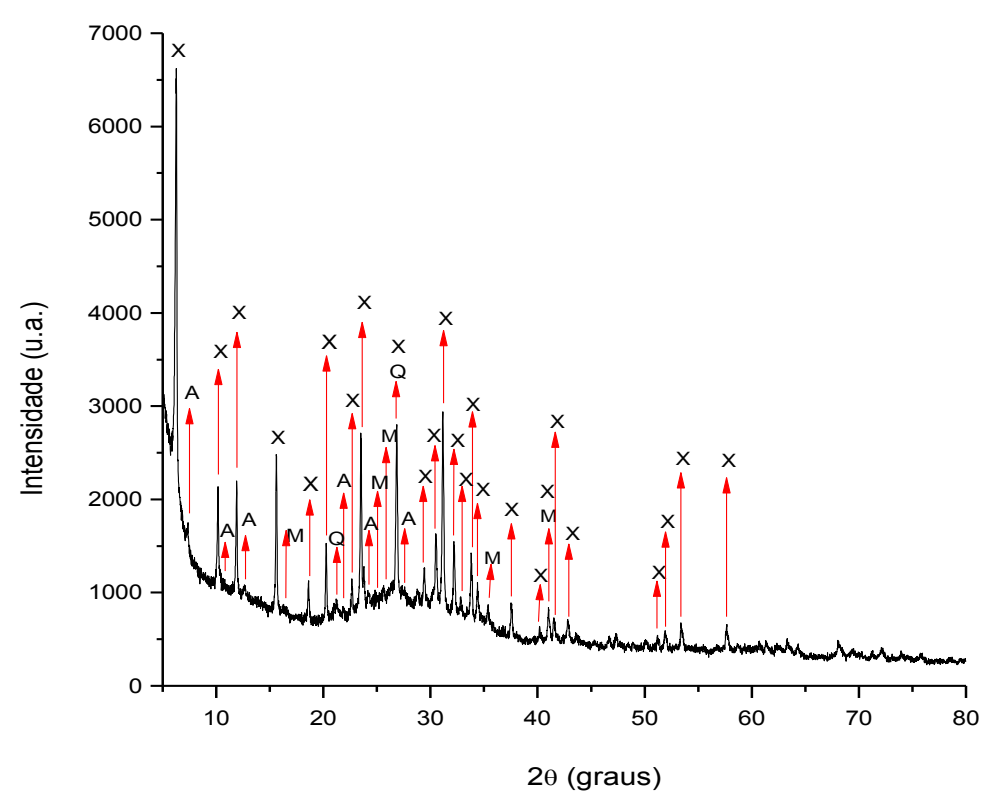

FIGURA 1 - Difratograma do produto de síntese de número 1 (X = Zeólita $X$, A = Zeólita $A, Q=$ Quartzo e $M=$ Mulita)

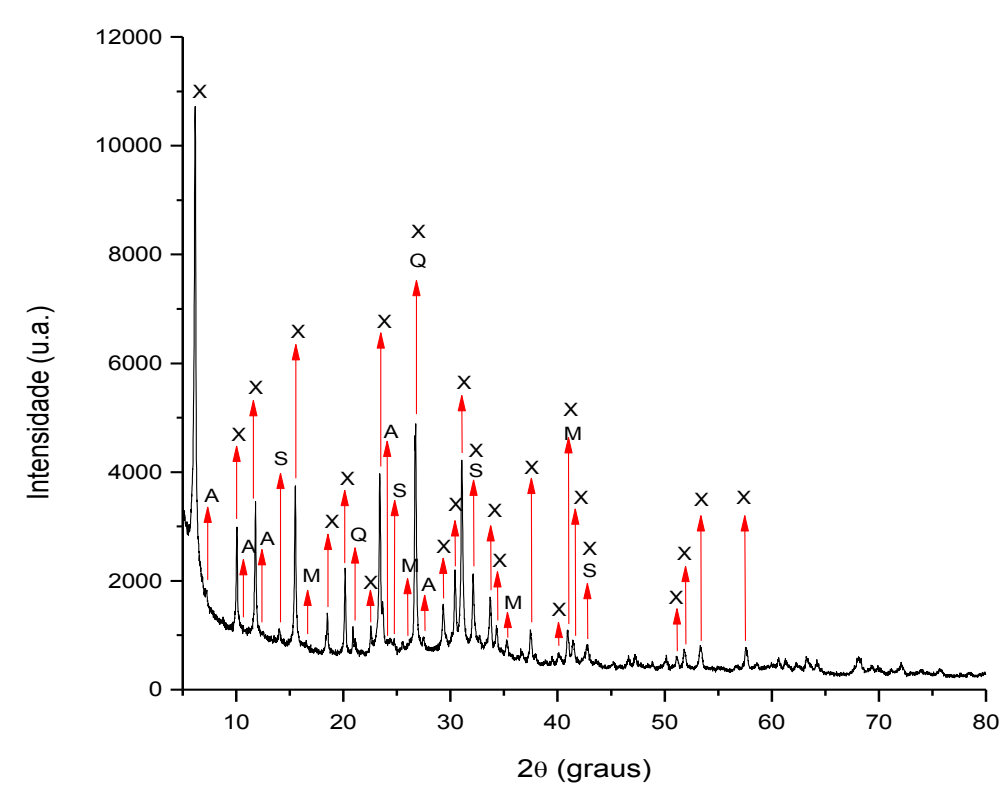

FIGURA 2 - Difratograma do produto de síntese de número 2 (X = Zeólita $X$, $\mathrm{A}=$ Zeólita $\mathrm{A}, \mathrm{S}=$ Zeólita Sodalita, $\mathrm{Q}=$ Quartzo e $\mathrm{M}=$ Mulita) 


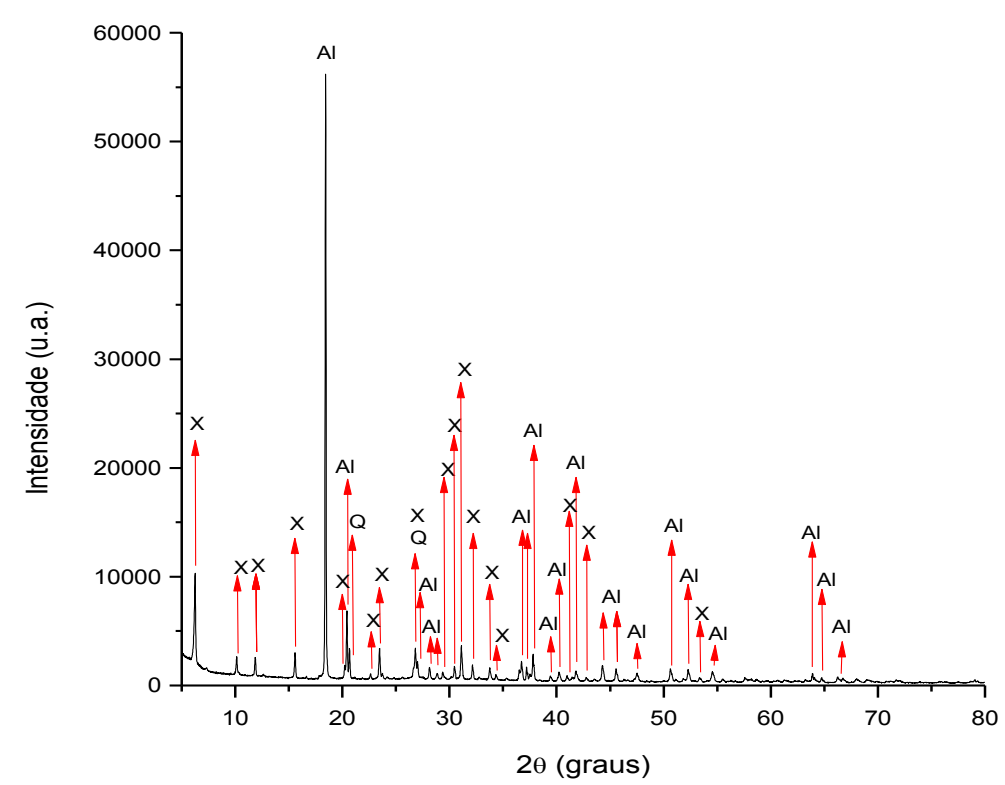

FIGURA 3 - Difratograma do produto de síntese de número 3 (Al = Hidróxido de alumínio, $\mathrm{X}=$ zeólita $\mathrm{X}$ e $\mathrm{Q}=$ Quartzo)

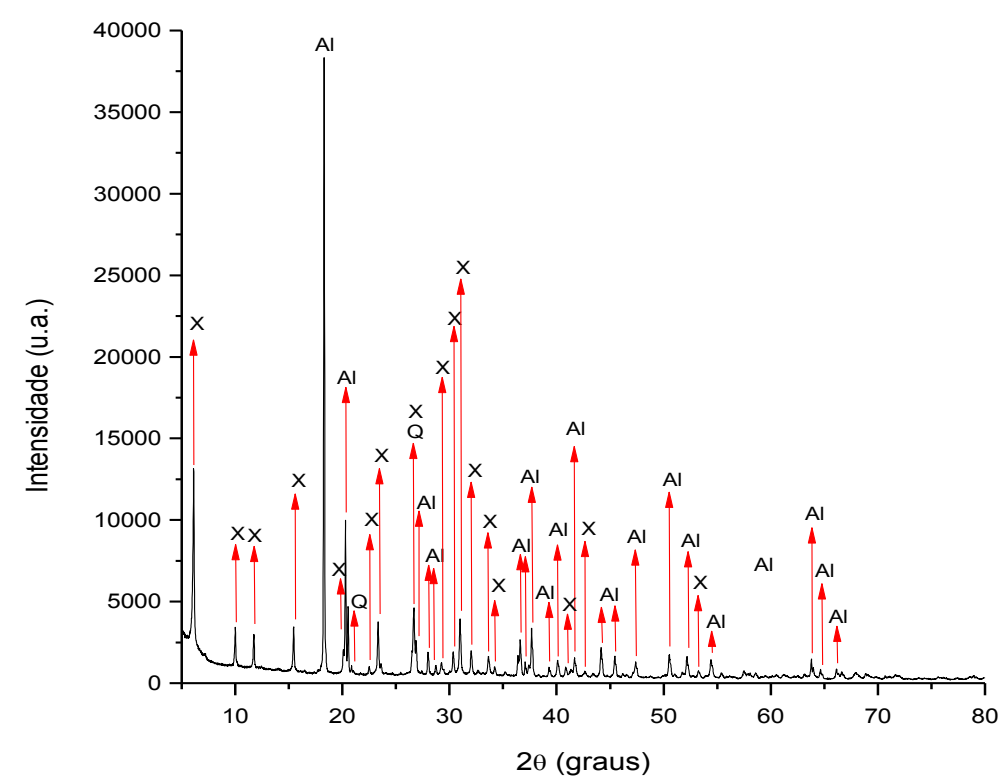

FIGURA 4 - Difratograma do produto de síntese de número 4 (Al = Hidróxido de alumínio, $X=$ zeólita $X$ e $Q=$ Quartzo) 


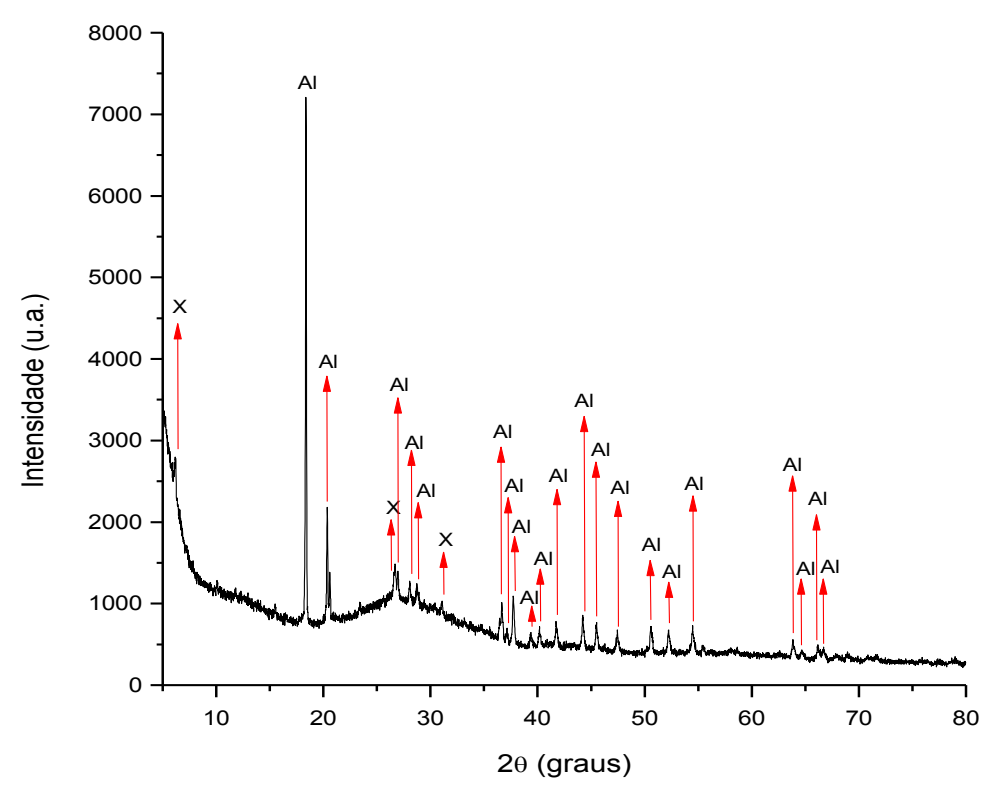

FIGURA 5 - Difratograma do produto de síntese de número 5 (Al = Hidróxido de alumínio, $X$ = zeólita X e $Q=$ Quartzo)

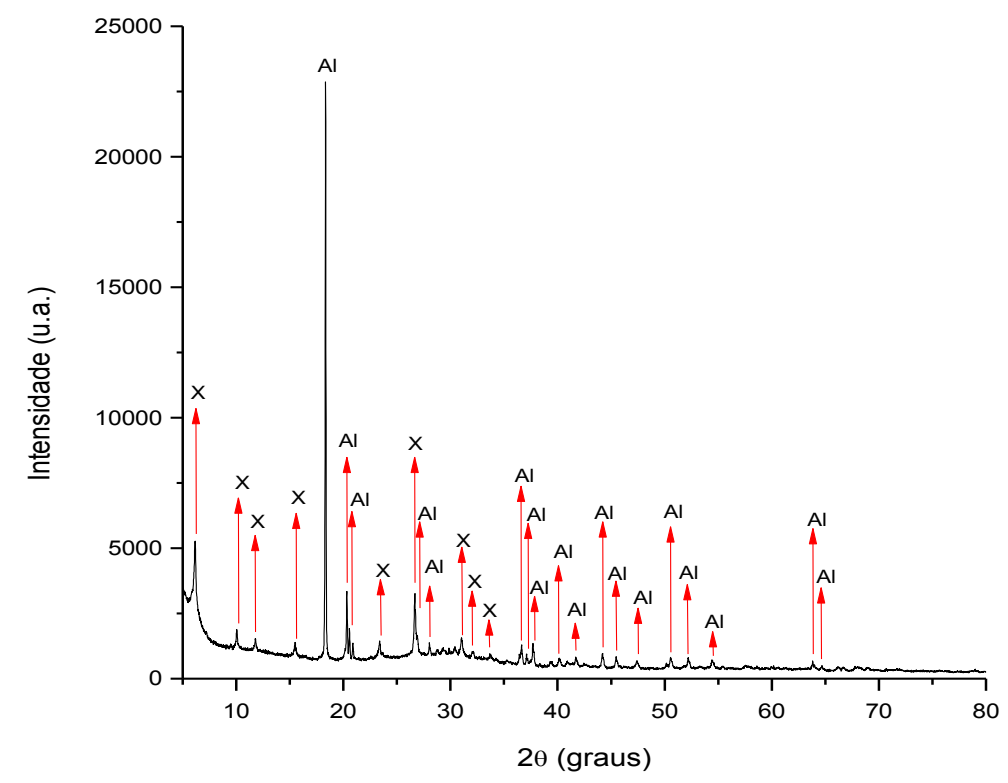

FIGURA 6 - Difratograma do produto de síntese de número 6 (Al = Hidróxido de alumínio, X = zeólita X e Q = Quartzo) 


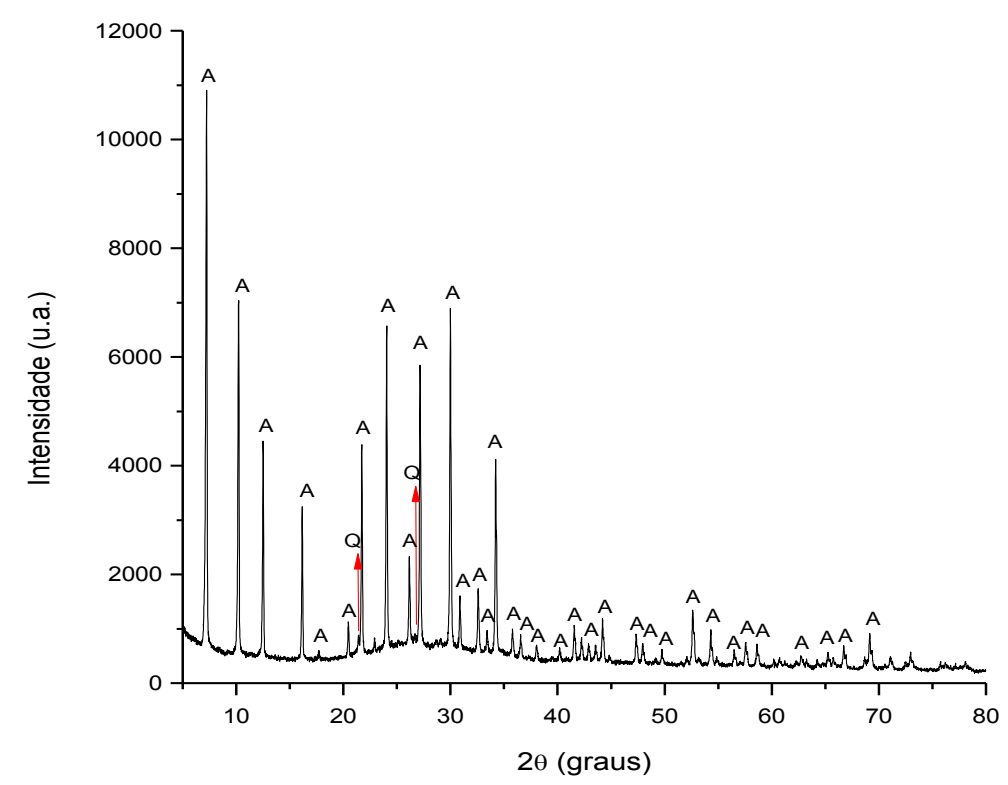

FIGURA 7 - Difratograma do produto de síntese de número 7 ( $A$ = Zeólita $A$ e $\mathrm{Q}=$ Quartzo)

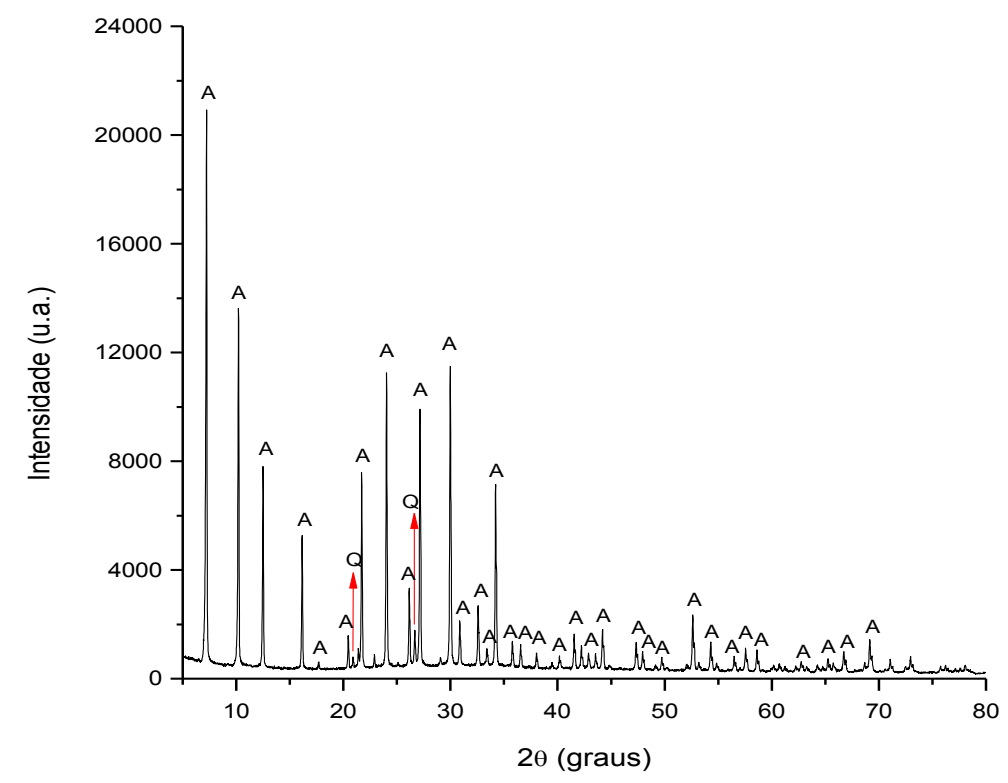

FIGURA 8 - Difratograma do produto de síntese de número 8 ( $A$ = Zeólita $A$ e $\mathrm{Q}=$ Quartzo) 


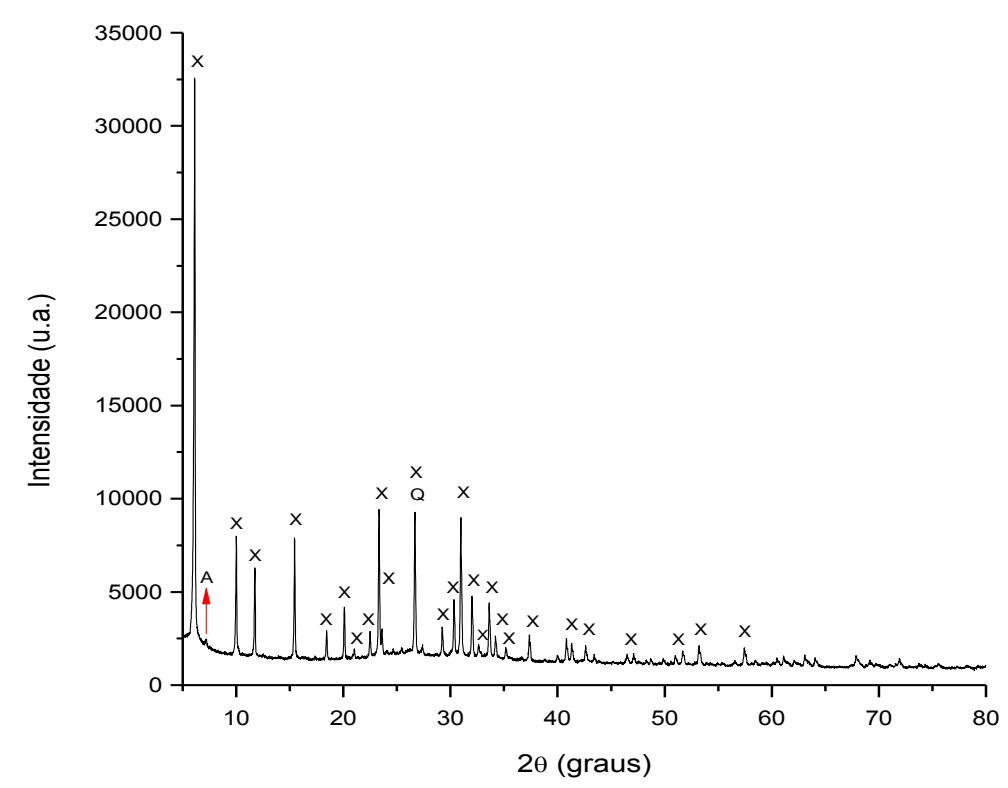

FIGURA 9 - Difratograma do produto de síntese de número $9(X=$ Zeólita $X$, $A=$ Zeólita $A$ e $Q=$ Quartzo)

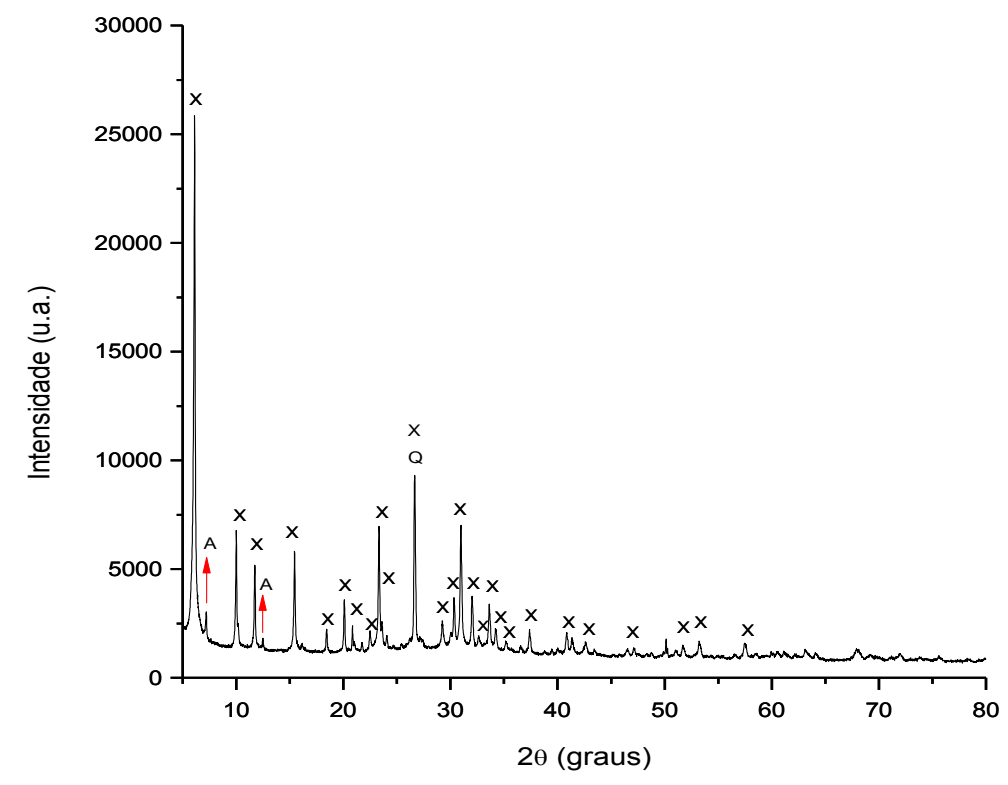

FIGURA 10 - Difratograma do produto de síntese de número $10(X=$ Zeólita $X$, A = Zeólita A e Q = Quartzo) 


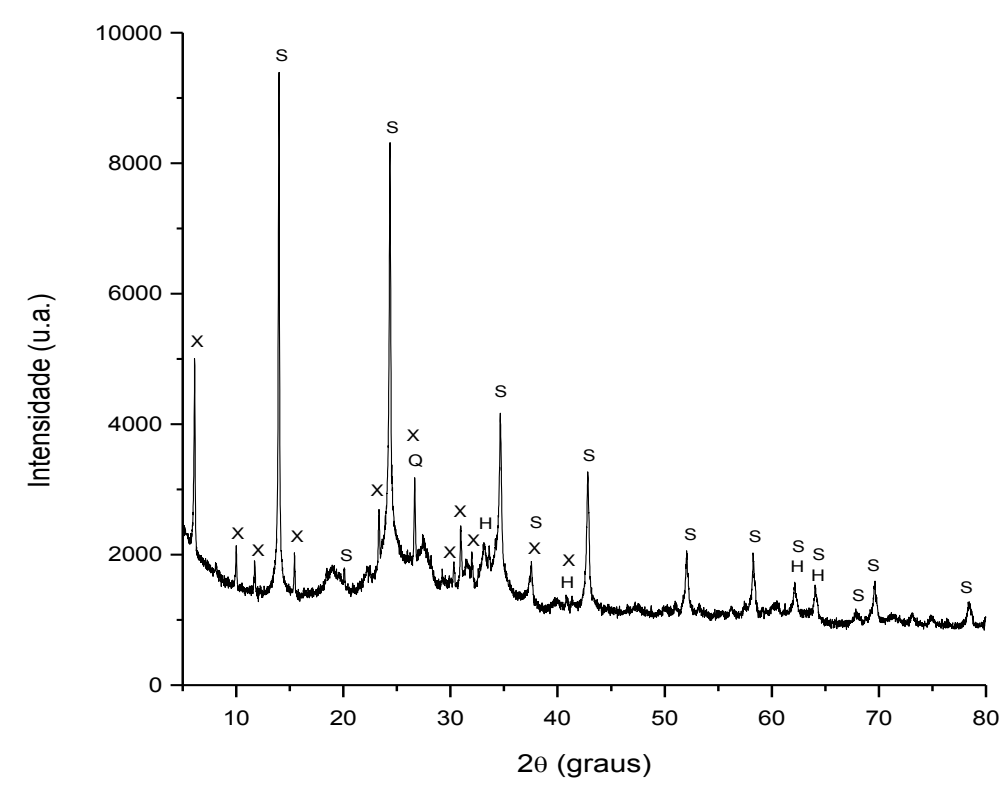

FIGURA 11 - Difratograma do produto de síntese de número 11 (X = Zeólita X, $\mathrm{S}=$ Zeólita Sodalita, $\mathrm{Q}=$ Quartzo e H = Hematita)

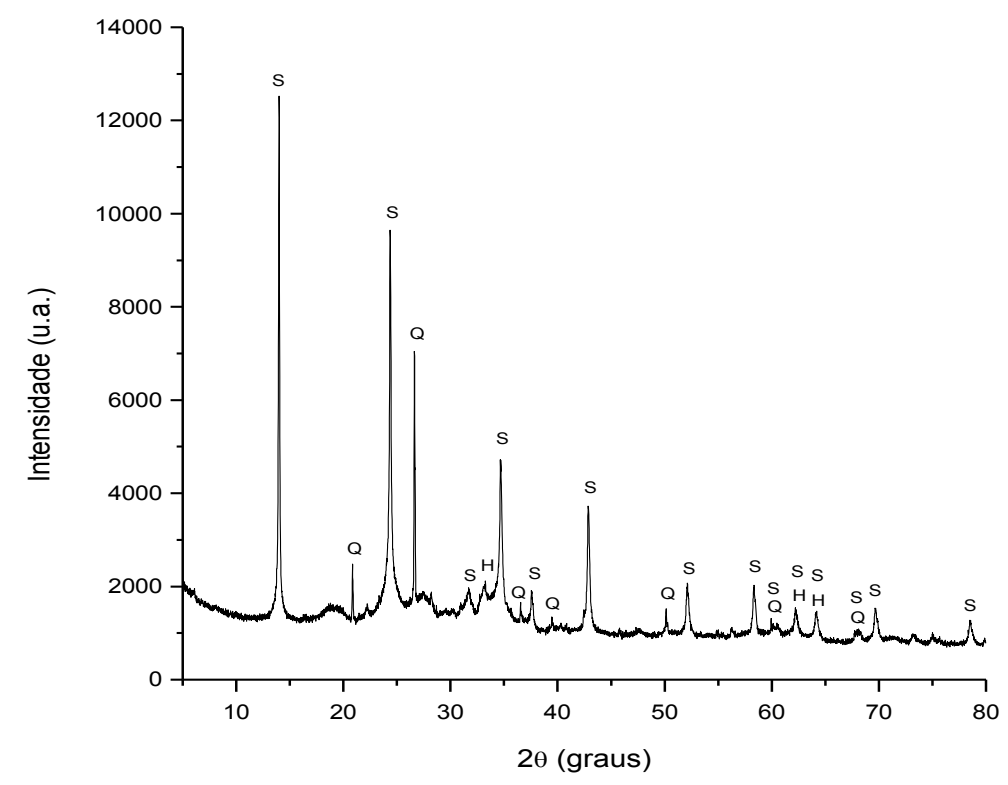

FIGURA 12 - Difratograma do produto de síntese de número 12 ( $\mathrm{S}$ = Zeólita Sodalita, $\mathrm{Q}=$ Quartzo e $\mathrm{H}=$ Hematita) 


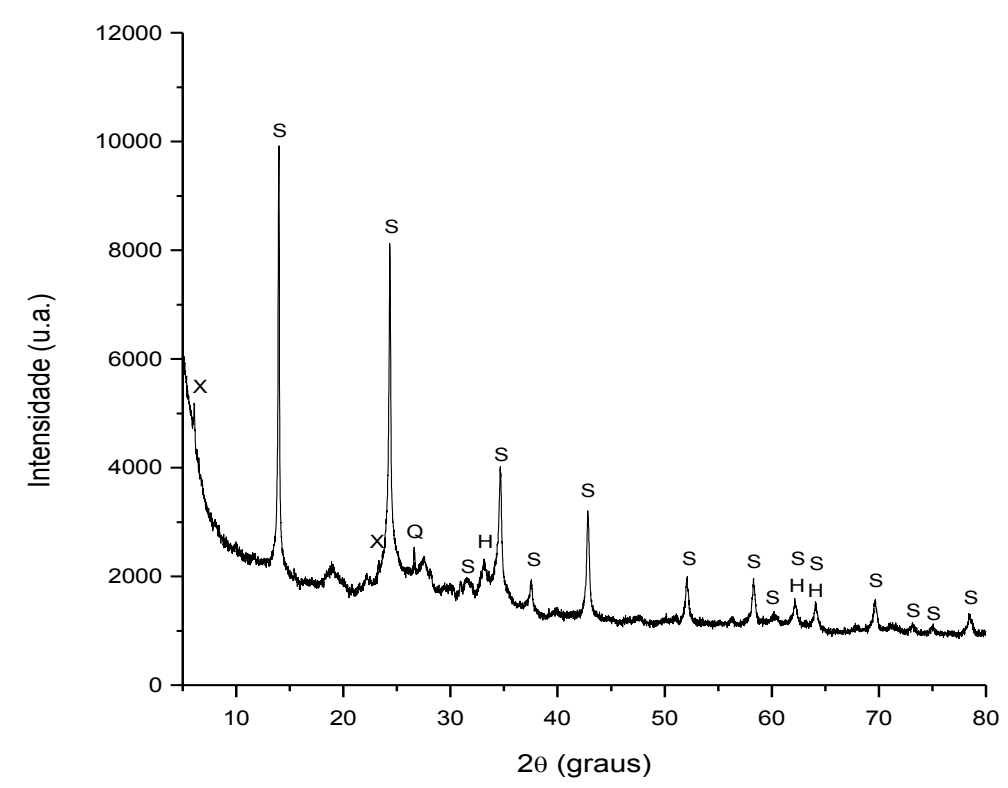

FIGURA 13 - Difratograma do produto de síntese de número 13 ( $S$ = Zeólita Sodalita, $\mathrm{X}=$ Zeólita $\mathrm{X}, \mathrm{Q}=$ Quartzo e $\mathrm{H}=$ Hematita)

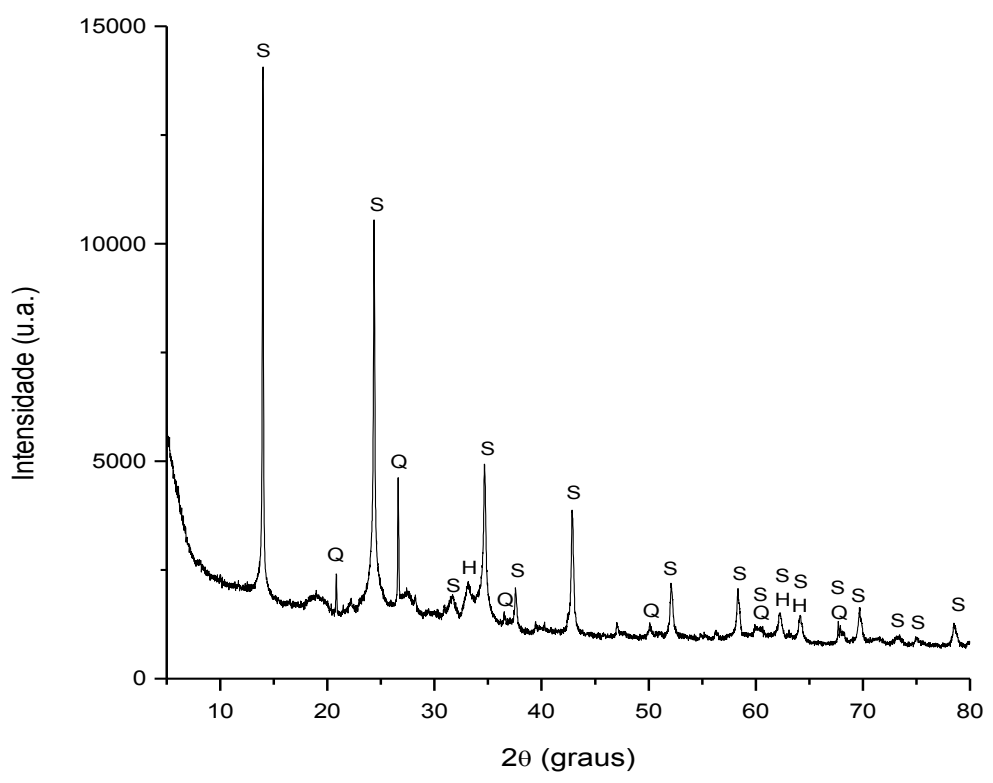

FIGURA 14 - Difratograma do produto de síntese de número 14 ( $\mathrm{S}$ = Zeólita Sodalita, $\mathrm{Q}=$ Quartzo e $\mathrm{H}=$ Hematita) 
OBS: os produtos referentes às sínteses de números 15, 16, 17 e 18 foram selecionados e seus respectivos difratogramas encontram-se no item 5.2.2 (caracterização das zeólitas selecionadas) do tópico de resultados e discussão.

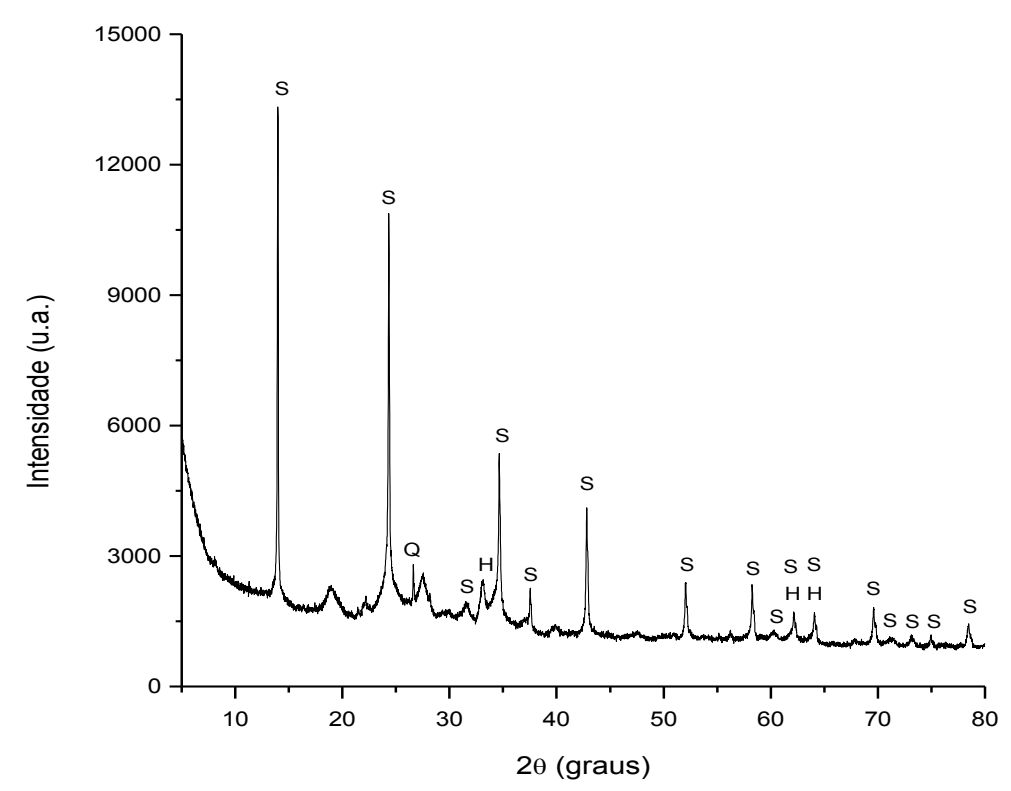

FIGURA 15 - Difratograma do produto de síntese de número 19 ( $\mathrm{S}$ = Zeólita Sodalita, $\mathrm{Q}=$ Quartzo e $\mathrm{H}=$ Hematita)

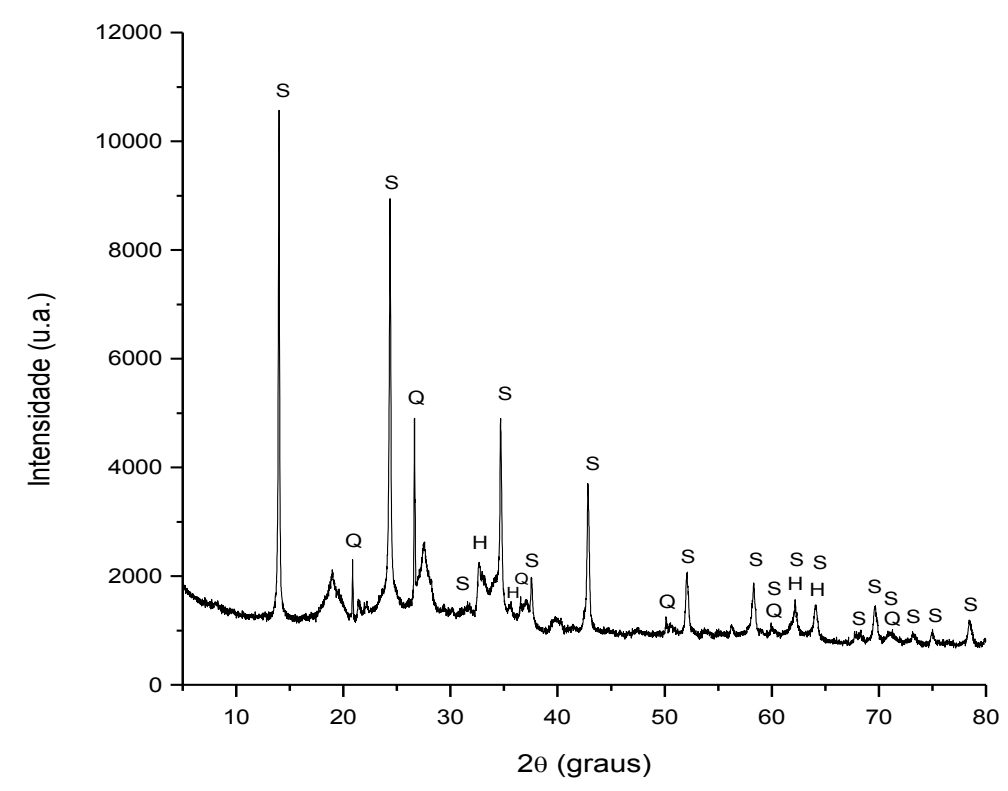

FIGURA 16 - Difratograma do produto de síntese de número 19 ( $\mathrm{S}$ = Zeólita Sodalita, $\mathrm{Q}=$ Quartzo e $\mathrm{H}=$ Hematita) 
APÊNDICE B - Difratogramas de raios $X$ das zeólitas com elevado grau de pureza sintetizadas a partir das cinzas de carvão da Usina Termelétrica Presidente Médice

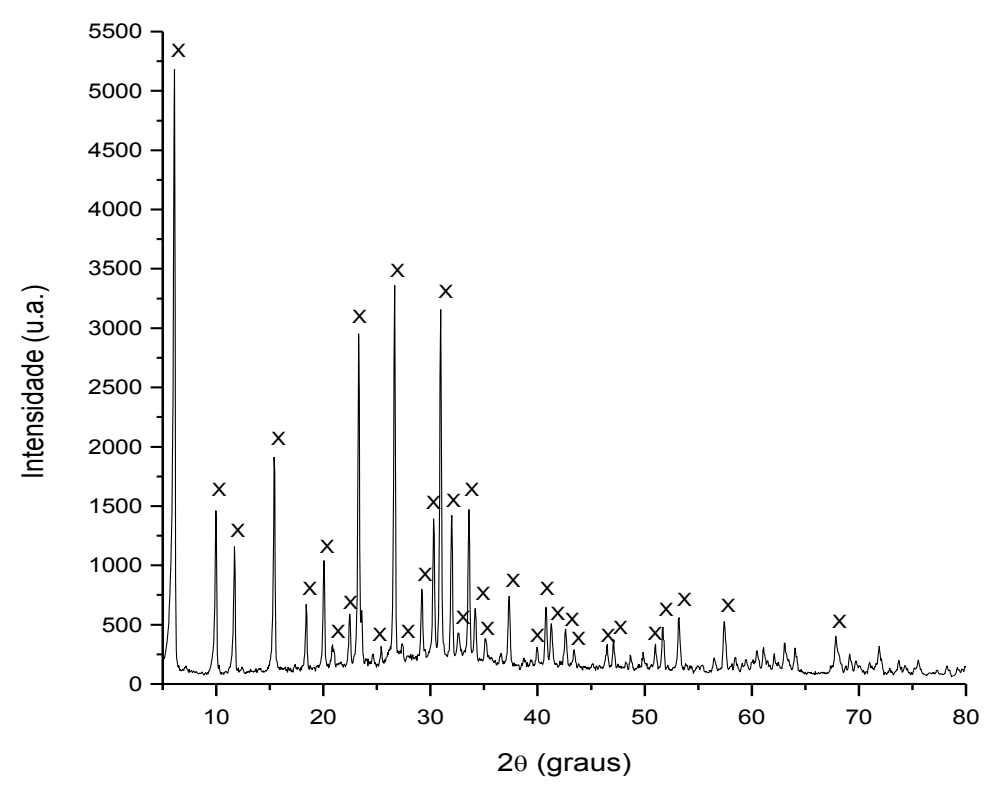

FIGURA 1 - Difratograma da zeólita $X$ sintetizada por processo de duas etapas com fusão prévia a partir da cinza da UTPM ( $\mathrm{X}=$ Zeólita $\mathrm{X})$

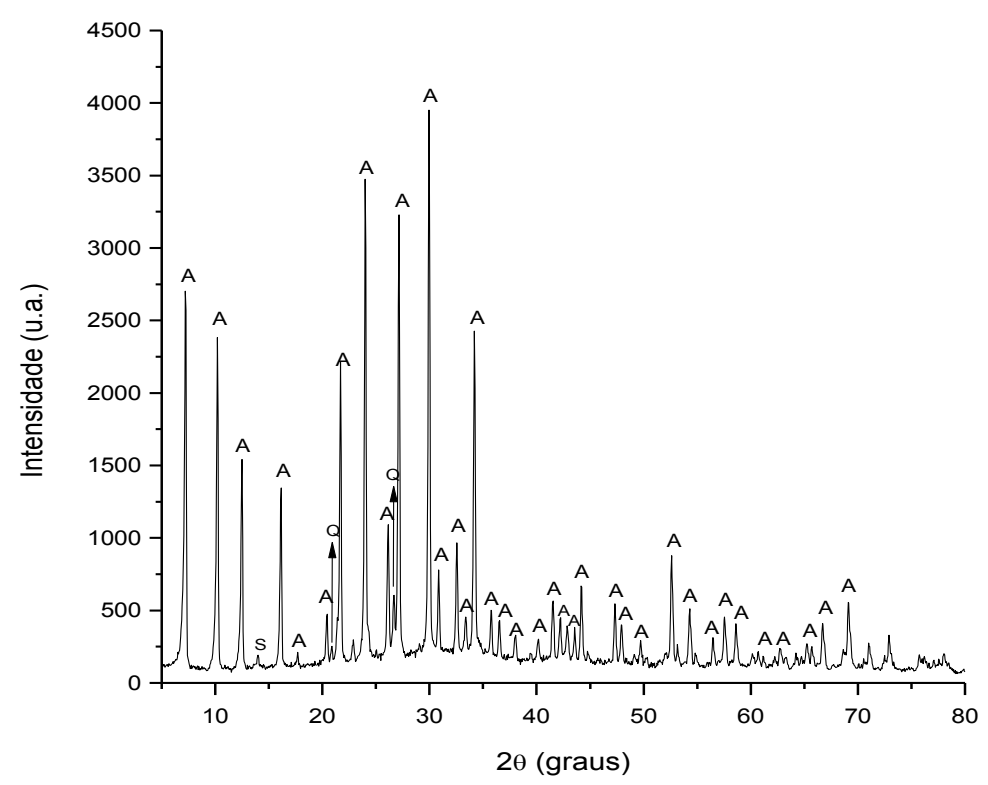

FIGURA 2 - Difratograma da zeólita $A$ sintetizada por processo de duas etapas com fusão prévia a partir da cinza da UTPM $(A=$ Zeólita $A, Q=$ Quartzo, $S=$ Zeólita Sodalita) 


\section{REFERÊNCIAS BIBLIOGRÁFICAS}

ANEEL - Agência Nacional de Energia Elétrica - <http://www.aneel.gov.br>. Acessado em 25/03/2010.

AGUIAR, M. R. M. P., NOVAES, A. C., GUARINO, A. W. S. Remoção de metais pesados de efluentes industriais por aluminossilicatos. Quim. Nova. n. 6B, v. 25, p. 1145-1154, 2002.

AHMARUZZAMAN, M. A review on the utilization of fly ash. Prog. Energ. Combust., v. 36, p. 327-363, 2010.

AMRHEIN, C., HAGHNIA, G. H., KIM, T. S., MOSHER, P. A., GAGAJENA, R. C., AMANIOS, T., LA TORRE, L. Synthesis and properties of zeolites from coal fly ash. Environ. Sci. Technol., v.30, p.735-742, 1996.

ATKINS, P.; JONES, L. Princípios de Química - questionando a vida moderna e o meio ambiente. Porto Alegre: Bookman, 2001.

Australian Institute of High Energetic Materials - Zeolites for water and wastewater treatment: An overview - <http://www.ausihem.org >. Acessado em 08/03/2012.

BACCOUCHE, A., SRASRA, E., EL MAAOUI, M. Preparation of Na-P1 and sodalite octahydrate zeolites from interstratified illite-smectite, Applied Clay Science., v. 13, p. 255-273, 1998.

BANG-SUP, S., SUNG-OH, L., NAM-PYO, K. Preparation of zeolitic adsorbent from waste coal fly ash. J. Chem. Eng., v.12, p. 352 - 356, 1995.

BARRER, R. M. J. Chem. Soc. p. 2158, 1948.

BINIWALE, R., RAYALU, S., HAZAN, M. Z. Cost estimates for production of fly ash based zeolite-A. J. Sci. Ind. Res., v. 60, p. 574-579, 2001.

BP Statistical Review of World Energy - <http://www.bp.com/worldenergy>. Acessado em 20/12/2011. 
BRAGA, A. A. C. e MORGON, N. H. Descrições estruturais cristalinas de zeólitos. Quim. Nova. n.1, v. 30, p. 178-188, 2007.

BRUNO, V. R. M. Adsorção de cobre e chumbo em material particulado: efeito da matéria orgânica dissolvida. 2000. Tese (Doutorado) - Universidade Estadual de Campinas, São Paulo.

BUHRKE, V. E., JENKINS, R., SMITH, D. K. Preparation of specimens for X-ray fluorescence and X-ray diffraction analysis. London: Wiley-VCH, 1998.

CAMPANER, V. P. O carvão no município de Figueira/PR: da mineração à utilização. Monografia apresentada ao Curso de Graduação em Geografia Universidade Estadual de Londrina - 2005.

CARRISCO R. C. C.; POSSA, M. V. Carvão Mineral: Aspectos gerais e econômicos. Série Estudos e Documentos. Rio de Janeiro: CETEM - Centro de Tecnologia Mineral/CNPq, 1995.

CARVALHO, T. E. M., FUNGARO, D.A, IZIDORO, J.C. Adsorção de corante reativo laranja 16 de soluções aquosas por zeólita sintética. Quím. Nova, v.33, n. 2, p. 358-363, 2010.

CGTEE - Companhia de Geração Térmica e Energia Elétrica $<$ http://www.cgtee.gov.br/>. Acessado em 14/01/2013.

CHANG, H. L.; SHIH, W. H. A general method for the conversion of fly ash into zeolites as ion exchangers for cesium. Ind. Eng. Chem. Res., v. 37, p. 71-78, 1998.

CHANG, H. L.; SHIH, W. H. Synthesis of zeolites A and X from fly ashes and their ion-exchange behavior with cobalt ions. Ind. Eng. Chem. Res., v. 39, p. 41854191, 2000.

CHUBU ELECTRIC POWER < http://www.chuden.co.jp/english/>. Acessado 15/12/2010.

Clean Japan Center - Catálogo da empresa em inglês - Impresso. 1991.

COPEL - Companhia Paraense de Energia - < http://www.copel.com/>. Acessado em 25/03/2010. 
COSTA, S. R. M., FARIAS, T. J., FERNANDES, T. S. PAZ, C. S. Utilização de zeólitas modificadas com terras raras no craqueamento catalítico de petróleo. Trabalho de conclusão de curso apresentado ao Curso de Graduação em Química Industrial - Faculdades Oswaldo Cruz - 2012.

DEPOI, F. S., POZEBON, D., KALKREUTH, W. D., BÜRGUER, T. S. Caracterização de carvões e suas cinzas provenientes da região sul do Brasil. In: REUNIÃO ANUAL DA SOCIEDADE BRASILEIRA DE QUÍMICA, QA-207., 31 de maio-03 junho, 2007, Águas de Lindóia. Resumos... São Paulo.

DEPOI, F. S., POZEBON, D., KALKREUTH, W. D. Chemical characterization of feed coals and combustion-by-products from Brazilian power plants. Int. Journal Coal Geol. v. 76, p. $227-236,2008$.

ELLIOT, A. D. An investigation into the hydrothermal processing of coal fly ash to produce zeolite for controlled release fertilizer applications. 2006. Tese (doutorado) - Curtin University of Technology, Australia.

EL-NAGGAR, M. R., EL-KAMASH, A. M., EL-DESSOUKY, M. I., GHONAIM, A. K. Two-step method for preparation of $\mathrm{NaA}-\mathrm{X}$ zeolite blend from fly ash for removal of cesium ions. J. Hazard. Mater., v. 154, p. 963-972, 2008.

ENDRES, J.C.T., FERRET, L. S., FERNANDES, I. D., HOFMEISTER, L. C. The removal of $\mathrm{Fe}, \mathrm{Zn}, \mathrm{Cu}$ and $\mathrm{Pb}$ from wastewaters using chabazite zeolites produced from southern brazilian coal ashes. In: INTERNATIONAL ASH UTILIZATION SYMPOSIUM, 4., 2001, Lexington, Kentucky, USA. Proceedings... Lexington: University of Kentucky, p. 478-484, 2001.

EPE - Empresa de Pesquisa Energética - <http://www.epe.gov.br>. Acessado em 19/02/2010.

FERNÁNDEZ-PEREIRA, C. GALIANO, Y. L., RODRÍGUEZ-PIÑERO, M. A., VALE, J., QUEROL, X. Utilisation of zeolitised coal fly ash as immobilising agent of a metallurgical waste. J. Chem. Technol. Biotechnol., v.77, p. 305-310, 2002.

FERREIRA, K.D. Uso de zeólitas na redução do teor do cátion níquel de efluentes galvânicos. 1998. Dissertação (mestrado) - Escola Politécnica da Universidade de São Paulo, São Paulo.

FERRET, L.S. Zeólitas de cinzas de carvão: síntese e uso. 2004. Tese (Doutorado) - Universidade Federal do Rio Grande do Sul, Porto Alegre. 
FOLETTO, E. L., CASTOLDI, M., OLIVEIRA, L. H., HOFFMAN, R., JAHN, S. L., Conversion of rice husk ash into zeolitic materials. Latin American Applied Research., v.39, p. 75-78, 2009

FONSECA, R. J. Monitoramento e avaliação da emissão de dutos e fontes estacionárias de indústrias cerâmicas por meio de método potenciométrico e fluorescência de raios $\boldsymbol{X}$. 2007. Dissertação (Mestrado) - Universidade Estadual de Campinas, Campinas, São Paulo.

FUNGARO, D.A., FLUES, M.S.M., CELEBRONI, A.P. Estabilização de solo contaminado com zinco usando zeólitas sintetizadas a partir de cinzas de carvão. Quím. Nova., v. 27, p. 582-585, 2004.

FUNGARO, D.A.; IZIDORO, J. C. Tratamento de efluentes industriais usando material zeolítico preparado com cinzas de carvão. In: XIX Prêmio Jovem Cientista, Porto Alegre: Gráfica e Editora Comunicação Impressa, 2004.

FUNGARO, D.A., IZIDORO, J.C., ALMEIDA, R. S. Remoção de compostos tóxicos de solução aquosa por adsorção com zeólita sintetizada a partir de cinzas de carvão. Ecl. Quím., v.30, n. 2, p. 31-35, 2005.

FUNGARO, D.A.; IZIDORO, J.C. Estudo da remoção de íons metálicos em água utilizando zeólitas sintetizadas com cinzas de carvão. Tchê Quím., v.3, p. 21-30, 2006a.

FUNGARO, D.A.; IZIDORO, J.C. Remediação de drenagem ácida de mina usando zeólitas sintetizadas a partir de cinzas leves de carvão. Quím. Nova, v.29, n. 4 , p. $735-740,2006 b$.

FUNGARO, D.A.; IZIDORO, J.C. Utilização de material zeolítico quimicamente ativado no descoramento de óleo vegetal. Revista Capixaba de Ciência e Tecnologia., n. 1, p. 69-72, 2006c.

FUNGARO, D.A., REVA, J., IZIDORO, J. C., Remoção de vermelho do congo de solução aquosa por zeólitas de cinzas de carvão: estudo cinético e análise de isotermas de equilíbrio. Tchê Quím., v.6, n. 12, p. 25-32, 2009a.

FUNGARO, D.A., IZIDORO, J.C., BRUNO, M.Aplicação de material zeolítico sintetizado de cinzas de carvão como adssorvente de poluentes em água. Ecl. Quím., v.34, n. 1, p. 45-50, 2009b. 
GARCÍA, J. M. Síntesis y caracterización de zeolitas y materiales compuestos zeolita/carbón. Aplicaciones para la eliminación de $\mathrm{SO}_{2} .2001$. Tese (Doutorado), Universidade de Alicante, Alicante, Espanha.

GIANNETTO, G. Zeolitas - caracteristicas, propiedades y aplicaciones industriales. Caracas: EdIT Editorial Innovación Tecnológica, 1990.

GOBBI, S.A., ENGERT, A.H., RUBIO, J. Avaliação do uso de zeólita sintética para a remoção de nitrogênio amoniacal de águas e efluentes. Porto Alegre: LTM/UFRGS, 2004.

HEMMINGS, R. T.; BERRY, E. E. Speciation in size and density fractioned fly ash. Fly ash and conversion by-products: characterization, utilization and Disposal. Materials Research Society. Symposia Proceedings... p. 3-38, 1985.

HEMMINGS, R. T.; BERRY, E. E. Speciation in size and density fractioned fly ash. On the glass in coal fly ashes: recent advances. Materials Research Society. Symposia Proceedings... p. 91-103, 1988.

HENMI, T. Synthesis of hydroxi-sodalite ("zeolite") from waste coal ash. Soil Science Plant Nutrition., v.33, p. 517 - 521, 1987.

HÖLLER, H.; WIRSCHING, G.U. Zeolite formation from fly ash. Fortschr. Mineral., v.63, p. 21-43, 1985.

HOLLMAN, G. G., STEENBRUGGEN, G., JANSSEN-JURKOVICOVÁ, M. A twostep process for the synthesis of zeolites from coal fly ash. Fuel. V. 78, p. $1225-$ 1230, 1999.

HUI, K. S.; CHAO, C. Y. H. Effects of step-change of synthesis temperature on synthesis of zeolite 4A from coal fly ash. Microporous and Mesoporous materials., v. 88, p. 145-151, 2006.

International Zeolite Association - Index of Natural Zeolites Datasheets $<$ http://www.iza-online.org/natural/index.htm>. Acessado em 08/03/2012a.

International Zeolite Association - Database of Zeolite Structures - <http://www.izastructure.org/databases $>$. Acessado em 08/03/2012b. 
IYER, R. S.; SCOTT, J. A. Power station fly ash - a review of value-added utilization outside of the construction industry. Resour. Conserv. Recy., v. 31, p. 217-228, 2001.

IZIDORO, J. C. Estudos sobre a remoção de íons metálicos em água usando zeólitas sintetizadas a partir de cinzas de carvão. 2008. Dissertação (Mestrado) - Instituto de Pesquisas Energéticas e Nucleares, São Paulo.

IZIDORO, J. C., FUNGARO, D. A., SANTOS, F. S., WANG, S. Characteristics of Brazilian coal fly ashes and their synthesized zeolites. Fuel Proc. Tech., v. 97, p. 38-44, 2012a.

IZIDORO, J. C.; FUNGARO, D. A. Utilização de resíduos de usinas termelétricas a carvão na síntese de zeólitas e sua aplicação na remoção de $\mathrm{Zn}^{2+}$ e $\mathrm{Cd}^{2+}$ em água. Rev. Bras. Pesq. Des., v. 9, p. 101-106, 2007.

IZIDORO, J. C. et al. Synthesis of zeolites $X$ and A from fly ashes for cadmium and zinc removal from aqueous solutions in single and binary ion systems. Fuel (2012b), http://dx.doi.org/10.1016/j.fuel.2012.07.060

JANSEN, J. C. The preparation of molecular sieves. A-Synthesis of Zeolites. In: H. van BEKKUM, E. M., FLANIGEM, J. C., JANSEN, (Eds): Introduction to zeolite science and pratice. Amsterdan: Elsevier, cap. 4, p. 77-136, 1991.

KERR, G.T. Synthetic Zeolites. Scientific American, p. 82 - 87, july, 1989.

KIKUCHI, R. Application of coal ash to environmental improvement.

Transformation into zeolite, potassium fertilizer, and FGD absorbent. Resour. Conserv. Recy., v. 27, p. 333-346, 1999.

KITTEL, C. Introdução à física do estado sólido. Traduzido por Adir M. Luiz. Universidade Federal do Rio de Janeiro. Ed. Guanabara Dois S. A. 1978.

KOLOUSEK, D.; SEIDL, V.; PROCHAZKOVA, E.; OBSASNIKOVA, J.; KUBELKOVA, L.; SVETLIK, I. Ecological utilization of power-plant fly ashes by heir alteration to phillipsite: hydrothermal alteration, application. Acta Univ. Carol. Geol., v. 37, p. 167-178, 1993.

LANCHANCE, G. R.; CLAISSE, F. Quantitative X-ray fluorescence analysis Theory and Aplication. London: Wiley, 1995. 
LIN, C-F., LO, S-S, LIN, H-Y, LEE, Y. Stabilization of cadmium contaminated soils using synthesized zeolite. J. Hazard. Mater., v. 60, p. 217-226, 1998.

LUSTER - Mapa do Brasil - < http://www.lusterluminarias.com.br/>. Acessado em 08/12/2010.

MAIA, A. A. B., ANGÉLICA, R. S., SOUZA, C. A G., NEVES, R. F. The use of kaolin wastes from the Amazon region on the synthesis of zeolite A. Cerâmica., v.53, p. 319-324, 2007.

MIGNONI, M. L., DETONI, C., PERGHER, S. B. C. Estudo da Síntese da zeólita ZSM-5 a partir de argilas naturais. Quím. Nova., v.30, p. 45-48, 2007.

MORENO, N., QUEROL, X., AYORA, C., ALASTUEY, A., FERNÁNDEZ-

PEREIRA, C., JANSSEN-JURTOKICOVÁ, M. Potential environmental applications of pure zeolitic material synthetized from fly ash. J.Environ. Eng., v. 127, p. 9941002, 2001a.

MORENO, N., QUEROL, X., AYORA, C., FERNÁNDEZ-PEREIRA, C., JANSSENJURKOVICOVÁ, M. Utilization of zeolites synthetized from coal fly ash for the purification of acid mine waters. Environ. Sci. Technol., v. 35, p. 3526-3534, $2001 b$.

MORIYAMA, R., TAKEDA, S., ONOZAKI, M., KATAYAMA, Y., SHIOTA, K., FUKUDA, T., SUGIHARA, H., TANI, Y. Large-scale synthesis of artificial zeolite from coal fly ash with a small charge of alkaline solution. Fuel. v. 84, p. 14551461, 2005.

MOURA, M. J.; FIGUEIREDO, M. M. Aplicação das técnicas de picnometria de gás e de porosimetria de mercúrio à caracterização da madeira de E. globulus. Silva Lusitana., v. 10, p. 207-216, 2002.

MURAYAMA, N.; YAMAMOTO, H.; SHIBATA, J. Mechanism of zeolite from coal fly ash by alkali hydrotermal reaction. Int. J. Miner. Process, v. 64, p. 1-17, 2002.

NASCIMENTO, M., SOARES, P. S., M., SOUZA, V. P. Adsorption of heavy metal cátions using coal fly ash modified by hydrothermal method. Fuel. v. 88, p. 17141719, 2009.

OJHA, K., PRADHAN, N. C., SAMANTA, A. M. Zeolite from fly ash: synthesis and characterization. Bull. Mater. Sci., v. 27, p. 555-564, 2004. 
OKADA, Y. Syntheis of zeolite using fly ash on closed system. Japanese J. Soil Sci. and Plant Nutr., v.62, p. 1-6, 1991.

PADILHA, A. F.; FILHO, F. A. Técnicas de análise microestrutural. São Paulo: Hemus Editora Limitada, 1985.

PAPROCKI, A. Síntese de zeólitas a partir de cinzas de carvão visando sua utilização na descontaminação de drenagem ácida de mina. 2009.

Dissertação (Mestrado) - Pontifícia Universidade Católica do Rio Grande do Sul, Porto Alegre.

PETROVIC, I., NAVROTSKY, A., DAVIS, M. E., ZONES, S. I. Thermochemical study of the stability of frameworks in high silica zeolites. Chem. Mater., v. 5, p. 1805-1813, 1993.

PIRES, M.; QUEROL, X. Characterization of Candiota (South Brazil) coal and combustion by-product. Int. J. Coal Geol. v. 60, p. 57-72, 2004.

POOLE, C., PRIJATAMA, H., RICE, N. M. Synthesis of zeolite adsorbents by hydrothermal treatment of PFA wastes: a comparative study. Minerals

Engineering. v. 13, p. 831-842, 2000.

QUANTACHROME INSTRUMENTS

<http://www.quantachrome.com/technologies/>. Acessado em 02/06/2010.

QUEROL, X., ALASTUEY, A., LÓPEZ-SOLER, A., PLANA, F., ANDRÉS, J. M., JUAN, R., FERRER, P., RUIZ, C. R. A fast method for recycling fly ash: microwave-assisted zeolite synthesis. Environ. Sci. Technol., v.31, p. 2527 2533, 1997a.

QUEROL, X., PLANA, F., ALASTUEY, A., LÓPEZ-SOLER, A. Synthesis of Nazeolites from fly ash. Fuel, v.76, p. $793-799,1997 b$.

QUEROL, X., UMAÑA, J. C., PLANA, F., ALASTUEY, A., LÓPEZ-SOLER, A., MEDINACELI, A., VALERO, A., DOMINGO, M. J., GARCIA-ROJO, E. Synthesis of zeolites from fly ash at pilot plant scale. Examples of potential applications. Fuel, v.80, p. $857-865,2001$.

QUEROL, X., MORENO, N., UMANÃ, J. C., ALASTUEY, A., HERNANDÉZ, E., LÓPEZ-SOLER, A., PLANA, F. Synthesis of zeolites from coal fly ash: an overview. Int. Journal Coal Geol, v.50, p. 413 - 423, 2002. 
QUEROL, X., MORENO, N., ALASTUEY, A., JUAN, R., ANDRÉS, J. M., LÓPEZSOLER, A., AYORA, C., MEDINACELI, A., VALERO, A. Synthesis of zeolites of high ion exchange zeolites from coal fly ash. Geologica Acta., n. 1, v.5, p. 49-57, 2007.

RAHMAN, M. M., HASNIDA, N., WAN NIK, W. B. Preparation of zeolite Y using local raw matrial rice husk as a silica source. J. Sci. Res., v.2, p. 285-291, 2009.

RAYALU, S. MESHRAM, S. U., HASAN, M. Z. Highly crystalline faujasitic zeolites from fly ash. J. Hazard. Mater. v. B77, p. 123-131, 2000.

REBELO, F. M. R. Remoção de corantes têxteis usando resíduos industriais e adsorventes naturais de baixo custo. 2000. Dissertação (Mestrado) Faculdade de Engenharia da Universidade do Porto, Porto, Portugal.

RíOS, C. A., WILLIAMS, C. D., ROBERTS, C. L. A comparative study of two methods for the synthesis of fly ash-based sodium and potassium type zeolites. Fuel., v. 88, p. 1403-1416, 2009.

ROHDE, G. M., ZWONOK, O., CHIES, F., SILVA, N. I. W. Cinzas de carvão fóssil no Brasil - Aspectos técnicos e ambientais. Porto Alegre: CIENTEC. V. 1 (202 p), 2006.

RYU, T. G., RYU, J. C., CHOI, C. H., KIM, C. G., YOO, S. J., YANG, H. S., KIM, $\mathrm{Y}$. H. Preparation of Na-P1 zeolite with high cation exchange capacity from coal fly ash. J. Ind. Eng. Chem., v.12, p. 401-407, 2006.

SALGADO JUNIOR, L. P. S. Avaliação da contração de polimerização de uma resina composta fotopolimerizável de uso universal, variando-se a técnica de inserção do material, medida por picnômetro a gás. 2004. Dissertação (Mestrado) - Faculdade de Odontologia, Universidade de São Paulo, São Paulo.

SANTOS, F. S., IZIDORO, J. C., FUNGARO, D. A. Síntese de zeólita de cinzas de

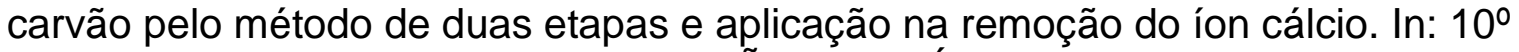
CONGRESSO NACIONAL DE INICIAÇÃO CIENTÍFICA - CONIC. 19 e 20 de Novembro, 2010, São Paulo. Resumos... São Paulo.

SARBAK, Z., STANCZYK, A., KRAMER-WACHOWIACK, M. Characterization of surface properties of various fly ashes. Powder technology., v. 145, p. 82-87, 2004. 
SCAPIN, M. A. Aplicação da difração e fluorescência de raios X (WDXRF): ensaios em argilominerais. 2003. Dissertação (Mestrado) - Instituto de Pesquisas Energéticas e Nucleares, São Paulo.

SCOTT, J., GUANG, D., NAERAMITMARNSUK, K., THABUOT, M., AMAL, R. Zeolite synthesis from coal fly ash for the removal of lead ions from aqueous solution. J. Chem. Technol. Biotechnol., v. 77, p. 63-69, 2001.

SKOOG, D. A., HOLLER, F. J., NIEMAN, T. A. Princípios de Análise Instrumental. 5ª edição. São Paulo: Bookman, 2002.

SHIGEMOTO, N., SHIRAKAMI, K., HIRANO, S., HAYASHI, H. Preparation and characterization of zeolites from coal ash. Nippon Kagaku Kaishi, v.5, p. $484-$ 492, 1992.

SHIGEMOTO, N., HAYASHI, H., MIYUARA, K. Selective formation of Na-X zeolite from coal fly ash by fusion with hydroxide prior to hydrothermal reaction. J. Mater. Sci., v. 28, p. 4781-4786, 1993.

SHIGEMOTO, N., SUGIYAMA, S., HAYASHI, H. Characterization of Na-X, Na-A, and coal fly ash zeolites and their amorphous precursors by IR, MAS NMR and XPS. J. Mater. Sci., v. 30, p. 5777-5783, 1995.

SINGER, A., BERKGAUT, V. Cation exchange properties of hydrotermally treated coal fly ash. Environ. Sci. Technol., v. 29, p. 1748-1753, 1995.

SINGH, D. N. \& KOLAY, K. Simulation of ash-water interaction and its influence on ash characteristics. Progress in Energy and Combustion Science. v. 28, p. 267- 299, 2002.

SRINIVASAN, A., GRUTZECH, M.W. The adsorption of $\mathrm{SO}_{2}$ by zeolites synthesized from fly ash. Environ. Sci. Technol., v.30, p. 1464-1469, 1999.

TANAKA, H.; FUJII, A. Effect of stirring on the dissolution of coal fly ash and synthesis of pure-form Na-A and -X zeolites by two-step process. Adv. Powder Technol. v. 20, p. 473-479, 2009.

TEIXEIRA, V. G., COUTINHO, F. M. B., GOMES, A. S. Principais métodos de caracterização da porosidade de resinas á base de divinilbenzeno. Quim. Nova. n. 6, v. 24, p. $808-818,2001$. 
Tractebel Energia <http://www.tractebelenergia.com.br/>. Acessado em 26/03/2010.

UMAÑA-PEÑA, J. C. Síntesis de zeolitas a partir de cenizas volantes de centrales termoeléctricas de carbón. 2002. Tese (Doutorado) - Universitat Politécnica de Catalunya, Barcelona, Espanha.

UNIVERSIDADE FEDERAL DE SANTA CATARINA. Departamento de Engenharia Mecânica. Laboratório de Caracterização Microestrutural e Análise de Imagens. Disponível em <http://www.materials.ufsc.br>. Acessado em $11 / 06 / 2010$.

UNIVERSIDADE FEDERAL DO RIO GRANDE DO SUL - UFRGS. Carvão e meio ambiente. Centro de Ecologia/UFRGS. - Porto Alegre: Ed. Universidade/UFRGS, 2000.

WANG, C., LI, J., SUN, X., WANG, L., SUN, X. Evaluation of zeolites synthesized from fly ash as potential adsorbents for wastewater containing heavy metals.

Journal of Environmental Sciences., v. 21, p. 127-136, 2009.

WANG, H., ZHANG, Q., SONG, C., LIU, F. Synthesis of zeolites by alkaline activations of fly ash. Journal of University of Science and Technology Beijing., v. 8, p. 161-163, 2001.

WANG, S-F., LI, J-S., WANG, L-J., SUN, X-Y. Influence of NaOH concentrations on synthesis on pure-form zeolite A from fly ash using two stage method. $J$. Hazard Mater., v. 55, p. 58-64, 2008.

WANG, S.; ZHU, Z. H. Characterisation and environmental application of an Australian natural zeolite for basic dye removal from aqueous solution. J. Hazard Mater., v. B136, p. 946-952, 2006.

WANG, S.; WU, H. Environmental-benign utilisation of fly ash as low-cost adsorbents. J. Hazard. Mater. v. B136, p. 482-501, 2006.

World Energy Council - <http://www.worldenergy.org/>. Acessado em 12/02/2010.

YAPING, Y., XIAOQIANG, Z., WEILAN, Q., MINGWEN, W. Sysnthesis of pure zeolites from supersaturated silicon and aluminum alkali extracts from fused coal fly ash. Fuel, v.87, p. 1880-1886, 2008. 